CROSS-LINKING AND MODIFICATION OF SATURATED ELASTOMERS USING FUNCTIONALIZED AZIDES 
The studies described in this thesis are part of the Research Programme of the Dutch Polymer Institute, Eindhoven, the Netherlands, project \#580.

\section{Graduation committee}

\section{Chairman}

prof. dr. F. Eising

University of Twente

Promotor

prof. dr. ir. J.W.M. Noordermeer

University of Twente

Assistant promotor

dr. A.G. Talma

University of Twente/

Akzo Nobel, Polymer Chemicals

\section{B.V.}

Members

prof. dr. ir. M.M.C.G. Warmoeskerken

University of Twente

prof. dr. P.J. Dijkstra

University of Twente

prof. dr. ir. D.M. Bieliński

Technical University of Łódź

dr. ir. M. van Duin

DSM Elastomers Global R\&D

Cross-linking and modification of saturated elastomers using functionalized azides

By Agata Joanna Zielińska

PhD Thesis, University of Twente, Enschede, the Netherlands

With summary in English, Dutch and Polish

Copyright @ 2011 A.J. Zielińska, Enschede, the Netherlands

All rights reserved

Cover design by A.J. Zielińska, picture by Piotr Długołęcki 


\title{
CROSS-LINKING AND MODIFICATION OF SATURATED ELASTOMERS USING FUNCTIONALIZED AZIDES
}

\section{DISSERTATION}

\author{
to obtain \\ the degree of doctor at the University of Twente, \\ on the authority of the rector magnificus, \\ prof. dr. H. Brinksma,
} on account of the decision of the graduation committee, to be publicly defended on Friday, $1^{\text {st }}$ of July 2011 at 16.45

by

Agata Joanna Zielińska born on $4^{\text {th }}$ of November 1981

in Tomaszów Mazowiecki, Poland 
This dissertation has been approved by:

prof. dr. ir. J.W.M. Noordermeer

Promotor

dr. A.G. Talma

Assistant Promotor 
${ }^{1}$ If I speak in the tongues of men and of angels, but do not have love, I am only a resounding gong or a clanging cymbal. ${ }^{2}$ If I have the gift of prophecy and understand all mysteries and all knowledge, and if I have a faith that can move mountains, but do not have love, I am nothing. ${ }^{3}$ If I give all I possess to the poor and give over my body to be burned, but do not have love, I gain nothing.

${ }^{4}$ Love is patient, love is kind. It does not envy, it does not boast, it is not proud. ${ }^{5}$ It does not dishonor others, it is not self-seeking, it is not easily angered, it keeps no record of wrongs. ${ }^{6}$ Love does not delight in evil but rejoices with the truth. ${ }^{7}$ It always protects, always trusts, always hopes, always perseveres.

1 Corinthians 13:1-7

1 Korinthiërs 13:1-7

1 Kor 13:1-7

To my son and husband 



\section{Table of contents}

Chapter 1 Introduction: Cross-linking/modification of saturated

Chapter 2 Literature Review: Organic peroxides and azides in cross-linking and modification of polymers

Chapter 3 Comparison of different azides with respect to their reactivity towards EPM rubber

Chapter 4 Cross-linking of EP(D)M-rubbers with di-azides: Mechanical properties of vulcanizates

Chapter 5 Coagents as potential vulcanization aids in di-azides crosslinking

Chapter 6 Modification of EPM-rubber using mono-azides

Chapter 7 Mechanistic study on the reaction between SA/AF functionalities and saturated hydrocarbons

Chapter 8 Di-azides cross-linked, iPP/EPDM-based thermoplastic vulcanizates

Appendix A Recycling of di-azides cross-linked EPM

Summary

Samenvatting

Podsumowanie

Symbols and abbreviations

Bibliography 

Chapter 1

Introduction:

Cross-linking/modification of saturated hydrocarbon based elastomers with organic azides 


\section{$E P(D) M-r u b b e r$}

While the commodity polymers: poly(ethylene) (PE) and poly(propylene) (PP) are hard, semi-crystalline materials, the random copolymer of ethylene and propylene (EPM) is a soft, easily flowing, amorphous polymer with interesting elastic properties. The letters $(E)$ and $(P)$ stand for ethylene and propylene respectively, while $(M)$ indicates the class of elastomers with fully saturated main chain, as defined in ISO 1629. The EPMelastomers have typical ethylene-contents of 45-70 wt \%. At high ethylene incorporation a low-level of crystallinity can develop which usually melts at $30-90{ }^{\circ} \mathrm{C}$. The higher ethylene content allows for the copolymer to be extended with larger amounts of fillers and shows enhanced strength. Main limitation however, is inferior elastic recovery especially at low temperatures.

The structures of highly unsaturated natural rubber (NR) and saturated EPM-rubber are given in Scheme 1.1. The absence of double bonds in the backbone causes that the EPM has very good ozone resistance as well as better thermal stability compared to unsaturated rubbers like NR. Atmospheric factors, particularly ozone, greatly accelerate weathering of elastomers with double bonds located in the main chain. ${ }^{1,2}$ Another advantage of ethylene-propylene rubber is that it can be highly extended with fillers and mineral oil what allows for economical compounding.

(A)<smiles>CC(=CCC(C)(C)C)CCC(C)(C)C</smiles>

(B)

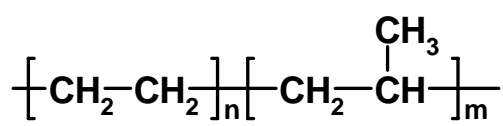

Scheme 1.1: Structures of: (A) NR and (B) EPM

The common disadvantage of the ethylene/propylene based polymers whether it is PE, PP or EPM-rubber is lack of chemical functionalities and inadequate compatibility with other polymers, what limits their applications. This disadvantage is difficult to overcome due to low reactivity of the fully saturated hydrocarbon chains. The problem is especially significant for EPM-rubber, as in order to obtain the elastic properties, the raw polymer needs to be cross-linked. A general way to overcome the lack of reactivity of saturated polymers is by pursuing free-radical reactions, usually initiated by thermal decomposition of peroxides. Peroxide cross-linking of EPM is commercially applied. Also grafting of unsaturated monomers, for example maleic anhydride (MA) initiated by peroxides is performed on an industrial scale. ${ }^{3}$ One major disadvantage of peroxideinduced processes however is the lack of selectivity which leads to a number of side reactions. The peroxide chemistry is described more extensively in Chapter 2.

Compared to the most common sulfur cross-linking, peroxide vulcanization leads to inferior dynamic mechanical properties. Moreover, the EPM compounds can not be 
extended with aromatic oils, which are highly reactive towards free radicals, and even when more expensive paraffinic plasticizers are applied the efficiency of the peroxidecuring is still low and requires addition of coagents. ${ }^{4,5}$ To allow for sulfur-curing, ethylene-propylene-terpolymers were developed which contain a certain amount of unsaturation. In the history of EPDM (ethylene-propylene-diene rubber) many dienes have been tested as third monomer, and 5-ethylidene-2-norbornene (ENB) is currently the most commonly used. ${ }^{6}$ Other commercial dienes are dicyclopentadiene (DCPD) and vinyl-norbornene (VNB). Out of the two double bonds of these dienes, Scheme 1.2 , one in the strained ring is most reactive and thus consumed during polymerization, while the second double bond allows for sulfur vulcanization. The lower reactivity of the second double bond towards polymerization is to minimize branching reactions. It is due to branching that the amount of diene which can be incorporated into the polymer is significantly limited.

(A)

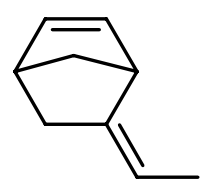

(B)

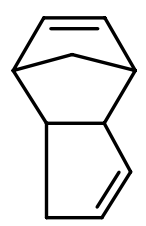

(C)

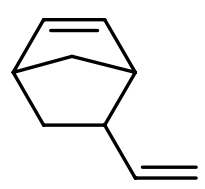

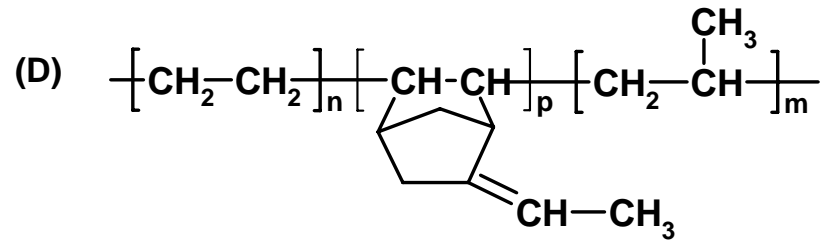

Scheme 1.2: Structures of commercially applied dienes (A) ENB; (B) DCPD and (C) VNB, and most common EPDM-rubber: (D) ENB-EPDM (ethylene-propylene-5-ethylidene-2-norbornene)

The double bonds present after polymerization are not located in the polymer backbone and therefore EPDM is still considered as a saturated M-class rubber, Scheme 1.2(D). EPDM shows practically the same high ozone-resistance as EPM. Although incorporation of the diene into the ethylene-propylene chain allows for sulfur vulcanization, the efficiency of the curing-reaction is much lower compared to butadiene- or isoprene-based R-rubbers containing $\mathrm{C}=\mathrm{C}$ unsaturation on every fourth carbon atom along the polymer chain. The amount of diene which can be incorporated into EPDM is typically below $10 \mathrm{wt} \%$. Still most of the EPDM products are sulfur-cured and also when peroxides are applied the efficiency of the reaction is significantly improved in comparison to EPM. Consequently, the amount of coagents required for peroxide vulcanization of ENB- and DCPD-EPDMs is greatly reduced relative to EPMs. In case of VNB-EPDM, due to its highly reactive towards free radical terminal unsaturation, even lower amounts of peroxides are needed than for ENB- and DCPDEPDMs still resulting in similar mechanical properties. ${ }^{7}$ 


\section{Aim of the thesis}

Organic azides are known to be reactive not only toward alkenes but more remarkably also towards alkanes. Thus it is interesting to investigate their reaction especially with saturated types of elastomers, like EP(D)M, which are most difficult to cross-link. The aim of the project is to design and synthesize new azide compounds which will be applied for cross-linking purposes and modification. The general concept is that the substances carrying one azide functionality can be grafted on the side of the polymer chain while the di-functional compounds are tested as cross-linking agents.

The mono-azides used for modification may, besides an azide group which will react with the elastomeric chain, also contain a second functional group designed to provide desired properties. It should be understood however that in the present study the main focus was on understanding and quantifying of the azide/polymer reaction rather than on tailoring the elastomer's properties for any specific purpose.

The di-azides are desired to react with high efficiency to ensure a sufficient cross-link density. Generally, it is expected that di-azide vulcanization can result in superior dynamic/mechanical properties over peroxide-curing while maintaining good thermal stability. During peroxide-curing the polymer molecules are linker together by rigid carbon-carbon bonds what results in inferior dynamic/mechanical properties compared to sulfur-curing. Azides cross-linking should lead to structures where the whole azide compound act as a bridge between two polymeric chains providing properties more similar to sulfur-curing while maintaining good thermal stability.

\section{Structure of the thesis}

Chapter 2 provides a brief introduction into how rubber found its way into the present world. The main part however is dedicated to give an overview of peroxides and azide chemistry. The processes of cross-linking and modification of polymers are especially emphasized.

The synthetic routes and reactivity of four main azide types: alkyl- and aryl-azides, sulfonyl azides and azidoformats are presented in Chapter 3. Mono- and di-functional molecules are investigated with respect of their reaction kinetics. Subsequently, the difunctional azides are tested with respect to their cross-linking efficiency for fully saturated EPM-rubber. The acyl-azide functionality was excluded from the study because of its high reactivity and Curtius rearrangement reaction, as known to take place.

The three most promising di-azides with respect to their reaction efficiency are investigated as cross-linking agents for EPM and EPDM compounds in Chapter 4. Mechanical properties of compounds cross-linked with various di-azides, dicumyl 
peroxide (DCP) and a DCP/coagent combination are compared. Studied is also the effect of paraffinic plasticizers on the efficiency of the reaction.

Peroxide curing is usually supported by addition of coagents, which significantly enhance the reaction efficiency, especially when the compounds contain plasticizing oils. Chapter 5 describes an investigation for the most common coagents, included in a compound composition and present during the azides reaction.

Modification studies are presented in Chapter 6. EPM-rubber is modified with various mono-sulfonyl azides and mono-azidoformates in a reactive mixing process. Subsequently the properties of the treated polymer are determined as well as the efficiency of the azide reaction.

Chapter 7 is dedicated to reveal the reaction mechanism between sulfonyl azide/azidoformate functionalities and saturated hydrocarbon molecules. During this study the polymeric chains are substituted by a low molecular weight model hydrocarbon, making the reaction mixture much easier to analyze by means of modern instrumental techniques.

Finally, in Chapter 8 the di-azides which proved to be effective curing agents for EPDM in static conditions, are applied to produce iPP/EPDM-based dynamically vulcanized thermoplastic elastomers (TPV). The mechanical properties are described of the produced TPVs and for some samples also the morphological structure is quantified.

\section{References}

1. K.C. Baranwal and H.L. Stephans, "Basic Elastomer Technology", Rubber Division American Chemical Society, $1^{\text {st }}$ edition, Akron, USA (2001).

2. J. White and S. De, "Rubber technologist's handbook" Rapra technology limited, Shewsbury, UK (2001).

3. D.J. Burlett and J.T. Lindt, Rubber Chem. Technol., 66, 415 (1993).

4. H.G. Dikland, "Co-agents in peroxide vulcanization of EP(D)M rubber", PhD thesis, University of Twente, Enschede, The Netherlands (1992).

5. M. M. Alvarez Grima, "Novel co-agents for improved properties in peroxide cure of saturated elastomers", PhD thesis, University of Twente, Enschede, The Netherlands (2007).

6. S. Cesca, J. Polym. Sci. Macromolecular Reviews, 10, 99 (1975).

7. M. van Duin and H.G. Dikland, Rubber Chem. Technol., 76, 132 (2003). 


\title{
Chapter 2
}

\section{Literature Review: \\ Organic peroxides and azides in cross-linking and modification of polymers}

\begin{abstract}
The major advantage of elastomers without double bonds in the main chain, such as EPM and EPDM, is their high stability compared to unsaturated elastomers: better resistance to oxygen, ozone as well as enhanced heat and irradiation stability. A disadvantage of the saturation is the lack of reactivity. Organic azides are known to be reactive not only towards alkenes but more significantly also towards alkanes. Therefore it is interesting to investigate their reactivity with saturated elastomers as alternatives for cross-linking or grafting reactions vs. the more common peroxide based systems. Mono-functional azide compounds can be grafted on a polymer chain, while di- or multi-functional azide compounds are designed for cross-linking.
\end{abstract}




\subsection{Rubbers (elastomers)}

Rubbers are a family of polymers with unique viscoelastic properties which allow the materials to undergo large reversible deformations. The term rubber is thus often used interchangeably with the term elastomer (elastic polymer). The polymer chains are mostly carbon-hydrogen based but they can also contain other elements like nitrogen, oxygen or silicon. The raw elastomers consist of coiled and entangled macromolecules which can easily disentangle and slip along each other as no bonds exist between them. Non cross-linked rubber behaves as a viscous liquid with low strength and permanent deformation. To obtain the elastic properties typical for rubber products the polymers need to be cross-linked.

Natural rubber (NR) prepared by drying the latex extracted from the tree "Hevea Brasiliensis" was the first to be discovered. It was brought to Europe form Latin America at a time the new continent was discovered. The local Indians knew about it long before. Aside from a few natural product impurities, NR is essentially a polymer consisting of isoprene units (>99 \% cis-1,4-polyisoprene) and is the only elastomer that possesses certain elastic properties even without cross-linking. All other elastomers were developed much later and consist of synthetic polymers. One of the first: "Buna$S$ " based on polymerization of butadiene and styrene was commercially produced in Germany in the 1920's and shortly after in the US. ${ }^{1,2}$ It was prepared as a substitute for NR in war time when the supply of NR was a difficult issue. The properties of this first synthetic rubber were inferior however compared to NR, with not very high yields. Ethylene-propylene rubber which is investigated in the studies presented in this thesis was developed along with a number of other polymers in the 1950's when Karl Ziegler introduced a new class of polymerization catalysts. The new catalyst system, significantly improved by Giulio Natta, opened a whole new range of possibilities in polymer chemistry allowing for the synthesis of high molecular weight, linear polymers of different stereospecific structure.
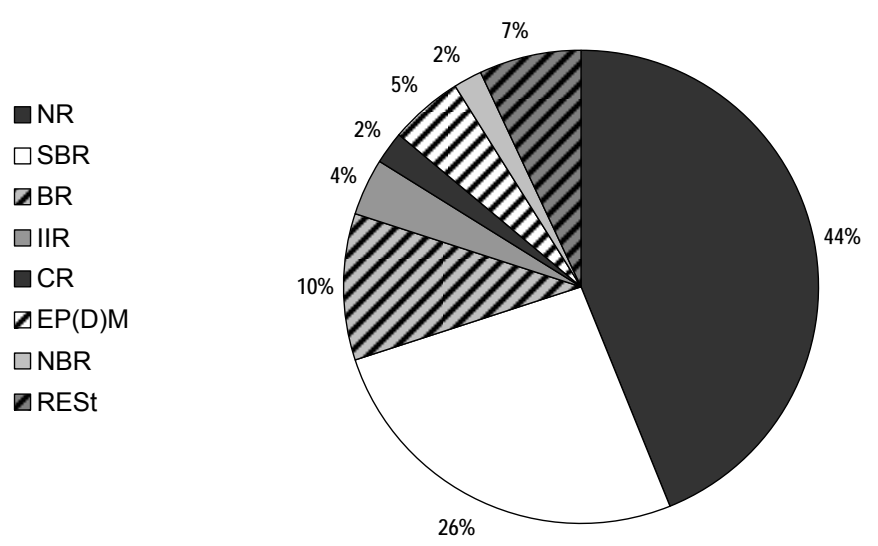

Fig. 2.1: World production of NR in comparison with different synthetic rubbers 
The use of elastomers covers a wide range of applications, from automotive to household to industrial products. Tires and tubes represent the main uses of rubber, accounting for around $56 \%$ of the total consumption. The total world rubber production was around 22.8 million tonnes in 2008 , of which around $44 \%$ was Natural Rubber, Fig. $2.1^{3}$

\subsection{Vulcanization}

Vulcanization (cross-linking or curing) is a chemical process in which polymer molecules are linked to other polymer molecules by sulfur or carbon bridges to create three-dimensional network structures. As a consequence, raw rubber is transformed into an elastic material. The commonly accepted, basic relations between crosslink density and mechanical properties of rubber products are shown in Fig. 2.2.,

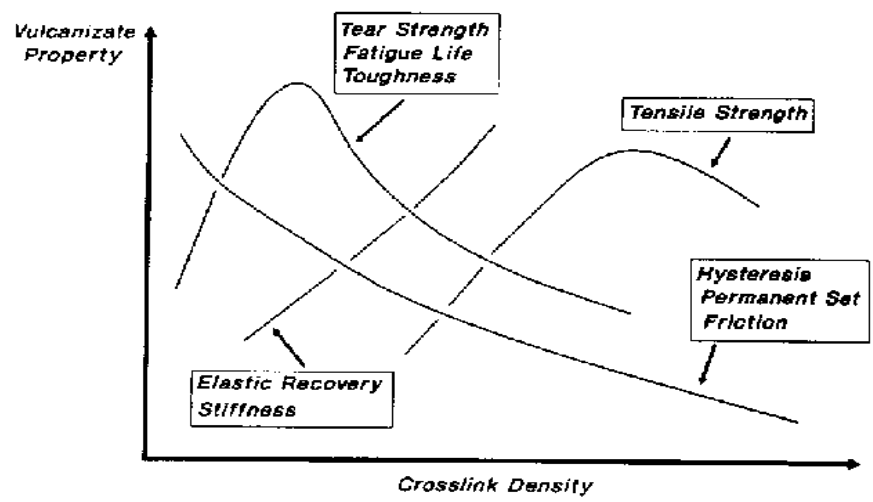

Fig. 2.2: Relationship between properties of vulcanized rubber and crosslink density

In 1839 Charles Goodyear (US) was the first one to discover the vulcanization process, when as the story tells he accidentally spilled a mixture of NR and sulfur on a hot stove. Independently, at around the same time, a similar observation was made by Thomas Hancock (UK). The name of the process comes from the Roman god of fire, Vulcanus, as vulcanization is usually carried out under high temperature conditions. The discovery however, did not trigger the instant development of rubber industry and many years passed before vulcanized rubber found its right applications. The rapid development of elastomeric products dates back to the last decade of the XIX's century. At that time it turned into one of the most successful rubber applications: the pneumatic tire.

The relations shown in Fig 2.2 are very general and the properties change significantly depending also on polymer and curing system. As mentioned above, sulfur was the first cross-linker to be discovered and together with activators and accelerators is still by far the most frequently used curing system. The di-azide compounds, which are the 
subject of this thesis, are designed however to compete rather with the peroxide-based curing systems. Organic peroxide curing is the second most common vulcanization technique and is mostly applied when the rubber material requires high thermal stability or when the nature of the polymers makes sulfur cross-linking impossible. The structures of sulfur and peroxide cross-links are shown in Scheme 2.3. The carboncarbon bond resulting from peroxide cross-linking is more stable $(80 \mathrm{kcal} / \mathrm{mol}$ bond energy) than the carbon-sulfur bond ( $64 \mathrm{kcal} / \mathrm{mol}$ bond energy) and sulfur-sulfur bonds (34 kcal/mol bond energy), formed during sulfur vulcanization. ${ }^{1}$

(A)

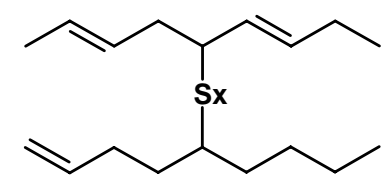

(B)

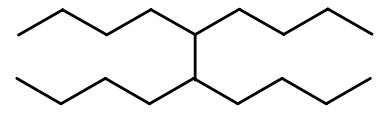

Scheme 2.3: Structures of: (A) sulfur cross-link $x=1-8$; and (B) carbon-carbon bond created during peroxide curing

The carbon-carbon $(\mathrm{C}-\mathrm{C})$ bonds formed during peroxide vulcanization provide characteristic properties, quite different from sulfur curing in which the polymeric chains are connected by much more flexible sulfur bridges (Sx). Thanks to the flexibility and lability of sulfur cross-links the vulcanizates show very good dynamic/ mechanical properties. Other advantages which make sulfur curing so successful are low costs, adjustable scorch delay and the fact that the vulcanization can be carried out at atmospheric conditions. Peroxide vulcanization in open air, in contact with atmospheric oxygen, leads to surface degradation and consequent unwanted stickiness. The lability of sulfur bridges however also brings certain disadvantages by making the cross-links thermally unstable leading to rearrangement at high temperatures. This results in reversion and inferior properties, compared to peroxide curing, particularly the set properties at high temperatures.

\subsection{Organic peroxides}

\subsubsection{Polymer cross-linking with peroxides}

Organic peroxides are compounds of the general structure: RO-OR'. The relatively weak oxygen-oxygen bond breaks easily leading to the formation of two oxygen centered radicals: RO', and initiates the free radical processes. Peroxide cross-linking was studied already at the beginning of XX'th century, but the method was a not very popular as the first peroxides were extremely reactive. ${ }^{6,8}$ They gained their importance in late the 1950's, when dicumyl peroxide (DCP) was introduced, Scheme 2.4. DCP used as a reference curing system in the present thesis, was far more stable than any other peroxide developed and used before. 


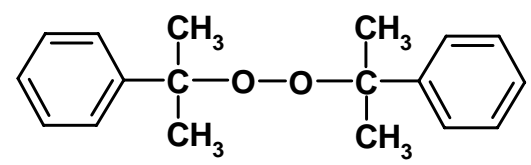

Scheme 2.4: Structure of dicumyl peroxide

Peroxides are usually characterized by their half-life time $\left(t_{1 / 2}\right)$, defined as the time required to decompose one half of the initial amount of compound at a given temperature. Thus after one half-time $50 \%$ of the peroxide has decomposed, $75 \%$ after two half-times, $87.5 \%$ after three half-times while after seven half-times approximately $99 \%$ of the initial peroxides will have reacted. This value is crucial for the vulcanization process as it determines both cure rate and scorch time. For a typical peroxide, $t_{1 / 2}$ drops by $1 / 3$ of its value for each $10{ }^{\circ} \mathrm{C}$ increase in temperature. Normally, it is advisable for rubber to be vulcanized long enough to ensure that only a trace of un-reacted peroxide remains. The residual peroxide can initiate oxidation as well as generate undesirable additional cross-linking to the product.

Peroxide decomposition is a first order reaction, which determines the kinetics of the whole cross-linking process (initiation). The oxygen centered radicals are so energetic that once formed they react immediately creating new carbon centered radicals (propagation) which either continue the reactions or immediately give a stable product (termination). ${ }^{7,10}$ The reaction between a radical and a molecule always leads to another radical as the total number of the electrons remains odd. Two most common propagation reactions are abstraction and addition to a multiple bond. During a peroxide/polymer reaction it is the abstraction which takes place most of the time. The addition is preferred in the presence of terminal unsaturation and is typical for polymerization processes. Typically the peroxy-radical abstracts a hydrogen atom from the polymer chain creating a macro-radical. Because the amount of hydrogen atoms on polymer chains is very high, their concentration does not vary significantly during the reaction process and the kinetics of the whole process is determined only by the peroxy-radical concentration. Finally during the last, termination step two macroradicals created during the propagation process couple to form a carbon-carbon bond. Scheme 2.5 shows the three basic steps in peroxide vulcanization. 
a. Initiation: The peroxide undergo homolytic cleavage to form two oxygen centered radicals:

$\mathrm{R}-\mathrm{O}-\mathrm{O}-\mathrm{R} \longrightarrow 2 \mathrm{RO}$.

b. Propagation:

=> Abstraction: A peroxy-radical abstracts a hydrogen atom from a polymer:

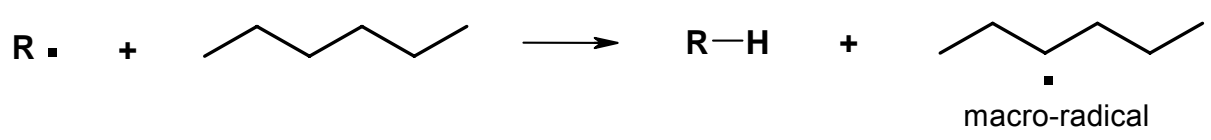

=>Addition: A peroxy-radical adds to terminal unsaturation:

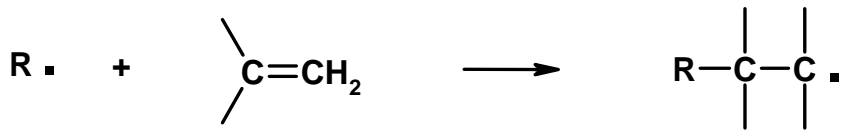

c. Termination: Two radicals on neighboring polymer chains couple to form a $\mathrm{C}-\mathrm{C}$ bond.

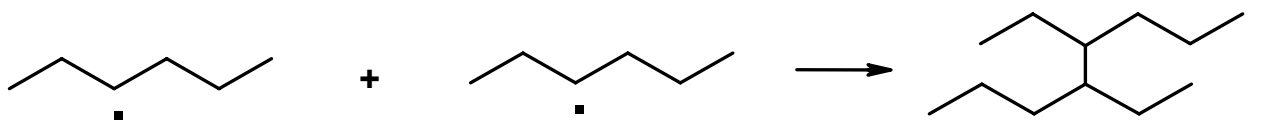

Scheme 2.5: Three steps required during peroxide reaction

Although Scheme 2.5 may seem rather simple, depending on the system and the reaction conditions there are a number of possible side reactions. The radical reactions are known for their low selectivity which usually leads to multiple reaction products and makes peroxide cross-linking very complex. In the case of hydrocarbonbased polymers, for instance, the peroxide treatment of PE leads to cross-linking and an increase of molecular weight, while the addition to PP may lead to quite the opposite effect, causing reduction of the molecular weight. ${ }^{10,11}$ The reason for this different behavior is the tendency of PP towards rearrangement, which at low peroxide concentration $(<0.5 \%)$ is far more favorable then cross-linking. As shown in Scheme 2.6, electron rearrangement commonly known as $\beta$-scission causes polymer degradation and is highly undesirable. EP(D)M rubbers are also sensitive to $\beta$ scission which most likely will occur at the propylene units. Therefore, the higher the propylene content of EP(D)M, the more $\beta$-scission reaction. Increased randomness of the copolymer or lower propylene content may help to minimize this unwanted sidereaction. ${ }^{1}$ 
(A)

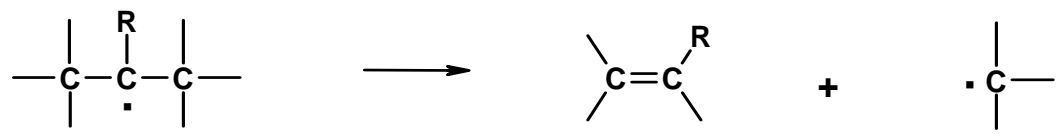

(B)

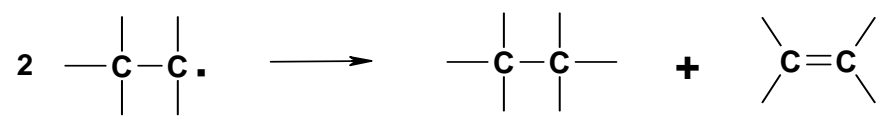

Scheme 2.6: Typical side reactions: (A) $\beta$-scission reaction and (B) disproportionation

Another common side reaction is the disproportionation, Scheme $2.6(\mathrm{~B})$, which does not lead to a decrease of the molecular weight of the polymer but does lower the efficiency of the peroxide. It is also important to know that the presence of acidic substances, such as certain fillers, may causes heterolytic or ionic decomposition of peroxide molecules and as a consequence that no radicals are formed. ${ }^{9,10}$

There are still a number of other side reactions with varying relevance. One of them is the reaction with atmospheric oxygen, what makes peroxide-curing unsuitable to be performed in an open air atmosphere as mentioned before, as it results in surface degradation of the product via it oxidation. This side reaction is especially inconvenient, as continuous vulcanization with hot air is a very common production method for continuous sulphur vulcanizates: like profiles, which cannot be done with peroxide vulcanization this way.

The peroxy-radicals can abstract hydrogen atoms not only from the polymers but from any other available source. That is especially important in case of rubber compounds which contain significant amounts of oil; EPDM for example may contain more than $100 \mathrm{phr}$. Due to the high abstractability (acidic H's) of benzylic and allylic hydrogens, the use of aromatic oils needs to be avoided as it will significantly interfere with the cross-linking reaction. The order of hydrogen acidity is: phenolic $>$ benzylic $>$ allylic $>$ tertiary $>$ secondary $>$ primary. ${ }^{6}$ For peroxide curing therefore usually paraffinic oils are added which are much less reactive and consume less radicals than aromatic and naphthenic oils.

To improve the efficiency of peroxide cross-linking, especially in the presence of plasticizing oils, multi-functional additives, better known as coagents, are commonly added to the system. ${ }^{12,13}$ In Chapter 5 of this thesis the effect of coagents on di-azide curing is investigated, including a general introduction into coagents/peroxide reactions.

\subsubsection{Polymer modification: maleation with help of peroxides}

Presently maleic anhydride (MA) is the most successful modification agent for polymers. MA-functionalized polyolefins show significantly enhanced adhesion and compatibility. The main advantage of this compound is its dual-functionality; MA has an "ene" or radically active double bond and the nucleophilically reactive anhydride 
groups: Scheme 2.7. Normally the reactions with polymers proceed via the double bond resulting in an anhydride grafted backbone. The saturated polymers like PE, EPM and PP are usually modified in a radical process with addition of a suitable initiator; usually a peroxide. ${ }^{15-18}$ In case of the unsaturated polymers MA can be also grafted via the thermally induced "ene" addition reaction. ${ }^{19-21}$

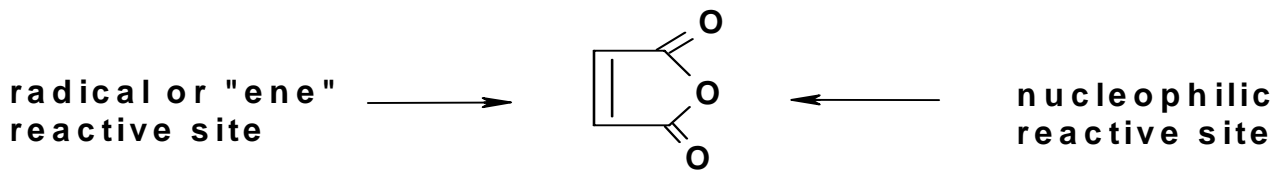

Scheme 2.7: Maleic anhydride reactive sites

On industrial scale functionalization of PE, PP and EPM with MA is carried out most frequently via continuous, reactive extrusion. Once the substrate polymer is molten the MA and the radical initiator are mixed in. Alternatively, the modification process can be performed in a solution, where the polymer is dissolved in a suitable solvent, and the MA and initiator are introduced at elevated temperature. The grafting starts with decomposition of the radical-initiator which abstracts hydrogen from a polymer chain. Scheme 2.8 shows the EPM/MA reaction under free radical conditions.
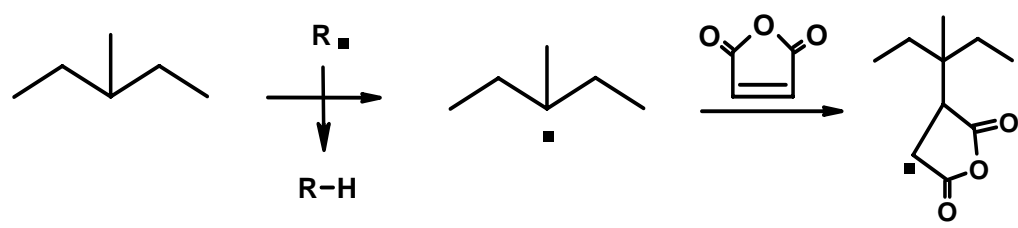
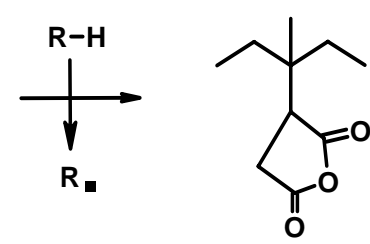

Scheme 2.8: Mechanism for peroxide-initiated grafting of MA on EPM

In case of PP and EPM, MA is grafted mostly on tertiary carbon atoms as they give more stable radicals. Due to the higher reactivity the secondary radicals are less likely to be formed and it was observed that more than three methylene, $\left(\mathrm{CH}_{2}\right)$ sequences are needed in order to graft the MA on a poly-methylene backbone. For the polyolefins with tertiary carbon atoms like PP or EPM the single anhydride ring grafting, rather than polymerization of MA, is achieved, most likely due to fast $\mathrm{H}$-transfer. ${ }^{16}$ In case of PE which is build mainly from methylene units, some short oligomeric MA structures are formed as well. In general, MA grafting on PE is accompanied by branching and/or cross-linking, and grafting on PP by $\beta$-scission. It was reported that MA has the tendency to react with terminal unsaturations which are formed during $\beta$-scission. The reaction mechanism for the MA grafting of EPM is considered to be a combination of the mechanism proposed for PE and PP. 


\subsection{Azides}

The azide functionality is a resonance hybrid of a linear structure consisting of three nitrogen atoms connected together. Organic azides are known to undergo a number of reactions, like reduction to amine for instance. They are commonly used intermediates in organic chemistry. One of the synthetic methods to introduce amine functionality is reduction of the azide with metal/Lewis acid systems shown in Scheme $2.9(\mathrm{~A}){ }^{22-26}$ Due to its extraordinary stability towards water, oxygen and the majority of organic synthetic conditions, the azide group has become one of the most crucial functional groups for click chemistry, Scheme: 2.9 (B). ${ }^{27-30}$ Although presently the 1,3-dipolar cycloaddition of azides to alkynes is commonly employed, for some time the reaction was not given much attention due to safety concerns.

(A)

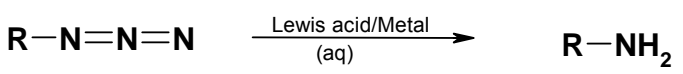

(B)
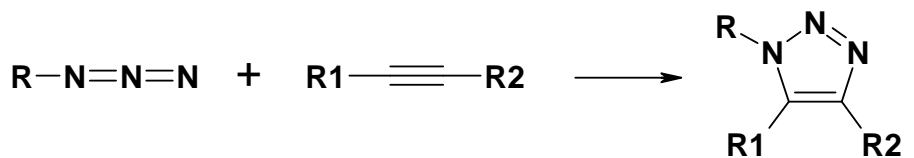

Scheme 2.9: Examples of common azide reactions; (A) reduction to amine and (B) 1,3-dipolar cycloaddition of azides to alkynes

Quite generally available in laboratory environments is sodium azide, $\mathrm{NaN}_{3}$. This salt, highly water soluble, is very useful as a starting material in the preparation of other azides. It is also commonly used as gas-forming component in car airbags. The most famous of the organic azides is AZT (azidothymidine), a drug which was the first approved HIV-treatment. ${ }^{31} \mathrm{AZT}$, known also as "Zidovudine", is included in the "Essential Drugs List", which is the list of minimum medicals for basic health care. The drug was first synthesized in the 1960's when there was a great interest in azide chemistry. ${ }^{32-36}$

In the present study the reactions between various azides and saturated hydrocarbons are investigated. When exposed to elevated temperature or radiation the azide functionality decomposes, separating off a nitrogen molecule and yielding a highly reactive nitrene species. The idea of nitrene formation during alkyl-azides decomposition was proposed already in the 1890's. At around the same time also the synthesis of sulfonyl azide was reported. The reactions of sulfonyl azides and azidoformates with saturated hydrocarbons are usually highly efficient. That is most likely due to the nature of this groups which restricts the possibility of rearrangement. ${ }^{36}$ In the case of other azides groups rearrangement is often so fast that it is questionable whether the nitrene intermediate actually occurs. The famous Curtius rearrangement of acyl-azides to an isocyanate for instance, takes place well below $100{ }^{\circ} \mathrm{C}$, what makes the acyl-azide group the least stable one., ${ }^{7,37,38}$ The stability of various types of 
azide groups is investigated in Chapter 3 of this thesis. Overall however, all small organic azide molecules may decompose violently and thus certain precautions are recommended during their handling. ${ }^{39}$ The higher molecular weight members are correspondingly less sensitive. In case of sulfonyl azides for instance it is claimed that they are safe to handle, provided there are more than three carbon atoms per sulfonyl azide group.

The general decomposition mechanism of the azide functionality involves the generation of a nitrogen molecule $\left(\mathrm{N}_{2}\right)$ and a nitrene, which is an uncharged, electron deficient and highly reactive species. Although nitrenes can be created by other methods, azide decomposition is by far the most common one. ${ }^{7}$ The nitrene can subsequently undergo a variety of reactions, one of them the reaction with saturated hydrocarbons. Experiments show that in case of sulfonyl azides the nitrene is initially formed in a singlet state with two paired electrons, but it can change into a lower energy triplet state where the electrons are unpaired: Scheme 2.10. It is assumed that both states, singlet as well as triplet, can react with saturated hydrocarbons.

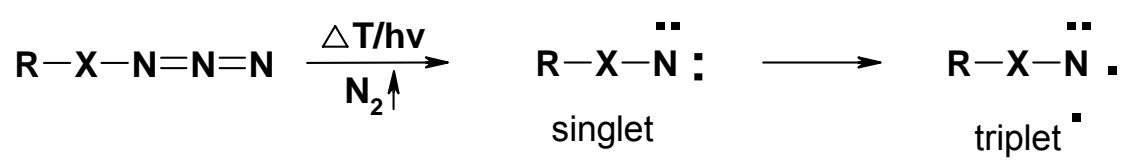

Scheme 2.10: Proposed azide decomposition mechanism

The nitrenes in the singlet state insert into a saturated carbon-hydrogen bond, with retention of the configuration, while the triplet nitrene can abstract hydrogen or other atoms to give free radicals: Scheme 2.11. The triplet state initiates a radical process and thus should not be much different from the peroxides reaction. The most interesting however is the insertion of the nitrene into the saturated hydrocarbon chain. This unique reaction proceeds without any side products, which are the largest disadvantages of the free radical processes. Experiments have shown that sulfonyl azides and azidoformates react mostly via the insertion mechanism, although the triplet formation could never be fully excluded. ${ }^{7,36,40}$

(A)

$$
\begin{aligned}
& \text { (A) } \mathrm{R}-\mathrm{X}-\ddot{\mathrm{N}}:+\mathrm{H}-\mathrm{R} \longrightarrow \mathrm{R}-\mathrm{X}-\mathrm{NH}-\mathrm{R} \\
& \text { (B) } \mathrm{R}-\mathrm{X}-\mathrm{N} \cdot+\mathrm{H}-\mathrm{R} \longrightarrow \mathrm{R}-\mathrm{X}-\dot{\mathrm{NH}}+\mathrm{R} \cdot
\end{aligned}
$$

Scheme 2.11: Scheme of nitrene/saturated hydrocarbon reactions: (A) nitrene in singlet state, insertion and (B) nitrene in triplet state, hydrogen abstraction and radical formation

In presence of a double bond the nitrene can be involved in several addition reactions. They add to an unsaturated carbon-carbon bond forming an aziridine ring or add to 
aromatic rings, resulting in their expansion or other rearrangements, Scheme $2.12^{7,41}$ Aryl-nitrenes often undergo termination reactions by dimerization and, as mentioned above, dependent on the particular azide group the general nitrene reactions may not occur due to rapid rearrangement.

(A)

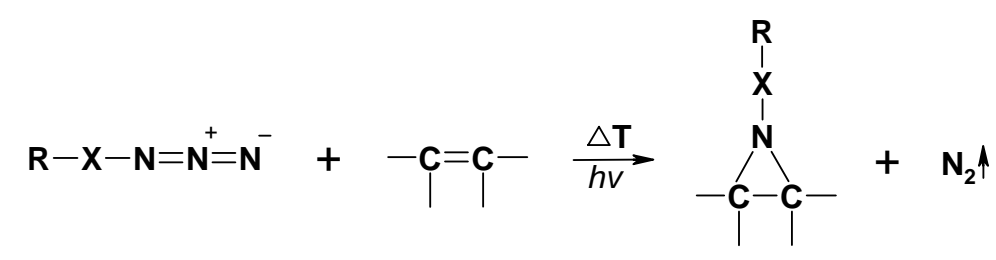

(B)

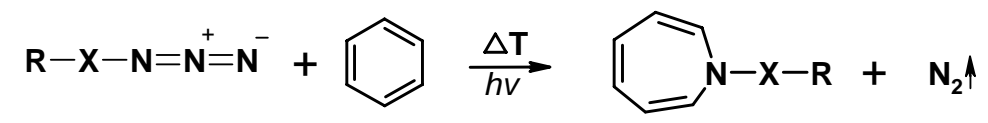

(C) $2 \mathrm{Ar}-\mathrm{N}=\mathrm{N}^{+}=\mathrm{N}^{-} \quad \underset{h v}{\stackrel{\Delta \mathrm{T}}{\longrightarrow}} \quad \mathrm{Ar}-\mathrm{N}=\mathrm{N}-\mathrm{Ar}+2 \mathrm{~N}_{2} \uparrow$

(D) $\quad \mathbf{R C O}-\mathbf{N}=\mathbf{N}^{+}=\mathbf{N}^{-} \underset{h v}{\stackrel{\Delta T}{\longrightarrow}} \mathbf{R C}=\mathbf{N}=\mathbf{O}+\mathbf{N}_{2} \uparrow$

Scheme 2.12: Other nitrene reactions: (A) aziridine formation, (B) expansion of aromatic ring, azepine formation, $(C)$ dimerization and $(D)$ Curtius rearrangement

The nitrene has its carbon analog known as carbene, which can undergo similar reactions. Like nitrenes also the carbenes are reactive towards both alkenes and alkanes. The carbenes are considered however to be much more reactive, as practically all have a life time shorter then one second. ${ }^{7,42-45}$

\subsubsection{Azide cross-linking}

Cross-linking of polymers using poly-functional azide compounds can be seen as the result of reaction of one azide unit with a polymer chain and a second azide unit with another polymer chain. A patent from 1950 introduces diphenyl-4,4'-di(sulfonyl azide) as a potential cross-linking and foaming agent. ${ }^{46}$ The curing was carried out by heating the polymer/di-sulfonyl azide mixture to a temperature at which the sulfonyl azide decomposed. Around ten years later Breslow was the first to apply substances containing azide groups for elastomer cross-linking. In one of the first patents various sulfonyl azides were applied as curing agents for vinyl ether polymers. ${ }^{47}$ Shortly after, a variety of sulfonyl azides and azidoformates were investigated, as cross-linking agents for different kinds of polymers. ${ }^{48-56}$ The main goal in elastomer cross-lining was to reduce material degradation resulting from free radical reactions. The study focused on sulfonyl azides and azidoformate compounds, which are straightforward to synthesize from corresponding chlorides and which react with a high efficiency under thermal activation, Scheme 2.13. 
(A) $[\mathrm{N}=\mathrm{N}=\mathrm{N}-\stackrel{\mathrm{O}}{\mathrm{C}}-\mathrm{O}-]_{\mathrm{x}} \mathrm{R}$

(B) $\left[\mathrm{N}=\mathrm{N}=\mathrm{N}-\prod_{\mathrm{O}}^{\mathrm{O}}\right]_{\mathrm{x}} \mathrm{R}$

Scheme 2.13: Structure of: (A) polyazidoformates and (B) polysulfonylazides

The rubber compounds can be prepared using conventional mixing procedures and the vulcanizates produced are described as flexible, solvent resistant, and odor free. Additives commonly used in rubber vulcanizates can also be used, for example: extender oils, fillers, pigments, plasticizers, stabilizers, etc. In some cases due to formation of nitrogen some porosity may occur, depending on the viscosity of the compound, molding pressure and crosslink density. In case of polychloroprene, the cross-linking efficiency was greatly reduced by the acidity generated during the reaction (hydrogen chloride release). This effect can be minimized by magnesium oxide ( $\mathrm{MgO}$ ) addition, which acts as an acid trapping agent. In addition to most common hydrocarbon based elastomers also other polymers like polyurethanes, polyacrylates or silicone rubbers are reported to be effectively cross-linked. In this study the main focus was on saturated polymers which are most difficult to cure by conventional cross-linking systems based on sulfur or peroxide.

Recently there is quite some interest in di-sulfonyl azides cross-linking, with 1,3benzenedisulfonyl azide (1,3BDSA) being most successful: Scheme 2.14. 1,3BDSA has been investigated as cross-linking agent for various elastomers, both unsaturated and saturated, such as NR, BR, CR, SBR, EP(D)M, VMQ and IIR. ${ }^{57-59}$ According to the data obtained the degree of unsaturation of the polymer has a large influence on the 1,3BDSA reaction kinetics: cis-polyisoprene is less reactive than styrene-butadiene rubber, while cross-linking of ethylene-propylene copolymers proceeds even slower. The reaction kinetics of various azidoformates and sulfonyl azides are investigated in Chapters 3 and 4 .

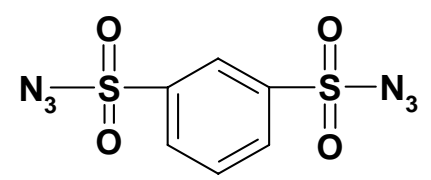

Scheme 2.14: Structure of 1,3BDSA

The use of di-sulfonyl azides, 1,3BDSA in particular, for cross-linking of polyolefins, polyolefin containing blends and various fibers is described in a number of patents and publications. Generally, sulfonyl azides are preferred over azidoformates due to their higher decomposition temperature which allows for melt mixing with thermoplastics. ${ }^{60-}$ 70 It has been shown that di-sulfonyl azides are able to effectively crosslink polyethylene as well as polypropylene. Moreover, no signs of formation of low 
molecular species after PP treatment suggest that free radical reactions are negligible. The di-sulfonyl azides can be applied to introduce long chain branching and so control melt processability of the polyolefins.

Upon thermal decomposition of sulfonyl azides, sulphur dioxide will be formed in a certain quantity depending on the reaction conditions. The mechanisms behind the formation of $\mathrm{SO}_{2}$ are not fully unravelled yet, but the proposed reaction path is shown in Scheme 2.15. During pyrolysis of pure sulfonyl azides, the formation of $\mathrm{SO}_{2}$ makes the reaction order deviate from one after at least one half-life time of the compound. ${ }^{71}$ Therefore nitrenes or products from nitrene reactions are suspected to catalyze this process. On the other hand, once mixed with polymer most of the sulfonyl azides show clear first order kinetics up to $90 \%$ conversion, although still a certain amount of $\mathrm{SO}_{2}$ formation is observed.

$$
\begin{aligned}
\mathrm{R} \cdot+\mathrm{R}^{\prime}-\mathrm{SO}_{2}-\mathrm{N}_{3} \longrightarrow \mathrm{R}^{\prime}-\mathrm{SO}_{2} \cdot+\mathrm{R}-\mathrm{N}_{3} \\
\mathrm{R}^{\prime}-\mathrm{SO}_{2} \cdot \longrightarrow \mathrm{R}^{\prime} \cdot+\mathrm{SO}_{2}
\end{aligned}
$$

Scheme 2.15: Possible mechanism of sulfur dioxide formation

\subsubsection{Azide modification}

It has been found in a number of studies that compounds containing one azide functionality can be used to chemically modify polymers without cross-linking taking place. ${ }^{72-83}$ The azides were mixed into the polymers via simple milling or extrusion, as well as they could be dissolved in a polymer-containing solution. Modifications similar to cross-linking were performed using sulfonyl azide and azidoformate compounds. It is assumed that the reaction mechanism is the same for mono- as well as for difunctional azides, Scheme 2.11. The modification process was carried out by heating the polymer/mono-azide mixture above the decomposition temperature of the azide or by exposing it to irradiation.

The general idea is that compounds can be synthesized so as to contain one azide group and also other functional groups which will affect changes in the treated polymers. One of the first attempts was to directly bond common additives such as dyes, stabilizers or antistatic agents to the polymers and thus prevent their physical removal or migration. More recently, different authors modified LDPE and SBR rubber using a mono-sulfonyl azide compound containing an aniline functionality, Scheme 2.16. ${ }^{79,80}$ The mono-azides were also applied as silica coupling agent and for fibre/polyolefin modification. ${ }^{81-84}$ 


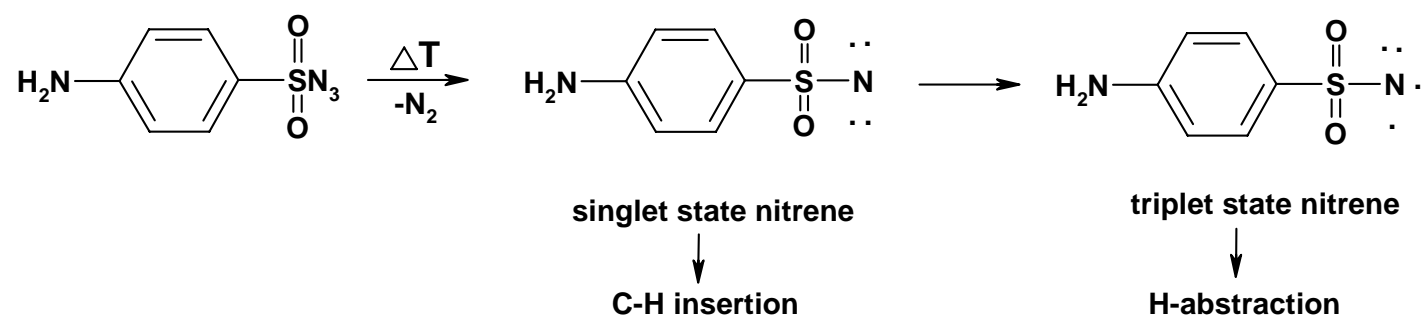

Scheme 2.16: Pathways of sulfonyl azide reaction to introduce aniline functionality

Overall, the largest problem, during the modification is that despite an increase in azide loading the changes in grafting efficiency are very small. While especially in the case of the sulfonyl azide based compounds a strong dark discoloration is observed. This problem is often related to the low solubility of the polar azide compounds in the polymer matrix.

\subsection{References}

1. K.C. Baranwal and H.L. Stephans, "Basic Elastomer Technology", Rubber Division American Chemical Society, $1^{\text {st }}$ edition, Akron, USA (2001).

2. J. White and S. De, "Rubber Technologist's Handbook", Rapra Technology Itd., Shawbury (2001).

3. International Rubber Study Group, "Rubber industry report" nr. 10-12, 8 (2009).

4. A.Y. Coran, "Vulcanization" in Science and Technology of Rubber, $3^{\text {th }}$ edition, Elsevier Academic Press (2005).

5. A.Y. Coran, J. Appl. Pol. Sci., 87, 24 (2003).

6. J.B. Class, Rubber World, 220, 35 (1999).

7. M.B. Smith and J. March, "March's advanced organic chemistry reactions, mechanisms and structure", $5^{\text {th }}$ edition, John Wiley \& Sons, New York (2001).

8. I.I. Ostromislenski, J. Russ. Phys. Chem. Soc., 47, 1467 (1915).

9. F. Barroso-Bujans, R. Verdejo, M. Pérez-Cabero, S. Agouram, I. Rodríguez-Ramos, A. Guerrero-Ruiz, and M.A. López-Manchado, Eur. Polym. J., 45, 1017 (2009).

10. P. R. Dluzneski, Rubber Chem. Technol. 74, 451 (2001).

11. D. Bacci, R. Marchini, and M.T. Scrivani, Polym. Eng. Sci., 45, 333 (2005)

12. H.G. Dikland, "Co-agents in peroxide vulcanization of $E P(D) M$ rubber", $P h D$ thesis, University of Twente, Enschede, The Netherlands (1992).

13. M. M. Alvarez Grima, "Novel co-agents for improved properties in peroxide cure of saturated elastomers", PhD thesis, University of Twente, Enschede, The Netherlands (2007).

14. L.J. Krebaum, W.C.L. Wu, and J.M. Machonis, U.S. Patent 3,882,194 (1975).

15. D.J. Burlett and J.T. Lindt, Rubber Chem. Technol., 66, 415 (1993).

16. W. Heinen, C.H. Rosenmoller, C.B. Wenzel, H.J.M. de Groot, J. Lugtenburg and M. van Duin, Macromolecules, 29, 1151(1996). 
17. W. Heinen, "Grafting of polyolefins and miscibility in copolymer mixtures", PhD thesis, Universiteit Leiden, The Netherlands (1996).

18. B. Lu and T.C. Chung, Macromolecules, 31, 5943 (1998).

19. S.W. Caywood, U.S. Patent $4,010,223$ (1977).

20. M.R. Thompson, C. Tzoganakis, and G.L. Rempel, Polym. Eng. Sci., 38, 1694 (1998).

21. M.R. Thompson, C. Tzoganakis, and G.L. Rempel, Polymer, 39, 327 (1998).

22. E.J. Corey and J.O. Link, J. Am. Chem. Soc., 114, 1906 (1992).

23. F.J. Lopez and D. Nitzan, Tetrahedron Lett., 40, 2071 (1999).

24. C.B. Li, P. W. Zheng, Z.X. Zhao, W. Q. Zhang, M.B. Li, Q.C. Yang, Y. Cui and Y.L. Xu, Chin. Chem. Lett., 14, 773 (2003).

25. L. Benati, G. Bencivenni, R. Leardini, D. Nanni, M. Minozzi, P. Spagnolo, R. Scialpi and G. Zanardi, Org. Lett., 8, 2499 (2006).

26. A. Kamal, N. Shankaraiah, N. Markandeya and Ch.S. Reddy, Synlett, 1297 (2008).

27. H.C. Kolb, M. G. Finn and K.B. Sharpless, Angew. Chem. Int. Ed., 40, 2004 (2001).

28. V.V. Rostovtsev, L.G. Green, V.V. Fokin and K.B. Sharpless, Angew. Chem. Int. Ed., 41, 2596 (2002).

29. E.H.D. Donkers, "Block copolymers with polar and non-polar blocks", PhD thesis, Technical University Eindhoven, The Netherlands (2006).

30. J.M. Baskin and C.R. Bertozzi, Aldrichimica Acta, 43, 15 (2010).

31. S. Broder, Antiviral research, 85, 1 (2010).

32. J.P. Horwitz, J Chua and M.J. Noel, Org. Chem. Ser. Monogr, 29, 2076 (1964).

33. L. Horner and A. Christmann, Angew. Chem. Int. Ed. Engl. 2, 599 (1963).

34. R.A. Abramovitch and B.A. Davis, Chem. Rev., 64, 149 (1964).

35. G. L'abbe, Chem. Rev., 69, 345 (1968).

36. W. Lwowski, "Nitrenes" by John Wiley \& Sons, Inc. New York, US (1970).

37. S. Linke, G.T. Tisue and W. Lwowski, J. Am. Chem. Soc., 89, 6308 (1967).

38. http://www.organic-chemistry.org/namedreactions/curtius-rearrangement.shtm (last login 14-12-2010).

39. M. Peer, Spec. Chem., 18, 256 (1998).

40. M.F. Sloan, T.J. Prosser, N.R. Newburg, and D.S. Breslow, Tetrahedron Lett., 5, 2945 (1964).

41. W. Lwowski and R.L. Johnson, Tetrahedron Lett., 8, 891 (1967).

42. Goodyear, T.G.T.R.C., G.B. Patent 1010125 (1965).

43. M.S. Lishanskii, V.A. Tsitokhtsev, and N.D. Vinogradova, Rubber Chem. Technol., 40, 934 (1967).

44. M. Aglietto, Macromolecules, 22, 1492 (1989).

45. M. Aglietto, Polmer, 30, 1133 (1989).

46. J.B. Ott, U.S. Patent 2,518,249 (1950).

47. D.S. Breslow, U.S. Patent 3,058,957 (1962).

48. D.S. Breslow and H.M. Spurlin, U.S. Patent 3,058,944 (1962).

49. D.S. Breslow, U.S. Patent 3,211,752 (1965).

50. D.S. Breslow and H.M. Spurlin, U.S. Patent 3,203,937 (1965)

51. G.B. Patent 982,777 (1965). 
52. G.B. Feild and P.L. Johnstone, U.S. Patent $3,298,975$ (1966).

53. D.S. Breslow and F.E. Piech, U.S. Patent 3,322,733 (1967).

54. G.B. Patent 1,087,045 (1967).

55. D.S. Breslow, W.D. Willis and L.O. Amberg, Rubber Chem. Technol., 43, 605 (1970).

56. E.E. Bostick and A.R. Gilbert, U.S. Patent 3,583,939 (1971).

57. J.L. de Benito Gonzalez, L. Ibarra Rueda and L. Gonzalez Hornandez, Kautsch. Gummi Kunstst., 43, 146 (1990).

58. J.L. de Benito Gonzalez, L. Ibarra Rueda and L. Gonzalez Hornandez, Kautsch. Gummi Kunstst., 43, 697 (1990).

59. L.G. Hernandez, A.R. Diaz and J.L. de Benito Gonzalez, Rubber Chem. Technol., 65 , 869 (1992).

60. R.H. Terbrueggen, R. E. Drumright and T. H. Ho, WO Patent 0052091 (2000).

61. R.H. Terbrueggen, R. E. Drumright and T. H. Ho, U.S. Patent 6277916 (2001).

62. M.A. Lopez Manchado and J.M. Kenny, Rubber Chem. Technol., 74, 204 (2001).

63. J.K. Jorgensen, E. Ommundsen, A. Stori and K. Redford, Polymer, 46, 12073 (2005).

64. J.K. Jorgensen, A. Stori, K. Redford and E. Ommundsen, Polymer, 46, 12256 (2005).

65. R.H. Terbrueggen, R.E. Drumright and T.H. Ho, W.O. Patent 0052091 (2000).

66. R.H. Terbrueggen, R.E. Drumright and T.H. Ho, U.S. Patent 6277916 (2001).

67. D.A. Baker, G.C. East and S.K. Murhopadhyay, J. Appl. Polym. Sci., 79, 1092 (2001).

68. D.A. Baker, G.C. East and S.K. Murhopadhyay, J. Appl. Polym. Sci., 83, 1517 (2002).

69. D.A. Baker, G.C. East and S.K. Murhopadhyay, J. Appl. Polym. Sci., 84, 1309 (2002).

70. K. Borve and K. Redford, E.U. Patent 1,423,466 (2004).

71. D.S. Breslow, M.F. Sloan, N.R. Newburg and W.B. Renfrew, J. Am. Chem. Soc., 91, 2273 (1969).

72. D.S. Breslow, U.S. Patent $3,220,985$ (1965).

73. D.S. Breslow, U.S. Patent $3,284,421$ (1966).

74. D.S. Breslow, U.S. Patent 3,321,452 (1967).

75. S.E. Cantor, U.S. Patent 4,031,068 (1977).

76. S.E. Cantor, Polymer Preprint, 18, 471 (1977).

77. R.D. Porter and S.W. Waisbrot, U.K. Patent 1,526,498 (1978).

78. R.R. Eschborn and H. Kaiser, U.S. Patent 4,309,453 (1982).

79. S.A. Bateman and D.Y. Wu, J. Appl. Polym. Sci., 84, 1395 (2002).

80. L. Gonzalez, A. Rodriguez, J.L. de Benito and A. Marcos-Fernandez, J. Appl. Polym. Sci., 63, 1353 (1997).

81. Q. Li and C. Tzoganakis, Int. Polym. Proc., 3, 311 (2007).

82. L. Ibarra, Kautsch. Gummi Kunstst., 47, 578 (1994).

83. L. Ibarra, Kautsch. Gummi Kunstst., 48, 860 (1995).

84. L. Gonzalez, A. Rodriguez, J.L. de Benito and A. Marcos, Rubber Chem. Technol., 69, 266 (1996). 


\title{
Chapter 3
}

\section{Comparison of different azides with respect to their reactivity towards EPM rubber}

\begin{abstract}
Azides are known as a class of organic compounds that are very reactive, amongst others towards alkenes and alkanes. At elevated temperatures the azide-group decomposes, releasing a nitrogen molecule and creating a highly reactive nitrene species, which is able to react with fully saturated hydrocarbon polymer chains. In this chapter the properties of four different azide functionalities are investigated: alkyl azides: $\mathrm{R}-\mathrm{N}_{3}$; aryl azides: R$\mathrm{C}_{6} \mathrm{H}_{4}-\mathrm{N}_{3}$; sulfonyl azides: R-SO $-\mathrm{N}_{3}$; and azidoformates: R-O-C(O)- $\mathrm{N}_{3}$. The aim of the study is to determine and compare the properties of different types of azide functionalities and their ability to react with saturated EPMrubber. Several di-azide compounds are tested with respect to their crosslinking efficiency for EPM. An overview of synthetic routes towards different azide types is given as well.
\end{abstract}




\subsection{Introduction}

The reactivity of an azide group is greatly influenced by its direct environment, and it is the direct neighboring group that determines the decomposition temperature and the reaction path of the azide. The significance of the direct environment structure in azide chemistry becomes clear when comparing properties of different azide classes. ${ }^{1}$ Acylazides for instance are known to be the most reactive. The Curtius rearrangement, mechanism shown in Scheme 3.1, which involves the pyrolysis of acyl-azides to an isocyanate takes place below $100{ }^{\circ} \mathrm{C} .^{2}$ On the other hand alkyl-azides, which are widely applied in click chemistry, are stable till well over $200{ }^{\circ} \mathrm{C} .{ }^{3}$ An example of a click chemistry reaction with alkyl-azide as starting ingredient is given in Scheme 3.2.

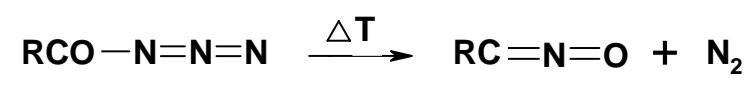

Scheme 3.1: Curtius rearrangement of acyl-azide

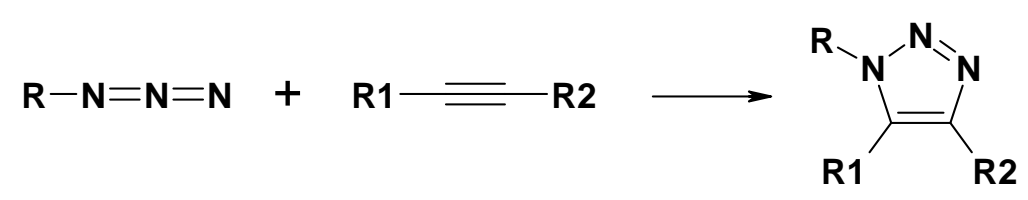

Scheme 3.2: Click chemistry reaction with alkyl azide

This chapter will give an overview of the properties and also the synthetic routes for four types of azide functionalities. The sulfonyl azide and azidoformate are the first choice as they were earlier investigated for cross-linking, as well as for modification of a variety of elastomers. ${ }^{4-16}$ Aryl- and alkyl-azides are described as the most stable ones ${ }^{1}$, and therefore they seem suitable to start experiments with, in order to obtain a better feel for how to handle and store this type of compounds. The fact that arylazides are often commercially available is an additional advantage.

According to safety reports ${ }^{17}$, small organic molecules containing the azide structure tend to decompose violently, irrespective what type of direct molecular environment the azide group has. To make an azide compound relatively safe, the "rule of six" ought to be applied. Six carbon atoms or other atoms of similar size per azide functionality provide sufficient safety. In the study described in this thesis, most of the azides meet this requirement and no safety problems were ever experienced during experimentation. 


\subsection{Experimental}

\subsubsection{Materials}

4-Metoxybenzyloxycarbonyl azide (M-BAF, $95 \%$ ), 4-acetamidobenzenesulfonyl azide (A-PhSA, 97 \%), 2,6-bis(4-azidobenzylidene)-4-methylcyclohexanone (2,6 DPhA, 97 $\%$ ), 3,3'-diazido-diphenyl sulfone (3,3'SDPhA, $97 \%$ ) and 4-azidophenyl isothiocyanate (NCS-PhA, $97 \%$ ) were purchased from Sigma-Aldrich company. 6-Azido-nhexylamine (AHA, $97 \%$ ) was obtained from Fluorochem.

The other azides were synthesized from the corresponding bromides and chlorides. Bisphenol-A-bis(chloroformate) (95\%), tri(ethylene glycol)-bis(chloroformate) (97\%), benzyl chloroformate (95\%), phenyl chloroformate (99\%), 1,3-benzenedisulfonyl chloride (97\%), benzenesulfonyl chloride (99\%), 1,12-dibromododecane (95\%) and 1,6-dibromohexane (96\%) were all purchased from Sigma-Aldrich; sodium azide (99 $\%)$ from Acros. Sodium hydrogen sulfite and chlorosulfonic acid (99\%) were also purchased from Acros.

Ethylene/propylene copolymer rubber, EPM (Keltan 3200A), ethylene content $49 \%$, Mooney viscosity $\mathrm{ML}(1+4) 100^{\circ} \mathrm{C}$ of 51 , was kindly supplied by DSM Elastomers BV. Carbon black (N-550) was obtained form Cabot Corporation. The coagent: N,N'-mphenylenebismaleimide (HVA-2, $97 \%$ ) was purchased from Acros. Dicumyl peroxide (DCP, Perkadox BC-40, 40 \% on carrier) was kindly provided by Akzo Nobel.

\subsubsection{Characterization of the products}

\section{${ }^{1} \mathrm{H}$-NMR spectroscopy}

Proton magnetic resonance spectroscopy ( $\left.{ }^{1} \mathrm{H}-\mathrm{NMR}\right)$ was performed on a Bruker 300 $\mathrm{MHz}$ NMR spectrometer at $25{ }^{\circ} \mathrm{C}$ with deuterated chloroform $\left(\mathrm{CDCl}_{3}\right)$ as solvent and tetramethylsilane (TMS) as a standard. The purity of the synthesized compounds was calculated by integration of the ${ }^{1} \mathrm{H}-\mathrm{NMR}$ spectra according to the eq. 3.1.

$$
\frac{I n^{\text {product }} \times M w^{\text {product }}}{I n^{\text {product }} \times M w^{\text {product }}+\sum\left(\operatorname{In}^{\text {impurity }} \times M w^{\text {impurity }}\right)} \times 100 \%
$$

Where:

In = integration of a proton;

$M w=$ molecular weight of a species. 


\section{FT-IR spectroscopy}

Fourier transform infrared (FT-IR) spectra were recorded on a Perkin Elmer 100 Series system using an Attenuated Total Reflectance (ATR) attachment, which enables samples to be examined in the solid or liquid state without further preparation. The spectra were recorded with a resolution $4.0 \mathrm{~cm}^{-1}$, the number of scans was 16 and the scan range $4000-650 \mathrm{~cm}^{-1}$.

DSC

Thermal properties of the different di- and mono-azides were measured using a Perkin-Elmer DSC 7. Differential scanning calorimetry (DSC) measurements provided information about the melt properties and also the decomposition temperatures of the particular azides. The samples were weighed into stainless cups with a rubber ring and the experiments were carried out using an empty cup as a reference. All azides were tested in pure form at a heating rate of $10{ }^{\circ} \mathrm{C} / \mathrm{min}$ using nitrogen as purge gas.

For kinetic studies, some of the azides were dissolved in chlorobenzene $(0.1 \mathrm{M}$ solution) and around $15 \mathrm{mg}$ of the solution was scanned with a heating rate of 3 ${ }^{\circ} \mathrm{C} / \mathrm{min}$. The azide may react with the solvent, but the reaction rate is still proportional to the heat production. This method is also commonly applied to measure the kinetic parameters of organic peroxides.

\section{Rubber compounding}

To investigate the cross-linking ability of the different di-azides, $100 \mathrm{phr}$ of EPM and $60 \mathrm{phr}$ of carbon black were mixed in a Brabender Plasticorder internal mixer of 370 $\mathrm{cm}^{3}$ volume, with a fill factor of $70 \%$. A fixed amount of $4.4 \mathrm{mmol}$ of each di-azide was added later on a Schwabenthan two roll mill at a temperature around $40{ }^{\circ} \mathrm{C}$. The reference sample was cured with $4.4 \mathrm{mmol}$ ( $3 \mathrm{phr}$ ) of peroxide and $7.5 \mathrm{mmol}(2 \mathrm{phr}$ ) of coagent. The curatives were compared on a molar basis instead of weight basis, in order to obtain a fair comparison of the functionalities of the different chemical species. In abstraction reactions, one mole of peroxide can in principle form one mole of cross-links, so the maximum efficiency of a peroxide in the present case is one. ${ }^{18}$ For the purpose of the present study, the maximum efficiency of di-azides was assumed to be one as well.

\section{Compound characterization}

The cure characteristics of the different compounds were determined using a Rubber Process Analyzer, RPA 2000, from Alpha Technologies. The torque value (S') was measured at $0.2 \mathrm{deg}$ strain and $0.833 \mathrm{~Hz}$ frequency. The optimal vulcanization temperature estimated based on the DSC data was $150{ }^{\circ} \mathrm{C}$ for the azidoformates and $180^{\circ} \mathrm{C}$ for both sulfonyl-azides and 2,6DPhA. The other aryl-azide, 3,3'SDPhA shows 
a maximum decomposition at around $200{ }^{\circ} \mathrm{C}$, the $1,6 \mathrm{DAH}$ at $220^{\circ} \mathrm{C}$ and $1,12 \mathrm{DAD}$ at $230{ }^{\circ} \mathrm{C}$. Subsequently, some of the compounds were cured by compression molding into $2 \mathrm{~mm}$ thick samples in a Wickert laboratory press, for duration of $\mathrm{t}_{90}$ of the specific compounds. The mechanical properties of the vulcanized samples were determined using a Zwick tensile tester, according to the conditions given in ISO 37, on dumb-bell shaped specimens (Type 2) and at a testing rate of $500 \mathrm{~mm} / \mathrm{min}$. The hardness of the specific compounds was measured with a Zwick hardness tester, Shore A type, according to DIN 53517.

\subsubsection{Synthesis of non-commercial azides}

An overview of both commercial and synthesized azides is given in Tables 3.1 (a), (b), (c) and (d).

\section{Alkyl azides}

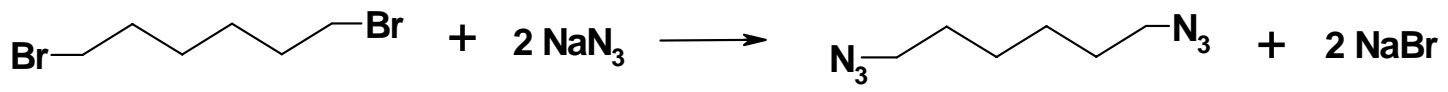

Scheme 3.3: Synthesis of 1,6-diazidohexane

Both 1,6-diazidohexane (1,6DAH) and 1,12-diazidododecane (1,12DAD) were synthesized in a similar manner from the corresponding bromides according to the recipe reported by Alvarez and Alvarez. ${ }^{19}$ The 1,6-diazidohexane reaction scheme is shown in Scheme 3.3. Both di-alkyl azides appear at room temperature as transparent oily liquids. The reaction yield of $1,6 \mathrm{DAH}$ based on the starting material was $85 \%$. The purity calculated from the ${ }^{1} \mathrm{H}-\mathrm{NMR}$ spectrum according to eq. 3.1 was $95 \%$. ${ }^{1} \mathrm{H}-\mathrm{NMR}$ $\left(\mathrm{CDCl}_{3}\right): \delta 1.28(\mathrm{~m}, 16 \mathrm{H}), \delta 1.55(\mathrm{~m}, 4 \mathrm{H}), \delta 1.3 .2(\mathrm{t}, 4 \mathrm{H})$. The 1,12DAD had a purity of 93 \%. Yield: $80 \%$. ${ }^{1} \mathrm{H}-\mathrm{NMR}\left(\mathrm{CDCl}_{3}\right): \delta 1.28(\mathrm{~m}, 16 \mathrm{H}), \delta 1.55(\mathrm{~m}, 4 \mathrm{H}), \delta 1.3 .2(\mathrm{t}, 4 \mathrm{H})$.

\section{Sulfonyl azides (SA)}

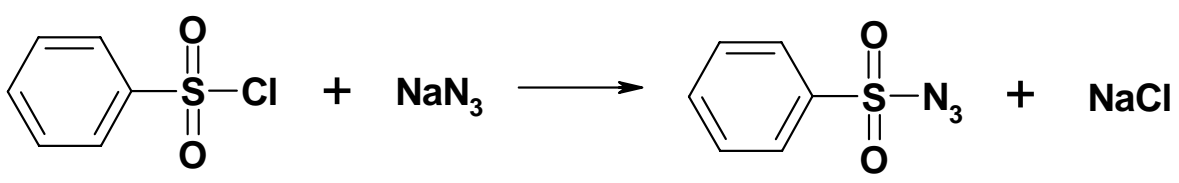

Scheme 3.4: Synthesis of phenylsulfonyl azide

Phenylsulfonyl azide (PhSA) was prepared from phenylsulfonyl chloride as shown in Scheme 3.4 . A solution of $1.9 \mathrm{~g}(0.029 \mathrm{~mol})$ sodium azide in $75 \mathrm{ml}$ water was added drop-wise to a solution of $5 \mathrm{~g}(0.028 \mathrm{~mol})$ phenylsulfonyl chloride dissolved in $150 \mathrm{ml}$ acetone. During the addition the temperature was kept below $5{ }^{\circ} \mathrm{C}$ using an ice-salt 
bath. The reaction was then carried out for 2 hours, with stirring and while maintaining a low temperature. The reaction mixture was extracted with dichloromethane and the organic layer was dried over $\mathrm{MgSO}_{4}$. After filtration of the $\mathrm{MgSO}_{4}$, the solution was evaporated under reduced pressure at low temperature to prevent decomposition. The reaction produces a transparent liquid with a purity of $99 \%$. Yield: $98 \%$. ${ }^{1} \mathrm{H}-\mathrm{NMR}$ $\left(\mathrm{CDCl}_{3}\right)$ : $\delta 7.61(\mathrm{t}, 2 \mathrm{H}), \delta 7.72(\mathrm{t}, 1 \mathrm{H}), \delta 7.98(\mathrm{~d}, 2 \mathrm{H})$.

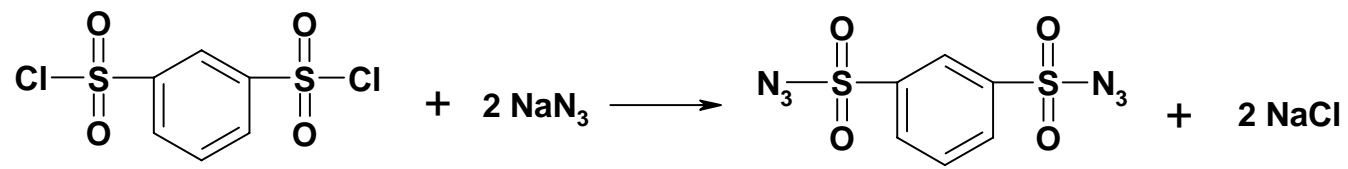

Scheme 3.5: Synthesis of 1,3-benzenedisulfonyl azide

1,3-Benzenedisulfonyl azide (1,3BDSA) was synthesized from 1,3-benzenedisulfonyl chloride and sodium azide by the Forster-Fiertz reaction as described in literature. ${ }^{20,21}$ The scheme of this reaction is shown in Scheme 3.5. The white powder of 1,3BDSA was $99 \%$ pure with a melting point of $84-86{ }^{\circ} \mathrm{C}$ (lit. $84-85{ }^{\circ} \mathrm{C}$ ). ${ }^{20}$ Yield: $97 \%$. ${ }^{1} \mathrm{H}-\mathrm{NMR}$ $\left(\mathrm{CDCl}_{3}\right): \delta 7.90(\mathrm{t}, 1 \mathrm{H}), \delta 8.28(\mathrm{~d}, 2 \mathrm{H}), \delta 8.52(\mathrm{~s}, 1 \mathrm{H})$.

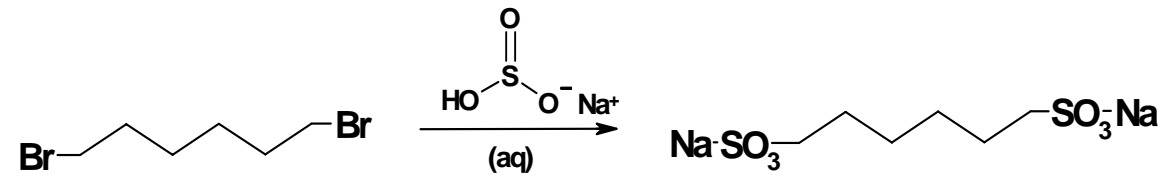

Step I

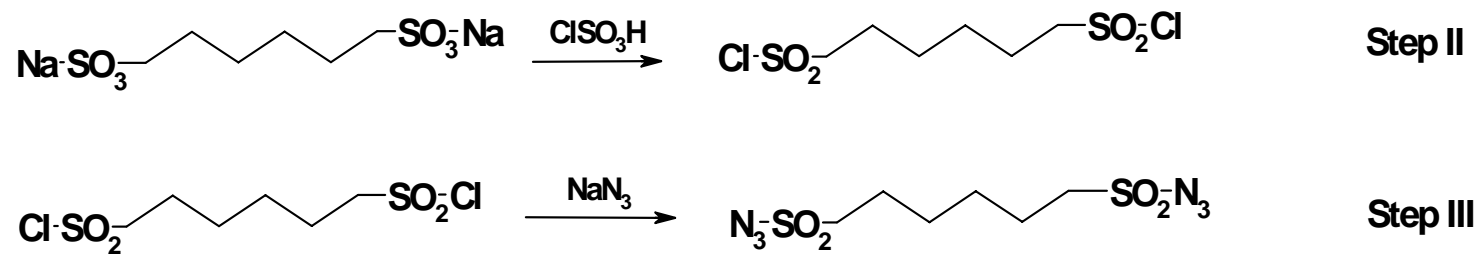

Scheme 3.6: Synthesis of 1,6-hexanedisulfonyl azide

1,6-Hexanedisulfonyl azide (1,6HDSA) was synthesized in a three step reaction as shown in Scheme 3.6. The first step involves refluxion of 1,6-dibromohexane with a saturated aqueous solution of sodium hydrogen sulfite (or sodium sulfite) until the organic layer disappears (around $48 \mathrm{~h}$ ). In the second step 1,6-hexanedisulfonic acid, the di-sodium salt was vigorously stirred with chlorosulfonic acid; the reaction was carried out at room temperature for around $24 \mathrm{~h}$. The last step is the same ForsterFiertz reaction as in the case of 1,3BDSA. A more precise description can by found elsewhere. ${ }^{20}$ The product was isolated as a brown powder with a purity of $98 \%$ and melting point of $87-89{ }^{\circ} \mathrm{C}$ (lit. $89-90{ }^{\circ} \mathrm{C}$ ). The reaction yield was around $40 \% .{ }^{1} \mathrm{H}-\mathrm{NMR}$ $\left(\mathrm{CDCl}_{3}\right): \delta 1.54-1.58(\mathrm{~m}, 4 \mathrm{H}), \delta 1.91-1.99(\mathrm{~m}, 4 \mathrm{H}), \delta 3.3(\mathrm{t}, 4 \mathrm{H})$. 


\section{Azidoformates (AF)}

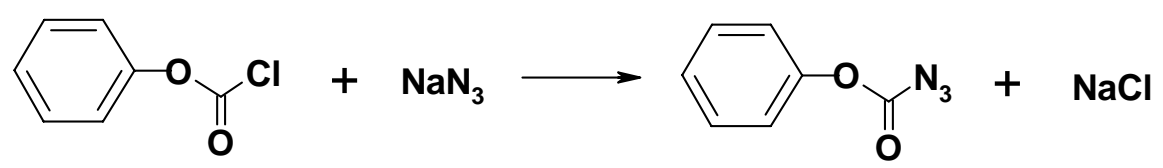

Scheme 3.7: Synthesis of phenylazidoformate

Phenylazidoformate (PhAF) was synthesised form phenylchloroformate in the same way as was described for phenylsulfonyl azides, Scheme 3.7. PhAF was obtained as a brown liquid, $98 \%$ pure. Yield: $97 \%$. ${ }^{1} \mathrm{H}-\mathrm{NMR}\left(\mathrm{CDCl}_{3}\right): \delta 7.25(\mathrm{~d}, 2 \mathrm{H}), \delta 7.37(\mathrm{t}, 1 \mathrm{H})$, $\delta 7.4(t, 2 \mathrm{H})$.

The other di- and mono-azidoformates were prepared in a similar manner from corresponding chloroformates:

Benzyl azidoformate (BAF) appeared at room temperature as a transparent oil with a purity of $94 \%$. Yield: $95 \%$. ${ }^{1} \mathrm{H}-\mathrm{NMR}\left(\mathrm{CDCl}_{3}\right)$ : $\delta 5.21(\mathrm{~s}, 2 \mathrm{H}), \delta 7.37(\mathrm{~m}, 5 \mathrm{H})$. In this case the starting material which was a benzyl chloroformate, contained a certain amount of benzyl chloride. The amount of benzyl chloride in the final product determined by integration of the ${ }^{1} \mathrm{H}-\mathrm{NMR}$ signals was around $5 \%$.

4,4'-Isopropylidenediphenyl azidoformate (4,4'DAF) was obtained as brown crystals, $95 \%$ pure with a melting point of $68-71{ }^{\circ} \mathrm{C}$. Yield: $91 \% .{ }^{1} \mathrm{H}-\mathrm{NMR}\left(\mathrm{CDCl}_{3}\right): \delta 1.67(\mathrm{~s}$, $6 \mathrm{H}), \delta 7.06(\mathrm{~d}, 4 \mathrm{H}), \delta 7.22(\mathrm{~d}, 4 \mathrm{H})$.

Tri(ethylene-glycol)-di-azidoformate (GDAF) was obtained as a oily liquid with a purity of $98 \%$. Yield: $96 \%$. ${ }^{1} \mathrm{H}-\mathrm{NMR}\left(\mathrm{CDCl}_{3}\right)$ : $\delta 3.65-3.75(\mathrm{~m}, 8 \mathrm{H}), \delta 4.35-4.38(\mathrm{~m}, 4 \mathrm{H})$.

Table 3.1(a) Investigated alkyl azides

\begin{tabular}{c|c|ccc}
\hline \multirow{2}{*}{ Abbreviation } & Structure & \multicolumn{3}{|c}{ Thermal Characteristics (DSC) } \\
& $\begin{array}{c}\text { Melt. point } \\
\left({ }^{\circ} \mathrm{C}\right)\end{array}$ & $\begin{array}{c}\text { Onset of Dec. } \\
\left({ }^{\circ} \mathrm{C}, \pm 2\right)\end{array}$ & $\begin{array}{c}\text { Max. Dec. } \\
\left({ }^{\circ} \mathrm{C}, \pm 1.1\right)\end{array}$ \\
\hline 1,6DAH & $\mathrm{NH}_{2}$ & - & 214 & 244 \\
1,12DAD & $\mathbf{N}_{3}\left(\mathrm{CH}_{2}\right)_{6} \mathbf{N}_{3}$ & - & 201 & 225 \\
& $\mathbf{N}_{3}\left(\mathrm{CH}_{2}\right)_{12} \mathbf{N}_{3}$ & - & 210 & 236 \\
\hline
\end{tabular}


Table 3.1(b) Investigated aryl azides

\begin{tabular}{c|c|cc}
\hline \multirow{2}{*}{ Abbreviation } & Structure & \multicolumn{2}{c}{$\begin{array}{c}\text { Thermal Characteristics (DSC) } \\
\text { Melt. point } \\
\left({ }^{\circ} \mathrm{C}\right)\end{array}$} \\
\hline Onset of Dec. \\
$\left({ }^{\circ} \mathrm{C}, \pm 2\right)$
\end{tabular}

Table 3.1(c) Investigated sulfonyl azides

\begin{tabular}{|c|c|c|c|c|}
\hline \multirow{2}{*}{ Abbreviation } & \multirow{2}{*}{ Structure } & \multicolumn{3}{|c|}{ Thermal Characteristics (DSC) } \\
\hline & & $\begin{array}{c}\text { Melt. point } \\
\left({ }^{\circ} \mathrm{C}\right)\end{array}$ & $\begin{array}{c}\text { Onset of Dec. } \\
\left({ }^{\circ} \mathrm{C}, \pm 2\right)\end{array}$ & $\begin{array}{l}\text { Max. Dec. } \\
\left({ }^{\circ} \mathrm{C}, \pm 1.1\right)\end{array}$ \\
\hline PhSA & & - & 134 & 192 \\
\hline A-PhSA & & $107-111$ & 131 & 187 \\
\hline $1,3 B D S A$ & & $84-86$ & 120 & 184 \\
\hline $1,6 \mathrm{HDSA}$ & & $87-89$ & 137 & 204 \\
\hline
\end{tabular}

Table 3.1(d) Investigated azidoformates

\begin{tabular}{|c|c|c|c|c|}
\hline \multirow{2}{*}{ Abbreviation } & \multirow{2}{*}{ Structure } & \multicolumn{3}{|c|}{ Thermal Characteristics (DSC) } \\
\hline & & $\begin{array}{l}\text { Melt. point } \\
\left({ }^{\circ} \mathrm{C}\right)\end{array}$ & $\begin{array}{c}\text { Onset of Dec. } \\
\left({ }^{\circ} \mathrm{C}, \pm 2\right)\end{array}$ & $\begin{array}{l}\text { Max. Dec. } \\
\left({ }^{\circ} \mathrm{C}, \pm 1.1\right)\end{array}$ \\
\hline PhAF & & - & 115 & 159 \\
\hline BAF & & - & 114 & 161 \\
\hline M-BAF & & $30-32$ & 109 & 160 \\
\hline 4,4'DAF & & $68-71$ & 109 & 157 \\
\hline GDAF & & - & 104 & 158 \\
\hline
\end{tabular}


In summary, the yields of the two alkyl-azides, 1,6DAH and 1,12DAD were 85 and 80 $\%$ respectively, although according to literature data it is possible to achieve higher efficiencies. ${ }^{19}$ The sulfonyl-azides and azidoformates synthesized from corresponding chlorides showed a higher reaction yield, always above $90 \%$ 1,6HDSA was synthesized from 1,6-dibromohexane in multi step reaction and therefore in this case the yield, estimated on basis of the starting material was only $40 \%$. The purity of the final products determined by integration of the ${ }^{1} \mathrm{H}-\mathrm{NMR}$ spectra was always between 93 - $99 \%$ for all synthesized compounds.

\subsection{Results and discussion}

\subsubsection{FT-IR characterization of the azides}

All compounds, whether synthesized or commercially obtained, were characterized using Fourier Transform Infrared Spectroscopy (FT-IR). The alkyl-azides are characterized by medium intensity alkyl bands at $2855-2936 \mathrm{~cm}^{-1}$ and $1455-1465 \mathrm{~cm}^{-1}$, and strong azide bands at 2088-2092 $\mathrm{cm}^{-1}$. The aryl-azides show the azide bands at $2102-2109 \mathrm{~cm}^{-1}$ and the aromatic ring bands at $1589-1596 \mathrm{~cm}^{-1}$. The sulfonyl-azides have strong azide bands at $2117-2147 \mathrm{~cm}^{-1}$, and sulfonyl bands at $1347-1367 \mathrm{~cm}^{-1}$ and $1153-1159 \mathrm{~cm}^{-1}$. The azidoformates show strong absorptions at $2205-2129 \mathrm{~cm}^{-1}$ : the azide bands, and at $1716-1735 \mathrm{~cm}^{-1}$ and $1193-1217 \mathrm{~cm}^{-1}$ : the two formate bands. Some examples of spectra of different azide types are shown in Fig. 3.1.

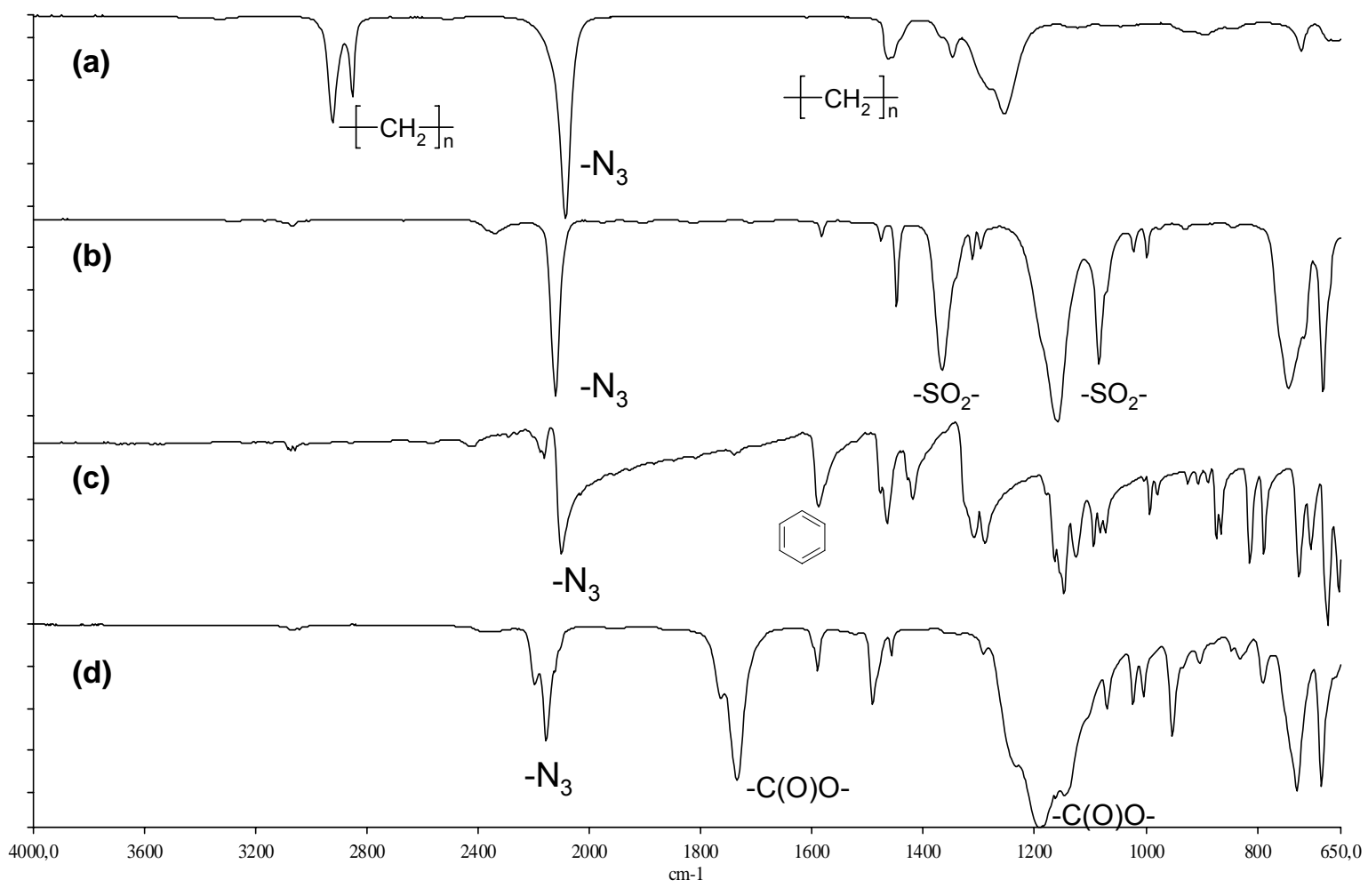

Fig. 3.1: FT-IR spectra of (a): 1,12DAD; (b): PhSA; (c): 3,3'SDPhA and (d): PhAF 
Though generally all the azides absorb at around $2100 \mathrm{~cm}^{-1}$, there are some differences. The alkyl-azides and sulfonyl-azides give very characteristic, sharp signals; the aryl-azide bands appear as sharp peaks at the high wavelength side and become very broad on the low wavelength side. The azidoformate bands are not very sharp, rather wide and resemble two overlapping signals though the intensity of the second peak varies for the different molecules.

\subsubsection{Thermal properties of the azides}

To determine the thermal properties of the different mono- and di-azides, DSC analysis was performed. The compounds were examined in the pure state with a scanning rate $10{ }^{\circ} \mathrm{C} / \mathrm{min}$. Overall, all DSC curves show large exothermic peak due to azide decomposition as shown in Figs. 3.2 (a) - (d). The obtained data confirm that the temperature range in which decomposition of a particular azide occurs, is greatly influenced by the type of azide functionality. From all the investigated azides, the alkylazides are the most stable, though the temperature range in which the particular compounds do decompose are different. Out of the three alkyl-azides tested, 1,6DAD is most reactive with the onset of decomposition at $201^{\circ} \mathrm{C}$, and maximum rate at 225 ${ }^{\circ} \mathrm{C}$. The compounds with aryl-azide functionalities are already much more reactive. Two of the aryl-azides, 3,3'SDPhA and NCS-PhA, start to react respectively at 136 and $147{ }^{\circ} \mathrm{C}$ and reach their maximum decomposition rates at 198 and $206{ }^{\circ} \mathrm{C}$. The third aryl-azide, 2,6 DPhA decomposes even faster, immediately once it has reached its melting point, and the maximum of the decomposition curve is at $166{ }^{\circ} \mathrm{C}$.

(a)

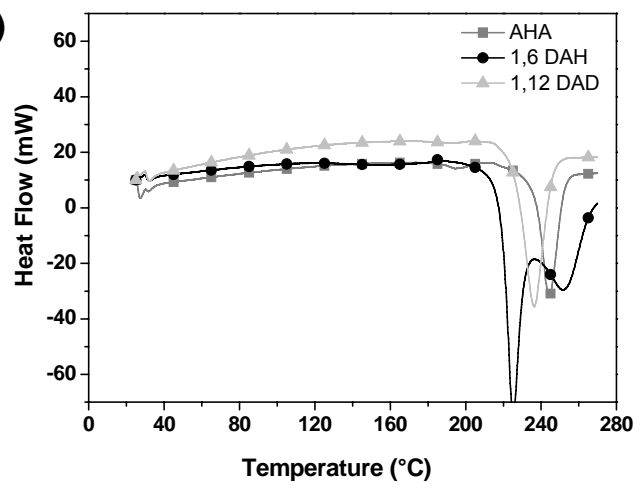

(b)

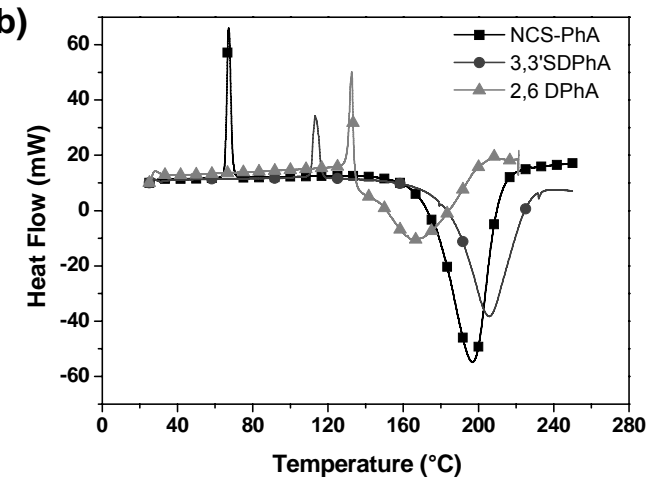


(c)

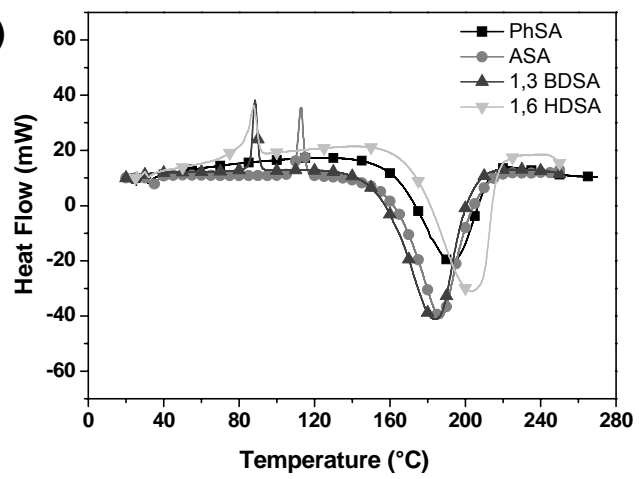

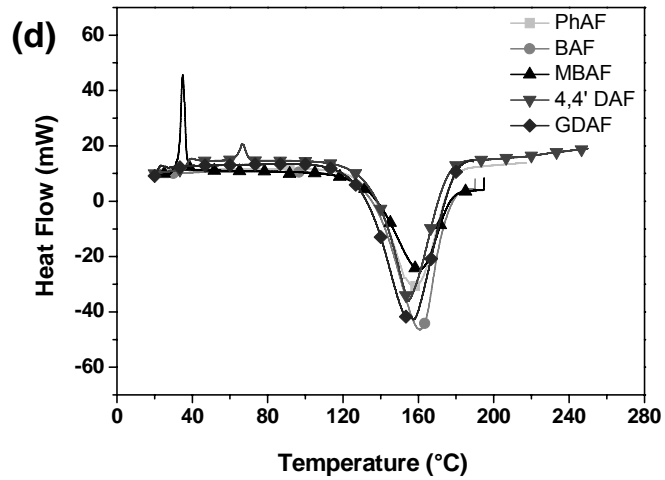

Fig. 3.2: DSC curves of (a): alkyl-azides; (b): aryl-azides; (c): sulfonyl azides, (d): azidoformates

Out of the four investigated sulfonyl-azides, the $1,3 \mathrm{BDSA}$ starts to react first at $120{ }^{\circ} \mathrm{C}$ while the onset of $1,6 \mathrm{HDSA}$ decomposition is at $137^{\circ} \mathrm{C}$. The azidoformates have the lowest decomposition temperatures and both mono- and di-functional molecules decompose in a very similar temperature range. At a given heating rate all azidoformates have the onset of the exothermic peaks between $109-115^{\circ} \mathrm{C}$ and their maximum at $157-161{ }^{\circ} \mathrm{C}$. The temperatures close to the maximum of the exothermic peaks were later on used as reaction temperatures for vulcanization. The exact temperatures corresponding to the onset and the maximum of the decomposition path for each of the investigated azides are given in Tables 3.1 (a) - (d).

\subsubsection{Cross-linking abilities of the di-azides}

To determine which of the investigated azide types have the highest potential as cross-linking agents for saturated elastomers, the EPM-compound was prepared and cured with a fixed amount of $4.4 \mathrm{mmol}$ of each di-azide. The pure rubber, even after cross-linking, hardly had any strength. Therefore carbon black reinforced EPMcompound was used to obtain more clear differences between the performances of each di-azide.

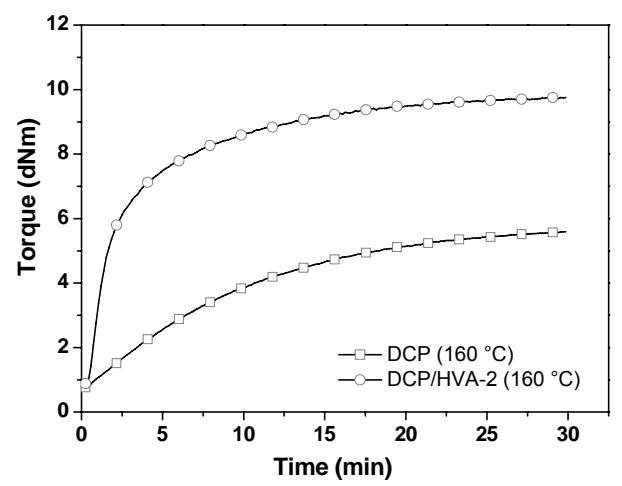

Fig. 3.3: Cure curves of the reference samples 


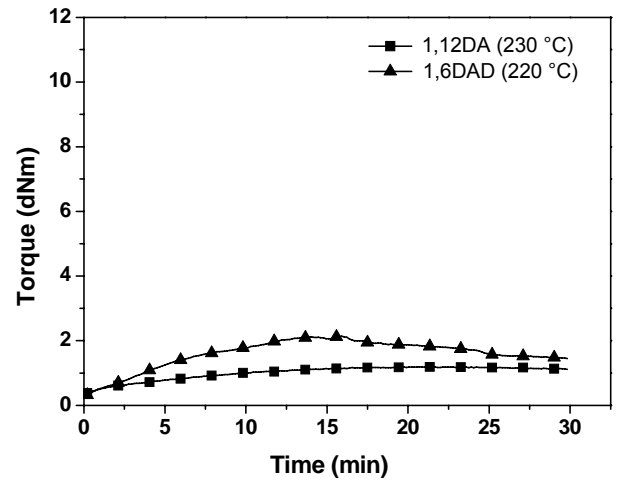

Fig. 3.4: Cure curves of di-alkyl azides

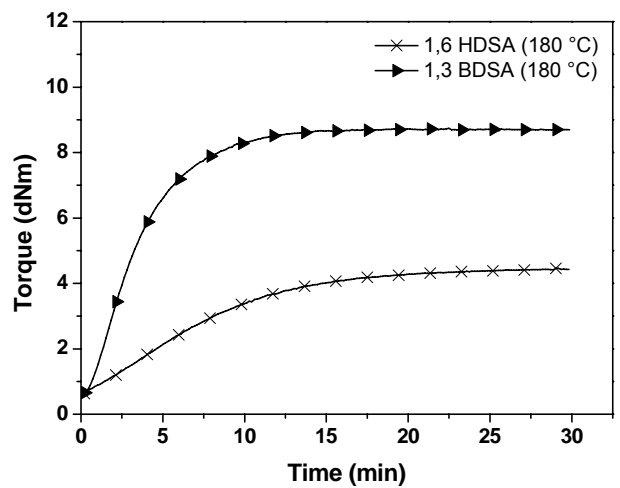

Fig. 3.6: Cure curves of di-sulfonyl azides

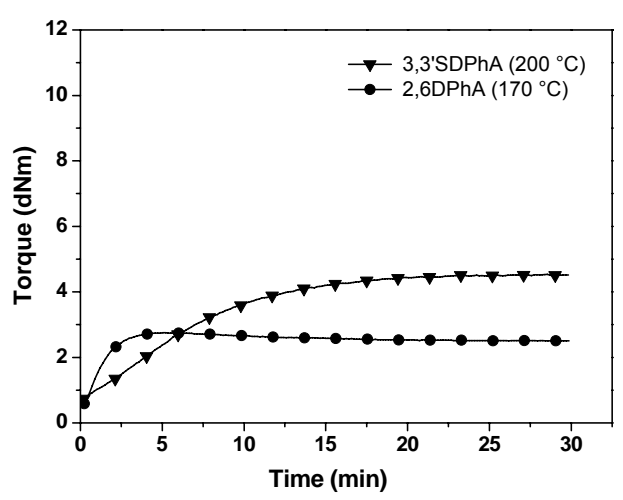

Fig. 3.5: Cure curves of di-aryl azides

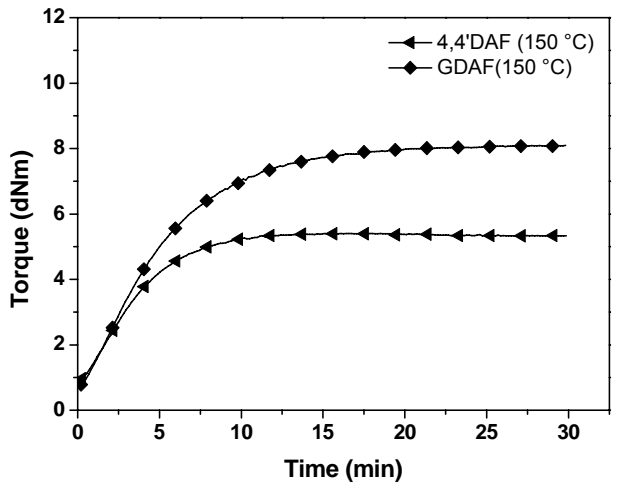

Fig. 3.7: Cure curves of di-azidoformates

The same EPM-compound vulcanized with peroxide, both with and without coagent, was used as a reference. Fig. 3.3 shows the cure curves for the peroxide-cured samples. Figs. $3.4-3.7$ show the cure characteristics of various di-azides at their respective optimum decomposition temperatures. The cure characteristics clearly show that the peroxide alone is not efficient enough in vulcanization of the EPMcompound and that the use of coagent is necessary to provide a sufficient cross-link level. As to the di-azide curing, both di-alkyl azides: 1,6DAH and 1,12DAD hardly introduce any cross-links into the polymer. The slight increase in torque can be caused by a minor amount of cross-linking or can even be due to the inner pressure created by nitrogen that is released at the high temperature. This lack of cross-linking can be explained by the fact that alkyl-azides are known to undergo a rearrangement reaction, with 1,2-hydrogen shift, as shown on Scheme 3.8. ${ }^{22}$

$$
\mathrm{RCH}_{2}-\mathrm{N}=\mathrm{N}=\mathrm{N} \quad \frac{\Delta \mathrm{T}}{-\mathrm{N}_{2}} \quad \mathrm{R}-\underset{\mathrm{H}}{\stackrel{\Gamma}{\mathrm{C}}-\overline{\mathrm{N}}} \longrightarrow \mathrm{RCH}=\mathrm{NH}
$$

Scheme 3.8: Possible rearrangement mechanism of alkyl-azides 
This reaction is described in literature as proceeding very fast. Despite a number of studies into these aspects, the real mechanism of this rearrangement is still not fully clear. $^{23,24}$ The question is whether, once the azide group is decomposed, a free nitrene is created or not. The results of the present investigation do not contribute to the elucidation of the mechanism but they exclude this type of di-alkyl azides as suitable curing agents for saturated elastomers.

For the two di-aryl azides, 2,6DPhA and 3,3'SDPhA, the rheograms show some torque developments that indicates cross-link formation. However, the torque level is still low, even compared to the sample vulcanized by peroxide only. Furthermore, the cured samples contained a lot of porosity. Because of the poor curing properties of the dialkyl azides and the porosity problems with the di-aryl azides, they were not further tested. Also their high decomposition temperatures are a disadvantage.

The two di-sulfonyl azides, 1,3BDSA and 1,6HDSA, lead to surprisingly dissimilar results. $1,3 \mathrm{BDSA}$, which is already known from literature as a good curing agent, leads to high torque values similar to those obtained by using the peroxide coagent crosslinking system. The performance of $1,6 \mathrm{HDSA}$ on the other hand, was more comparable to that of the di-aryl azides and therefore it was also excluded from the mechanical testing. The two di-azidoformates also lead to quite different results. GDAF curing gives a high torque value, similar to the performance of $1,3 B D S A$, while the second diazidoformate, 4,4'DAF results in an intermediate torque level.

\subsubsection{Mechanical properties of vulcanizates}

The mechanical properties of the compounds cured with peroxide, peroxide/coagent combination and the three di-azides that showed the best crosslink ability: 1,3BDSA, GDAF and 4,4'DAF, are given in Figs. 3.8 - 3.11 for tensile strength, elongation at break, moduli $100 \%, 200 \%$ and $300 \%$ and hardness.

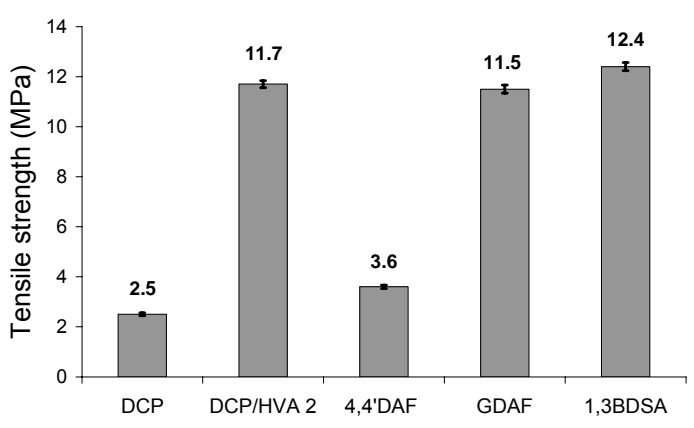

Fig. 3.8: Tensile strength obtained with different di-azides, DCP and DCP/HVA-2

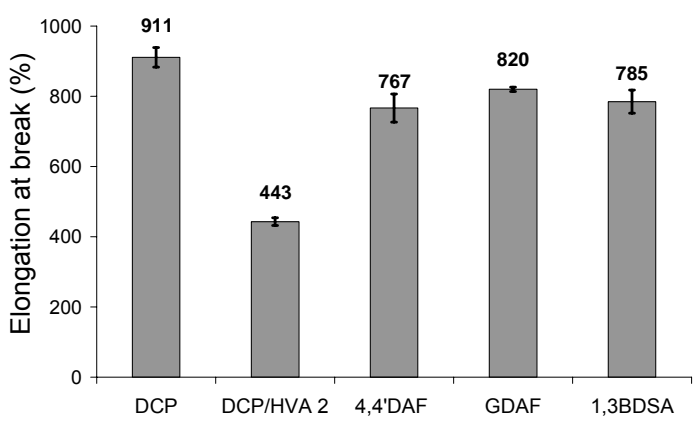

Fig. 3.9: Elongation at break obtained with different di-azides, DCP and DCP/HVA-2 


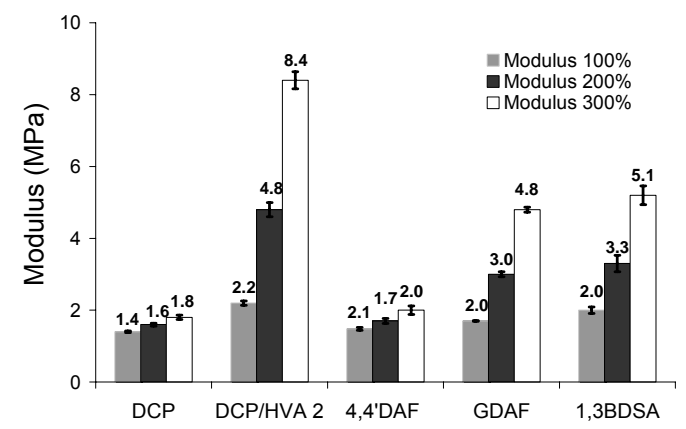

Fig. 3.10: Modulus at 100, 200 and $300 \%$ obtained with different di-azides, DCP and DCP/HVA-2

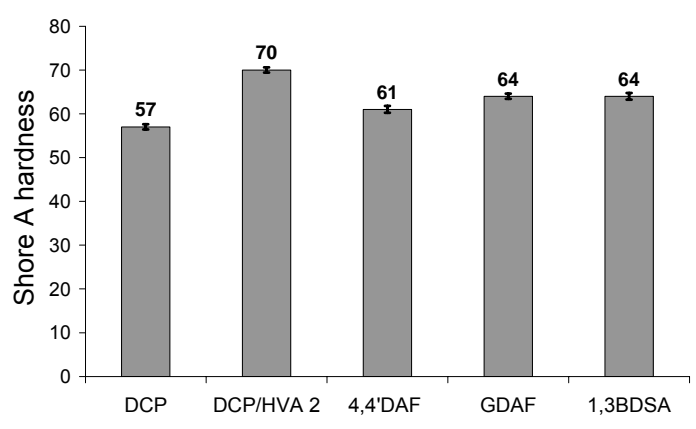

Fig. 3.11: Shore A hardness obtained with different di-azides, DCP and DCP/HVA-2

When comparing the mechanical properties of the carbon black reinforced EPM vulcanized with 1,3BDSA to the conventional peroxide/coagent system, it appears that the di-azide results in higher tensile strength and elongation at break but lower moduli and hardness. The tensile strength and moduli of the sample vulcanized with 4,4'DAF are only slightly higher than those obtained with peroxide only. The other diazidoformate, GDAF, gives high overall performance compared to the 1,3BDSA, as well as to the peroxide/coagent curing system. The large differences in mechanical properties of the two di-azidoformates are likely to be caused by either a variation in spatial structure of AF-group or a different solubility in EPM as a result of their respective chemical structures. It is also worth to mention that the di-azide cured samples are easy to release from the mould, where the peroxide/coagent cured sample showed the well-known bad release properties for such a system.

The comparison between the different di-azides: alkyl-, aryl-, sulfonyl-azides and azidoformates has shown that not all are suitable for cross-linking via thermal decomposition. The di-alkyl azides hardly introduce any cross-links, thus cannot be used as a curative. Both di-aryl azides lead to high porosity and result in very low strength material. However, the di-azidoformates and di-sulfonyl azide perform very well, looking at $1,3 B D S A$ and GDAF as examples. For that reason the following experiments were focused on molecules with azidoformate or sulfonyl azide functionalities only.

\subsubsection{Reaction kinetics of sulfonyl azides and azidoformates}

Based on DSC scans performed on some of the selected sulfonyl-azides and azidoformates dissolved in chlorobenzene, the kinetic parameters were calculated. Genneraly, the reaction kinetics of the azides are not very well described and therefore it was assumed that for each particular compound order of the decomposition reaction is close but not equal to one $(n \neq 1)$. The only exception was made for ASA which did not dissolve completely in chlorobenzene and thus the 
concentration of the investigated solution was not known. In this case a first order reaction was assumed $(n=1)$ for which the conversion of the reaction does not depend on the beginning concentration. The conversion rate of the decomposition reaction was calculated according to eq. 3.2.

$$
\frac{d x}{d t}=k C_{0}^{n-1}(1-x)^{n}
$$

Where:

$x=$ the degree of conversion as determined by the heat generation of the reaction;

$t=$ time;

$C_{o}=$ the beginning concentration;

$n=$ the reaction order;

$k=$ the rate constant described by the Arrhenius' equation, given as eq. 3.3.

$$
k=A e^{-E_{a} / R T}
$$

Where:

$A=$ the pre-exponential factor;

$E_{a}=$ the activation energy;

$R=$ the gas constant;

$T=$ temperature.

Combining eqs. 3.2 and 3.3 in logarithmic form:

$$
\ln \left(\frac{d x}{d t}\right)=\ln \left(C_{o}^{-1} A\right)+E_{a}\left(-\frac{1}{R T}\right)+n \ln \left(C_{o}(1-x)\right)
$$

The activation energy, reaction order and the rate constant were calculated from eq. 3.4 using a multi-linear regression method and the results are given in Table 3.2.

Table 3.2 Rate constant, activation energy and reaction order of some azides

\begin{tabular}{c|c|c|c}
\hline Curatives & $\begin{array}{c}\boldsymbol{1} \\
(1 / \mathrm{s})\end{array}$ & $\begin{array}{c}\boldsymbol{E}_{\mathbf{a}} \\
(\mathrm{kJ} / \mathrm{mole})\end{array}$ & $\boldsymbol{n}$ \\
\hline GDAF & $3.3 * 10^{13}$ & 131.5 & 0.74 \\
4,4 'DAF & $6.5 * 10^{15}$ & 144.6 & 1.09 \\
MBAF & $7.8 * 10^{14}$ & 139.7 & 1.07 \\
1,3 BDSA & $2.2 * 10^{12}$ & 127.1 & 0.96 \\
ASA & $6.2 * 10^{15}$ & 158.3 & $\mathbf{1}$ \\
\hline BPO & $\mathbf{6 . 9} * \mathbf{1 0}$ & $\mathbf{1 2 2 . 3}$ & $\mathbf{1}$ \\
DCP & $\mathbf{9 . 2} * \mathbf{1 0}$ & $\mathbf{1 5 2 . 7}$ &
\end{tabular}


For half-life times $\left(t_{1 / 2}\right)$ of 0.1 hour, 1.0 hour and 10 hours the corresponding temperatures were calculated according to the eq. 3.5. The kinetic parameters of organic peroxides are commonly presented in exactly the same way, what makes it easy to compare.

$$
T_{1 / 2}=\left(R / E_{a}\right)\left(\ln \left(A C_{0}^{n-1}(n-1) t_{1 / 2}\right)-\ln \left(2^{n-1}-1\right)\right.
$$

The half-life times of investigated azides as well as of dibenzoyl peroxide (BPO) and dicumylperoxide (DCP) are shown in Fig. 3.12. As could be expected already from the previous DSC experiments at set temperature, the mono- and di-azidoformates have shorter half-life times compared to the sulfonyl-azide. Overall BPO has the shortest half-life time as well-known for peroxy-acids, while the line corresponding to DCP decomposition lies exactly between two investigated azide types. Thus to reach a certain half-life time, azidoformates require somewhat lower, and sulfonyl-azides somewhat higher temperatures compared to the DCP.

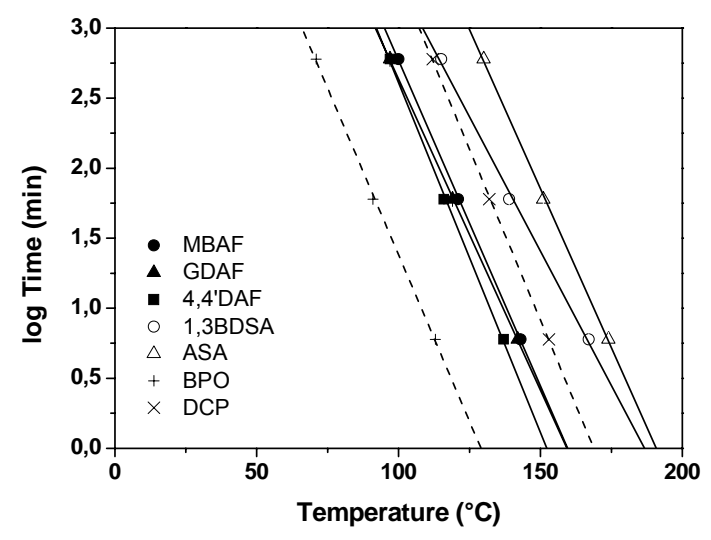

Fig. 3.12: Half -life times of various curatives

As to the inclination of the lines, dependent on the particular azide, they are equally or a little less steep than for the peroxides. Where peroxides are known for their sharp decomposition in temperature relative to e.g. sulfur vulcanization systems, the data show that the azides position themselves more or less in the same range; indicating that the $E_{a}$ for both systems are within the same range. 
Table 3.3 Compounds in increasing stability order

\begin{tabular}{c|c}
\hline Curatives & $\mathrm{T}\left({ }^{\circ} \mathrm{C}\right)$ at $\mathrm{t}_{\mathbf{1 / 2}}=\mathbf{0 . 1 h}$ \\
\hline BPO & $\underline{113}$ \\
4,4'DAF & 137 \\
GDAF & 142 \\
MBAF & 143 \\
DCP & $\underline{153}$ \\
1,3BDSA & 167 \\
ASA & 174 \\
\hline
\end{tabular}

The compounds in increasing order of stability are given Table 3.3. The most reactive of the investigated compounds, BPO has a half-life time of 0.1 hour already at $113^{\circ} \mathrm{C}$. To reach the same half-life time, azidoformates require around $20-30$ and DCP $40{ }^{\circ} \mathrm{C}$ higher temperature. To reach the half-life time of 0.1 hour, sulfonyl-azides require still $15-20^{\circ} \mathrm{C}$ more then DCP.

\subsection{Conclusions}

Di-azides are easy to synthesize from their respective di-chlorides or bromides with a high yield. Of the four different azide functionalities investigated in this chapter, the alkyl-azides are not suitable for vulcanization purposes. They only react at high temperature above $200{ }^{\circ} \mathrm{C}$, and secondly are not reactive towards polymer chains due to a very quick rearrangement reaction. Di-aryl azides do give some, though unsatisfactory cross-linking, but excessive formation of porosity in the samples, which makes them unsuitable also for vulcanization purposes. Di-sulfonyl azides and diazidoformates perform very well with respect to their reaction temperature of 180 and $150{ }^{\circ} \mathrm{C}$, which is in a practical vulcanization range. The best performing di-azides are 1,3BDSA and GDAF.

As to the reaction kinetics of sulfonyl azides and azidoformates, they are equally reactive as dicumyl peroxide, and the activation energies are also in a comparable range.

\subsection{References}

1. G. L'Abbe, Chem.Rev., 69, 345 (1969).

2. S. Linke, G.T. Tisue and W. Lwowski, J. Am. Chem. Soc., 89, 6308 (1967).

3. H.C. Kolb, M. G. Finn and K. B. Sharpless, Angew. Chem. Int. Ed., 40, 2004 (2001).

4. D.S. Breslow, U.S. Patent 3,284,421 (1966).

5. R.D. Porter, S.W. Waisbrot, U.S. Patent 3,991,131 (1976).

6. S.E. Cantor, U.S. Patent 4,031,068 (1977). 
7. L. Gonzalez, A. Rodriguez, J.L. de Benito and A. Marcos, Rubber Chem. Technol., 69, 266 (1996).

8. L. Gonzalez, A. Rodriguez, J.L. de Benito and A. Marcos-Fernandez, J. Appl. Polym. Sci., 63, 1353 (1997).

9. D.S. Breslow and H.M. Spurlin, U.S. Patent 3,058,944 (1962).

10. D.S. Breslow, U.S. Patent 3,211,752 (1965).

11. D.S. Breslow and H.M. Spurlin, U.S. Patent 3,203,937 (1965).

12. H.W. Bost and J.E. Mahan, U.S Patent 3,282,864 (1966).

13. D.S. Breslow, W.D. Willis and L.O. Amberg, Rubber Chem. Technol., 43, 605 (1970).

14. J.L. de Benito Gonzalez, L. Ibarra Rueda and L. Gonzalez Hornandez, Kautsch. Gummi Kunstst., 43, 146 (1990).

15. J.L. de Benito Gonzalez, L. Ibarra Rueda and L. Gonzalez Hornandez, Kautsch. Gummi Kunstst., 43, 697 (1990).

16. M.A. Lopez Manchado and J.M. Kenny, Rubber Chem. Technol., 74, 204 (2001).

17. M. Peer, Spec. Chem., 18, 256 (1998).

18. P.R. Dluzneski, Rubber Chem. Technol. 74, 451 (2001).

19. S.G. Alvarez and M.T. Alvarez, Synthesis, 4, 413 (1997).

20. D.A. Baker, G.C. East and S.K. Murhopadhyay, J. Appl. Polym. Sci., 79, 1092 (2001).

21. J.K. Jorgensen, E. Ommundsen, A. Stori and K. Redford, Polymer, 46, 12073 (2005).

22. M.B. Smith and J. March, "March's advanced organic chemistry reactions, mechanisms and structure", $5^{\text {th }}$ edition, New York (2001).

23. J.M. Dyke, J. Phys. Chem. A 108, 5299 (2004).

24. J.I. Arenas and J.I. Marcos, Int. J. Quantum Chem. 84, 241 (2001). 


\title{
Chapter 4
}

\section{Cross-linking of EP(D)M-rubbers with di-azides: Mechanical properties of vulcanizates}

\begin{abstract}
For vulcanization of fully saturated elastomers, peroxide/coagent systems are commonly applied. Problems encountered with peroxides are reduced efficiencies, especially in the presence of plasticizing oils, and unwanted side reactions resulting in surface degradation (oxygen inhibition) and volatiles. In this chapter, di-azides are presented as alternatives to peroxide vulcanization systems, particularly in combination with the use of plasticizing oil. The performance of three di-azides; tri(ethylene glycol)di(azidoformate) (GDAF), 4,4'-isopropylidenediphenyl azidoformate (4,4'DAF) and 1,3-benzenedisulfonyl azide (1,3BDSA) is investigated. For the evaluation of the practical product performance, carbon black filled and oil extended compounds of EPM and EPDM-rubbers are used. It is also investigated how the presence of carbon black and oil influences the diazide reaction kinetics.
\end{abstract}




\subsection{Introduction}

Ethylene-Propylene (EPM) and Ethylene-Propylene-Diene (EPDM) copolymer rubbers are known for their high stability which results in an excellent ozone and heat resistance, but at the same time makes the materials difficult to cross-link. Especially EPM-rubber, without any double bonds in its structure, is quite an extreme example of a low reactivity polymer and it is not possible to vulcanize it with sulfur. The common way to overcome the low reactivity of EPM is by applying a free radical reaction initiated by a peroxide. However, the peroxides on their own are often unsatisfactory and to improve the efficiency of the peroxy-radical reaction a coagent is required. The positive effect of a coagent is especially significant in oil-containing compounds. It is well known that extender oils, particularly of the aromatic or naphthenic type show a strong de-activating effect on peroxides. ${ }^{1}$

Generally, rubber compounds consist of three main ingredients: polymer, filler and oil, where mostly carbon black or silica is the reinforcing filler and oil acts as a plasticizer. ${ }^{2}$ After these ingredients are mixed, the curatives are added and the compound is vulcanized. Although the role of oil is to improve the processability of a rubber compound, its influence is also visible in the properties of the final product. Even for sulfur cured materials, where no reaction with a plasticizer is expected, when increasing the amount of oil, higher loadings of curatives are required to keep the hardness and the modulus constant.

Azides are a class of organic compounds that are known for their reactivity towards alkanes. $^{3-17}$ Hence, it is interesting to study their performance in cross-linking of saturated $\operatorname{EP}(D) M$-rubbers. Generally, it is expected that di-azide vulcanization can result in superior dynamic/mechanical properties over peroxide-curing while maintaining good thermal stability. During peroxide-curing the polymer molecules are linked together by rigid carbon-carbon bonds, which results in inferior dynamic/mechanical properties of the vulcanizates compared to sulfur curing. Azide cross-linking should lead to structures where the whole azide compound acts as a bridge between two polymeric chains providing properties more similar to sulfur-curing while maintaining good thermal stability.

The di-azides investigated in this chapter are two di-azidoformates: tri(ethylene glycol)di(azidoformate) (GDAF) and 4,4'-isopropylidenediphenyl azidoformate (4,4'DAF) and one di-sulfonyl azide: 1,3-benzenedisulfonyl azide (1,3BDSA). They were selected based on the experiments described in the previous chapter. The di-azidoformates were subject of very few investigations and according to our knowledge the GDAF has never been mentioned in literature before. The 1,3BDSA on the other hand, is widely described as an effective curing agent for a number of polymers, saturated as well as unsaturated, and although other di-sulfonyl or di-azidoformate molecules are also 
mentioned, none of them is described nearly as well. ${ }^{8,10,13,14,18-21}$ For that reason the 1,3BDSA was taken along as a kind of reference for the di-azides performance.

The deactivating effect of plasticizing oil may be of particular interest in the present study, because of the close similarity between the saturated molecular structure of EPM and paraffinic oils and the non-selective tendency of azides to react with saturated hydrocarbons. It is therefore of importance to compare the di-azides performance with a peroxide/coagent curing system in combination with the use of plasticizing oils.

\subsection{Experimental}

\subsubsection{Materials}

The rubbers used for the experiments were an EPM (Keltan 3200 A) with ethylene content 49 wt\% and Mooney viscosity ML $(1+4) 100{ }^{\circ} \mathrm{C}$ of 51 and an ENB-EPDM (Keltan 4802) with ethylene content $52 \mathrm{wt} \%$, ethylidene-norbornene content $4.5 \mathrm{wt} \%$ and Mooney viscosity $\mathrm{ML}(1+4) 125^{\circ} \mathrm{C}$ of 77 , both supplied by DSM Elastomers BV. Paraffinic oils, Sunpar 150 (specific gravity: 0.88 at $15.6^{\circ} \mathrm{C}$, visc. $95 \mathrm{cSt}$ at $40{ }^{\circ} \mathrm{C}$ ) and highly purified white paraffinic oil (specific gravity: $0.85-0.87$ at $15.6{ }^{\circ} \mathrm{C}$, visc. $90-105$ $\mathrm{cSt}$ at $40{ }^{\circ} \mathrm{C}$ ) were obtained from Sun Oil Cie and ChevronTexaco, respectively. Carbon black N550 was supplied by Cabot Corporation. The co-agent: N,N'-mphenylenebismaleimide (HVA-2) was purchased from Acros. Dicumyl peroxide (DCP, Perkadox BC-40, $40 \%$ pure) was provided by AkzoNobel. All three di-azides: GDAF, 4,4'DAF and 1,3BDSA were synthesized from the corresponding chlorides and sodium azide as described in Chapter 3.

\subsubsection{Characterization of the products}

\section{Rubber compounding}

To investigate the influence of the paraffinic oils on the di-azide cross-linking, EPM compounds with different plasticizer contents were prepared. The compositions of the compounds are shown in Table 4.1 (comps. I-VII). Two types of paraffinic oils were investigated with different purities. All compounds were prepared using a Brabender Plasticorder internal mixer of $370 \mathrm{~cm}^{3}$ volume, using a fill factor of $70 \%$. The regular paraffinic oil extended samples were then vulcanized with $9.56 \mathrm{mmol}$ of each di-azide. Samples vulcanized with DCP peroxide and a peroxide/coagent combination were used as reference. Additionally the compounds containing high purity white parafinic oil were cross-linked with $9.56 \mathrm{mmol}$ of 4,4DAF. All curatives were added in a second step on a Schwabenthan two roll mill at a temperature of about $40{ }^{\circ} \mathrm{C}$. The compositions of the curing recipes are shown in Table 4.2. 
Table 4.1: Various EPM and EPDM based compounds (phr)

\begin{tabular}{lccccccccc}
\hline Components & I & II & III & $\underline{\text { IV }}$ & V & VI & VII & VIII & $\underline{\text { IX }}$ \\
\hline EPM, Keltan 3200 A & 100 & 100 & 100 & 100 & 100 & 100 & 100 & - & - \\
EPDM, Keltan 4802 & - & - & - & - & - & - & - & 100 & 100 \\
Carbon Black, N550 & 60 & 60 & 60 & 60 & 60 & 60 & 60 & 60 & 60 \\
Regular Paraf. Oil & - & 10 & 20 & 30 & - & - & - & - & 30 \\
White Paraf. Oil & - & - & - & - & 10 & 20 & 30 & - & - \\
\hline
\end{tabular}

Table 4.2: Curing recipe for samples containing regular paraffinic oil, Sunpar 150

\begin{tabular}{lccccc}
\hline Curatives (comp. I-IV) & Content (mmol) & & & \\
\hline 4,4'DAF & 9.56 & - & - & - & - \\
GDAF & - & 9.56 & - & - & - \\
1,3BDSA & - & - & 9.56 & - & - \\
DCP & - & - & - & 9.56 & 4.4 \\
HVA-2 & - & - & - & - & 7.5 \\
\hline
\end{tabular}

Next, the performance of various di-azides was investigate in combination with EPM and EPDM compounds containing carbon black and paraffinic oil, Sunpar 150, as these resemble more closely the composition of regular products: compositions IV and IX in Table 4.1. Both compounds were vulcanized with varying amounts of di-azides and the peroxide/coagent cross-linking system, the exact curing recipes in phr and in mmol are given in Table 4.3. It should be pointed out that the amounts of di-azides used to cross-link the compounds are much lower than the amounts of curatives in the reference package, regardless of how they are compared, on basis of mmol or phr.

Table 4.3: Curing recipes for EPM and EPDM compounds in phr and (mmol)

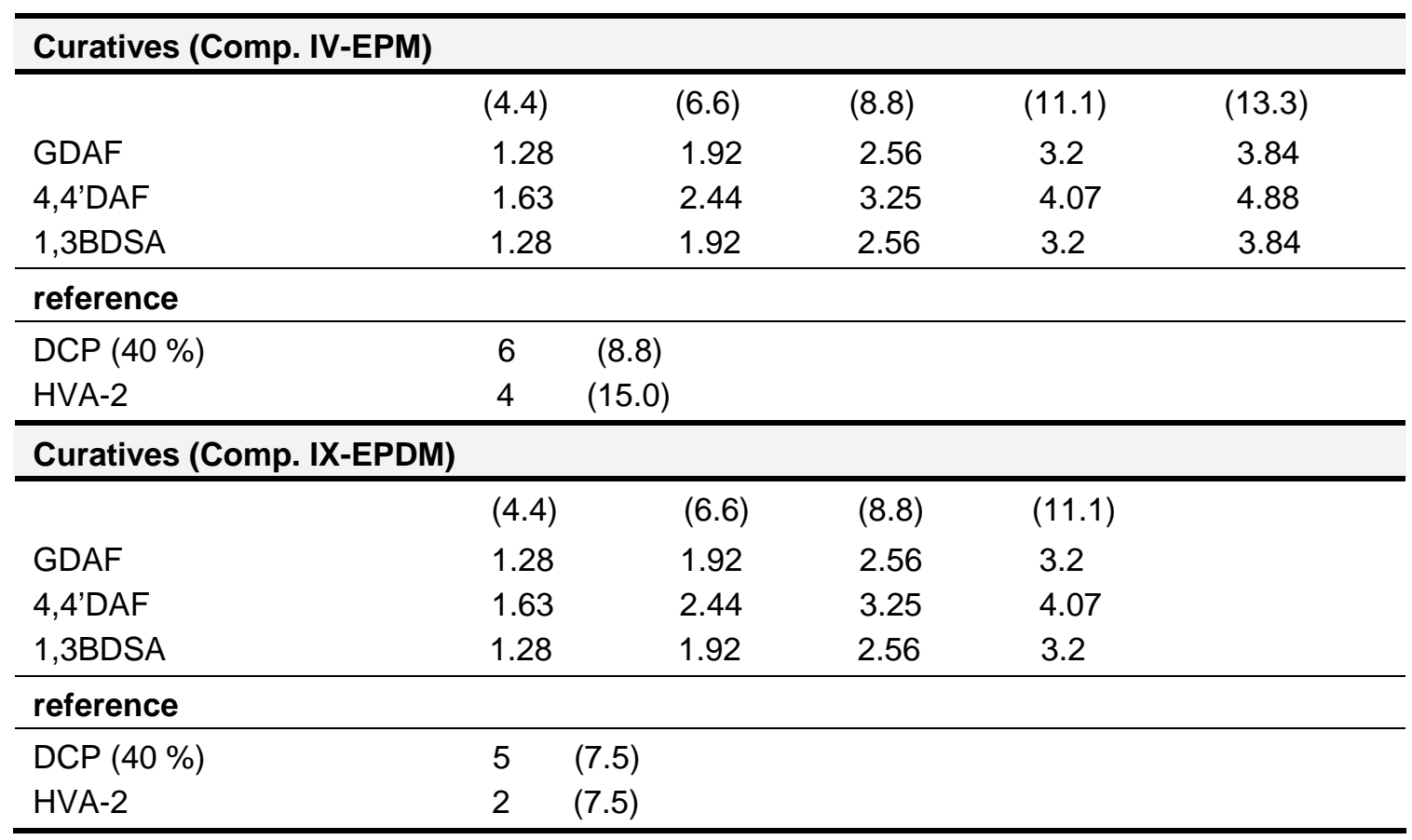




\section{Compound characterization}

The Mooney viscosity $\mathrm{ML}(1+4) 100^{\circ} \mathrm{C}$ was determined using a Mooney viscometer MV200 VS from Alpha Technologies according to ISO R289. The cure characteristics were determined using a Rubber Process Analyzer, RPA 2000, from Alpha Technologies. A strain of $0.2 \mathrm{deg}$ and a frequency of $0.83 \mathrm{~Hz}$ were fixed for every cycle. Due to different decomposition kinetics, as explained in Chapter 3, the vulcanization temperature was chosen as $150{ }^{\circ} \mathrm{C}$ for the di-azidoformates, 4,4'DAF and GDAF and $180{ }^{\circ} \mathrm{C}$ the for the di-sulfonylazide, 1,3BDSA. The reference DCP/HVA-2 curing was carried out at $160{ }^{\circ} \mathrm{C}$. The compounds were vulcanized by compression molding in a Wickert laboratory press WLP $1600 / 5^{\star} 4 / 3$ at 100 bar, for the duration of $t_{90}$ of the specific compounds in $2 \mathrm{~mm}$ thick sheets. During preparation of the samples it was observed that the di-azide cured vulcanizates were easy to release from the mould, which remained clean. On the other hand, the peroxide/coagent cured samples are well known for their tendency to stick to the mould what makes the preparation more time consuming.

\section{Cross-link density}

The un-polar components present in vulcanized samples like oil and non-cross-linked rubber were removed by 48 hours Soxhlet extraction with tetrahydrofuran (THF). Subsequently, the samples were dried in a vacuum oven until all THF was removed. To determine the crosslink density, the dried samples were weighed and swollen in cyclohexane for 72 hours at room temperature. The masses of the swollen samples were determined after lightly wiping their surface with absorbing paper. Since cyclohexane evaporates quite quickly at room temperature, once the swollen rubber piece was taken out from the solvent the mass was determined as quickly as possible. The overall crosslink density was calculated according to the Flory-Rehner equation ${ }^{22}$ eq. 4.1:

$$
v=-\frac{1}{V_{0}} \times \frac{\ln \left(1-V_{r}\right)+V_{r}+\chi V_{r}^{2}}{V_{r}^{1 / 3}-1 / 2 V_{r}}
$$

Where:

$v=$ the overall crosslink density per unit volume;

$V_{0}=$ the molar volume of cyclohexane;

$V_{r}=$ the volume fraction of EPM in the swollen sample acc. to eq. 4.2;

$\chi=$ the Flory-Huggins parameter, depending on polymer-swelling agent interaction, calculated using the relationship $\chi=0.281+0.278 \mathrm{v}_{\mathrm{r}}{ }^{23}$ 


$$
V_{r}=\frac{m_{r}}{m_{r}+m_{s} \times \frac{\rho_{r}}{\rho_{s}}}
$$

Where:

$m_{r}=$ the mass of the rubber network;

$m_{s}=$ the mass of the solvent in the swollen sample at equilibrium conditions;

$\rho_{r}=$ the density of the rubber;

$\rho_{s}=$ the density of the solvent.

Originally, the Flory-Rehner equation was developed for non-filled systems and it should be corrected when applied for filler-reinforced compounds. ${ }^{24}$ In the present study all investigated compounds were carbon black reinforced but, as the filler loading was fixed at 60 parts, its influence can be considered to be the same for every sample. Therefore, the Flory-Rehner equation was applied without further correction and the crosslink density figures need to be considered as relative values.

\section{Mechanical properties}

The stress-strain properties of the vulcanized compounds were measured using a Zwick tensile tester with dumb-bell shaped specimens of Type 2 and a nominal rate of moving the clamps of $500 \mathrm{~mm} / \mathrm{min}$, according to ISO 37. The hardness of the cured materials was measured using a Zwick hardness tester Shore A type, according to DIN 53517. The compression sets were measured at $23^{\circ} \mathrm{C}$ for 72 hours and at 70 and 100 ${ }^{\circ} \mathrm{C}$ for 24 hours, according to ISO 815 .

\section{Di-azides vulcanization kinetics}

The di-azides curing kinetics were established in both EPM as well as EPDM-rubber. To investigate how the presence of standard rubber compounding ingredients influence the vulcanization process, the kinetic parameters were measured in pure rubbers, as well as in carbon black filled and oil extended mixtures, compositions I, IV, VIII and IX in Table 4.1. The amount of di-azides was $4.4 \mathrm{mmol}$ per 100 phr of rubber in all cases. The reaction rate constants and the activation energies of the di-azides reactions were calculated from the rheomether cure curves. These kind of calculations are very common in rubber technology and a description of the method is given in DIN 53 529. First the cure characteristics at three different temperatures are determined. The degree of conversion of the reaction is considered proportional to the torque development and can then be calculated according to eq. 4.3. 


$$
\alpha=\frac{S_{(t)}^{\prime}-S_{\text {min }}^{\prime}}{S_{\text {max }}^{\prime}-S_{\text {min }}^{\prime}}
$$

Where:

$\alpha=$ the degree of conversion;

$S^{\prime}{ }_{(t)}=$ the measured torque at time $\mathrm{t}$;

$S^{\prime}{ }_{\text {min }}$ and $S^{\prime}{ }_{\text {max }}=$ the minimum and maximum torques respectively.

If the di-azides decomposition follows first order kinetics, the reaction rate constant $k$ $\left(s^{-1}\right)$ can then be calculated according to the rate law, eq 4.4 , with $n=1$. The exact reaction order for each di-azide was already established in Chapter 3.

$$
\ln (1-x)=-k^{n} \times t
$$

Once the reaction rate constants at different temperatures are determined, the activation energy can be calculated using the Arrhenius eq. 4.5. A similar method was used for instance to calculate silica flocculation in a tire tread compound. ${ }^{25}$

$$
\ln k=\ln A-\frac{E_{a}}{R T}
$$

Where:

$E_{a}=$ the activation energy $\left(\mathrm{Jmol}^{-1}\right)$;

$R=$ the gas constant $\left(8.314 \mathrm{Jmol}^{-1} \mathrm{~K}^{-1}\right)$;

$T=$ temperature $(\mathrm{K})$;

$A=$ pre-exponential factor, neglected during the calculation as being a constant.

\subsection{Results and discussion}

\subsubsection{Effect of different di-azides in oil-containing compounds}

The EPM-rubber was chosen for these first experiments because of its low reactivity, under the assumption that for this case the oil effect would be the most pronounced. In order to investigate the interaction between oil and different di-azides, compounds containing varying amounts of Sunpar 150 paraffinic oil were vulcanized with fixed amounts of each di-azide, compositions I-IV in Table 4.1. The curing recipe is given in Table 4.3. The three di-azides: 4,4'DAF, GDAF and 1,3BDSA were selected for the study based on previous experiments described in Chapter 3 , where they proved to be able to effectively cure EPM-rubber. Samples cured with peroxide, both with and 
without coagent, were taken as references. The delta torque values achieved with increasing oil content are shown in Fig. 4.1 (a). The same data but normalized to the oil free samples are shown in Fig. 4.1 (b).

(a)

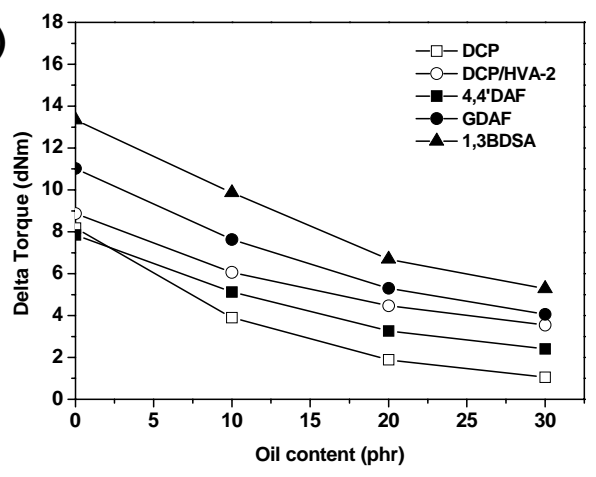

(b)

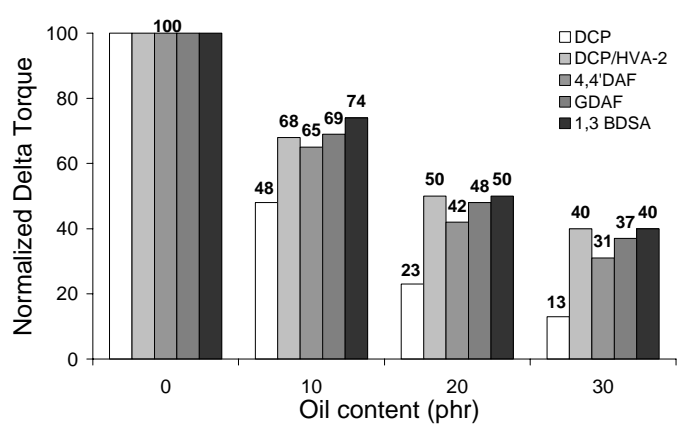

Fig. 4.1: Compounds with varied paraffinic oil contents cross-linked with different curatives; (a): Delta torque (\%) and (b): Relative drop in delta torque (\%)

Generally, the 1,3BDSA gives higher delta torque values than both di-azidoformates, which is especially significant if we take into account that the stiffness measured in this experiment not only depends on the created crosslinks network but also on the test temperature, being highest for 1,3BDSA: $180{ }^{\circ} \mathrm{C}$ vs. $160{ }^{\circ} \mathrm{C}$ for the peroxide cures, resp. $150{ }^{\circ} \mathrm{C}$ for GDAF and 4,4' DAF. The delta torque values are the second highest for GDAF cross-linking, followed by 4,4 'DAF. The lowest delta torque was achieved with DCP. How detrimental the oil effect on DCP-curing actually is can be seen very clearly in Fig. 4.1 (b). The peroxide by itself evidently performs the worst: it shows progressively lower values of the normalized delta torque, much more than all other compounds. All investigated di-azides show a sensitivity towards the presence of oil comparable to the peroxide/coagent combination for all oil-loadings. The diazidoformates, especially GDAF seem to be just a bit more sensitive to oil than 1,3BDSA.

\subsubsection{Comparison between the two types of oil: their influence on di-azides vulcanization efficiency}

Regular mineral paraffinic oils still contain a certain, though limited, amount of unsaturated and non hydrocarbon species and therefore the highly purified white paraffinic oil was also included in the study, compositions V-VII in Table 4.1. To measure the plasticizing effect of the oils, first the Mooney viscosities of the unvulcanized compounds were determined. For proper comparison between the data, the viscosities of the oil-containing compounds were normalized to the viscosity of the oil-free samples. The compounds were then vulcanized with $9.56 \mathrm{mmol}$ of 4,4'DAF, which was chosen as most oil sensitive. Figs. 4.2 (a) and (b) show both the values for 
the normalized viscosities and delta torques for samples with regular and high purity paraffinic oil.
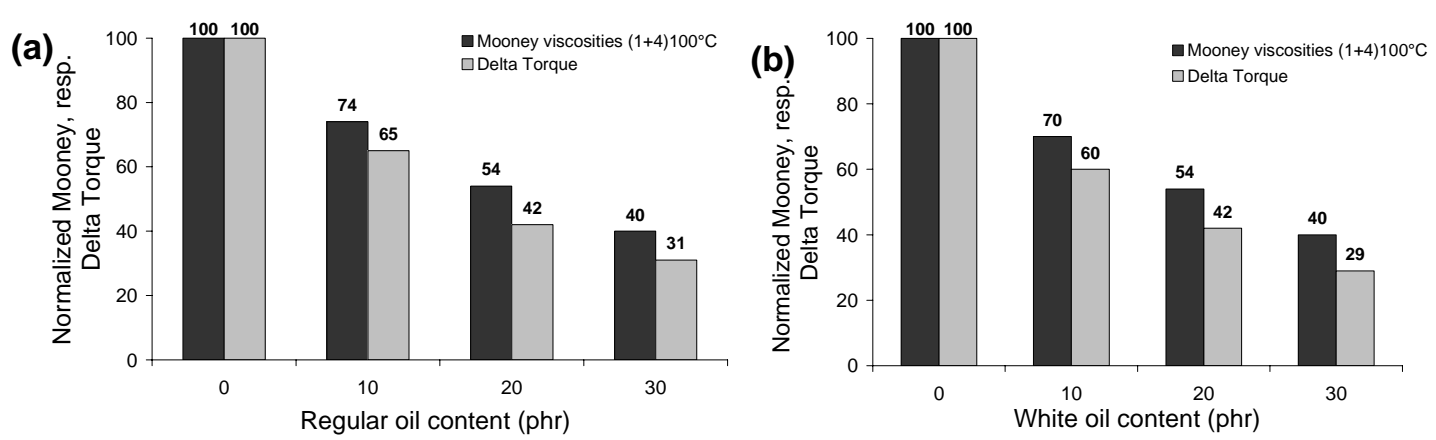

Fig. 4.2: Normalized viscosity and delta torque of EPM compounds containing 0-30 phr of; (a): regular paraffinic oil Sunpar 150 and (b): highly purified, white paraffinic oil

Dosing inaccuracy may have caused the slight difference in viscosities between the two series for the same oil content. Generally however, the different compounds have comparable viscosities: showing no relative difference in plasticizing effect for these two oils. The cross-link efficiency of 4,4'DAF is also practically the same regardless of which oil was used. For both types the values for Mooney viscosity and delta torque decrease with the amount of oil, where the drop in delta torque is somewhat higher than the drop in viscosity. If the assumption is made that the relative drop in viscosity due to the plasticizing effect of the oil should provoke a similar drop in delta torque, than the fact that the drop in delta torque is slightly higher indeed points to some, but little deactivation or consumption of di-azide by the oil. The purity of the oil apparently has little or no influence on this effect.

\subsubsection{Effect of di-azide content}

The EPM and EPDM compounds containing 60 parts of carbon black and 30 parts of regular paraffinic oil (comp. IV and IX in Table 4.1) were cross-linked with varied amounts of each di-azide to determine how the concentration of such curatives affects the material properties, Table 4.3. For comparison, the properties obtained using the peroxide/coagent curing system are reported as reference.

The rheometer data, given in Figs. 4.3 (a) and (b), show that for both rubbers the amount of cross-linking represented by delta torque increases with di-azide concentration. The increase however, is not linear and especially the for EPMcompound the differences at high di-azide contents are not very pronounced. The reference delta torque for peroxide/coagent, represented by a horizontal dotted line, is much higher for the EPDM than for the EPM compound and also the two diazidoformates, GDAF and 4,4'DAF give higher torques for EPDM. The 1,3BDSA on the other hand gives only slightly higher delta torques for EPDM. As a result, the difference in the 1,3BDSA and the two di-azidoformates performance is quite 
significant for the EPM but smaller for the EPDM. Of the two di-azidoformates the GDAF performs significantly better than 4,4'DAF. Generally, the di-azides result in lower delta torque compared to the peroxide/coagent curing, the only exception being EPM cured with a high 1,3BDSA concentration.

(a)

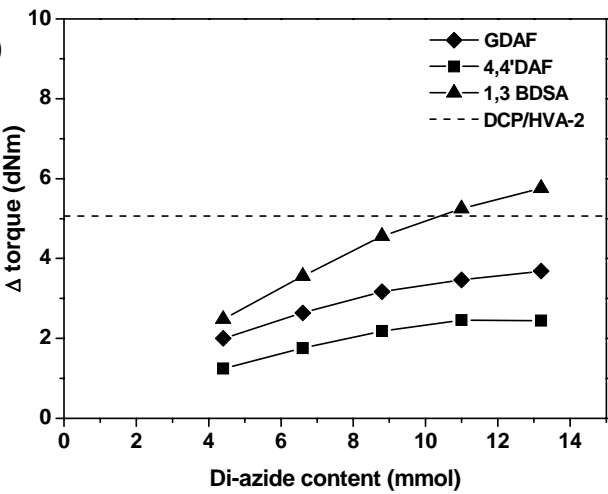

(b)

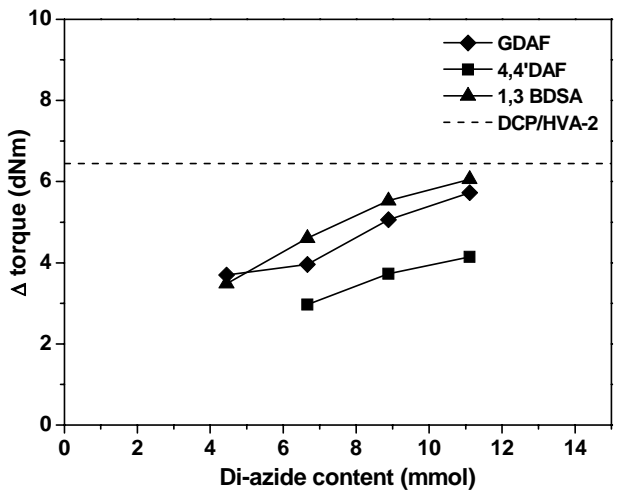

Fig. 4.3: Delta torque vs. di-azide contents; (a): EPM-compound and (b): EPDM-compound

The relative crosslink densities of the di-azide cured samples were estimated by equilibrium swelling. The same swelling test was also performed on the peroxide/coagent cured compound. Figs 4.4 (a) and (b) present the values measured for EPM and EPDM compounds, respectively. The cross-link densities of the EPM compounds show a maximum at the 1,3BDSA and GDAF concentrations of $11 \mathrm{mmol}$, and for both further addition has a negative effect. Thus there is no clear correlation with the delta torque values. On the other hand, the cross-link densities of EPDM show a close correlation with the delta torques seen in Fig. 4.3 (b). The values increase with di-azide content and at high loadings resemble the reference. Similar to delta torque also the crosslink density is slightly higher for 1,3BDSA compared to GDAF. Overall, the EPDM compounds have higher cross-link densities compared to EPM, irrespective of which curing agent is applied.

(a)

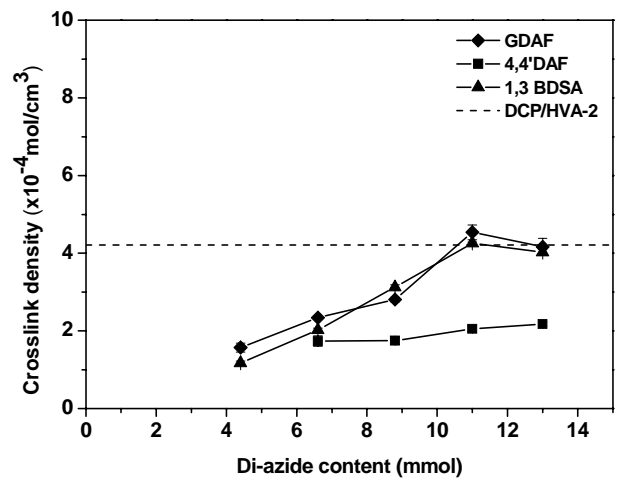

(b)

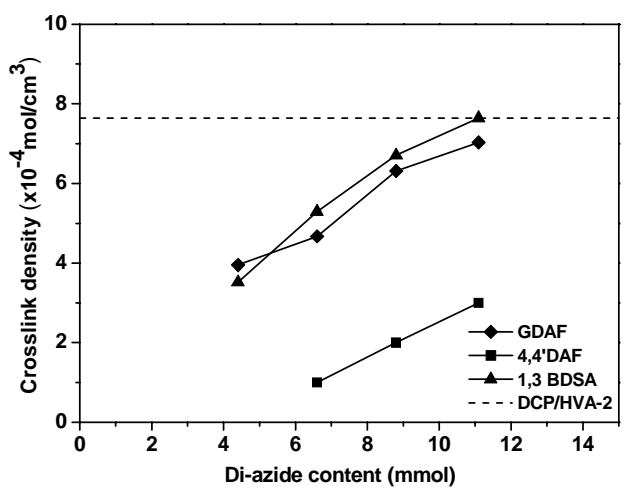

Fig. 4.4: Crosslink density vs. di-azide contents; (a): EPM-compound and (b): EPDM-compound 
The tensile stress-strain data for the compounds vulcanized till $t_{90}$ are shown in Figs. 4.5 (a) and (b). In case of the EPM-rubber both 1,3BDSA and GDAF result in very similar tensile strength values, which increase with di-azide loading till a maximum at $11 \mathrm{mmol}$, similar as what was observed with the crosslink density determined by swelling test. After that no further improvement can be seen anymore. Each of these two di-azides give tensile strengths equal to the peroxide/coagent reference at 8.8 mmol loading and exceed the reference value at $11 \mathrm{mmol}$ concentration. In case of EPDM-rubber the 1,3BDSA and GDAF result in tensile strengths which are well above the reference value for peroxide/coagent system. For each of them the maximum tensile strength is reached at $6.6 \mathrm{mmol}$ dosing. At this concentration GDAF exceeds the reference value by around 5 and 1,3BDSA by around $3 \mathrm{MPa}$. Consequently, much smaller amounts of the di-azides are required for EPDM cross-linking compared to EPM. Only about half the amount of the di-azide is needed to reach the optimum properties. The reference recipe also gives different tensile strengths for the two compounds and, although the peroxide content was nearly the same, much less of the coagent was used for the EPDM curing. Even after taking that into account, the amount of GDAF or 1,3BDSA required to effectively crosslink each of the two compounds is still less than only the amount of coagent in the reference recipe. This is admittedly another advantage of the di-azide curing. As could be expected already from the cross-link density measurements, for both EPM and EPDM compounds the 4,4 'DAF curing gives very low tensile strength values.
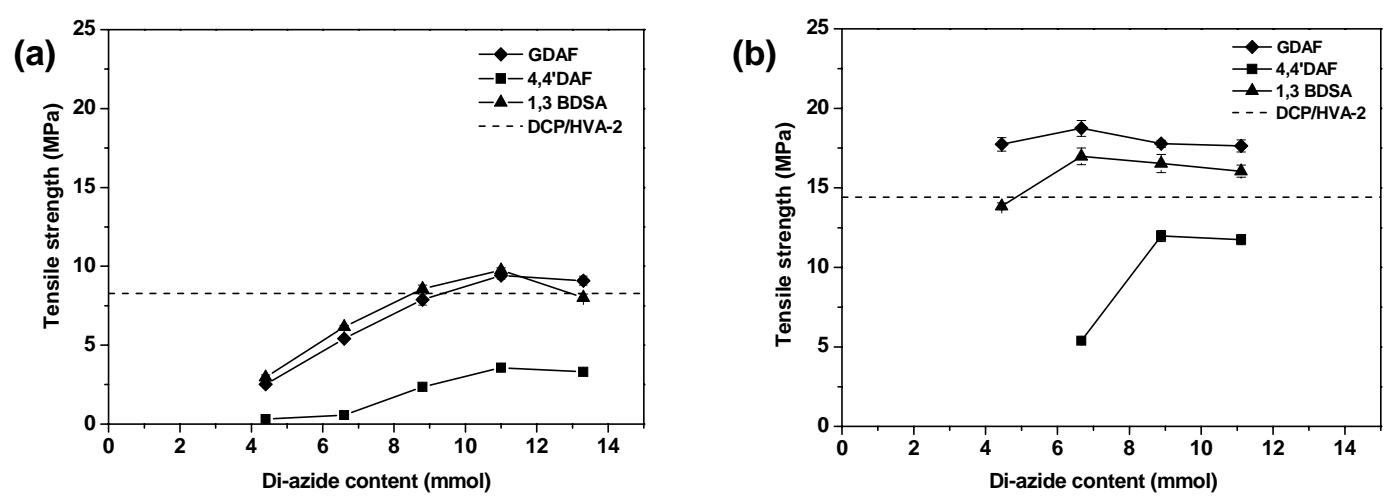

Fig. 4.5: Tensile strength vs. di-azide contents; (a): EPM-compound and (b): EPDM-compound

In general, the elongation at break of vulcanized rubbers decreases substantially with the amount of cross-linking and especially during peroxide curing its value is usually quite low. As shown in Figs. 4.6 (a) and (b) the di-azide cross-linking leads to materials with elongations at break much higher compared to the peroxide/coagent curing. For the EPM compound both 1,3BDSA and GDAF result in elongations at break which are double compared to the reference. Although some fluctuation occurs, the values show little dependence on the amount of 1,3BDSA or GDAF added. Contrary to that, with 
4,4'DAF curing the elongation at break changes significantly with concentration and an optimum value is achieved at $8.8 \mathrm{mmol}$. Higher or lower 4,4 'DAF contents lead to lower elongations: this behavior is quite erratic. The differences in elongation at break between di-azides and peroxide curing are even bigger for the EPDM compounds. At the optimum di-azide concentration, $6.6 \mathrm{mmol}$, the elongation at break is around 900 $\%$ for both di-azidoformates and around $800 \%$ for the di-sulfonyl azide, where the reference value is only $300 \%$. Thus the GDAF not only gives the highest tensile strength, but also the highest elongation. For all the EPDM compounds the elongation at break decreases proportionally to the loading and is similar for each di-azide. This is common behavior for all curing systems, as said before.
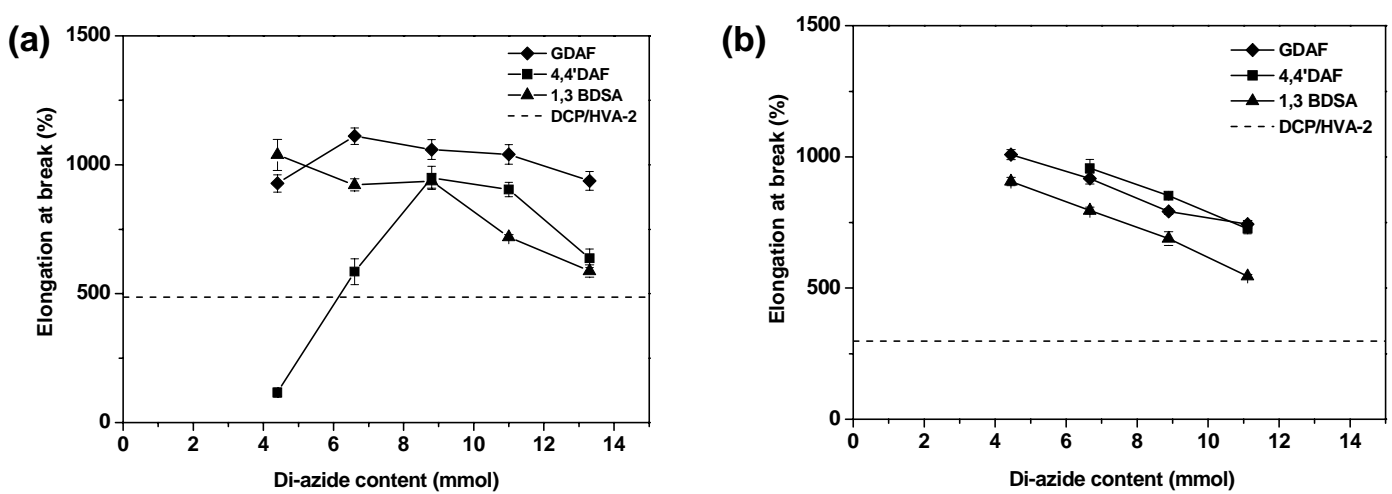

Fig. 4.6: Elongation at break vs. di-azide contents; (a): EPM-compound and (b): EPDMcompound

The moduli at 100 and $300 \%$ elongation are given in Figs. 4.7 and 4.8, respectively. Overall, the modulus values increase with di-azide content and are very similar for both rubbers. The GDAF results in much lower modulus compared to 1,3BDSA, which is still higher than 4,4'DAF. The sample with the highest 1,3BDSA content has a modulus at $100 \%$ similar to the reference value. While at $300 \%$ elongation for both compounds the highest modulus is obtained when using the reference, DCP/HVA-2 combination.

The Shore A hardness of the samples is shown in Figs. 4.9 (a) and (b). Generally, the hardness values correlate closely with the delta torque and the modulus, as is commonly the case, and are significantly higher for 1,3BDSA than for GDAF and 4,4'DAF cured samples. With high di-sulfonylazide content the EPDM reaches the same hardness as the peroxide/coagent reference. Overall the EPDM compounds have higher hardness compared to EPM. 

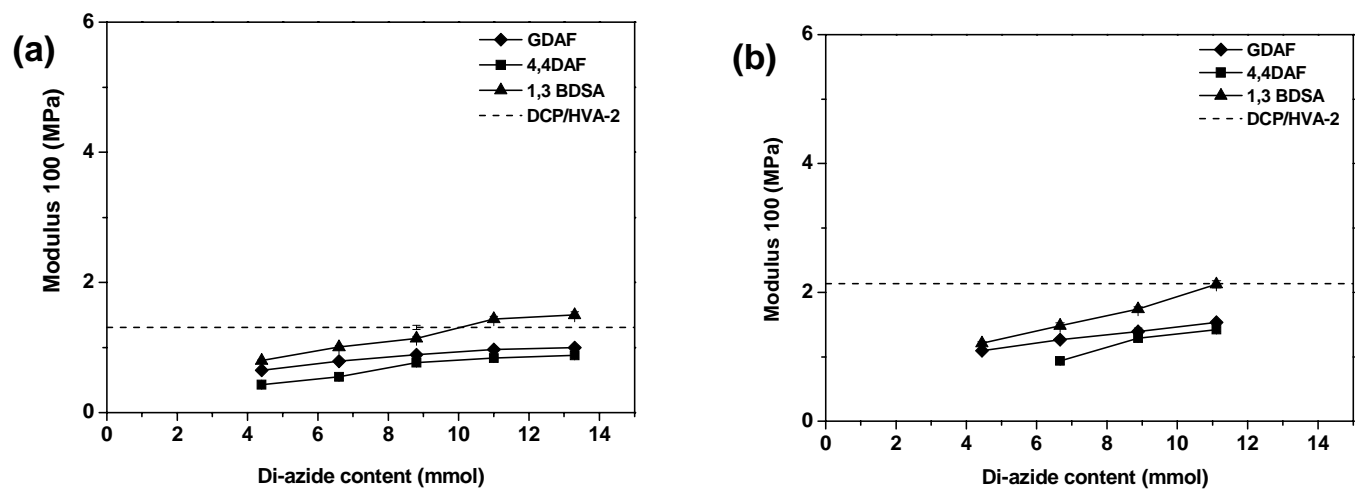

Fig. 4.7: Moduli $100 \%$ vs. di-azide contents; (a): EPM-compound and (b): EPDM-compound

(a)

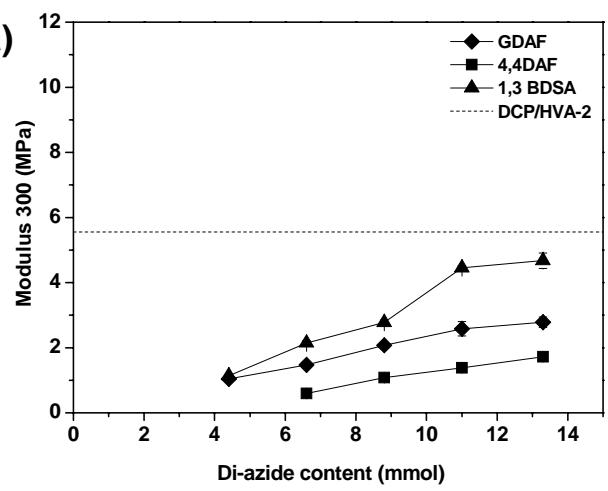

(b)

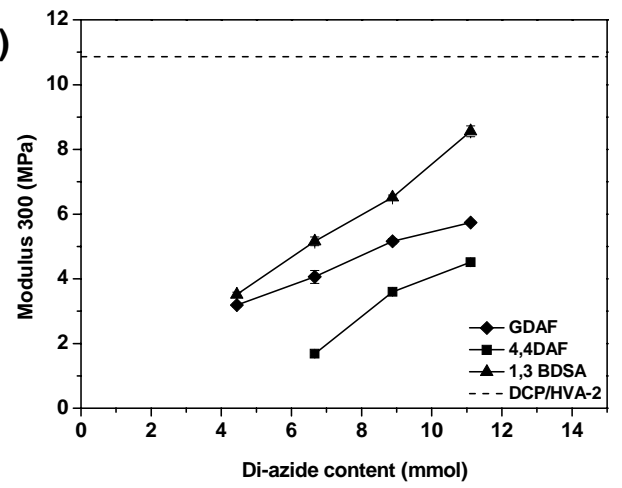

Fig. 4.8: Moduli $300 \%$ vs. di-azide contents; (a): EPM-compound and (b): EPDM-compound
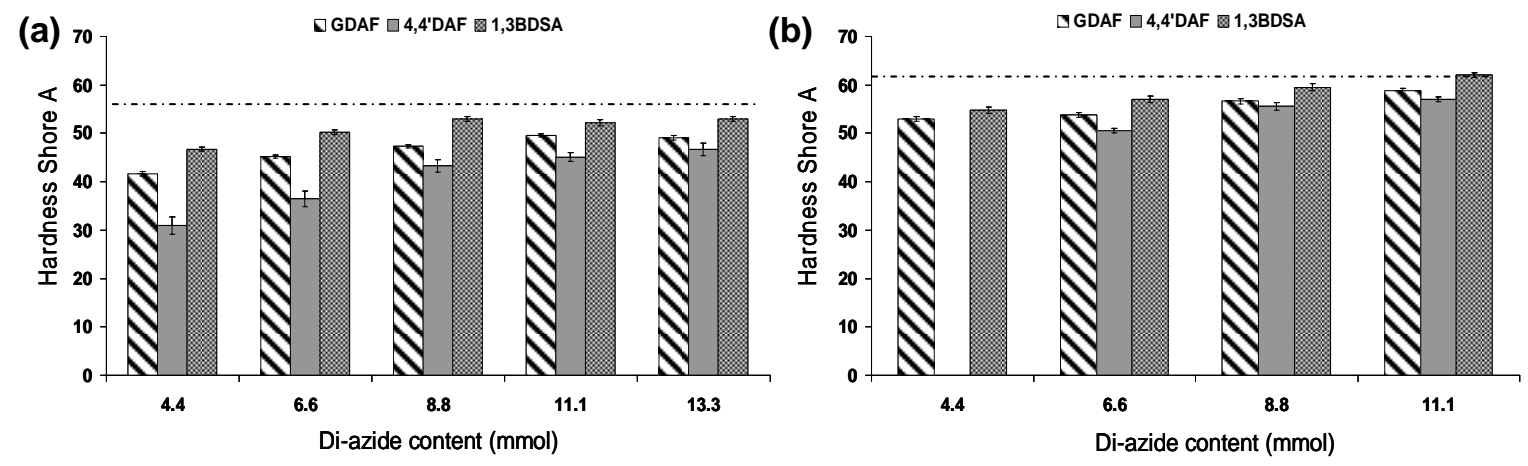

Fig. 4.9: Shore A hardness vs. di-azide contents; (a): EPM-compound and (b): EPDMcompound

One of the biggest advantages of peroxide curing is the good compression set properties of such vulcanizates at elevated temperatures. The compression set values of the EPDM compounds cured with peroxide/coagent curing system are usually below $10 \%$ and, most important, show little change with increasing the measurement temperature. Figs. 4.10 (a) and (b) present the compression sets of the EPM compound cured with $11 \mathrm{mmol}$ and EPDM with $6.6 \mathrm{mmol}$ of each di-azide and the reference peroxide/coagent system. The measurements were carried out at 23,70 and 
$100{ }^{\circ} \mathrm{C}$. The various recipes are applied because, as discussed above, the EPDM compound requires less curatives to reach the optimum properties. When comparing the two compounds, the EPM has clearly much worse compression set properties than EPDM. One of the reasons why the EPDM compound performs so much better can be the lower di-azide content: higher concentrations of the azide functionalities will produce more nitrogen gas which can negatively influence the compression set properties by creating some porosity in the sample. Even the EPDM compounds however, do not show compression sets as good as when the peroxide/coagent curing system is applied. Out of the three di-azides, 1,3BDSA gives the best compression set properties with little temperature dependence, which for the EPDM compound are between $11-15 \%$. As can be expected from the previous data 4,4'DAF shows the poorest performance.
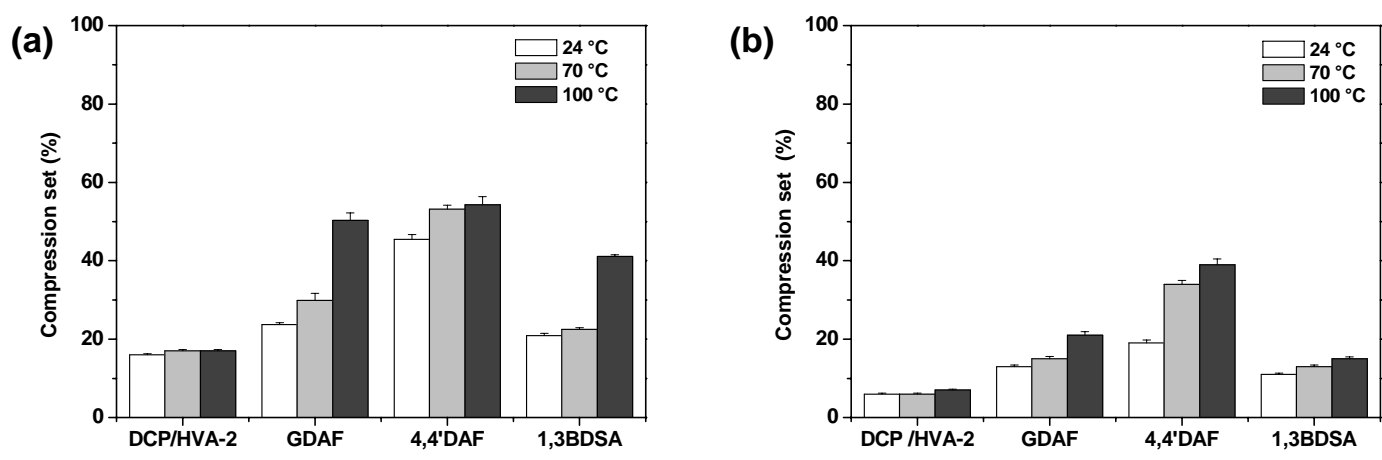

Fig. 4.10: Compression sets achieved with different di-azides; (a): EPM-compound, di-azide content $11 \mathrm{mmol}$ and (b): EPDM-compound, di-azide content $6.6 \mathrm{mmol}$

\subsubsection{Plasticizing effect}

The fact that GDAF results in high cross-link density and tensile strength but low modulus and hardness, which is especially pronounced for the EPM compound, suggests some plasticizing effect of this di-azide. It is well known that the addition of low molecular weight species tends to reduce the viscosity of the compound and improve processability. The plasticizing properties of different curatives were therefore investigated by measuring the Mooney viscosities at $100{ }^{\circ} \mathrm{C}$. Table 4.4 shows the viscosities of the un-vulcanized EPM compounds (comp. IV in Table 4.1) which contain $11 \mathrm{mmol}$ of each di-azide. This di-azide concentration produces EPM vulcanizates with the optimum properties, as shown earlier. The peroxide/coagent recipe contains 8.8 mmol of DCP and $15 \mathrm{mmol}$ of HVA-2, so more than double the amount of low molecular weight species is present in that sample. 
Table 4.4 Mooney viscosity of un-vulcanized EPM comp. IV

\begin{tabular}{c|c}
\hline Compound & ML (4+1) $100^{\circ} \mathbf{C}$ \\
\hline no cross-linker & 50 \\
DCP/HVA-2 & 44.5 \\
1,3BDSA (11 mmol) & 45 \\
GDAF $(11 \mathrm{mmol})$ & 41.5 \\
4,4'DAF $(11 \mathrm{mmol})$ & 42 \\
\hline
\end{tabular}

Generally, all curing agents lower the viscosity somewhat, when compared to the original curatives-free compound. In the case of the GDAF and 4,4'DAF however, the effect is most distinct. Both di-azidoformates lower the compound viscosity by around $8 \mathrm{MU}$ compared to the original masterbatch and around $3 \mathrm{MU}$ compared to the 1,3BDSA and peroxide/coagent curing system. At room temperature GDAF appears to be an oily liquid, 4,4'DAF are compact crystals and 1,3BDSA is a powder. Although the plasticizing effect of GDAF and 4,4'DAF on the un-vulcanized masterbatch is admittedly larger compared to the other investigated curing systems, it does not explain why GDAF softens the vulcanized material to the extents observed. It remains a point of uncertainty why this happens.

\subsubsection{Kinetic study on the di-azides reaction}

The vulcanization kinetics of di-azides were investigated in pure rubbers: EPM and EPDM, as well as in their carbon black reinforced and oil extended compounds using $4.4 \mathrm{mmol}$ of di-azides per $100 \mathrm{phr}$ of rubber used in each case: compositions I, IV, VIII and IX in Table 4.1. The way the kinetic parameters were calculated is presented by giving the reaction of GDAF with pure EPM-rubber as an example. First the cure characteristics at different temperature were determined: Fig. 4.11 (a).
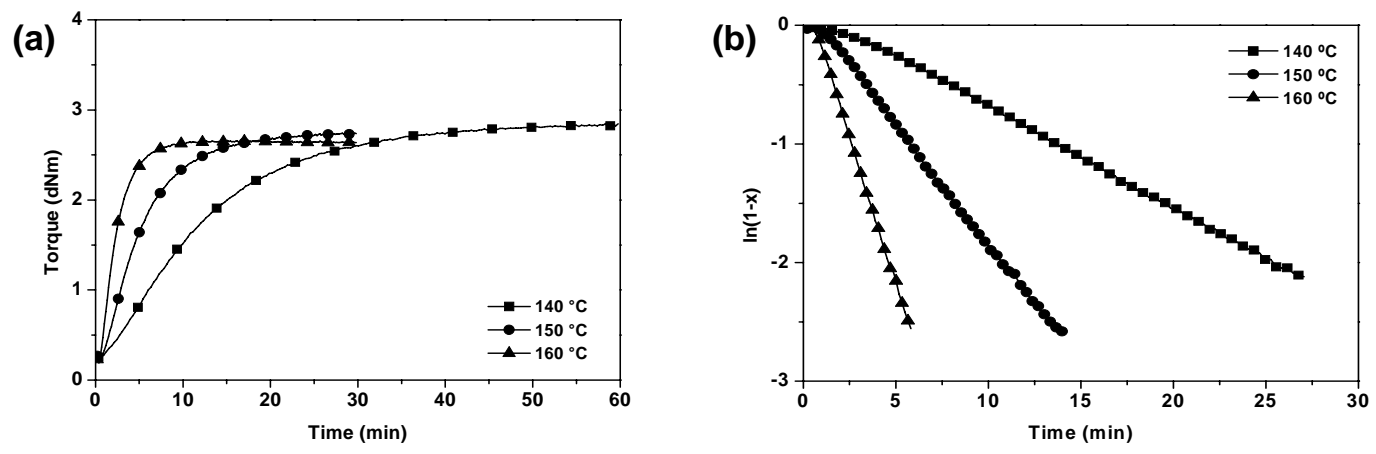

Fig. 4.11: EPM cured with GDAF at different temperatures; (a): curing characteristics and (b): conversion of the curing reaction calculated till $t_{90}$

The rheomether curves illustrate how the cross-linking reaction develops at a given temperature. The increase in torque is proportional to the conversion of the reaction. 
As the azide decomposition follows first order kinetics, by plotting the conversion of the reaction on a logarithmic scale versus time, according to eq. 4.4 a straight line is obtained: Fig. 4.11 (b), and the reaction rate constant can then be calculated. The activation energy can be estimated by applying the Arrhenius eq. 4.5: Fig. 4.12. The obtained kinetic parameters of GDAF, 4,4'DAF and 1,3BDSA decomposition are listed in Tables 4.5 - 4.7, respectively.

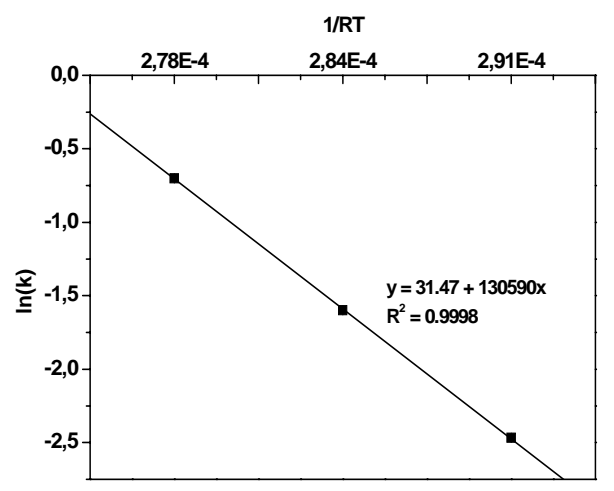

Fig. 4.12: Arrhenius plot of EPM cured with GDAF

Table 4.5 Reaction rates and activation energies of GDAF in different compounds

\begin{tabular}{|c|c|c|c|c|c|c|}
\hline \multirow[b]{2}{*}{ Temp. $\left({ }^{\circ} \mathrm{C}\right)$} & \multicolumn{2}{|c|}{ EPM } & \multicolumn{2}{|c|}{ EPM-CB* } & \multicolumn{2}{|c|}{ EPM-O* } \\
\hline & $k\left(s^{-1}\right)$ & $t_{90}(\min )$ & $k\left(s^{-1}\right)$ & $t_{90}(\min )$ & $k\left(s^{-1}\right)$ & $t_{90}$ (min) \\
\hline 140 & $1,42 * 10^{-3}$ & 29.6 & $1,48 * 10^{-3}$ & 26.8 & $1,32 * 10^{-3}$ & 31.2 \\
\hline 150 & $3,37^{\star} 10^{-3}$ & 12.4 & $3,60 * 10^{-3}$ & 11.2 & $3,2 * 10^{-3}$ & 12.8 \\
\hline 160 & $8,27^{\star} 10^{-3}$ & 5.3 & $8,58^{*} 10^{-3}$ & 4.9 & $7,62 * 10^{-3}$ & 5.6 \\
\hline $\mathrm{E}_{\mathrm{a}}\left(\mathrm{kJmol}^{-1}\right)$ & \multicolumn{2}{|c|}{131} & \multicolumn{2}{|c|}{130} & \multicolumn{2}{|c|}{131} \\
\hline & \multicolumn{2}{|c|}{ EPDM } & \multicolumn{2}{|c|}{ EPDM-CB* } & \multicolumn{2}{|c|}{ EPDM-O* } \\
\hline Temp. $\left({ }^{\circ} \mathrm{C}\right)$ & $k\left(s^{-1}\right)$ & $t_{90}(\min )$ & $k\left(s^{-1}\right)$ & $t_{90}(\min )$ & $k\left(s^{-1}\right)$ & $t_{90}(\min )$ \\
\hline 140 & $1,58 * 10^{-3}$ & 26.6 & $1,48 * 10^{-3}$ & 26.4 & $1,45^{\star} 10^{-3}$ & 28.0 \\
\hline 150 & $3,88^{*} 10^{-3}$ & 11.0 & $3,85^{\star} 10^{-3}$ & 10.6 & $3,57 * 10^{-3}$ & 11.4 \\
\hline 160 & $9,12^{\star} 10^{-3}$ & 4.9 & $8,93^{*} 10^{-3}$ & 4.7 & $8,62 * 10^{-3}$ & 5.0 \\
\hline $\mathrm{E}_{\mathrm{a}}\left(\mathrm{kJmol}^{-1}\right)$ & \multicolumn{2}{|c|}{130} & \multicolumn{2}{|c|}{133} & \multicolumn{2}{|c|}{132} \\
\hline
\end{tabular}

*CB: carbon black; O: carbon black and oil 
Table 4.6 Reaction rates and activation energies of 4,4'DAF in different compounds

\begin{tabular}{|c|c|c|c|c|c|c|}
\hline \multirow[b]{2}{*}{ Temp. $\left({ }^{\circ} \mathrm{C}\right)$} & \multicolumn{2}{|c|}{ EPM } & \multicolumn{2}{|c|}{ EPM-CB* } & \multicolumn{2}{|c|}{ EPM-O* } \\
\hline & $k\left(s^{-1}\right)$ & $t_{90}(\min )$ & $k\left(s^{-1}\right)$ & $t_{90}(\min )$ & $k\left(s^{-1}\right)$ & $t_{90}(\min )$ \\
\hline 140 & $1,87^{*} 10^{-3}$ & 22.3 & $2,25^{\star} 10^{-3}$ & 18.8 & $2,18^{*} 10^{-3}$ & 18.2 \\
\hline 150 & $4,72 * 10^{-3}$ & 9.2 & $5,35^{\star} 10^{-3}$ & 8.1 & $5,15^{\star} 10^{-3}$ & 7.8 \\
\hline 160 & $1,09 * 10^{-2}$ & 4.2 & $1,22 * 10^{-2}$ & 3.5 & $1,22 * 10^{-2}$ & 3.5 \\
\hline$E_{a}\left(\mathrm{kJmol}^{-1}\right)$ & \multicolumn{2}{|c|}{132} & \multicolumn{2}{|c|}{125} & \multicolumn{2}{|c|}{128} \\
\hline & \multicolumn{2}{|c|}{ EPDM } & \multicolumn{2}{|c|}{ EPDM-CB* } & \multicolumn{2}{|c|}{ EPDM-O* } \\
\hline Temp. $\left({ }^{\circ} \mathrm{C}\right)$ & $k\left(s^{-1}\right)$ & $t_{90}(\min )$ & $k\left(s^{-1}\right)$ & $t_{90}(\min )$ & $k\left(s^{-1}\right)$ & $t_{90}(\min )$ \\
\hline 140 & $2,18^{\star} 10^{-3}$ & 19.0 & $2,45^{\star} 10^{-3}$ & 17.0 & $2,15^{\star} 10^{-3}$ & 18.9 \\
\hline 150 & $5,25^{\star} 10^{-3}$ & 8.1 & $5,63^{\star} 10^{-3}$ & 7.5 & $5,27 * 10^{-3}$ & 8.0 \\
\hline 160 & $1,18^{\star} 10^{-2}$ & 4.0 & $1,34 * 10^{-2}$ & 3.3 & $1,24 * 10^{-2}$ & 3.6 \\
\hline $\mathrm{E}_{\mathrm{a}}\left(\mathrm{kJmol}^{-1}\right)$ & \multicolumn{2}{|c|}{125} & \multicolumn{2}{|c|}{126} & \multicolumn{2}{|c|}{130} \\
\hline
\end{tabular}

Table 4.7 Reaction rates and activation energies of 1,3BDSA in different compounds

\begin{tabular}{|c|c|c|c|c|c|c|}
\hline \multirow[b]{2}{*}{ Temp. $\left({ }^{\circ} \mathrm{C}\right)$} & \multicolumn{2}{|c|}{ EPM } & \multicolumn{2}{|c|}{ EPM-CB* } & \multicolumn{2}{|c|}{ EPM-O* } \\
\hline & $k\left(s^{-1}\right)$ & $t_{90}(\min )$ & $k\left(s^{-1}\right)$ & $t_{90}(\min )$ & $k\left(s^{-1}\right)$ & $t_{90}(\min )$ \\
\hline 170 & $2,2 * 10^{-3}$ & 18.0 & $2,3^{\star} 10^{-3}$ & 17.8 & $2,78^{*} 10^{-3}$ & 14.6 \\
\hline 180 & $5,08 * 10^{-3}$ & 8.6 & $6,48^{*} 10^{-3}$ & 8.0 & $5,47^{*} 10^{-3}$ & 7.8 \\
\hline 190 & $1,14^{\star} 10^{-2}$ & 4.0 & $9,83^{*} 10^{-3}$ & 4.5 & $1,12^{\star} 10^{-3}$ & 3.8 \\
\hline \multirow[t]{2}{*}{$E_{a}\left(\mathrm{kJmol}^{-1}\right)$} & \multicolumn{2}{|c|}{136} & \multicolumn{2}{|c|}{123} & \multicolumn{2}{|c|}{119} \\
\hline & \multicolumn{2}{|c|}{ EPDM } & \multicolumn{2}{|c|}{ EPDM-CB* } & \multicolumn{2}{|c|}{ EPDM-O* } \\
\hline Temp. $\left({ }^{\circ} \mathrm{C}\right)$ & $k\left(s^{-1}\right)$ & $t_{90}(\min )$ & $k\left(s^{-1}\right)$ & $t_{90}(\min )$ & $k\left(s^{-1}\right)$ & $t_{90}(\min )$ \\
\hline 170 & $3,6 * 10^{-3}$ & 11.8 & $3,72 * 10^{-3}$ & 10.8 & $3,18^{\star} 10^{-3}$ & 13.0 \\
\hline 180 & $7,32 * 10^{-3}$ & 6.0 & $7,28^{\star} 10^{-3}$ & 5.8 & $6,42 * 10^{-3}$ & 6.7 \\
\hline 190 & $1,54^{\star} 10^{-2}$ & 3.0 & $1,37 * 10^{-2}$ & 3.2 & $1,29 * 10^{-2}$ & 3.4 \\
\hline$E_{a}\left(\mathrm{kJmol}^{-1}\right)$ & \multicolumn{2}{|c|}{124} & \multicolumn{2}{|c|}{111} & \multicolumn{2}{|c|}{119} \\
\hline
\end{tabular}

${ }^{*} \mathrm{CB}$ : carbon black; O: carbon black and oil

Generally, the rate constants and the activation energy of the GDAF reaction are hardly changed by the compound composition. The oil seems to slow down the reaction and the carbon black speeds up, but the effects are rather small. The difference between the EPM and EPDM-rubber is not very pronounced as well. The second di-azidoformate: 4,4'DAF shows more significant changes in the kinetics parameters. When the pure rubbers are considered, the reaction proceeds slower in the EPM with higher activation energy. However, when carbon black and oil are introduced, the activation energy decreases for EPM and increases for EPDM. For 
both rubbers the optimal curing time $t_{90}$ seems to be slightly reduced by the carbon black addition, while the retarding effect of oil is observed only for the EPDM.

By using a similar method, the kinetics of 1,3BDSA decomposition in various rubbers, including EPM and EPDM, was studied by Benito Gonzalez et al. ${ }^{8,18}$ The outcome of this study indicated that the nature of the polymer had a significant influence on the disulfonylazide decomposition. The elastomers were ordered according to their reactivity towards 1,3BDSA: $\mathrm{BR}>\mathrm{SBR}>\mathrm{NR}>\mathrm{EPDM}>\mathrm{IIR}>\mathrm{VMQ}>\mathrm{EPM}$. The data obtained during the present study also show a faster 1,3BDSA vulcanization in the EPDMrubber. Although the exact values of the reaction rate and the activation energy are not exactly the same, the difference can be expected as the types of the polymers are different in both studies. The addition of carbon black lowers the activation energy with only minor changes in the reaction rates and similarly to 4,4'DAF, a retarding effect of the oil is observed only for the EPDM compound.

\subsection{Conclusions}

When comparing the normalized delta torque values upon increasing the paraffinic mineral oil content the efficiency of di-azide performance is similar to that of a peroxide/coagent combination and by far higher than for pure peroxide curing. The mechanical properties investigation showed, that both di-sulfonyl azide as well as diazidoformate are able to effectively react with a saturated polymer chain, though differences may exist based on the particular choice of di-azide. For both types of the di-azides curing reaches its optimum properties at a concentration of 11 and $6.6 \mathrm{mmol}$ (per 100 phr of rubber) for EPM and EPDM, respectively. Except for the compression sets, the measured properties exceed the performance of a peroxide/coagent curing system used as a reference. The compounds based on 1,3BDSA and GDAF show surprisingly large elongations at break, for EPM little dependent on the amount of curative added. The di-azidoformates have some ability to plasticize the vulcanized material. The effect is specially pronounced for the EPM compounds cured with GDAF which show high cross-link density and tensile strength, but at the same time have relatively low delta torque, hardness and moduli.

The reaction rate and activation energy of the di-sulfonyl azide: 1,3BDSA change significantly in the two rubbers, while the di-azidoformates and especially the GDAF have similar kinetic parameters in all compounds. Generally, the di-azide reactions proceed faster in EPDM. Apart from the reinforcing, respectively plasticizing effects, the influence of carbon black and paraffinic oil, on the di-azides reactivity are rather small and vary depending on di-azide and type of rubber. The degree of purity of the oil plays no role. 


\subsection{References}

1. M.M. Alvarez Grima, "Novel co-agents for improved properties in peroxide cure of saturated elastomers", PhD thesis, University of Twente, Enschede (2007).

2. J. White, S. De, "Rubber Technologist's Handbook" Rapra technology limited, (2001).

3. D.S. Breslow and H.M. Spurlin, U.S. Patent 3,203,937, Aug. 31, 1965.

4. D.S. Breslow, U.S. Patent 3,220,985, Nov. 30, 1965.

5. D.S. Breslow, U.S. Patent 3,284,421, Nov. 8, 1966.

6. Hercules inc, G.B. Patent 1,087,045, Oct. 11, 1967.

7. D.S. Breslow, W.D. Willis and L.O. Amberg, Rubber Chem. Technol. 43, 605 (1970).

8. J.L. Benito Gonzalez, L. Ibarra and L. Gonzalez, Kautsch. Gummi Kunstst. 43, 697 (1990).

9. R.H. Terbrueggen (Dow Chem. Co.), WO Patent 0,052,091, Sep. 8, 2000.

10. M.A. Lopez Manchado and J.M. Kenny, Rubber Chem. Technol. 74, 198 (2001).

11. M.B. Smith and J. March, "March's advanced organic chemistry reactions, mechanisms and structure", $5^{\text {th }}$ edition, John Wiley\&Sons, New York (2001).

12. S.A. Bateman and D.Y. Wu, J. Appl. Polym. Sci. 84, 1395 (2002).

13. J.K. Jorgensen and A. Stori, K. Redford, Polymer 46, 12256 (2005).

14. J.K. Jorgensen and A. Stori, K. Redford, Polymer 46, 12073 (2005).

15. Q. Li and C. Tzoganakis, Int Polym Proc 22, 311 (2007).

16. K. Borve, K. Redford and A. Stori, EP Patent 1,423,466, Jun. 2, 2004.

17. K. Borve, K. Redford and A. Stori, U.S. Patent 7,056,987, Feb.17, 2006.

18. J.L. Benito Gonzalez, L. Ibarra and L. Gonzalez, Kautsch. Gummi, Kunstst. 43, 146 (1990).

19. D.A. Baker, G.C. East and S.K. Mukhopadhyay, J. Appl. Polym. Sci. 79, 1092 (2001).

20. D.A. Baker, G.C. East and S.K. Mukhopadhyay, J. Appl. Polym. Sci. 83, 1517 (2002).

21. D.A. Baker, G.C. East and S.K. Mukhopadhyay, J. Appl. Polym. Sci. 84, 1309 (2002).

22. P.J. Flory and J. Rehner Jr., J. Chem. Phys. 11, 521 (1943).

23. H.G. Dikland, "Co-agents in peroxide vulcanization of EP(D)M rubber", PhD thesis, University of Twente, Enschede (1992).

24. G. Kraus, J. Appl. Pol. Sci., 7, 861 (1963).

25. S. Mihara, "Reactive processing of silica-reinforced tire rubber", PhD thesis, University of Twente, Enschede (2009). 


\title{
Chapter 5
}

\section{Coagents as potential vulcanization aids in di-azides cross- linking}

\begin{abstract}
As shown in the previous chapters of this thesis, some of the di-functional azides are able to effectively vulcanize even fully saturated EPM-rubber. At this moment the most common way for cross-linking this type of elastomers is by a free radical reaction initiated by peroxides. In the case of highly saturated elastomers however, the cross-link efficiency of peroxides is rather low and thus a multi functional compound, the so called coagent, is required in order to obtain a sufficient degree of cross-linking. Although it was assumed beforehand that di-azides have a different curing mechanism than peroxides, nevertheless it seemed interesting to investigate whether a coagent would have a similar positive effect on di-azide curing as well. In the present study the effect of various coagents on di-azide curing is investigated. Subsequently, the maleimide/azidoformate reaction is looked into more closely, as it is this combination which gives the best results.
\end{abstract}




\subsection{Introduction}

Coagents are multi-functional organic molecules, highly reactive towards free radicals. They are commonly applied to improve the efficiency of peroxide vulcanization of various polymers, especially in oil-extended compounds. They are also successfully used in radiation-cure processes, e.g. by electron beam radiation, without the low molecular weight organic peroxides being present. ${ }^{1}$ Depending on their effect on cure characteristics, coagents are generally classified as either Type I or Type II. ${ }^{2-4}$ Coagents of Type I tend to form reactive radicals resulting in higher cross-link density as well as higher curing rate compared to vulcanization with peroxides only. To this category belong substances like acrylates, methacrylates, their zinc salts, maleimides and vinyl esters. Coagents of Type II, on the other hand, tend to form more stable radicals which increase the state of cure without increasing the cure rate, thus without reducing the scorch time. The second category includes allylic compounds and low molecular weight high-vinyl polymers like 1, 2-polybutadiene.

Due to their high affinity towards radicals the coagent molecules help to minimize side reactions like chain scission and disproportionation and thus to improve the crosslinking efficiency of peroxides to a large extent. In this context, N,N'-mphenylenedimaleimide (HVA-2) in combination with dicumyl peroxide was commonly used as reference curing system through the entire thesis. Though the exact mechanism of coagent reactions during vulcanization is still a subject of ongoing research, it was shown that in some cases the molecules can be incorporated into the polymer network and create bridges between the polymer chains. ${ }^{2,3,5-11}$ The reaction mechanism according to which e.g. a bis-maleimide co-agent is incorporated between two polymer chains was proposed already in 1959 by Kovacic and Hein. ${ }^{11}$ The reaction scheme is shown in Fig. 5.1. According to this mechanism a peroxy-radical first reacts with a polymer chain to create a macroradical $(I)$ which very quickly incorporates a coagent molecule giving a new free radical (II). In the next step a chain transfer reaction by a hydrogen abstraction will occurs leading to the formation of a new macroradical. When the second maleimide functionality in the symmetrical molecule proceeds through an analogous sequence, a coagent containing cross-link is formed. Besides the one mention above however, there is also a number of other mechanisms proposed which lead to the same product. 


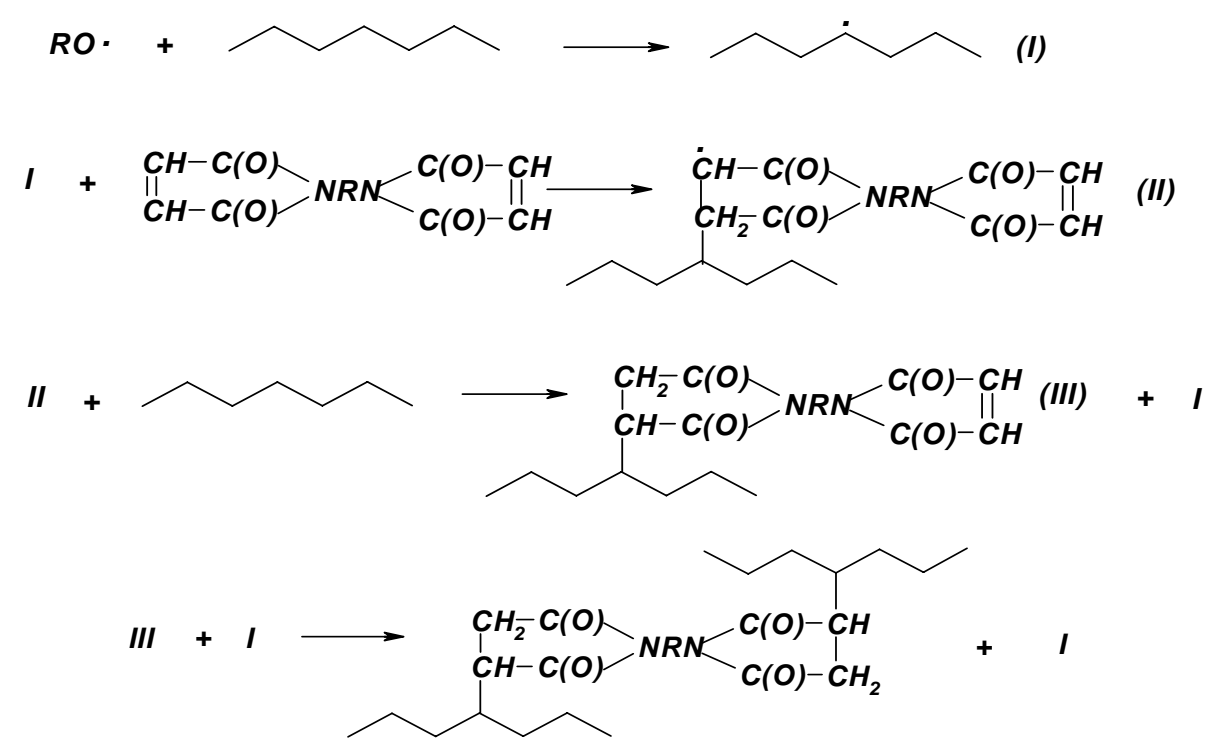

Scheme 5.1: Suggested reaction mechanism of di-maleimide coagents

In general, the coagents are rather polar molecules and therefore tend to phase separate from a non-polar rubber matrix and become homo-polymerized. For some time it was believed that Type I coagents which are more polar and much more reactive towards free radicals, will react with themselves more readily then a Type II coagent. The work presented by Dikland showed however, that also the coagents of Type II, like TAIC tend to homo-polymerize to a large extent. ${ }^{7-9}$ The homo-polymerized coagents domains are co-vulcanized with a rubber matrix and behave as filler particles. The ratio of homo-polymerization and reaction with elastomer will vary, depending on type of elastomer, coagents concentration and their readiness to become homo-polymerized. Another consequence of the polarity difference can be migration of the coagents to the rubber surface.

In the present study the effect of various coagents on di-azide curing was investigated. The main motivation for this work was a short note in one of the few papers which deals with di-azide curing. ${ }^{12}$ When studying the cross-linking of a variety of elastomers using tetramethylene-bis(azidoformate) the observation was made that a small addition of certain additives, with sulfur given as an example, results in improved cross-link efficiency.

\subsection{Experimental}

\subsubsection{Materials}

A masterbatch I consisting of EPM rubber and carbon black only, was prepared using a Brabender internal mixer of $370 \mathrm{~cm}^{3}$ volume, employing a fill factor of $70 \%$. Masterbatch II was prepared at DSM Elastomers B.V. using a larger internal mixer, 3.5 
L volume: Francis Shaw KI Mark 4, with a fill factor of $75 \%$. Masterbatch II contained EPM rubber, carbon black and paraffinic oil. The EPM-rubber (Keltan 3200A) was provided by DSM Elastomers B.V. itself. Carbon black: N-550 was supplied by Cabot Corporation and the paraffinic oil, Sunpar 150 (specific gravity: 0.88 at $15.6{ }^{\circ} \mathrm{C}$, visc. $95 \mathrm{cSt}$ at $40^{\circ} \mathrm{C}$ ) was obtained from the Sun Oil Cie. The exact recipe of both masterbatches is given in Table 5.1.

Table 5.1 Masterbatch compositions (phr)

\begin{tabular}{lcc}
\hline Components & Masterbatch I & Masterbatch II \\
\hline EPM (Keltan 3200A) & 100 & 100 \\
Carbon black (N-550) & 60 & 60 \\
Paraffinic oil (Sunpar 150) & - & 30 \\
\hline
\end{tabular}

The coagents: trimethylolpropane trimethacrylate (TRIM or TMPTMA, $96 \%$ ), triallylcyanurate (TAC, $97 \%$ ) and ethylene dimethacrylate (EDMA, $98 \%$ ) were purchased from Sigma-Aldrich. N,N'-m-phenylenedimaleimide (HVA-2, $97 \%$ ), N,N'-pphenylenedimaleimide (BMI PP, $98 \%$ ) and N-phenylmaleimide (PhMI, $97 \%$ ) were supplied by Acros, 1,3-bis(citraconimido)methyl-benzene (Perkalink 900) from Flexsys. Dicumyl peroxide (DCP, Perkadox BC-40, 40\% on carrier) was kindly provided by Akzo Nobel. Sulfur $\left(\mathrm{S}_{8}, 100 \%\right)$ was obtained from Merck and the cyclohexane from by Biosolve.

The three investigated di-azides: 4,4'DAF (4,4'-isopropylidenediphenyl azidoformate), GDAF (tri(ethylene-glycol)-di-azidoformate) and 1,3BDSA (1,3-benzenedisulfonyl azide) were synthesized from the corresponding chlorides and sodium azide as described in Chapter 3. The mono-azidoformate: 4-methoxybenzyloxycarbonyl azide (M-BAF, $95 \%$ ) was obtained from Sigma-Aldrich.

\subsubsection{Characterization of the products}

\section{Compound characterization and vulcanization}

Curatives were added to the masterbatch compounds using a Schwabenthan two roll mill at a temperature close to $40^{\circ} \mathrm{C}$. The cure characteristics of each compound were measured using a torsional dynamic rheometer, RPA 2000 from Alpha Technologies. The same conditions: strain of $0.2 \mathrm{deg}$ and a frequency of $0.833 \mathrm{~Hz}$ were applied for every cycle. The delta torque, which is the maximum of the measured torque $(\mathrm{MH})$ minus the minimum torque $(\mathrm{ML})$, was used to estimate the extent of cross-linking or state of cure. As explained in Chapter 3, due to different decomposition kinetics the vulcanization temperature was taken as $150^{\circ} \mathrm{C}$ for the two di-azidoformates: 4,4'DAF and GDAF; $160{ }^{\circ} \mathrm{C}$ for $\mathrm{DCP}$ and $180{ }^{\circ} \mathrm{C}$ for di-sulfonyl azide: 1,3BDSA. The 
compounds were vulcanized by compression moulding in a Wickert laboratory press WLP $1600 / 5^{\star} 4 / 3$ at 100 bar, for the duration of $t_{90}$ of the specific compounds into $2 \mathrm{~mm}$ thick sheets.

\section{Mechanical properties}

Crosslink density of the samples was calculated according to the Flory-Rehner equation, based on equilibrium swelling data in cyclohexane, as described in Chapter 4. The stress-strain properties of the vulcanized compounds were measured using a Zwick tensile tester according to the conditions described in ISO 37. Dumb-bell shaped specimens of Type 2 were used and a nominal rate of the moving clamps of 500 $\mathrm{mm} / \mathrm{min}$. The hardness of the vulcanized samples was measured with a Zwick hardness tester Shore A type, according to DIN 53517.

\subsection{Results and discussion}

\subsubsection{Effects of different coagents on di-azide cross-linking}

Investigated in the present study were the most frequently used coagents of Type I and Type II. Due to its similarity to one of the most common di-maleimide coagents HVA-2, Perkalink 900 was tested as well. This substance was recently introduced as new antireversion agent for sulfur vulcanization, but not as a coagent for peroxide vulcanization. ${ }^{13,14}$ Elemental sulfur, $\mathrm{S}_{8}$ was also included as a kind of reference, since its positive effect on di-azide cross-linking was already reported. ${ }^{12}$ The chemical structures of all investigated substances are shown in Table 5.2. The selected diazides: 4,4'DAF, GDAF and 1,3BDSA are described extensively in the previous chapters of this thesis and through with different efficiency, all of them proved to be effective curing agents for EP(D)M rubbers.

Masterbatch I and Masterbatch II were cured with di-azide in combination with each of the additives listed below. To eliminate a potentially negative effect of plasticizing oil on the reaction, the Masterbatch I is left completely free of oil, and consequently requires only a small amount of curatives. The concentration of di-azides used to cure this Masterbatch was $4.4 \mathrm{mmol}$ and of the additive $3 \mathrm{mmol}$ per $100 \mathrm{~g}$ of rubber, which is roughly half of the usual peroxide curing recipe for an oil-extended compound. 
Table 5.2 Overview of all tested substances

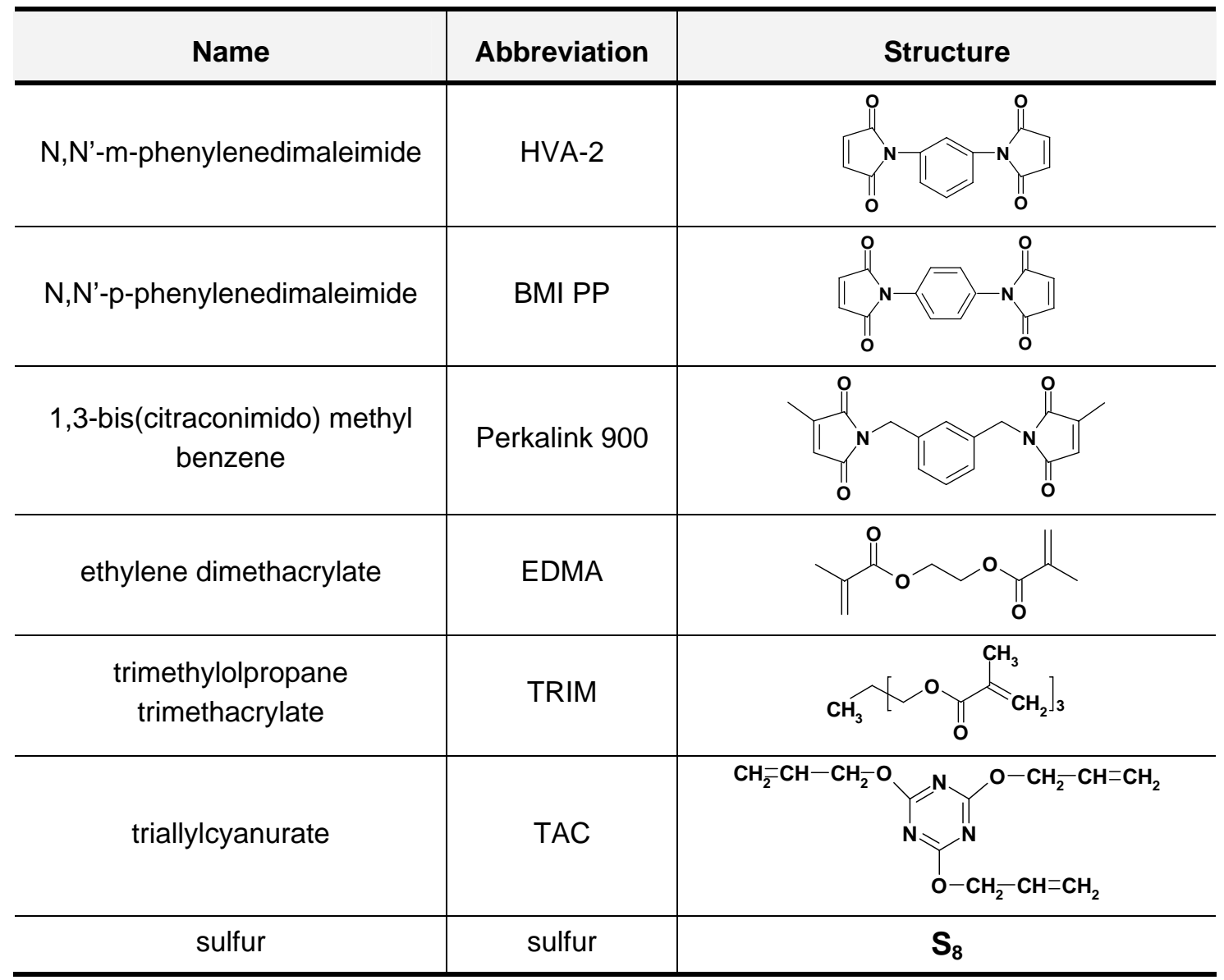

First, the effectiveness of the various additives was judged based on they influence on the cure characteristic. When analyzing the rheomether data it was observed, that each of the tested substances changed the cure curve compared to the one obtained using the particular di-azide on their own. Unlike in peroxide cross-linking however, not all coagents improved the cure characteristic. Addition of some of them resulted in an increase in torque values, while others cause a drop. Another significant difference from what is normally seen during peroxide/coagent cross-linking of EPM is, that during di-azide curing the effect of the coagents was always rather small. Consistently however, several of the additives tended to change the cure curve in a similar way, independent of the di-azide used. It was assumed that, if addition of a certain substance caused an increase in torque value, this would also lead to an improvement of the mechanical properties. When addition of a certain compound caused a drop in torque value, the coagent was excluded from further testing.

The rheometer data which show what kind of effect different additives have on GDAF cross-linking are given in Figs. 5.1 (a) and (b) for a Masterbatch I and in Figs. 5.2 (a) and (b) for Masterbatch II. Figs. 5.1 (a) and 5.2 (a) show which of the tested additives had a positive effect on cure characteristics, while Figs. 5.1 (b) and 5.2 (b) show the ones whose influence was negative. For both masterbaches the results are very 
similar. Sulfur and the two di-maleimide coagents: BMI PP and HVA-2 make the torque value to rise independent of whether oil is present in the compound or not. On the other hand, additions of EDMA, TAC and Perkalink 900 decrease the torque values. TRIM is the only coagent which seemed to lower the cure curve when added to Masterbatch I, but to increase when added to Masterbatch II. In both cases however, the changes in cure characteristic are rather minor.
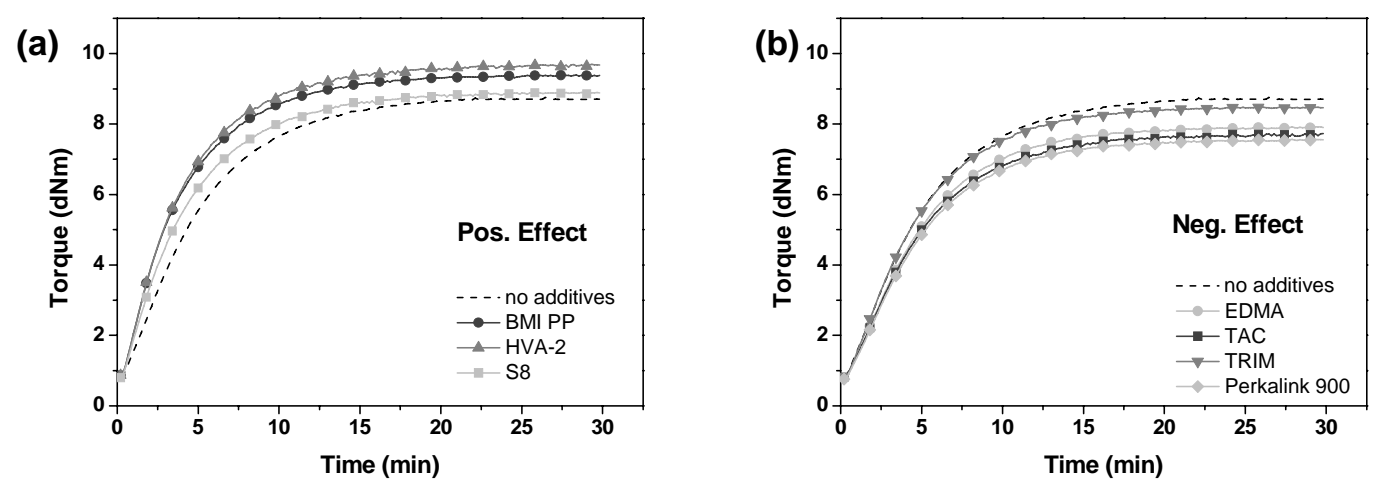

Fig. 5.1: Rheograms of Masterbatch I cured with GDAF and various additives; (a): positive effect and (b): negative effect
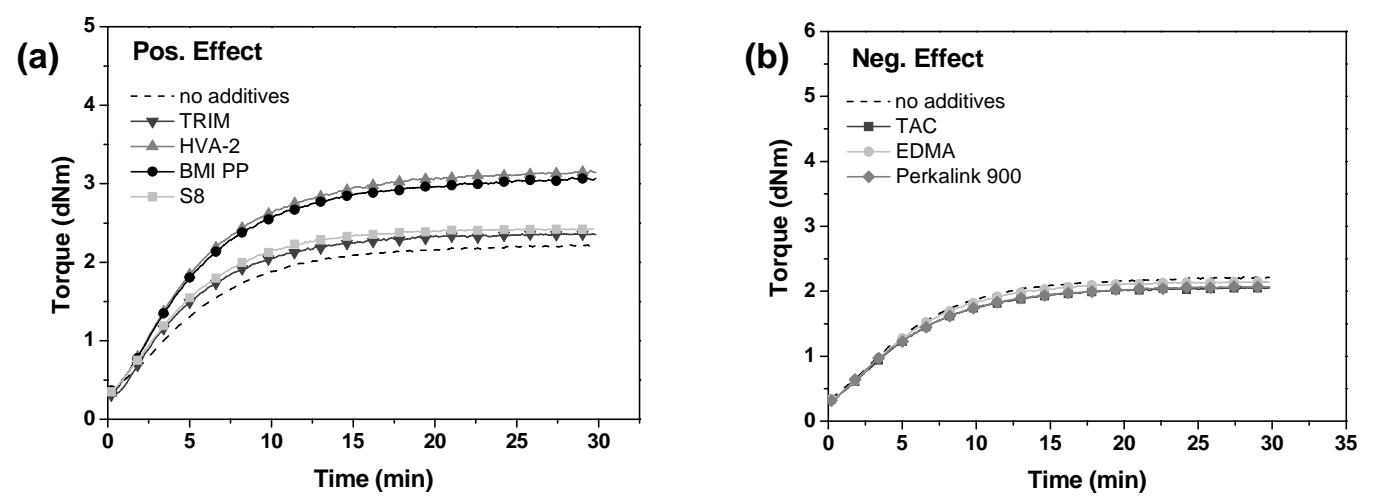

Fig. 5.2: Rheograms of Masterbatch II cured with GDAF and various additives; (a): positive effect and (b): negative effect

Based on the present study the positive effect of sulfur noticed by Breslow can be classified as rather small. A much bigger improvement is noticed when the two dimaleimide coagents are introduced, where the more common one: HVA-2 seems to work slightly better then its para-analog. Perkalink 900, despite it similarity with the HVA-2 co-agent, shows no positive effect on cure characteristics. EDMA and TAC are well known co-agents, widely applied in peroxide curing but still their addition to the diazide cured samples seems to have rather a deactivation than a boosting effect. Like HVA-2 both TRIM and EDMA are coagents of Type I, though the first one has maleimide functionality and the other two are of metacrylate type. TAC contains allylic functionalities and belongs to the group of coagents of Type II. Why some of the 
traditional coagents have a positive and others a negative influence on di-azides curing does not become clear from these experiments. It shows at least that the chemical mechanisms involved for the di-azide may be quite different from that for a peroxide.

\subsubsection{Effect of variation in HVA-2 content and of presence of plasticizing oil on di-azide cross-linking}

From a practical point of view the addition of oil into the rubber compound is necessary in order to obtain good processability of the material as well as the desired final properties. However, even the least reactive paraffinic oil will have a cross-link reduction effect during peroxide curing: see Chapter 4 . When cross-linking an oilcontaining compound the efficiency of peroxide can be significantly improved by addition of a coagent. As mentioned in Chapter 4, paraffinic plasticizers also have a certain deactivating effect on di-azide curing, though similar as observed for the peroxide/coagent combination and much less compared to the peroxide on its own. Therefore, the influence of HVA-2 on di-azide cross-linking was further investigated in both systems: with and without plasticizing oil. The exact curing recipes applied are given in Table 5.3.

Table 5.3 Curing recipes

\begin{tabular}{|c|c|c|c|c|}
\hline \multicolumn{5}{|c|}{ Masterbatch I and II (mmol) } \\
\hline $\mathrm{DCP}$ & 4.4 & - & - & - \\
\hline$\underline{4,4^{\prime} D A F^{\star}}$ & - & $\underline{4.4}$ & - & - \\
\hline GDAF & - & - & 4.4 & - \\
\hline 1,3BDSA & - & - & - & 4.4 \\
\hline HVA-2 & $0,1,3,5$ & $\underline{0,1,3,5}$ & $0,1,3,5$ & $0,1,3,5$ \\
\hline \multicolumn{5}{|c|}{ Masterbatch II (mmol) } \\
\hline DCP & 8.8 & & - & - \\
\hline GDAF & - & & 8.8 & - \\
\hline 1,3BDSA & - & & - & 8.8 \\
\hline HVA-2 & $0,2,6,10$ & & $0,2,6,10$ & $0,2,6,10$ \\
\hline
\end{tabular}

* 4,4'DAF was used only in the oil free Masterbatch I

To obtain a fair comparison between oil-free and oil-containing compounds, first the same amount of curatives was used to vulcanize Masterbatch I and Masterbatch II. The one exception was that 4,4'DAF due to its low efficiency in EPM cross-linking was tested only in the oil-free Masterbatch I. The oil extended Masterbatch II was subsequently vulcanized again, using doubled curing agent concentrations. To better understand the differences between peroxide and di-azide cross-linking, as well as to 
clarify how the coagents influence both of them, the DCP/HVA-2 combination was investigated as a reference.

The delta torque values achieved using the different curatives with varying HVA-2 content are shown in Figs. 5.3 - 5.5. The graphs (a) and (b) basically show the same sets of data. Graph (a) gives the delta torque values as they show on a rheometer trace, whiles graph (b) shows how much the torque values increase when the coagents are introduced. During peroxide/HVA-2 curing, addition of the coagent causes a significant increase in torque values. The addition of HVA-2 into di-azide cured samples results in higher torque values as well, but the effect is much less pronounced then for peroxide. The rheometer data further indicate that HVA-2 has a slightly larger influence on GDAF curing than on 1,3BDSA. For both di-azides however, the effect seems to be somewhat limited. A small addition of the coagent, around $3 \mathrm{mmol}$, raises the measured torque; any further additions have very little effect anymore. For comparison, during peroxide curing much bigger coagent contents can be added and still a positive effect is observed. Other remark is that in the presence of oil: Masterbatch II, the effect of HVA-2 is somewhat reduced relative to the oil-free Masterbatch I. What should be kept in mind though is, that the effect of the coagent on di-azide curing is measured specifically for the EPM-rubber and the observed relations can be quite different when the same curing recipe will be applied to other elastomers.
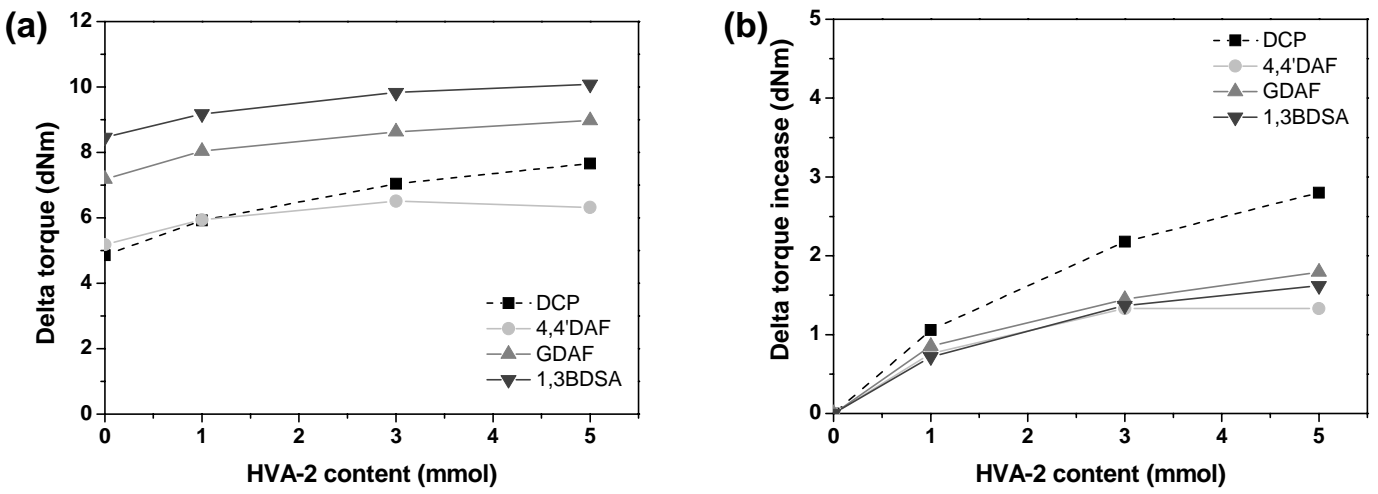

Fig. 5.3: Masterbatch I cured with $4.4 \mathrm{mmol}$ of various curatives (a): delta torque and (b): increase in delta torque value 

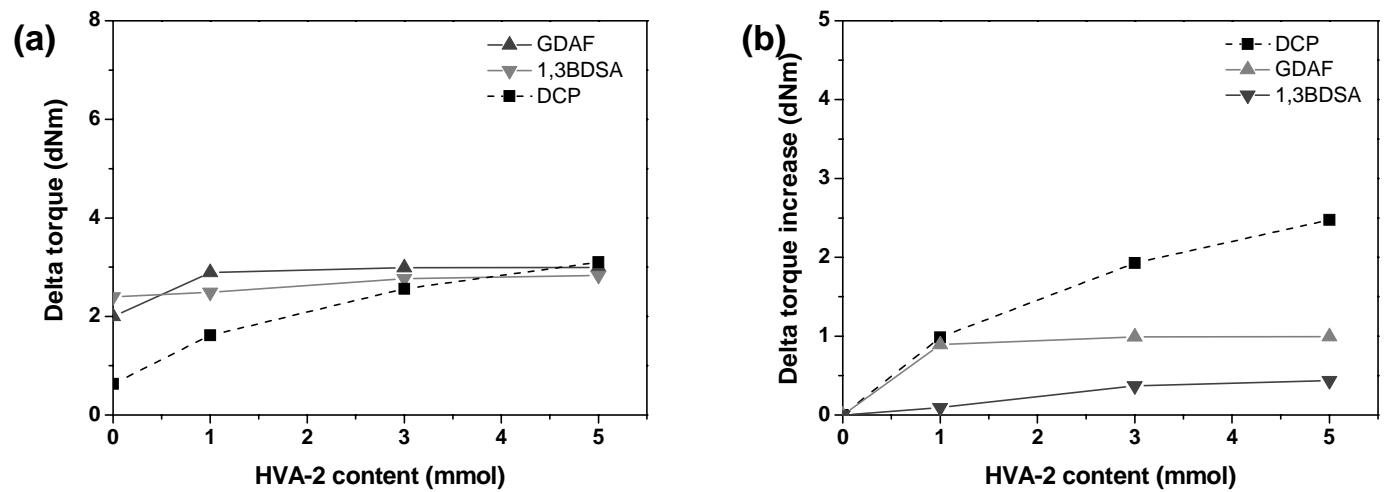

Fig. 5.4: Masterbatch II cured with $4.4 \mathrm{mmol}$ of; (a): delta torque and (b): increase in delta torque value
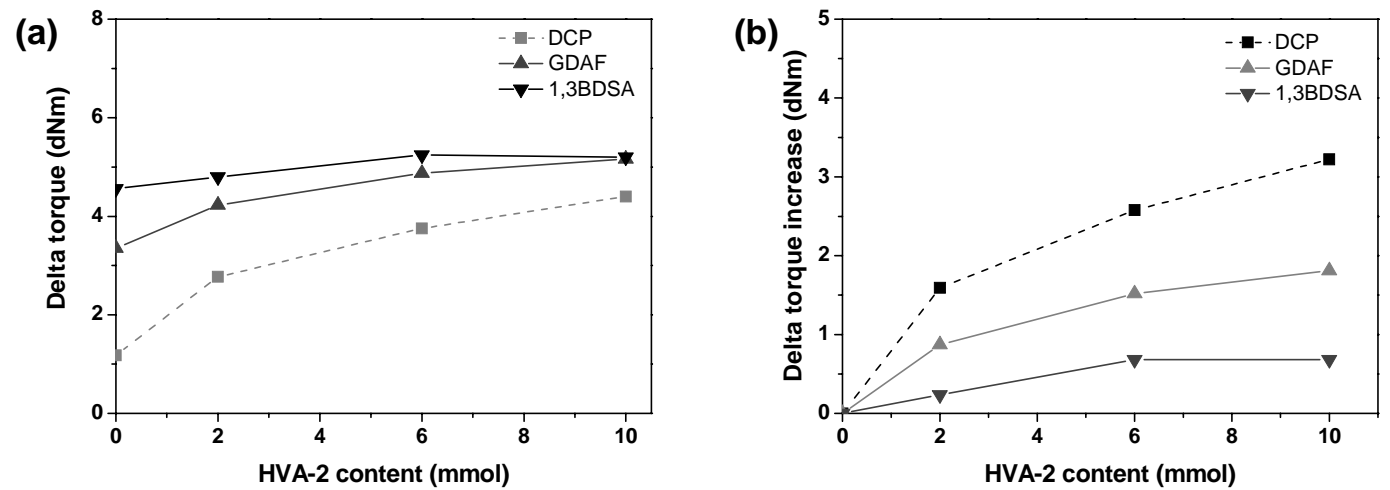

Fig. 5.5: Masterbatch II cured with $8.8 \mathrm{mmol}$ of (a): delta torque and (b): increase in delta torque value

When the two di-azidoformates: 4,4'DAF and GDAF were applied, a certain plasticizing effect was observed as described in Chapter 4. Although both 1,3BDSA and GDAF result in similar cross-link densities, the values of delta torque, moduli and hardness were significantly higher for samples vulcanized with 1,3BDSA. The same plasticizing effect can again be seen again in Fig. 5.5. When the compounds are vulcanized with the di-azides only, the torque measured for the 1,3BDSA cured sample is higher compared to GDAF. The effect is especially clear for the oil containing Masterbatch II. A similar trend is observed later on when comparing the hardness of this material.

\subsubsection{Influence of variation in HVA-2 content on tensile properties for various di-azides}

The stress-strain properties of Masterbatch I cured using different di-azides and dicumyl peroxide all in combination with varying HVA-2 concentrations are shown in Fig. 5.6 (a) - (d). The efficiency of peroxide is quite low, Fig. 5.6 (a) and it is practically 
not possible to obtain acceptable properties without the coagent being used. The addition of HVA-2 causes a significant improvement in tensile strength for the peroxide vulcanization. With $5 \mathrm{mmol}$ of the coagent the measured tensile strength is four times higher compared to the sample cross-linked with peroxide only. The coagent also increases the modulus and hardness of the compound, as shown in Fig. 5.7.
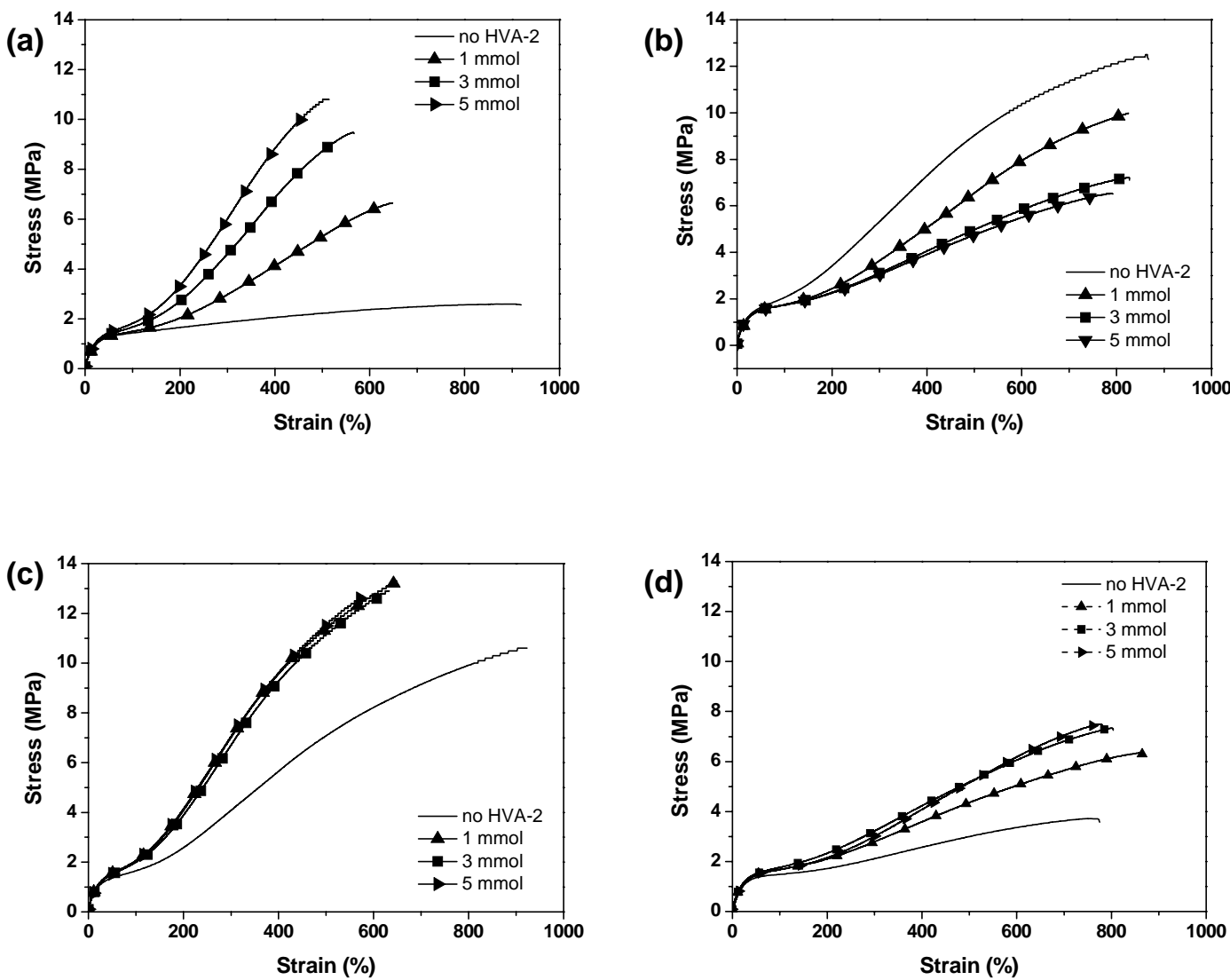

Fig. 5.6: The influence of HVA-2 on stress-strain properties measured for Masterbatch I cured with $4.4 \mathrm{mmol}$ of; (a): DCP; (b): 1,3BDSA; (c): GDAF and (d): 4,4'DAF

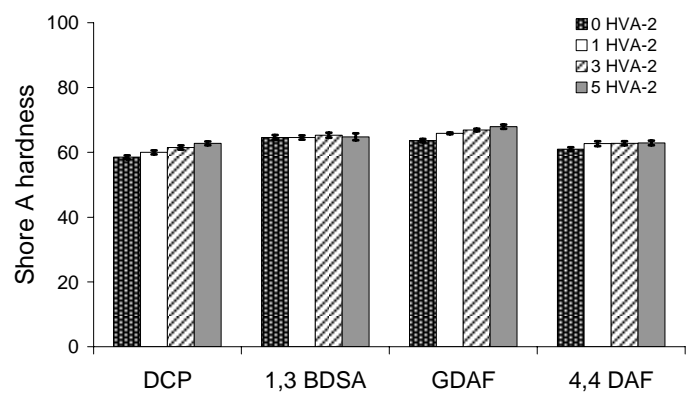

Fig. 5.7: Hardness vs. HVA-2 concentration for Masterbatch I

Despite a certain increase in torque values during 1,3BDSA cross-linking by HVA-2, there is no positive effect on the mechanical properties observed. On the contrary, even a small amount of the coagent causes a significant drop in tensile strength and 
moduli. The fact that hardness does not change much can be explained by the high viscosity of the compound. As will be shown later its value decreases when the same curing recipe is applied for the oil-extended Masterbach II. The mechanical properties of the 4,4'DAF and GDAF cross-linked compounds are enhanced by HVA-2 addition. A small amount of the di-maleimide coagent results in an increase of tensile strength, moduli and hardness, particularly in combination with GDAF.

The stress-strain properties of the oil-extended Masterbatch II cured with the same amounts of di-azides and coagents as Masterbatch I are shown in Figs. 5.8 (a) -5.10 (a). The properties measured with double amounts of curatives are given in Figs. 5.8 (b) -5.10 (b). Although the efficiency of the curatives is lower in the oil containing compound, when comparing the two sets of data it is observed that HVA-2 influences the stress-strain properties in a very similar way for both Masterbatches. As already mentioned in previous chapters, due to the close similarity between the saturated molecular structure of EPM and the paraffinic oils, it is obvious to expect that some of the curing species, whenever radicals or nitrenes, will not react with the polymer but with the oil instead.
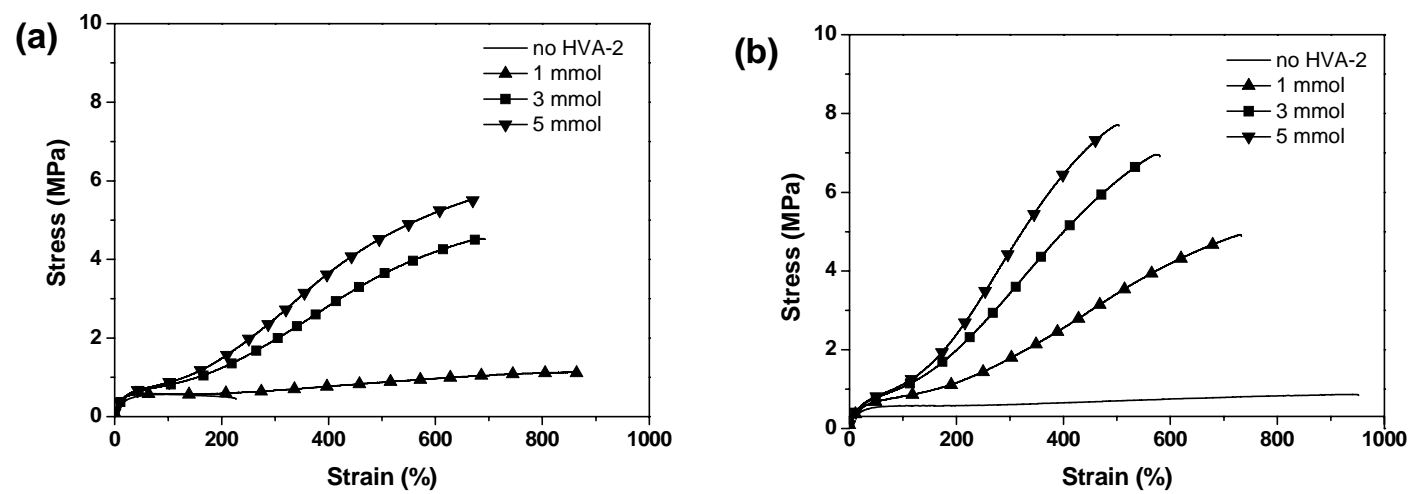

Fig. 5.8: Stress-strain properties of Masterbach II cured with DCP and various amounts of HVA2; (a): DCP $4.4 \mathrm{mmol}$; (b): DCP $8.8 \mathrm{mmol}$

The peroxide on its own has such a low efficiency in cross-linking the oil-extended EPM compound, that it is practically not possible to vulcanize it using only DCP. When a high peroxide concentration is applied the elongation at break can be somewhat increased, but there is no tensile strength development, as shown in Fig. 5.8. The material gains it strength only by coagent addition and its concentration seems to influence the final properties much more than the peroxide content. Although the main function of coagents in peroxide curing is to increase the tensile strength of the material, it appears that at the same time the elongation at beak is largely reduced. 
(a)

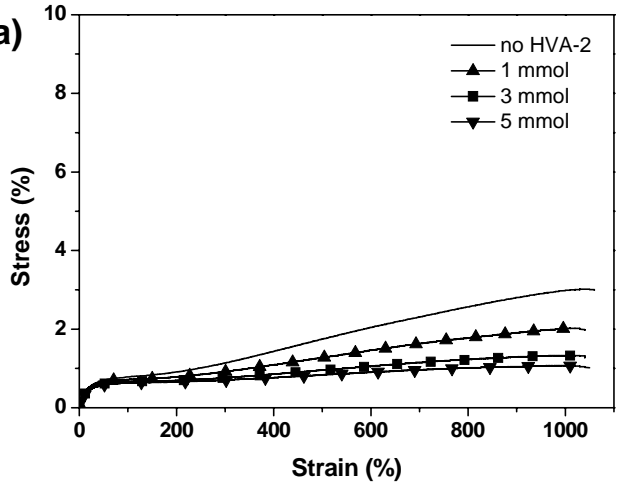

(b)

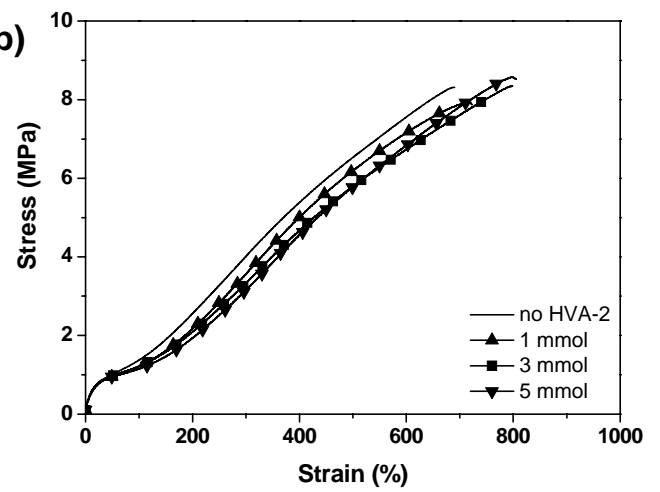

Fig. 5.9: Stress-strain properties of Masterbach II cured with 1,3BDSA and various amounts of HVA-2; (a): 1,3BDSA $4.4 \mathrm{mmol}$; (b): 1,3BDSA $8.8 \mathrm{mmol}$

Similar to what was observed for the oil-free Masterbatch, I the addition of HVA-2 into 1,3BDSA cross-linked Masterbatch II again results in reduction of the mechanical properties. With lower 1,3BDSA concentration the drop in mechanical properties caused by HVA-2 addition is more significant than for higher concentrations. This suggests that $8.8 \mathrm{mmol}$ of $1,3 \mathrm{BDSA}$ is already enough to create a highly dense crosslinked network and even if a certain amount of the di-azides will be deactivated by the coagents the properties do not change significantly anymore.
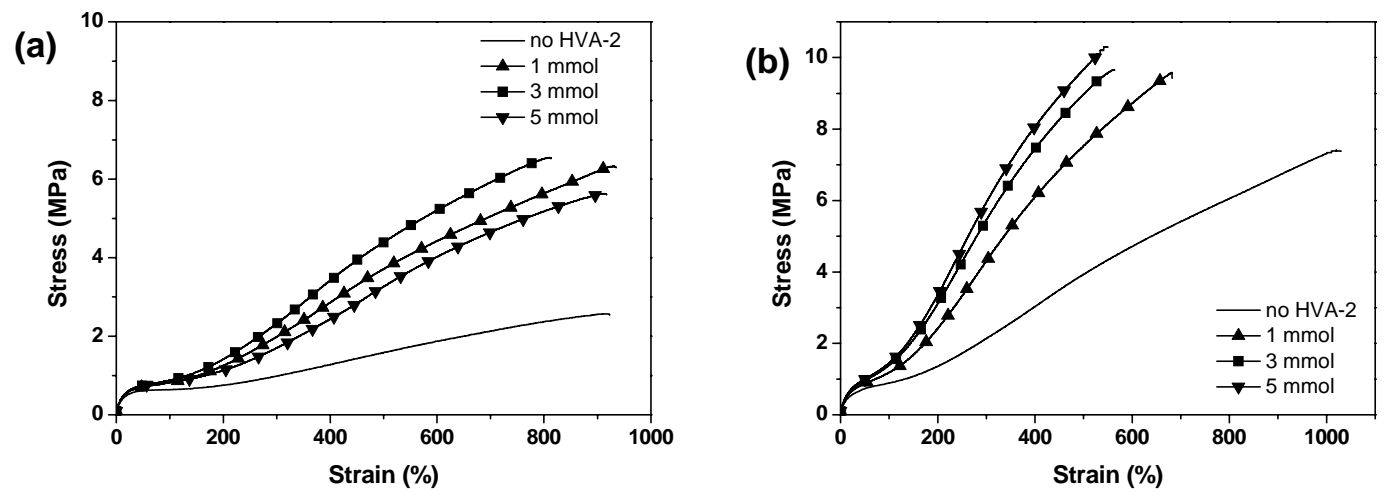

Fig. 5.10: Stress-strain properties of Masterbach II cured with GDAF and various amount of HVA-2; (a): GDAF $4.4 \mathrm{mmol}$; (b): GDAF $8.8 \mathrm{mmol}$

The combination of HVA-2 with GDAF brings to the system a certain improvement; the first small coagent addition increases the tensile strength and moduli quite significantly. As was observed also for the Masterbatch I however, with higher coagent loading further improvement of the properties is rather minor. Finally, making a rough estimate, it can be calculated that if on a molar basis the amount of HVA-2 is greater than the amount of GDAF, the positive effect of the coagent is completely lost and the properties instead of improving start to decrease. 
Cross-link density and hardness of the different compounds are given in Figs 5.11 and 5.12, respectively. Due to their low cross-link densities the swelling data of the samples cross-linked with $4.4 \mathrm{mmol}$ of DCP are not reliable. With higher peroxide content however, it can clearly be seen that the addition of HVA-2 results in a linear increase of both cross-link density and hardness, proportional to the coagent content.

(a)

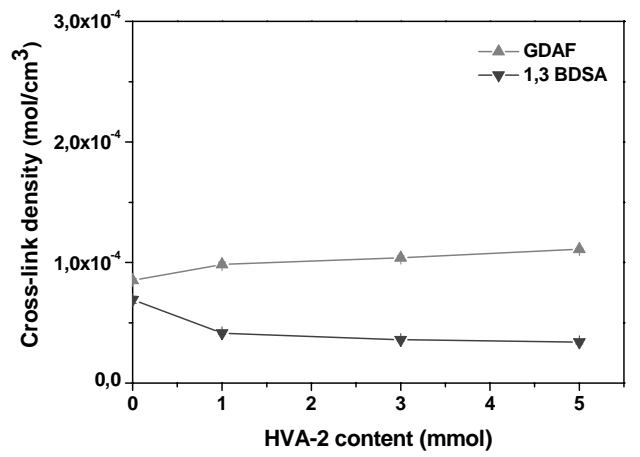

(b)

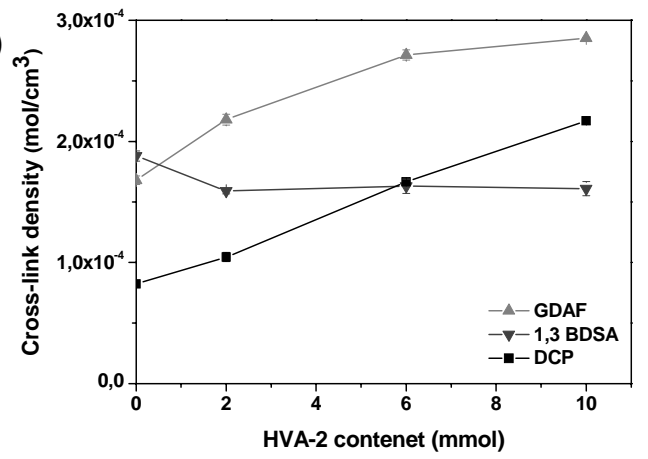

Fig. 5.11: Masterbatch II- influence of HVA-2 on crosslink density; (a): di-azides 4.4 mmol; (b): di-azides and DCP $8.8 \mathrm{mmol}$
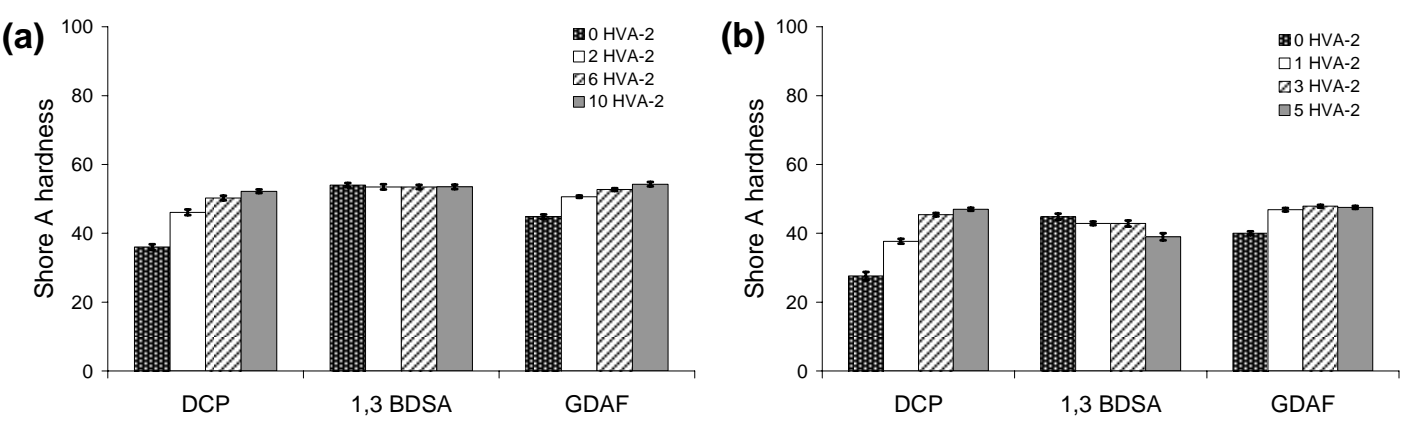

Fig. 5.12: Masterbatch II: influence of HVA-2 on hardness; (a): di-azides and DCP $4.4 \mathrm{mmol}$; (b): di-azides and DCP $8.8 \mathrm{mmol}$

The cross-link density data indicate clearly that addition of HVA-2 during 1,3BDSA curing results in deactivation of the azide. Irrespective of the 1,3BDSA concentration, the HVA-2 causes a reduction in cross-link density, moduli and hardness. Thus the increase in delta torque, as seen before, although minor, is rather surprising in retrospect.

The improvement in stress-strain properties, observed under HVA-2 addition during GDAF curing, can be explained by the increase in cross-link density: Fig. 5.11. It is however the enhancement of modulus and hardness that seems even more significant. As described in Chapter 4, the tensile strength and cross-link density of GDAF and 1,3BDSA cured samples are very similar. The main difference between the two di-azides was that the GDAF compounds were characterized by very low delta torque, moduli and hardness. The properties hardly improved with GDAF loading despite the rise in cross-link density. In the present context, HVA-2 noticeably helps to 
develop the stiffness of the GDAF vulcanizate. As shown in Fig. 5.12 only a small amount of the coagent increases the hardness by around 6 units on the Shore A scale. To complete the study, all substances which had any positive effect on di-azide cure were re-tested again. Masterbatch II was cured with $8.8 \mathrm{mmol}$ of GDAF and $5 \mathrm{mmol}$ of the various additives. The cure curves for the specific compounds show an identical dependence as given in Fig. 5.2 (a). The one difference is that in the new series of tests, with the higher curatives loading applied the measured torque values are larger as well. The stress-strain properties of the specific compounds are given in Fig. 5.13 and hardness Shore A in Fig. 5.14.
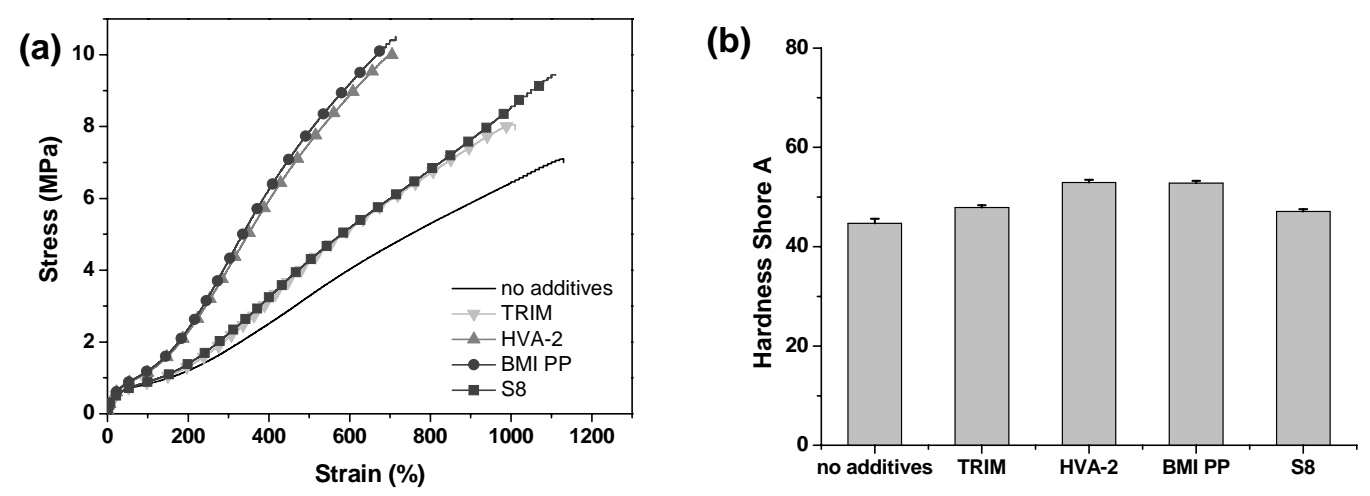

Fig. 5.13: Masterbatch II cured with $8.8 \mathrm{mmol}$ of GDAF and $5 \mathrm{mmol}$ of different additives; (a) stress-strain properties; (b) hardness

The data clearly indicate that although both elemental sulfur, as well as TRIM, can improve the mechanical properties of GDAF cured material, this effect is rather small. Compared on molar basis, the same amount of either one of the di-maleimide coagents will improve the properties much more. Both di-maleimide coagents: HVA-2 and BMI PP show an identical influence on stress-strain properties as well as on the hardness.

\subsubsection{Cross-linking mechanism: comparison of di- and mono- functional maleimides and azidoformates}

The di-maleimides are known not only as coagents, but also for their ability to crosslink a wide variety of polymers on their own. Highly unsaturated elastomers like NR, can be vulcanized with HVA-2 without additional catalyst being present, although the degree of cross-linking is relatively low. Polyethylene also can be vulcanized using dimaleimides, though a catalytic amount of peroxide is required. ${ }^{15-17}$ To gain a better understanding of the azidoformate-maleimide reaction, a new series of samples based on oil-extended Masterbatch II was prepared. The EPM-compound was cross-liked using mono- and di-azidoformates as well as mono- and di-maleimides. The exact curing recipes are listed in Table 5.4. The sulfonyl azides were exclude from this study 
because as shown above in the 1,3BDSA/HVA-2 combination the coagent had only a deactivation effect, resulting in cross-link density reduction.

Table 5.4 Curing recipes: Masterbatch II

\begin{tabular}{c|c|c|c|c|c|c|c}
\hline Curative & \multicolumn{7}{|c}{ Amount (mmol) } \\
\hline GDAF & - & 11 & 11 & 11 & - & - & - \\
M-BAF & - & - & - & - & 22 & 22 & 22 \\
HVA-2 & 10 & - & 5 & - & - & 5 & - \\
PhMI & - & - & - & 10 & - & - & 10 \\
\hline
\end{tabular}

To determine whether HVA-2 still produces cross-links once all potential radical sources are eliminated, a compound with only the coagent was prepared. The next samples contained combinations: GDAF/di-maleimide, GDAF/mono-maleimide, MBAF/di-maleimide and M-BAF/mono-maleimide. The cure characteristics of the GDAF (di-azidoformate) and M-BAF (mono-azidoformate) based compounds are given in Figs. 5.14 and 5.15, respectively. The dotted line in the first of the two figures represents the cure curve of the sample containing the HVA-2 alone: no torque development indicates absence of cross-link formation. When combined with GDAF only the di-functional maleimide, HVA-2 results in improved cross-link efficiency. The same concentration of maleimide groups in the form of mono-functionalized molecules has no influence on the reaction. If it is the maleimide functionality which helps the azide group to react more efficiently, there should not be a difference whether the coagent are available in the form of mono- or di-functional molecules. Thus it seems that it is the maleimide functionality which reacts with polymer and the azidoformate somehow triggers the reaction.

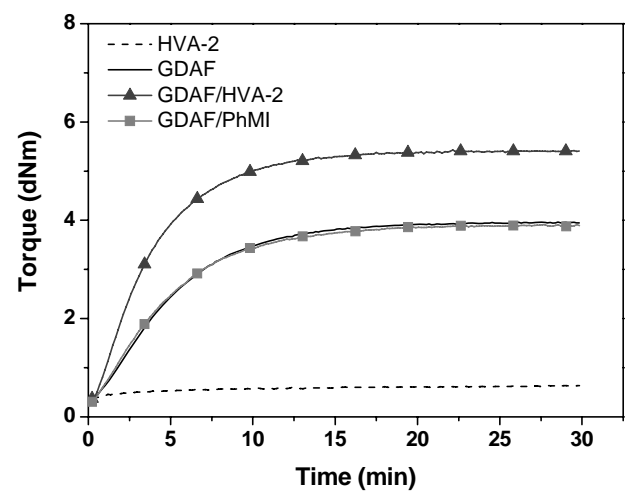

Fig. 5.14: Rheogram of samples cured with: GDAF and di- and mono-maleimide

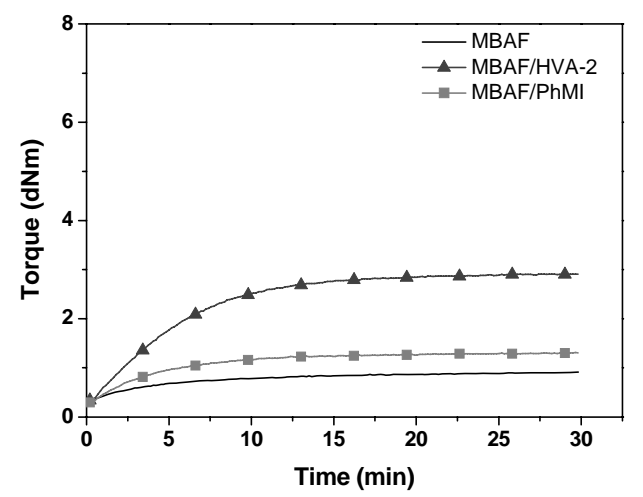

Fig. 5.15: Rheogram of samples cured with: MBAF and di- and mono-maleimide 
This kind of mechanism is also confirmed when the mono-azidoformate/ maleimide reaction is investigated, Fig. 5.15. The M-BAF on its own or in combination with the mono-maleimide, does not introduce any cross-links into the system. The combination M-BAF/HVA-2 however, raises the torque value significantly indicating network formation. The most probable product of the maleimide azidoformate reaction is shown in Scheme. 5.2 (A). Based on the experiments described above, formation of the two other structures is hardly possible. In case structure $(C)$ would be formed, the PhMI will block at least one of the azidoformate functionalities of GDAF and a decrease of delta torque would have been seen in Fig. 5.14. It should be kept in mind however, that this mechanism is still possible to occur during the sulfonyl azide reaction. As described in point 5.3.3, a certain deactivation of 1,3BDSA was observed with maleimide addition. Structure (B) is not likely to occur as well. With this type of cross-link it would not make a difference whenever the maleimide group is introduced in the form of mono- or difunctional molecules.

(A)

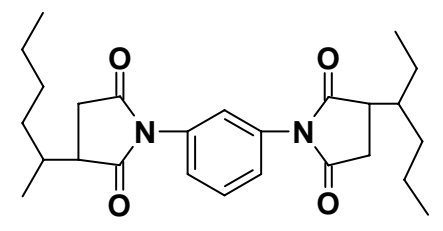

(B)

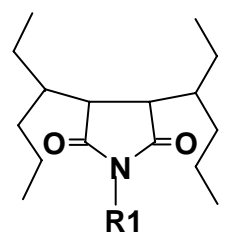

(C)

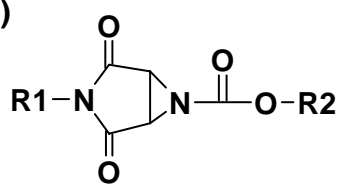

Scheme 5.2: Considered maleimide reaction product; (A): plausible; (B) and (C): not plausible

\subsection{Conclusions}

The role of a coagent in peroxide cross-linking is very important. Especially for saturated elastomers, when there is no or only a little amount of double bonds available, the addition of coagents is necessary in order to achieved a required crosslink efficiency. The peroxide/coagent curing system is also much less sensitive to efficiency reduction due to oil than the peroxides by themselves. The present study shows that a small addition of HVA-2 or sulfur to a di-azidoformate cross-linking system increases the cross-link efficiency. This effect however, is very limited and can not be compared to the role of a coagent in peroxide vulcanization. Out of the coagent types tested some even result in reduction of the properties. Two methacrylates: EDMA and TRIM behave slightly different from one another; the first one results in a reduction in properties, the second shows a certain though rather minor positive effect for a compound containing oil.

Although addition of any of the two di-maleimide coagents result in significant improvement of the properties, the effect is observed only for the low, initial coagent concentration and does not continue with increasing di-maleimide content. The 
maleimide molecules need to be di-functional and thus it seems that it is a role of the azidoformate to activate the maleimide functionality which then reacts with the polymer. It is also quite significant that the di-maleimides only interact efficiently in combination with di-azidoformates: 4,4' DAF or GDAF but not with the di-sulfonyl azide: 1,3BDSA.

\subsection{References}

1. W.C. Endstra, Kautsch. Gummi Kuntstst. 43, 790 (1990).

2. P.R. Dluzneski, Rubber Chem. Technol. 74, 451 (2001).

3. R.E. Drake and J.J. Hollyday, Rubber World 213, 22 (1995).

4. Sartomer, Application Bulletin, http://www.sartomer.com/TechLit/4117.pdf (2009).

5. M.M. Alvarez Grima, A.G. Talma, R.N. Datta and J.W.M. Noordermeer, Rubber Chem. Technol., 79, (2006)

6. Sartomer, Application Bulletin, http://www.sartomer.com/TechLit/4101.pdf (2009).

7. H.G. Dikland, "Co-agents in peroxide vulcanization of EP(D)M rubber", PhD thesis, University of Twente, Enschede (1992).

8. H.G. Dikland, L. van der Does and A. Bantjes, Rubber Chem. Technol. 66, 193 (1993).

9. H.G. Dikland, T. Ruardy, L. van der Does and A. Bantjes, Rubber Chem. Technol. 66, 693 (1993).

10. S.J. Oh and J.L. Koenig, Rubber Chem. Technol. 72, 74 (2000).

11. P. Kovacic and R.W. Hein, J. Am. Chem. Soc. 81, 1190 (1959).

12. D.S. Breslow, W.D. Willis and L.O. Amberg, Rubber Chem. Technol. 43, 605 (1970).

13. A. Schotman, P. Haeren, A. Weber, F. Wijk, J. Hofstraat, A. Talma, A. Steenbergen and R. Datta, Rubber Chem. Technol. 69, 727 (1996).

14. A. Talma and R. Datta, Rubber Chem. Technol. 71, 1073 (1998).

15. P. Kovacic and R.W. Hein, J. Am. Chem. Soc. 81, 1187 (1959).

16. P. Kovacic and R.W. Hein, Rubber Chem. Technol. 35, 520 (1962).

17. P. Kovacic and R.W. Hein, Rubber Chem. Technol. 35, 528 (1962). 


\title{
Chapter 6
}

\section{Modification of EPM-rubber using mono-azides}

\begin{abstract}
In the present chapter the mono-azide compounds are tested as carriers of functional groups for grafting onto fully saturated EPM-rubber. Investigated are three mono-azidoformates: PhAF, BAF and M-BAF and two monosulfonyl azides: PhSA and A-PhSA. The mono-azide/EPM reaction is carried out by reactive mixing which is demonstrated to be very efficient. The main issue seems to be the compatibly between rubber and the azide compound once structure of the latest become bit more complex. Simple phenyl- and benzyl-azides are very well soluble in EPM already at room temperature and their grafting efficiency is very high. The compatibility seems to decrease however once a second functional group is introduced; A-PhSA containing a polar acetamido-group is no longer soluble and does not react with EPM.
\end{abstract}




\subsection{Introduction}

In search for better and cheaper materials the polymer industry puts great interest in extending the technological applications of existing polymers rather than to develop completely new ones. By incorporating suitable functional groups the properties of polymers can be widely tailored. The motivation to functionalize certain polymers is dictated by the specific needs which in time of fast technological development are basically unlimited. The most common goals however, are either to enhance the resistance, improve adhesion or make the material more compatible with other polymers.

The main advantage of elastomers with a fully saturated backbone like EP(D)M is their superior stability against oxygen, ozone, heat and radiation. On the other hand, the disadvantage of the absence of carbon-carbon unsaturation is the lack of reactivity. Chemical modification could be a solution to increase polymer reactivity while retaining its high resistance. The EP(D)M rubbers are also characterized by low polarity, thus by introducing the right functional groups a better interaction with more polar polymers can be obtained, e.g. to use them as impact modifiers for those polymers (not further investigated in the context of this thesis). There are a number of studies dealing with extending commodity polyolefins: polyethylene (PE) and polypropylene (PP), by introducing a small amount of polar, reactive functionalities onto the polymer backbone..$^{1-3}$ The most common way to overcome the low reactivity of saturated polymers is to initiate a radical process. Ways more directly linked to the synthesis of the polymers, such as end-group functionalization or direct copolymerization, have also been investigated. ${ }^{1}$ Often used as suitable functionalized monomers are (meth)acrylic acid, acryl amine and maleic anhydride (MA), where the last one is most common. Grafting of MA starts with $\mathrm{H}$-abstraction from the polymer backbone and formation of a macroradical, which subsequently may add to a MA molecule resulting in desired grafting. ${ }^{3-6}$ However as all free-radical reactions, grafting of MA suffers from several disadvantages as lack of selectivity and occurrence of side reactions inevitable for radical processes. The reactions interfering with the grafting process are combination of two macro-radicals, yielding branches or even cross-linking, and disproportionation, yielding unsaturation highly sensitive to oxidation and $\beta$-scission leading to reduction of the molecular weight of the polymer chain. ${ }^{7}$

(A)<smiles>NC(=O)O[R]#[S-]</smiles>

(B)<smiles>NS(=O)(=O)[O-]</smiles>

Scheme 6.1: Chemical structure of $(A)$ mono-azidoformate modifier and (B) mono-sulfonyl azide modifier 
In the previous chapters it was shown that some of the di-functional azidoformates and sulfonyl azides are effective curing agents for EP(D)M-rubbers. It is now interesting from a mechanistic point of view to investigate the reaction of the mono-functionalized molecules as well. The molecules used for modification contain, besides one azide group also a second functional group $(-\mathrm{Fg})$, Scheme 6.1 , which will be attached this way to the side of the polymeric chain. Although this kind of approach is not entirely new, the modification reaction by definition requires interaction between ingredients of very different properties what is never a simple task. ${ }^{8-18}$ In the present study the focus is not on the functional group itself but the aim is to gain more understanding of the mono-azide/polymer reaction, because it also adds to understanding of the mechanism of the di-azide reactions to the polymer.

\subsection{Experimental}

\subsubsection{Materials}

The rubber used for the experiment was an EPM (Keltan 3200 A) with ethylene content $49 \mathrm{wt} \%$ and Mooney viscosity, ML $(1+4) 100{ }^{\circ} \mathrm{C}$ of 51 , supplied by DSM Elastomers BV. Dicumyl peroxide (DCP, Perkadox BC-40, 40 \% pure) was provided by AkzoNobel. The mono-azidoformate: 4-methoxybenzyloxycarbonyl azide (M-BAF, 95 $\%$ ) and 4-acetamidobenzenemono-sulfonyl azide (A-PhSA, $97 \%$ ) were purchased from Sigma-Aldrich. All other mono-azides: BAF, PhAF and PhSA were synthesized from the corresponding chlorides and sodium azide as described in Chapter 3 . The structures of the various mono-azides investigated are shown in Table 6.1.

\subsubsection{Methods}

\section{Solubility experiments}

EPM-rubber was vulcanized with $2.5 \mathrm{phr}$ of dicumyl peroxide at $160{ }^{\circ} \mathrm{C}$ to prevent flowing and pieces with size: $1 \mathrm{~cm}^{*} 1 \mathrm{~cm}^{*} 2 \mathrm{~mm}$ were cut. The samples were then extracted with hot acetone in a Soxhlet extractor for 48 hours to remove the nonrubber parts, and dried in a vacuum oven. The solubility of the mono-azides was determined by placing EPM pieces of exactly defined weight into a jar, such that it was on all sides covered with azide compound in the form of liquid or fine powder. Due to the prolonged period of time required for the study and the fact that some of the azide compounds had never been synthesized before, certain caution was recommended during their handling, therefore the experiments were performed only at room temperature. The weight increase of the samples was measured on a daily basis, after thorough cleaning of the surface. The experiment was stopped when the mass of the EPM pieces had become constant. 
Reactive mixing

EPM was modified with 4, 8 and $12 \mathrm{mmol}$ (per $100 \mathrm{~g}$ of rubber) of each mono-azide (Table 6.1). The ingredients were pre-mixed at room temperature using a Schwabenthan two-roll mill, to avoid contact of the pure azides with a hot mixer walls. The actual grafting was done in a Brabender PL2000 laboratory internal mixer with a chamber volume of $50 \mathrm{~cm}^{3}$. The rotor speed was $60 \mathrm{rpm}$ and a fill factor 0.85 was used. Based on the kinetic parameters determine in Chapter 3 , the initial temperature of the mixer: $\mathrm{T}_{\mathrm{s}}$ was 125 and $140{ }^{\circ} \mathrm{C}$ for the mono-azidoformates and $160{ }^{\circ} \mathrm{C}$ for the mono-sulfonyl azides. The final temperatures of the compounds after grafting as recorded in the mixer were respectively in the range of $152 \pm 3^{\circ} \mathrm{C}, 163 \pm 3{ }^{\circ} \mathrm{C}$ and 180 $\pm 3{ }^{\circ} \mathrm{C}$. Mixing time was 9 minutes, the same for all mono-azides. Virgin EPM mixed with exactly the same conditions but without any additives was taken as reference for changes in temperature and mixer torque.

Table 6.1 Overview of all tested mono-azides

\begin{tabular}{|c|c|c|c|}
\hline Name & Abbreviation & Structure & Mp. $\left({ }^{\circ} \mathrm{C}\right)$ \\
\hline phenyl mono-azidoformate & PhAF & & liquid \\
\hline benzyl mono-azidoformate & BAF & & liquid \\
\hline $\begin{array}{c}\text { 4-metoxybenzyloxycarbonyl } \\
\text { azide }\end{array}$ & M-BAF & & $30-32$ \\
\hline phenylmono-sulfonyl azide & PhSA & & liquid \\
\hline $\begin{array}{l}\text { 4-acetamidobenzenemono- } \\
\text { sulfonyl azide }\end{array}$ & A-PhSA & & 107-111 \\
\hline
\end{tabular}

Determination of grafting efficiency

\section{FT-IR spectroscopy}

Infrared spectra were recorded on a Perkin Elmer 100 Series system, using an Attenuated Total Reflectance (ATR) attachment. The infrared spectra were recorded with a resolution of $4.0 \mathrm{~cm}^{-1}$, the number of scans was 16 and the scan range 4000 $650 \mathrm{~cm}^{-1}$. Investigated were the modified EPM-rubbers as they came straight from the mixer, as well as the samples extracted with boiling acetone in a Soxhlet extractor for 
$24 \mathrm{~h}$, when all low molecular weight components not attached to polymer had been removed.

\section{${ }^{1} \mathrm{H}-\mathrm{NMR}$ spectroscopy}

After modification, $0.16 \mathrm{~g}$ of each grafted sample was dissolved in $2 \mathrm{ml}$ of $\mathrm{CDCl}_{3}$ and characterized using proton magnetic resonance spectroscopy ( $\left.{ }^{1} \mathrm{H}-\mathrm{NMR}\right)$. The measurements were performed on a Bruker $300 \mathrm{MHz} N M R$ spectrometer at $25^{\circ} \mathrm{C}$ with deuterated chloroform $\left(\mathrm{CDCl}_{3}\right)$ as solvent and tetramethylsilane (TMS) as standard.

\section{Material characterization}

\section{Mooney viscosity}

The Mooney viscosity $\mathrm{ML}(1+4) 100{ }^{\circ} \mathrm{C}$ was determined using a Mooney viscometer MV200 VS from Alpha Technologies according to ISO R289. Investigated were EPM samples grafted with mono-azidoformates at the $\mathrm{T}_{\mathrm{s}}: 125$ and $140{ }^{\circ} \mathrm{C}$ and with monosulfonyl azides at $\mathrm{T}_{\mathrm{s}}: 160^{\circ} \mathrm{C}$.

\section{Dynamic mechanical properties}

Temperature sweep dynamic mechanical measurements were performed on the modified samples as well as on the pure EPM, in the temperature range $95-215^{\circ} \mathrm{C}$ at $49.94 \%$ strain and a frequency of $3.14 \mathrm{rad} / \mathrm{s}$. A frequency sweep was carried out at $100{ }^{\circ} \mathrm{C}$ with $3.49 \%$ strain and angular frequency range $0.06-100 \mathrm{rad} / \mathrm{s}$. Both measurements were performed using a Rubber Process Analyzer, RPA 2000 from Alpha Technologies.

\subsection{Results and discussion}

\subsubsection{Solubility of the mono-azides in EPM}

The simple weight change method developed by Morris and Thomas and described in the experimental section was known to be effective in determining solubilities of sulfur and various accelerators in NR at a variety of temperatures. ${ }^{19}$ The same method was therefore applied to estimate the solubility in EPM of the various mono-azides listed in Table 6.1. The measurement was carried out at room temperature. The solubility data obtained are given in Fig. 6.1. To minimize the possible effect which the functional group $(-\mathrm{Fg})$ can have on the azide/polymer reaction, some of the investigated azides had very simple structures: PhAF, BAF and PhSA. On the other hand, M-BAF and APhSA demonstrate how the modification process can change once an additional $-\mathrm{Fg}$ is introduced. 


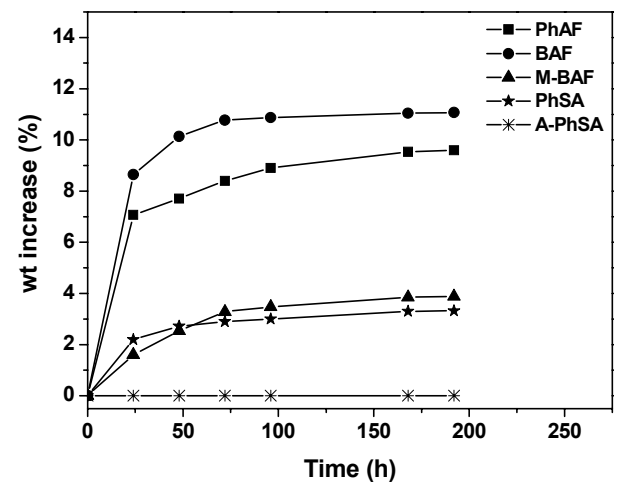

Fig. 6.1: Solubility of different mono-azides in EPM at $25^{\circ} \mathrm{C}$

All tested mono-azides are readily soluble in EPM already at room temperature, except for A-PhSA which does not dissolve noticeably, most probably due to the high polarity of the acetamide group. Compared to standard rubber curatives like sulfur and common accelerators, the solubility of the simply structured mono-azides: PhAF, BAF and PhSA is significantly higher. ${ }^{20}$ The weight increase of the EPM sample immersed into PhAF (phenyl mono-azidoformate) is about three times larger compared to the sample dipped into PhSA (phenyl mono-sulfonyl azide), thus the first one migrates and dissolves into the rubber much more readily. As the only difference between the two compounds is the type of azide functionality, the mono-azidoformate seems be more compatible with EPM than the mono-sulfonyl azide.

From the three mono-azidoformates tested BAF has the highest solubility indicating that the additional $-\mathrm{CH}_{2}$ - group relative to $\mathrm{PhAF}$ makes the azide compound more compatible with the EPM-rubber. The solubility of M-BAF is also high but about three to four times lower compared to BAF. Obviously when the second functional group is introduced into the azide (M-BAF vs. BAF and A-PhSA vs. PhAF) the solubility of the compound in the highly un-polar EPM-rubber decreases and in the worst case A-PhSA becomes practically nil.

\subsubsection{Reactive mixing}

The EPM-rubber was modified with 4, 8 and $12 \mathrm{mmol} / 100 \mathrm{~g}$ EPM of each mono-azide listed in Table 6.1. The ingredients were first pre-mixed on a two roll-mill at room temperature and then transferred into a small, laboratory internal mixer where the modification was carried out. The temperature and torque inside the chamber was monitored trough the entire reactive mixing process. The reproducibility of the temperature curves was very good and only minor changes between particular mixing cycles were observed. Fig 6.2 shows temperature developments during the reaction of (a) mono-azidoformates: $\mathrm{T}_{\mathrm{s}} 125^{\circ} \mathrm{C}$, and (b) mono-sulfonyl azides: $\mathrm{T}_{\mathrm{s}} 160{ }^{\circ} \mathrm{C}$. During 
compound loading the temperature inside the chamber drops by around $35^{\circ} \mathrm{C}$; at that moment the rubber/mono-azide mixture undergoes further homogenization. While the compound is heated up the reaction starts. Due to the shear generated during mixing, the temperature of the rubber inside the chamber is higher than the set temperature. After around $120-150$ seconds the optimum is reached; this is $150{ }^{\circ} \mathrm{C}$ for the monoazidoformates and $180{ }^{\circ} \mathrm{C}$ for the mono-sulfonyl azides, the same as the vulcanization temperatures for the corresponding di-functional compounds. As explained in Chapter 3 , due to their various decomposition kinetics the reaction temperature is different for the two azide functionalities.

(a)

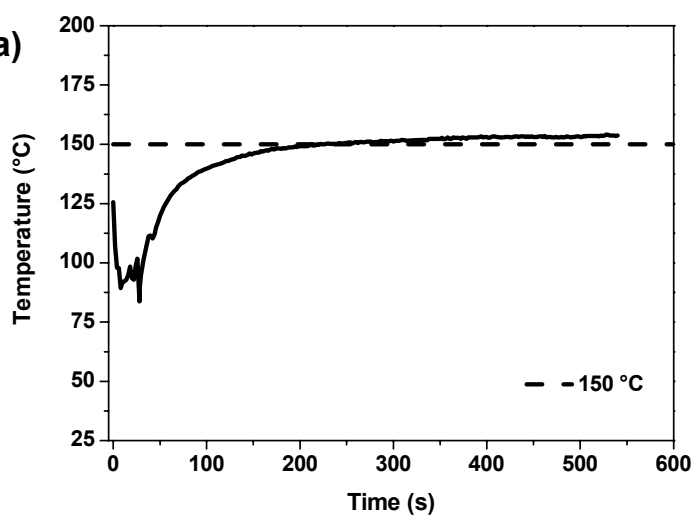

(b)

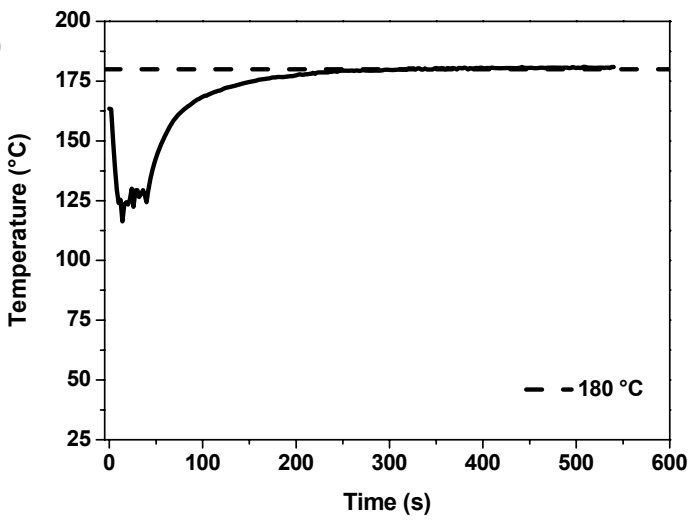

Fig. 6.2: Temperature development during the reaction of (a): mono-azidoformates, $T_{s} 125^{\circ} \mathrm{C}$ and (b): mono-sulfonyl azides, $T_{s} 160^{\circ} \mathrm{C}$

Unlike the temperature traces, the monitored mixer torque changes significantly with each modification agent showing noteworthy differences between the monoazidoformate and mono-sulfonyl azide reactions. When the EPM is modified with any of the mono-azidoformate compounds, Figs 6.3 (a), (b) and (c), the measured mixer torques are close to the reference: EPM without azide. M-BAF modification gives somewhat lower torque values indicating that during the reactive mixing process some degradation of the polymer might occur. The azides have two possible reaction mechanisms, see introduction to this thesis. Although the experimental data indicate that in case of azidoformate and sulfonyl azide functionalities the insertion reaction is the dominant one, the radical generated hydrogen abstraction can never be fully excluded. The generation of a radical may lead to $\beta$-scission of the EPM-chains at two adjacent propylene-groups. This always happens to some extent also with the peroxide ractions. $^{7}$ 
(a)

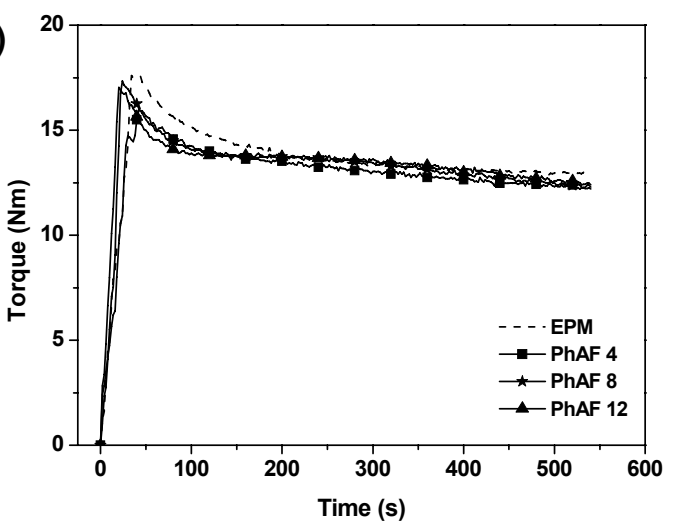

(c)

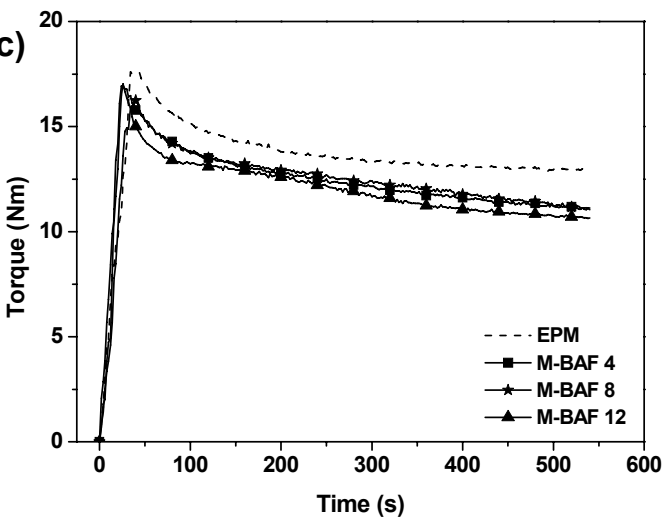

(e)

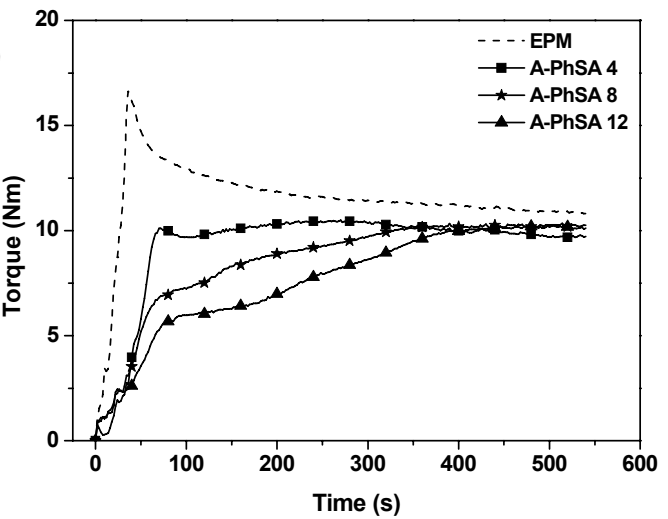

(b)

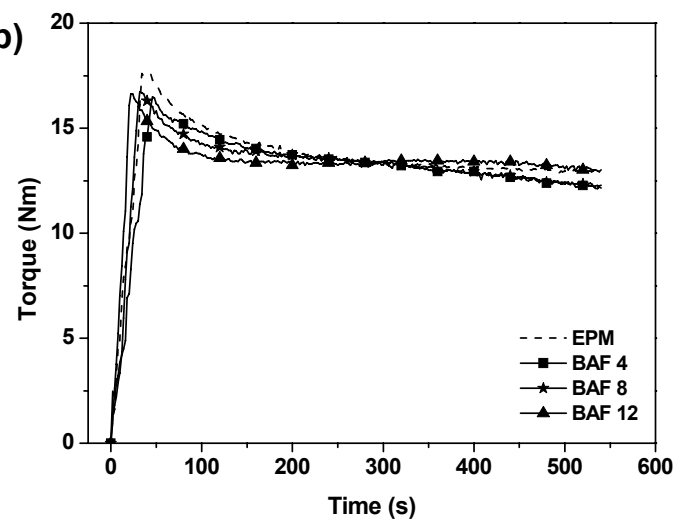

(d)

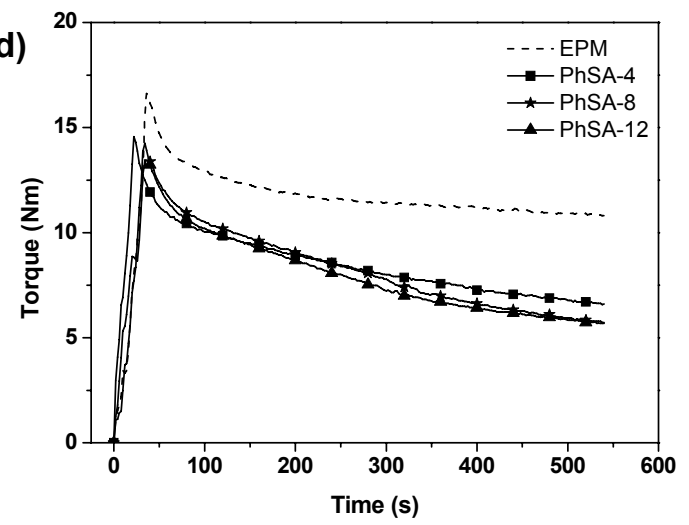

Fig. 6.3: Changes of torque during reactive mixing of (a): PhAF, (b): $B A F,(c): M-B A F$, (d): PhSA and (e): A-PhSA

Compared to the mixing of pure EPM-rubber, the torques measured during PhSA modification are increasingly lower, the more azide is added: Fig 6.3 (d). The set temperature as mentioned above is the same for each mixing cycle, thus the lower torque could be due to polymer degradation caused by the PhSA. Mixing of the EPM/A-PhSA compounds reveals behavior completely different from all other azide 
compounds, the stronger the more of the modifier is introduced. Once the compound is placed in the chamber the monitored torques are very low compared to virgin EPM mixing. Despite the fact that the initial torque decreases significantly when increasing the A-PhSA content, at the end of the mixing procedure the torques are the same for all three compounds, irrespective of azide content and close to virgin EPM. One of the possibilities is that this kind of behavior is caused by the poor miscibility of the A-PhSA in EPM. Above its melting temperature, A-PhSA phase separated from the rubber could act as a lubricant between the polymer and the rotors of the mixer, which function is however gradually lost once the azide starts to react.

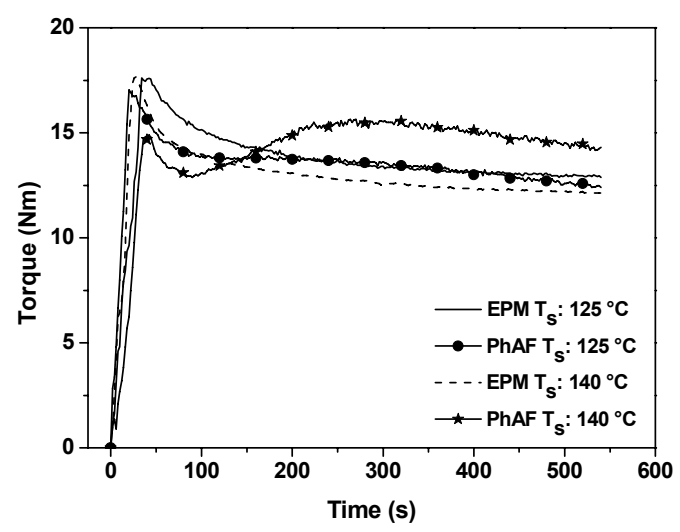

Fig. 6.4: Reactive mixing of PhAF/EPM, torque measured at $T_{s} 125^{\circ} \mathrm{C}$ and $140^{\circ} \mathrm{C}$

It turned out that when the mono-azidoformate modification was carried out at higher set temperature, higher torques started to develop. Fig 6.4 shows the increase in torque for the PhAF-reaction for set temperature $140{ }^{\circ} \mathrm{C}$ instead of $125{ }^{\circ} \mathrm{C}$. The same effect was also observed when the other two mono-azidoformates were processed though for M-BAF the increase was less pronounced. This behavior gets progressively worse with azide content and may indicate heavy branching or even cross-linking reactions. To exclude the last possibility, after modification a $2 \mathrm{~g}$ piece of each sample was immersed in THF and stirred. It turned out that all samples, also with the highest azide content completely dissolved. The PhSA and A-PhSA-modified EPM dissolve already after 4 hours, the mono-azidoformates reaction products need around 24 hours to dissolve. Cross-linking can therefore be excluded as the reason for the torque increase.

\subsubsection{Estimation of grafting efficiency}

FT-IR

Figs. 6.5 (a) and (b) show the infrared spectra of the EPM samples grafted with monoazidoformates and mono-sulfonyl azides, respectively; in both graphs there is also 
given the spectrum of virgin EPM. All samples show additional bands compared to unmodified rubber, also after extraction, which indicates that the azide compounds are indeed grafted onto EPM after the reaction in the internal mixer. The very characteristic azide band, observed at around $2100 \mathrm{~cm}^{-1}$ despairs completely after reaction.

(a)

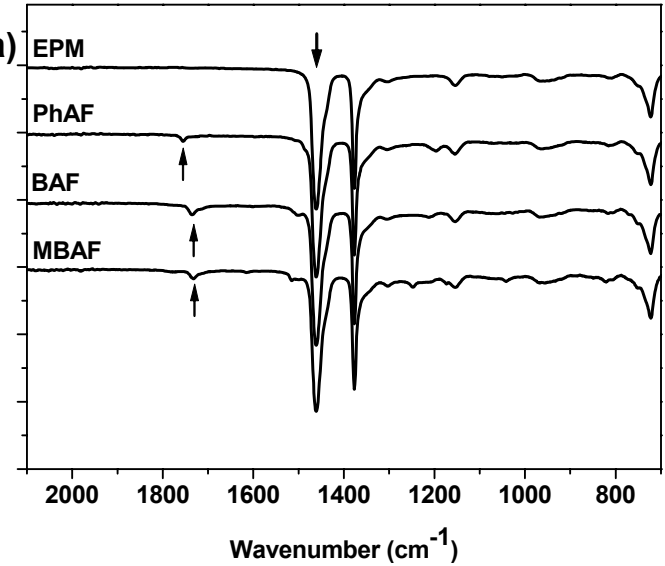

(b)

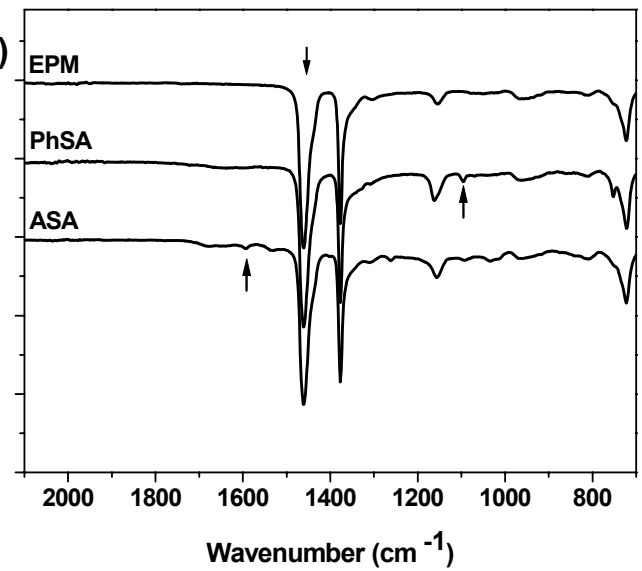

Fig. 6.5: FT-IR spectra of extracted EPM samples: virgin and modified with the highest monoazide content. Indicated by the arrows are bands used to estimate the grafting efficiency of (a): mono-azidoformates and (b): mono-sulfonyl azides

To obtain more information about the efficiency of the modification reaction a calibration study was carried out, based on height of the chosen signals. The bands selected for calibration purposes are indicated with arrows. All three monoazidoformates were quantified using the ester bands which for PhAF, BAF and M-BAF appear respectively at around 1754,1735 and $1732 \mathrm{~cm}^{-1}$. To characterize monosulfonyl azide compounds two different bands were used, for PhSA it was the sulfonyl band at $1095 \mathrm{~cm}^{-1}$ and for A-PhSA the amide band at $1594 \mathrm{~cm}^{-1}$. The band at $1461 \mathrm{~cm}^{-}$ ${ }^{1}$ for virgin EPM was taken as calibration reference. It is important that the band which is chosen for the calibration has a high intensity; it should not be too broad and preferably not overlap with the original bands of EPM. The sulfonyl group for instance is giving a strong signal at approximately $1150 \mathrm{~cm}^{-1}$ but the band was not selected for the calibration as it overlaps with an EPM signal. The relative intensity $(R I)$ of the particular azides bands chosen for the calibration was then calculated according to the following equation:

$$
R I_{x}=\frac{\text { Intensity }_{x_{\_} \text {band }}}{\text { Intensity }_{1461 \_b a n d}} \times 100 \%
$$


Figs. 6.6 (a)-(e) show the results for $R /$ versus varied azides content before and after extraction. The RI-values for the mono-azidoformates increase continuously with concentration and follow linear relations. The intensity of the peaks decreases significantly for various compounds after extraction which indicates that not all of the mono-azidoformates are chemically bound to the polymer. Both calibration curves, before and after extraction for all samples, cross the y-axis at a similar height, none of the curves is passing through the origin.
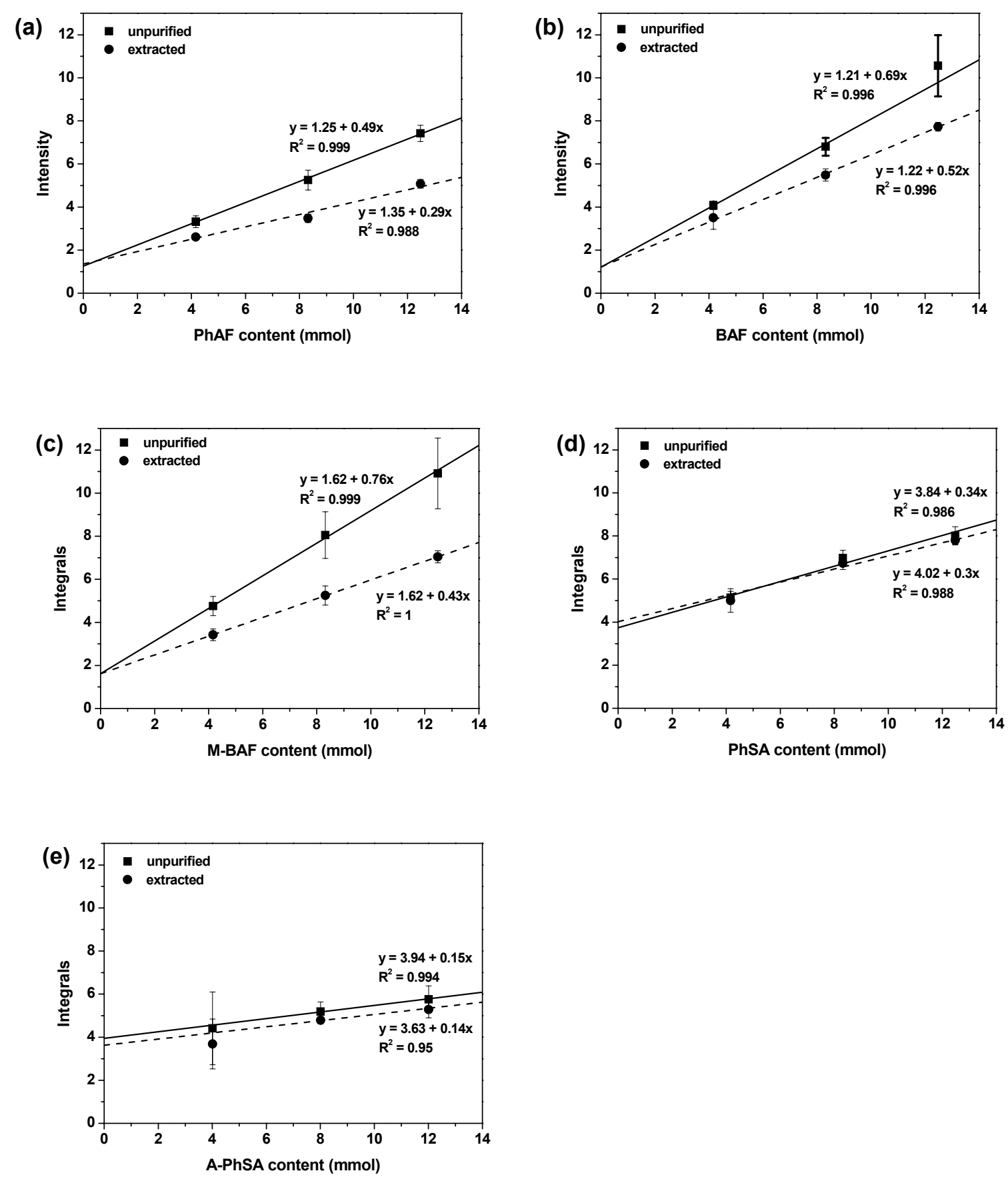

Fig. 6.6: Relative intensity vs. azide content, before and after extraction (a): PhAF; (b): BAF; (c): M-BAF; (d): PhSA and (e): A-PhSA 
Table 6.2 Grafting efficiency based on FT-IR data

\begin{tabular}{|c|c|c|c|c|c|}
\hline \multirow{2}{*}{ Name } & $\begin{array}{c}\text { Amount } \\
\text { (mol/100gEPM) }\end{array}$ & \multicolumn{2}{|c|}{ Relative Intensity (RI) } & \multirow{2}{*}{$\begin{array}{c}\text { Grafting } \\
\text { Efficiency }\end{array}$} & $\begin{array}{c}\text { Slope } \\
\text { After Extrac. }\end{array}$ \\
\cline { 3 - 4 } & Before Extr & After Extr. & 78 & \\
\hline \multirow{3}{*}{ PhAF } & 0.004 & 3.32 & 2.61 & 66 & $0.29 \pm 0.03$ \\
& 0.008 & 5.25 & 3.48 & 68 & \\
\hline \multirow{3}{*}{ BAF } & 0.012 & 7.42 & 5.08 & 86 & \\
& 0.004 & 4.08 & 3.51 & 80 & $0.52 \pm 0.06$ \\
& 0.008 & 6.8 & 5.49 & 73 & \\
\hline \multirow{3}{*}{ M-BAF } & 0.012 & 10.56 & 7.73 & 72 & \\
& 0.004 & 4.76 & 3.43 & 65 & $0.43 \pm 0.05$ \\
& 0.008 & 8.05 & 5.25 & 64 & \\
\hline \multirow{3}{*}{ PhSA } & 0.012 & 10.91 & 7.04 & 97 & \\
& 0.004 & 5.14 & 5.00 & 96 & $0.3 \pm 0.06$ \\
& 0.008 & 6.98 & 6.73 & 97 & \\
\hline \multirow{3}{*}{ A-PhSA } & 0.012 & 8.01 & 7.81 & - & \multirow{2}{*}{$0.14 \pm 0.09$} \\
& 0.004 & 4.41 & 3.68 & - & \\
\hline
\end{tabular}

The grafting efficiencies estimated based on the IR values before and after extraction are given in Table 6.2; they are almost identical for PhAF and M-BAF and slightly higher for BAF. The RI data of the mono-sulfonyl azides give quite different pictures compared to those of the mono-azidoformates. Most significantly, even at high azide loadings there is practically no difference between the RI-values before and after extraction. The intensity of the PhSA band increases with the concentration and the slope of the calibration curves are in the same range as the PhAF after extraction. On the other hand, the intensities of the A-PhSA bands are very similar for all loadings and remain rather constant in the range of standard deviation. What should be pointed out is that the ester- and amide-bands used for the mono-azidoformates and A-PhSA quantifications are both strong, while the sulfonyl-band chosen to characterize PhSA grafting is rather weak. It is characteristic for the IR method, that the size of the detected signal not only depends on the content but also on the absorption abilities of the particular group by which it is generated. Therefore the increase of the PhSA calibration bands can be smaller compared to the mono-azidoformates. There is no clear reason why the RI values of the A-PhSA grafted samples do not increase with azide loadings, as indicated by the slope of the calibration curve. Consequently, the grafting efficiencies of the A-PhSA-samples were not further estimated as they would most probably be unreliable. 


\section{${ }^{1} H-N M R$}

Once attached to the polymer, the signals from the azide molecules change significantly. The positions of the peaks shift slightly compared to the azide in the pure state as shown in Table 6.3, and more significantly, their shape becomes much wider and lower. By integrating the ${ }^{1} \mathrm{H}-\mathrm{NMR}$ spectra, the amount of azides grafted to $100 \mathrm{~g}$ of EPM and subsequently the efficiency of the modification reaction was calculated according to the eqs. 6.2 and 6.3 respectively.

$$
\begin{array}{r}
A G r=\frac{I^{\text {azide }}}{I n^{C H 2} \times M w^{C H 2}} \times 100 \\
G r E f f=\frac{A G r}{A I n t} \times 100 \%
\end{array}
$$

Where:

$A G r=$ amount of azide grafted to $100 \mathrm{~g}$ of EPM (moles);

AInt = initial azide content dosed per $100 \mathrm{~g}$ of EPM (moles);

GrEff = grafting efficiency $(\%)$;

In = integration of a proton-signal;

$M w=$ molecular weight of the basic EPM unit, $-\mathrm{CH}_{2-}$.

The determined grafting efficiencies had large standard deviations of $\pm 10 \%$. Nevertheless, the calculations produce a number which is an indication of how much of the initial azide amount has been chemically bonded to the EPM; the obtained data are listed in Table 6.3. The bold and underlined shiftings indicate the peaks which areas were taken to estimate the grafting efficiencies. Given between brackets is the number of protons which contribute to the particular signal. 
Table 6.3 Grafting efficiency based on ${ }^{1} \mathrm{H}-\mathrm{NMR}$ data

\begin{tabular}{|c|c|c|c|c|c|}
\hline Name & $\delta$ Pure Azide & $\begin{array}{l}\delta \text { Grafted } \\
\text { Azide }\end{array}$ & $\begin{array}{c}\text { Amount } \\
\text { (mol/100gEPM) }\end{array}$ & Peak Area & $\begin{array}{c}\text { Grafting } \\
\text { Efficiency } \\
( \pm 10)\end{array}$ \\
\hline \multirow{3}{*}{ PhAF } & \multirow{3}{*}{$\begin{array}{c}\delta 7.25(\mathrm{~d}, 2 \mathrm{H}), \delta 7.37 \\
(\mathrm{t}, 1 \mathrm{H}) \delta 7.4(\mathrm{t}, 2 \mathrm{H})\end{array}$} & \multirow{3}{*}{$\underline{\delta 7.52-7.72}$} & 0.004 & 0.008 & - \\
\hline & & & 0.008 & 0.02 & - \\
\hline & & & 0.012 & 0.03 & - \\
\hline \multirow{3}{*}{ BAF } & \multirow{3}{*}{$\begin{array}{c}\delta 5.21(\mathrm{~s}, 2 \mathrm{H}), \delta 7.37 \\
(\mathrm{~m}, 5 \mathrm{H})\end{array}$} & \multirow{3}{*}{$\frac{\delta 5.1(2 \mathrm{H})}{\delta 7.34}$} & 0.004 & 0.032 & 57 \\
\hline & & & 0.008 & 0.055 & 50 \\
\hline & & & 0.012 & 0.085 & 51 \\
\hline \multirow{3}{*}{ M-BAF } & \multirow{3}{*}{$\begin{array}{c}\delta 3.82(\mathrm{~s}, 3 \mathrm{H}), \delta 5.18 \\
(\mathrm{~s}, 2 \mathrm{H}), \delta 6.91(\mathrm{~d}, 2 \mathrm{H}), \\
\delta 7.35(\mathrm{~d}, 2 \mathrm{H})\end{array}$} & \multirow{3}{*}{$\begin{array}{c}\delta 3.8 \\
\delta 5.02 \\
\delta 6.89(2 \mathrm{H}) \\
\delta 7.31\end{array}$} & 0.004 & 0.028 & 50 \\
\hline & & & 0.008 & 0.065 & 58 \\
\hline & & & 0.012 & 0.096 & 56 \\
\hline \multirow{3}{*}{ PhSA } & \multirow{3}{*}{$\begin{array}{c}\delta 7.61(\mathrm{t}, 2 \mathrm{H}), \delta 7.72 \\
(\mathrm{t}, 1 \mathrm{H}), \delta 7.98(\mathrm{~d}, 2 \mathrm{H})\end{array}$} & \multirow{3}{*}{$\frac{\delta 7.51-7.86}{\underline{(5 \mathrm{H})}}$} & 0.004 & 0.133 & 95 \\
\hline & & & 0.008 & 0.201 & 72 \\
\hline & & & 0.012 & 0.297 & 70 \\
\hline \multirow{3}{*}{ A-PhSA } & \multirow{3}{*}{$\begin{array}{l}\delta 2.25(\mathrm{~s}, 3 \mathrm{H}), \delta 7.75 \\
(\mathrm{~d}, 2 \mathrm{H}), \delta 7.9(\mathrm{~d}, 2 \mathrm{H})\end{array}$} & \multirow{3}{*}{$\begin{array}{c}\delta 2.21 \\
\frac{\delta 7.6-7.8}{(4 \mathrm{H})} \\
\end{array}$} & 0.004 & 0.052 & 47 \\
\hline & & & 0.008 & 0.052 & 23 \\
\hline & & & 0.012 & 0.053 & 16 \\
\hline
\end{tabular}

The spectrum of PhAF-modified EPM shows more then one peak from the phenylgroup; further they overlap with a strong signal generated by the solvent. One small peak appears behind the chloroform signal and it was measured that its area increases proportionally to the azide content. Nevertheless the actual grafting efficiency was not calculated as it was unreliable. The other two mono-azidoformates: BAF and M-BAF show very similar grafting efficiencies of around $50-60 \%$, irrespective of the initial azide content. Based on the IR data the grafting efficiency of these azides was $\pm 60-80 \%$, but more significantly with both methods the values hardly changed when the azide loading was increased. The PhSA has the highest grafting efficiency as also seen with IR, which decreases somewhat when more of the azide is reacted. Finally, the same peak area is measured for each A-PhSA modification product, showing that only a small amount of the azide was actually grafted to the polymer. Given the impossibility to determine its grafting efficiency with IR and the low efficiency found with ${ }^{1} \mathrm{H}-\mathrm{NMR}$ it may be questioned whether A-PhSA grafts at all in appreciable quantities.

\subsubsection{Characterization of the physical properties}

\section{Mooney viscosity}

Fig. 6.7 shows the Mooney viscosities ML $(1+4) 100^{\circ} \mathrm{C}$, of the samples modified with mono-azidoformates at $\mathrm{T}_{\mathrm{s}} 125^{\circ} \mathrm{C}$ and mono-sulfonyl azides at $\mathrm{T}_{\mathrm{s}} 160{ }^{\circ} \mathrm{C}$. The dotted line represents virgin EPM; irrespective of whether the rubber was processed in the 
internal mixer or not, its viscosity remained always between 51-53 MU. The viscosity of the mono-azidoformates modified EPM increased somewhat with concentration but stayed in a similar range as the unmodified rubber. The highest Mooney was measured for A-PhSA-modified EPM and also in this case the values increased with more azide added. However, the other mono-sulfonyl azide PhSA gives the lowest Mooney viscosities, which drop with increasing azide content. The high viscosity of APhSA-modified EPM could be related to the polarity difference of the two components. As shown earlier, A-PhSA is the only azide which is completely insoluble in EPM at room temperature. The large polarity difference can lead to phase separation of the APhSA from the polymer which than reacts with itself and starts to act as filler particles. This behavior is well known to occur with some coagent molecules also during peroxide curing. $^{21,22}$

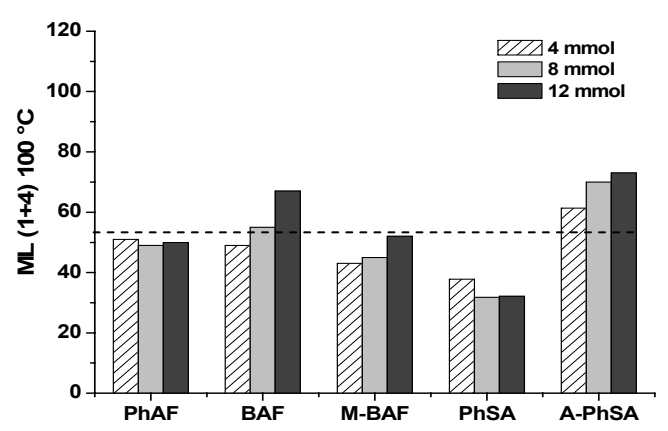

Fig. 6.7: Mooney viscosities of EPM modified with different azides: mono-azidoformates $T_{s}$ $125^{\circ} \mathrm{C}$, mono-sulfonyl azide $T_{s} 160^{\circ} \mathrm{C}$

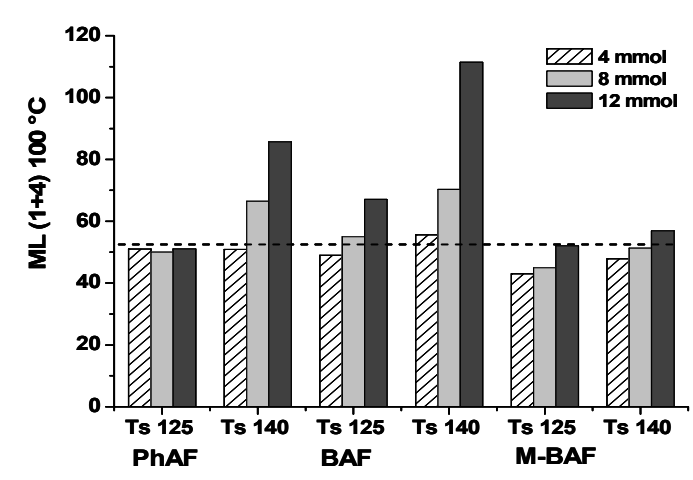

Fig. 6.8: Mooney viscosities of EPM modified with mono-azidoformates: solid line $T_{s} 125^{\circ} \mathrm{C}$, dotted line $T_{s} 140{ }^{\circ} \mathrm{C}$

Due to the increase in torque observed when the azidoformate modification was carried out at higher temperature: Fig 6.4, a comparison was made between the Mooney viscosities of EPM grafted with PhAF, BAF and M-BAF at various temperatures. Fig. 6.8 shows the $\mathrm{ML}(1+4) 100{ }^{\circ} \mathrm{C}$ values when the modification was carried out at $\mathrm{T}_{\mathrm{s}} 125$ and $140{ }^{\circ} \mathrm{C}$, corresponding to approximately 150 and $160{ }^{\circ} \mathrm{C}$ actual reaction temperature generated inside the internal mixer around 2 min after the sample was inserted. The viscosity of mono-azidoformate grafted EPM increases significantly with reaction temperature. In spite of a high grafting efficiency, confirmed by FT-IR and ${ }^{1} \mathrm{H}-\mathrm{NMR}$ analyzes, this effect was not observed for the mono-sulfonyl azide PhSA-grafted EPM. This indicates that the increase in viscosity may be a result of interactions between the urethane groups formed in the azidoformate/EPM reaction, Scheme $6.2(\mathrm{~A})$, vs. the reaction of the sulfonyl azide. Irrespective of reaction temperature or azide content, for the three mono-azidoformate compounds the highest viscosity is measured for BAF and the lowest for M-BAF. The possible explanation for 
this difference is that the simple structures of BAF and PhAF promote the urethane interaction while the methoxy-group of M-BAF creates steric hindrance.

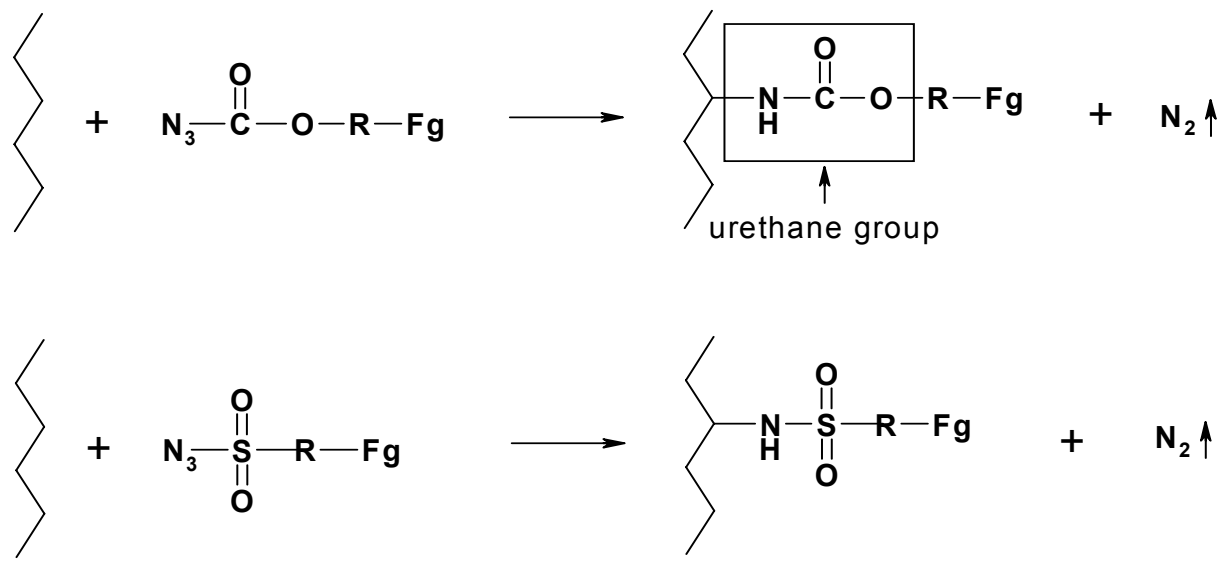

Scheme 6.2: Mono-azide/EPM reactions: (A) mono-azidoformate (urethane group formation) and (B) mono-sulfonyl azide

A possible explanation is that two urethane groups mutually react with formation of a sort of crosslink, most likely hydrogen bonding which is expected to occur in this kind of system. Although not completely excluded, a chemical reaction remains rather questionable. Firstly, as all of samples are completely soluble. Secondly, the largest viscosity increase was observed for the BAF-grafted EPM, while it is well known that during chemical reactions the aromatic compounds are better leaving groups compared to aliphatic, so that more changes would have been expected for the PhAFgrafted EPM and not from the BAF. It will be shown in Chapter 8 that only the urethane group derived from aromatic azidoformate reacts with amine compounds. Though not investigated here the high grafting efficiency and reactivity of PhAF may open the possibility of two step modification where more polar components are grafted to the polymer.

\section{Temperature sweep measurements}

The samples were also characterized by performing dynamic mechanical measurements in the temperature sweep mode. The experiments were carried out at low frequency of $3.14 \mathrm{rad} / \mathrm{s}$ with close to $50 \%$ strain, in a temperature range of 95-215 ${ }^{\circ} \mathrm{C}$. The measured storage modulus G' and loss modulus G' are assumed to be determined by two main factors. Breaking down of the polymer chains results in a certain degradation of the molecular weight and that will lower the values. On the other hand, interaction between the functional groups can cause the moduli to increase. Fig. 6.9 shows the G' and G' of virgin EPM rubber as well as after the mixing treatment conditions in the internal mixer at $\mathrm{T}_{\mathrm{s}} 125$ and $160{ }^{\circ} \mathrm{C}$, which are the same as used for 
the modification. Similar to Mooney viscosities, the physical heat treatment seems to have very little effect on the moduli as well.
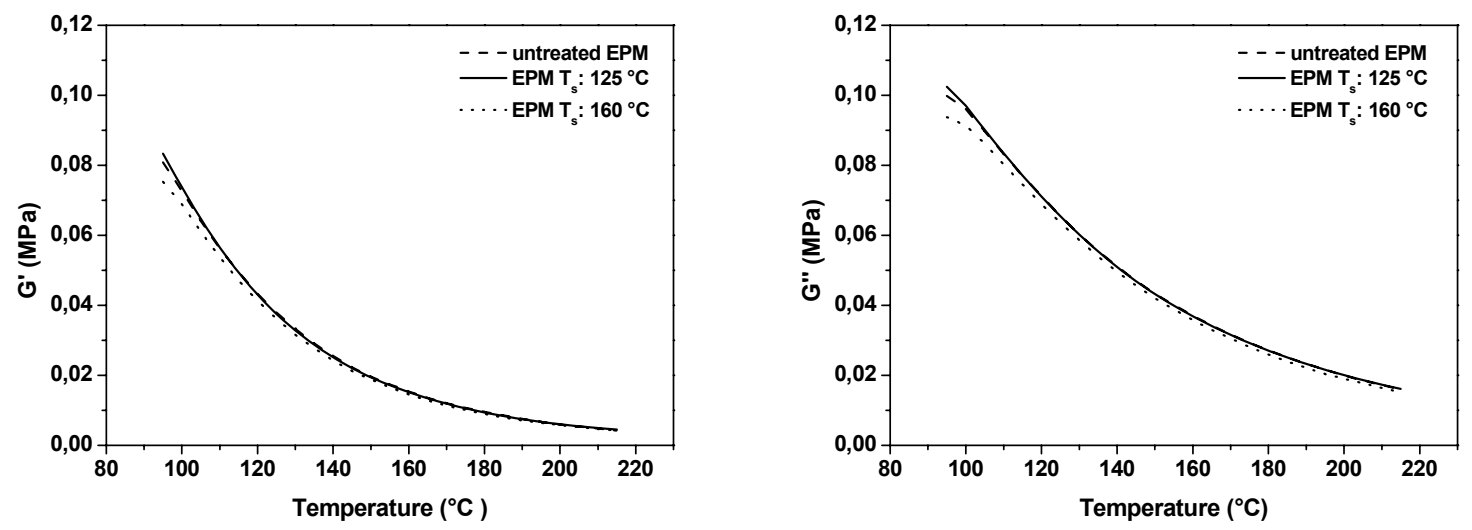

Fig. 6.9: Temperature sweep of untreated virgin EPM rubber and after heat treatment in the internal mixer

The G' and G" of samples grafted at $T_{s} 125^{\circ} \mathrm{C}$ with the three mono-azidoformates: PhAF, BAF and M-BAF, as measured on the RPA, are given in Figs. 6.10 (a) - (c). Compared to the unmodified EPM the storage moduli of azidoformate-grafted samples are mostly higher, the difference increasing with temperature. The G" is initially lower for the mono-azidoformate modified EPM but that changes gradually when the temperature is rising and at $215^{\circ} \mathrm{C}$ the modulus becomes equal or even higher than the reference. Overall, the increase in storage modulus is most significant for the BAFgrafted EPM. The data clearly show that during the $95-215^{\circ} \mathrm{C}$ temperature sweep high BAF-loadings give the lowest G" at low temperature, to become the largest at the high temperature end. Thus the increase in modulus is clearly linked with the functional groups interacting with each other.

(a)

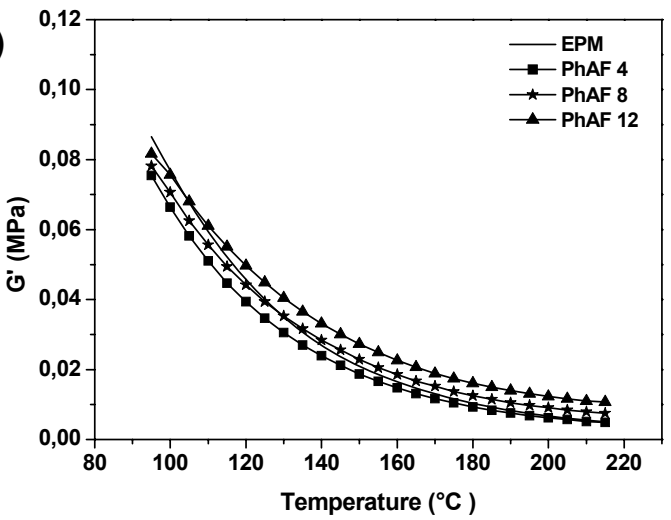

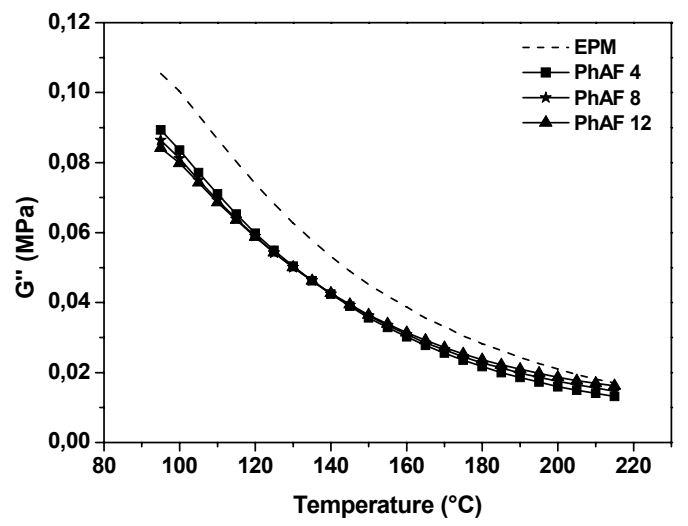


(b)

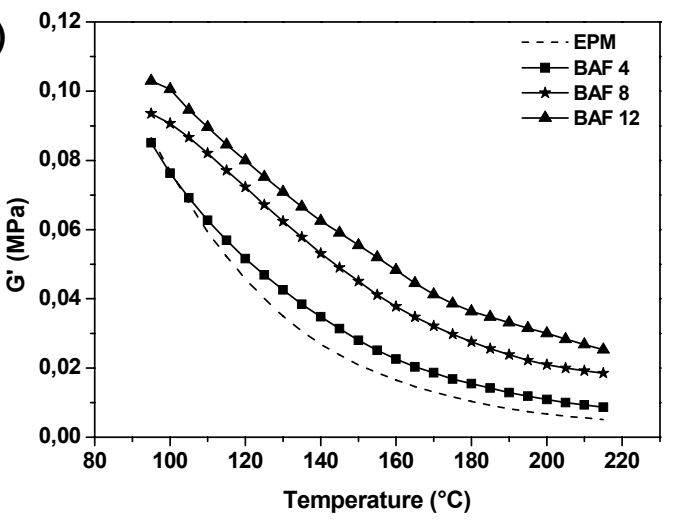

(c)

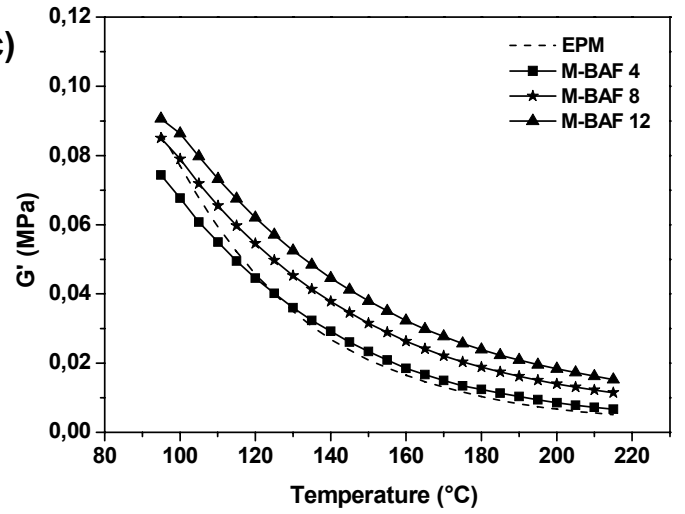

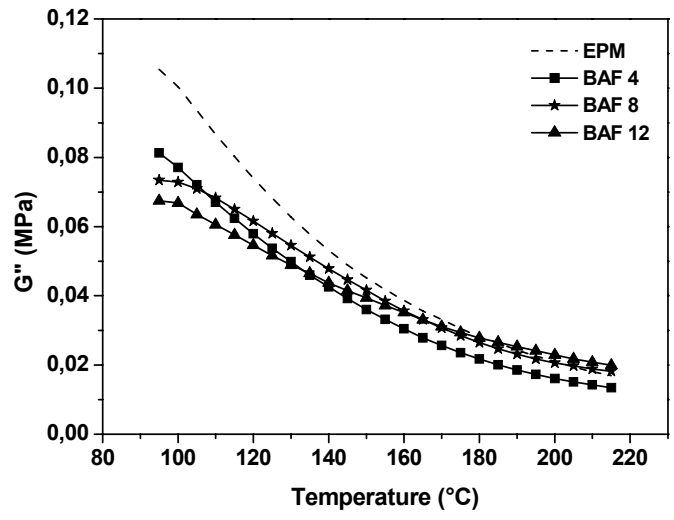

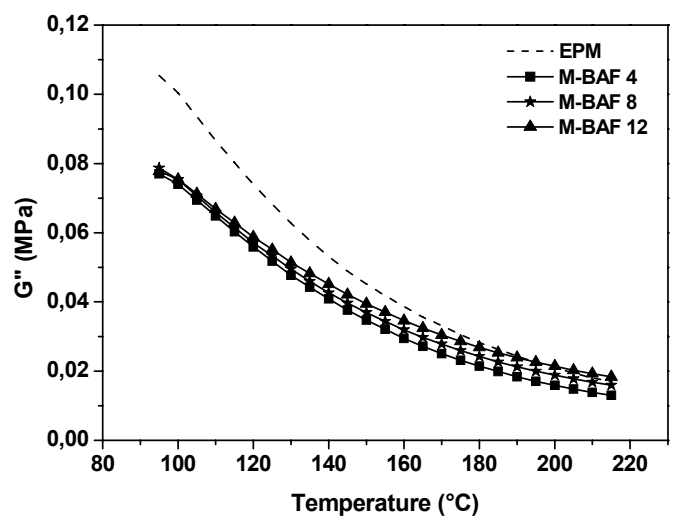

Fig. 6.10: Temperature sweep data of (a): PhAF, (b): BAF and (c): M-BAF

Figs. 6.11 (a) and (b) show G' and G" of EPM modified with the mono-sulfonyl azides: PhSA and A-PhSA. The PhSA modification significantly lowers the modulus as could already be expected from the Mooney viscosity data. The drop in both G' as well as G" is the most conspicuous for the azide content of $4 \mathrm{mmol}$ and further concentration increase does not bring much change. The moduli of A-PhSA-modified EPM are similar to the data obtained for unmodified EPM and undergo only little change with the azide loading. Thus A-PhSA modification is the only one for which the large G"decrease at the beginning of the temperature sweep is not observed. That raises once more the question whether or not the reaction with the polymer actually has occurred. 
(a)

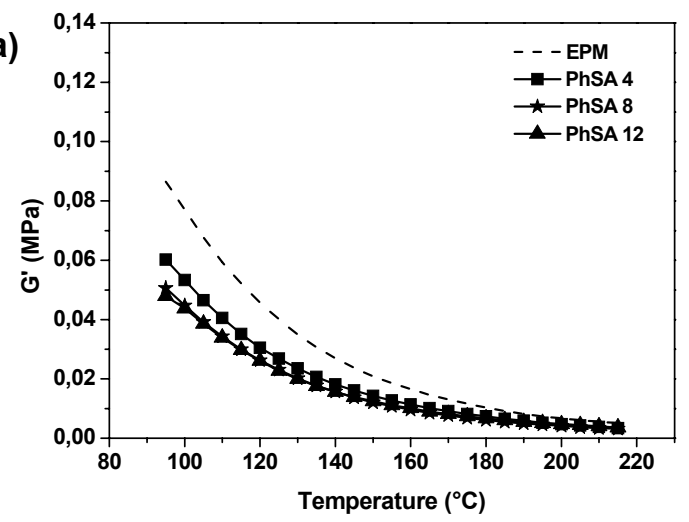

(b)

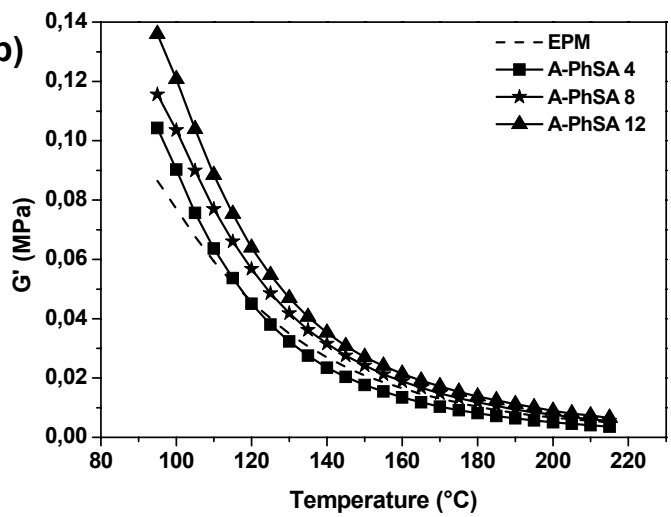

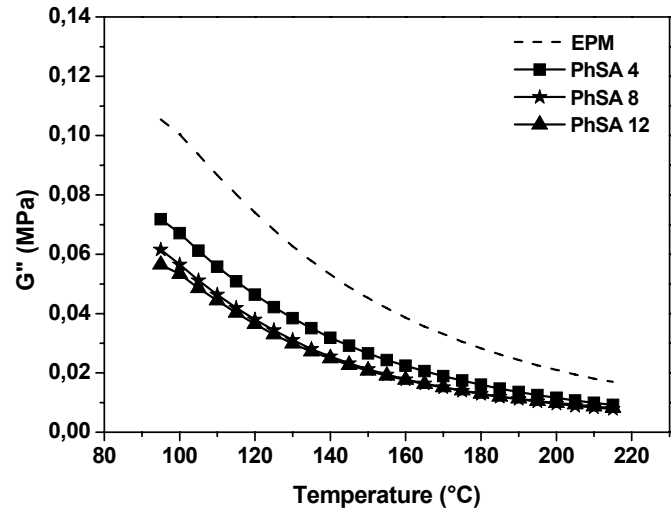

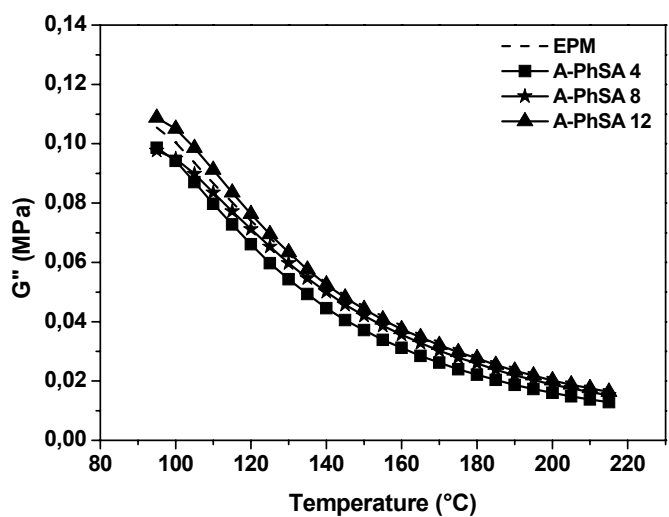

Fig. 6.11: Temperature sweep data of (a): PhSA and (b): A-PhSA

Figs. 6.12 (a) and (b) show the relative moduli obtained with the lowest $(4 \mathrm{mmol} / 100 \mathrm{~g}$ EPM) and the highest (12 mmol/100 $\mathrm{g}$ EPM) azide loading, in relation to unmodified EPM. Generally, the differences in G' are much bigger compared to G'. What seems to be most characteristic however, is that in relation to virgin EPM, both G' and G" of the mono-azidoformate modified samples tend to increase with temperature and the effect is proportional to the azide concentration. With high azide loading the $G$ ' is similar to the one for unmodified EPM at $100{ }^{\circ} \mathrm{C}$, while at $215{ }^{\circ} \mathrm{C}$ BAF, M-BAF and PhAF reach respective values 500, 300 and $200 \%$ above the EPM reference. The loss modulus of mono-azidoformate modified samples is much smaller compared to unmodified EPM-rubber; it rises however with the temperature, similar to G'. The fact that both moduli increase so considerably with temperature, suggests some form of cross-linking reaction where there is an interaction between the urethane groups. 

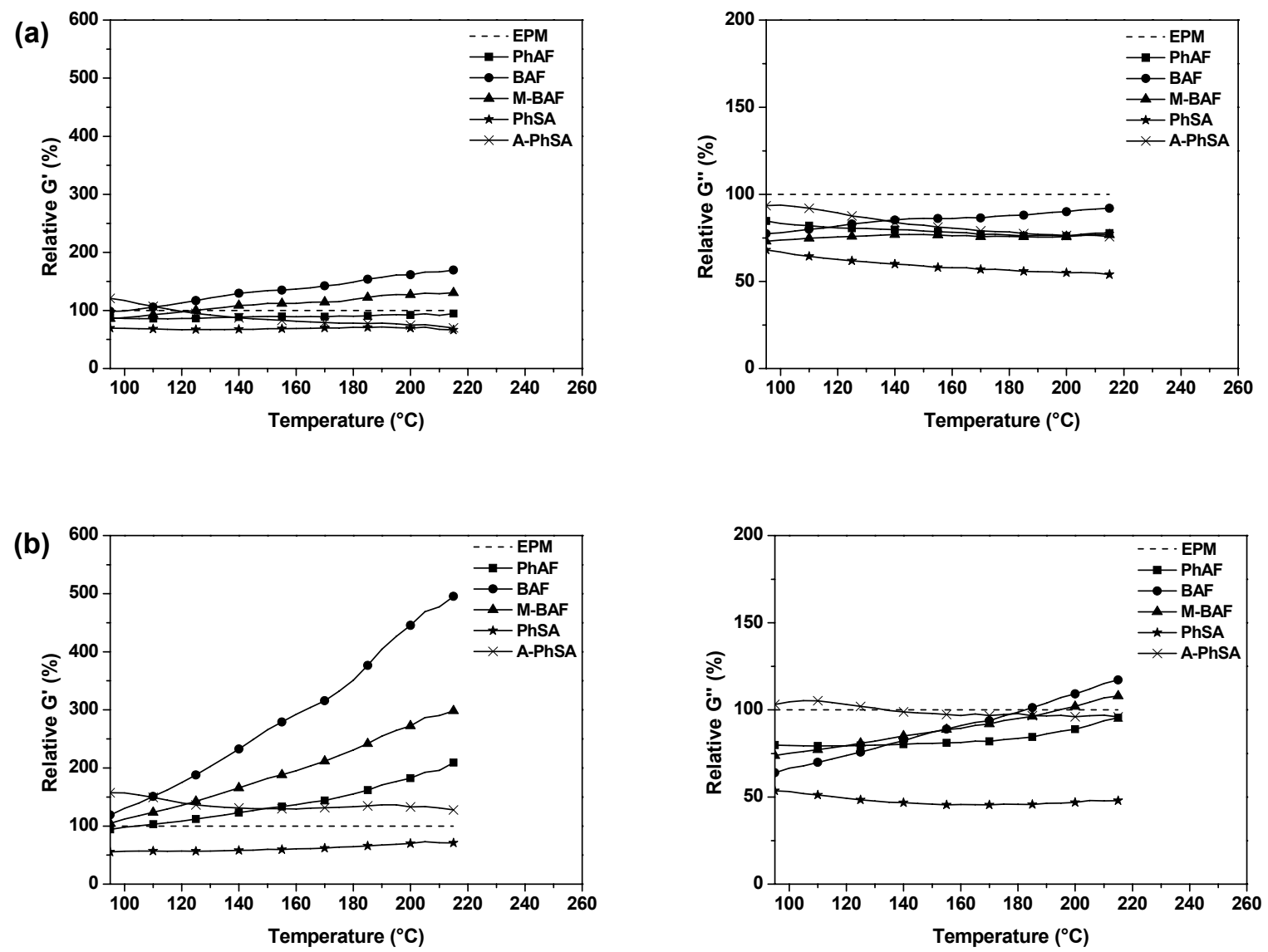

Fig. 6.12: Temperature sweep, relative effect G' and G" (a): azide loading $4 \mathrm{mmol} / 100 \mathrm{~g}$ EPM and (b) azide loading $12 \mathrm{mmol} / 100 \mathrm{~g}$ EPM

The mono-sulfonyl azide modified samples show quite different behavior from the mono-azidoformates. The moduli of EPM modified with any of the two sulfonyl azides do not increase with the temperature, independent of the concentration. As mentioned before both G' and G" measured for A-PhSA-modified EPM are very similar to unmodified rubber, indicating that little or no grafting has occurred. The PhSAmodification significantly lowers both moduli irrespective of the temperature. Both $G$ ' and G" are between $45-70 \%$ compared to virgin EPM.

\section{Frequency sweep measurements}

The samples were also characterized by performing a frequency sweep measurement at $100{ }^{\circ} \mathrm{C}$ and with $3.49 \%$ strain. Booij has shown by means of samples of model EPDMelastomers that the difference between the phase angles $\delta$ at angular frequencies of $10^{-1}$ and $10^{2} \mathrm{rad} / \mathrm{s}$, measured in the viscoelastic range can be taken as a measure for the degree of long-chain branching. ${ }^{23}$ The so called Delta delta $(\Delta \delta)$ quantity, eq. 6.4 decreases with increasing degree of branching. It was also shown that the values of $\delta$ at high frequency have some relation to viscosity, and are higher as the Mooney viscosity is lower. 


$$
\Delta \delta=\delta\left(10^{-1}\right)-\delta\left(10^{2}\right)
$$

Fig. 6.13 shows the phase angle as a function of the angular frequency for the samples modified with the highest loading of the various azide compounds. The $\Delta \delta$ values are indicated as well. Clearly the largest $\Delta \delta$ was measured for the unmodified EPM, which is known to be a linear polymer. The high steepness of the curve is due to the narrower molar mass distribution. The phase angle measured for A-PhSA-modified EPM is following a similar trend though the symmetrical shift towards lower values points towards higher Mooney viscosity, which confirms the values seen already in Fig. 6.7. The similar trend and very slight change relative to unmodified EPM again shows that little grafting has been achieved with A-PhSA.

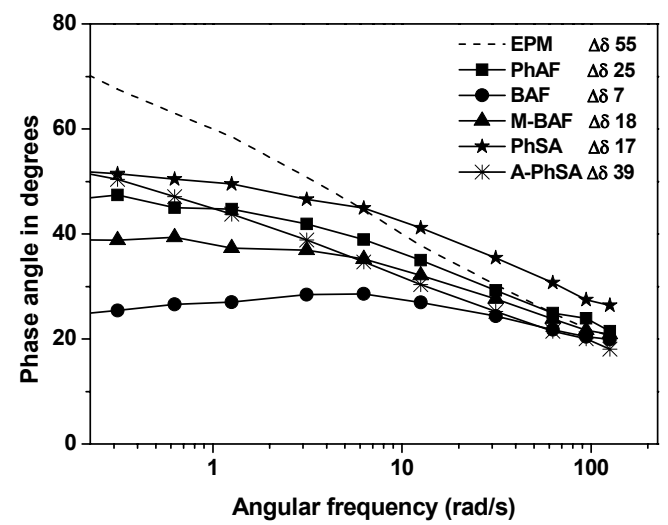

Fig. 6.13: Frequency sweep, phase angle measurement for mono-azides loading of $12 \mathrm{mmol} / 100 \mathrm{~g}$ EPM

The well documented non-branched structure of EPM turns out to correspond with a $\Delta \delta$ of $55^{\circ}$. The $\Delta \delta$ of $39^{\circ}$ for A-PhSA being so close to EPM is again an indication that there has been little reaction between the two. The relative rankings of PhAF: $25^{\circ}, \mathrm{M}-\mathrm{BAF}: 18^{\circ}$, PhSA: $17^{\circ}$ and BAF: $7^{\circ}$ indicates that more branching has occurred in the same order. For the mono-azidoformates this ranking does correspond with increasing G'-values measured at $100^{\circ} \mathrm{C}$, as shown in Fig. 6.10 .

\subsection{Conclusions}

This work has demonstrated that the azide-reaction is a powerful tool to graft various chemical groups to EPM polymer. Mono-sulfonyl azides give the highest grafting efficiency but need higher reaction temperatures than mono-azidoformates. As to the functional group which may be grafted via the azide reaction, the compatibility and consequently solubility of the azide turns out to be crucial. The solubility measurements show that the simple benzyl- and phenyl-azides easily dissolve in EPM already at room temperature. The compatibility seems to decrease however once the 
second functional group is introduced; A-PhSA containing a polar acetamido-group is no longer soluble and does not react with EPM. Generally, the azidoformate functionality is slightly more compatible with the EPM-rubber compared to a sulfonyl azide.

The FT-IR and ${ }^{1} \mathrm{H}-\mathrm{NMR}$ measurements show that, although not all mono-azidoformate molecules are chemically bound to the polymer, the grafting efficiencies stay the same for all azide loadings tested. Of all investigated mono-azides PhSA has the highest grafting efficiency. Compared to virgin EPM each of the mono-azidoformate modified samples is sensitive towards high temperatures but not the one grafted with monosulfonyl azides. The viscosities of these rubbers increased if the modification reaction was carried out at higher temperature. Both G' as well as G" of mono-azidoformate modified samples tended to rise with temperature and the effect was proportional to the azide concentration. The increase was most pronounced for BAF. The dynamical mechanical analyses gave indications that this was caused by dimerization of urethane groups between two grafted mono-azidoformates resulting in a sort of branching.

\subsection{References}

1. A. Guyot, Polymer Adv. Tech., 7, 61 (1994).

2. W. Heinen, "Grafting of polyolefins and miscibility in copolymer mixtures", PhD thesis, Leiden University, the Netherlands (1996).

3. B. Lu and T.C. Chung, Macromolecules, 31, 5943 (1998).

4. D.J. Burlett and J.T. Lindt, Rubber Chem. Technol., 66, 412 (1993).

5. M. van Duin, Recent Res Dev Macromol., 7, 1, (2003)

6. M. van Duin and H. Dikland, Polym Degrad Stabil., 92, 2287, (2007).

7. P.R. Dluzneski, Rubber Chem. Technol., 74, 451 (2001).

8. D.S. Breslow, U.S. Patent 3,220,985 (1965).

9. D.S. Breslow, U.S. Patent 3,284,421 (1966).

10. D.S. Breslow, U.S. Patent $3,321,452$ (1967).

11. R.D. Porter and S. W. Waisbrot, U.K. Patent 1,526,498 (1976).

12. S.E. Cantor, U.S. Patent 4,031,068 (1977).

13. S.E. Cantor, Polymer Preprint, 18, 471 (1977).

14. R.R. Eschborn and H. Kaiser, U.S. Patent 4,309,453 (1982).

15. L. Gonzalez, A. Rodriguez, J.L. de Benito and A. Marcos, Rubber Chem. Technol., 69, 266 (1996).

16. L. Gonzalez, A. Rodriguez, J.L. de Benito and A. Marcos-Fernandez, J. Appl. Polym. Sci., 63, 1353 (1997).

17. S.A. Bateman and D.Y. Wu, J. Appl. Polym. Sci., 84, 1395 (2002).

18. Q. Li and C. Tzoganakis, ANTEC, 1804 (2006).

19. M.D. Morris and A.G. Thomas, Rubber Chem. Technol., 68, 794 (1995).

20. R. Guo, A.G. Talma, R.N. Datta, W.K. Dierkes and J.W.M. Noordermeer, Macromol. Mater. Eng., 294, 330 (2009). 
21. H.G. Dikland, "Co-agents in peroxide vulcanization of EP(D)M rubber", PhD thesis, University of Twente, Enschede, the Netherlands (1992).

22. H.G. Dikland, L. van der Does and A. Bantjes, Rubber Chem. Technol. 66, 193 (1993).

23. H.C. Booij, Kautsch. Gummi Kunstst., 44, 128 (1991). 


\title{
Chapter 7
}

\section{Mechanistic study on the reaction between SA/AF functionalities and saturated hydrocarbons}

\begin{abstract}
As was revealed in Chapter 3 of this thesis, the sulfonyl azides (SA) and azidoformates (AF) are the most reactive towards fully saturated EPMrubber. Thus one di-sulfonyl azide: 1,3BDSA, and two di-azidoformates: GDAF and 4,4'DAF, were selected and extensively investigated as curing agents for $\operatorname{EP}(D) M$ rubber. Although the mechanical properties of the vulcanizates vary significantly with the particular di-azide used, all of them act as effective curing agents compared to a peroxide/coagent curing system. To explain the differences in properties as well as to obtain a deeper understanding of the reaction mechanism, model compound experiments are performed with 4-methylheptane as substitute for the saturated EPM-rubber backbone. Using gas chromatography/mass spectrometry (GC/MS) and high performance liquid chromatography/mass spectrometry (HPLC/MS) as analytical tools, a basic understanding of the reaction mechanisms between SA/AF functionalities and saturated hydrocarbons is obtained.
\end{abstract}




\subsection{Introduction}

The fact that sulfonyl azides (SA) and azidoformates (AF) have the ability to react with fully saturated hydrocarbons is commonly known, but in spite of a large number of studies which employed these reactions, the mechanisms involved are little understood. ${ }^{1-16}$ When exposed to elevated temperatures or radiation, azide groups decompose by releasing a nitrogen molecule and resulting in highly reactive nitrene species. Although in some cases the nitrene formation is questioned for compounds carrying SA and AF functionalities, this mechanism is well established. ${ }^{17-18}$ The nitrene is initially formed in the singlet state which subsequently can decay to the lower energy triplet form. The next step however, which is the reaction between a nitrene and a $\mathrm{C}-\mathrm{H}$ bond of a saturated polymer, is very unclear. Generally two possible reaction pathways are postulated: via insertion, if the nitrene is in its singlet form; or by hydrogen abstraction when the nitrene is in the triplet state. Experiments indicate that the insertion reaction is the dominant one. However, the possibility of hydrogen abstraction was never fully excluded. Often it is just assumed that both reactions occur simultaneously, without further explanation.

Model Compound Vulcanization (MCV), where low molecular weight models are used as substitutes for elastomeric polymers, is a very useful technique widely applied to investigate the vulcanization chemistry. When the cross-linked rubber itself is completely insoluble and thus impossible to analyze using standard analytical techniques, the low molecular hydrocarbons remain in a liquid form even after curing and can then be analyzed. In the present study 4-methylheptane was selected as a low-molecular-weight model for the random ethylene-propylene copolymer rubber (EPM). Scheme 7.1 shows the structures of the EPM and 4-methylheptane. The most important criteria for the model selection was the molecular similarity to the rubber. It was also desired that the model molecule is symmetric to reduce the number of possible reaction products, and due to the high reaction temperature, which for the sulfonyl azides is $180{ }^{\circ} \mathrm{C}$, it was important that the model possibly has a high boiling point.

(A)

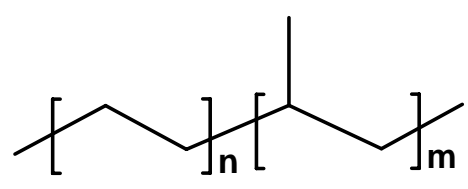

(B)

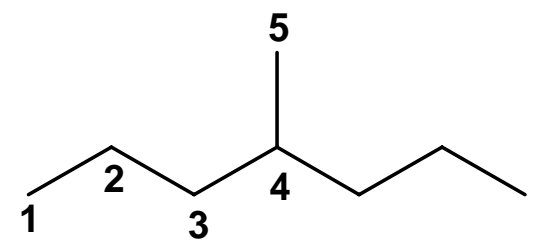

Scheme 7.1: Molecular structure of; (A) random ethylene-propylene copolymer and (B) 4methylheptane 
As known from sulfur or peroxides MCV studies, the cross-linking reaction, leads to the formation of a great number of products, usually of complex structures which even for a model remain challenging to be analyzed. ${ }^{19-21}$ The 4-methylheptane, selected for the present study has five different carbon atoms, as shown in Scheme 7.1 (B), and the azide functionality can potentially react with each one of them. To limit the number of possible reaction products and to gain some basic understanding of the azide chemistry, first the mono-azide compounds were used. To study the role of a coagent in the azide reaction, the series of model compounds included mixtures of mono-azide and phenylmaleimide, which is the mono-functional equivalent of the common dimaleimide coagent HVA-2. The use of coagents as potential aids in di-azides vulcanization was extensively investigated in Chapter 5 . The MCV study with four difunctional azides: 1,3BDSA, 1,6HDSA, GDAF and 4,4'DAF was executed later on, as the corresponding reaction mixtures were expected to be more complex to analyze. The di-azides proved to work as effective cross-linking agents for EPM-rubber based compounds, though the efficiency of some of them was better then of the others.

All model compounds with mono-azides, as well as the MCV products, were analyzed using HPLC/MS. However, the reaction mixtures of mono-functionalized compounds are only possible to be analyzed by means of $\mathrm{GC} / \mathrm{MS} .^{22}$ Although it is possible to investigate peroxide MCV products using GC/MS it turned out to be not possible to apply this technique for analyzing the di-azides model compounds. ${ }^{21}$ The most probable reasons are the high molecular weight of the reaction products and their polarity.

\subsection{Experimental}

\subsubsection{Materials}

All di- and mono-functionalized azides with structures given in Table 7.1 were synthesized according to the recipes and procedures described in Chapter 3. 4Methylheptane (98\%) was obtained from Fluka and N-phenylmaleimide (PhMI, $97 \%$ ) from Acros. Solvents used for the HPLC/MS analysis were water and acetonitrile, both MS-grades, supplied by Biosolve. 
Table 7.1 Structures of mono- and di-functionalized azides

\begin{tabular}{|c|c|c|c|}
\hline Mono-azides & Abbreviation & Structure & $\begin{array}{c}\text { mol. } \\
\text { weight }\end{array}$ \\
\hline Phenyl azidoformate & PhAF & & 163 \\
\hline Benzyl azidoformate & BAF & & 177 \\
\hline Phenylsulfonyl azide & PhSA & & 182 \\
\hline \multicolumn{4}{|l|}{ Di-azides } \\
\hline $\begin{array}{c}4,4^{\prime}- \\
\text { isopropylidenediphenyl } \\
\text { azidoformate }\end{array}$ & 4,4'DAF & & 366 \\
\hline $\begin{array}{l}\text { Tri(ethylene glycol) } \\
\text { diazidoformate }\end{array}$ & GDAF & & 288 \\
\hline $\begin{array}{l}\text { 1,3-benzenedisulfonyl } \\
\text { azide }\end{array}$ & $1,3 \mathrm{BDSA}$ & & 288 \\
\hline $\begin{array}{l}\text { 1,6-Hexanedisulfonyl } \\
\text { azide }\end{array}$ & $1,6 \mathrm{HDSA}$ & & 296 \\
\hline \multicolumn{4}{|l|}{ Coagent } \\
\hline N-phenylmaleimide & $\mathrm{PhMl}$ & & 173 \\
\hline
\end{tabular}

\subsubsection{Experimental procedures}

\section{Model compound Experiments}

4-Methylheptane and the pertinent azides were put into thick walled glass ampoules, with a small magnetic stirrer inside. The concentration of the mono-azides was 1.3 and di-azides 0.65 ( $\mathrm{mmol} / \mathrm{g}$ of solvent). Before closing the ampoules, the reagents mixture was flushed with nitrogen gas, to limit the amount of oxygen. The ampoules were then immersed in an oil bath of $150^{\circ} \mathrm{C}$ for the azidoformates, while the sulfonyl azides were heated up to $180{ }^{\circ} \mathrm{C}$. After 15 minutes the reaction was stopped by taking out the sample and quenching in a salt/water/ice bath. 


\section{GC/MS analysis}

The GC/MS analysis was performed on an Agilent GC (6890), and Agilent MSD (5973) system. The capillary column (Varian CP8913) had a nominal length of $30.0 \mathrm{~m}$, a diameter of $0.25 \mathrm{~mm}$ and a film thickness of $1.00 \mu \mathrm{m}$. The oven temperature was programmed to go from $30{ }^{\circ} \mathrm{C}\left(2 \mathrm{~min}\right.$. isothermal) to $300{ }^{\circ} \mathrm{C}$ at a heating rate of 10 ${ }^{\circ} \mathrm{C} / \mathrm{min}$. Generally, in all chromatographic techniques the separation occurs when the sample mixture is injected into the mobile phase. In the present GC system, helium was used as a carrier gas with a constant flow of $1.2 \mathrm{ml} / \mathrm{min}$. The undiluted reaction mixture was introduced onto the GC-column straight from the reaction ampoule.

\section{HPLC/MS analysis}

The HPLC/MS analysis was performed on an Agilent HPLC (1100 series), and Bruker MS (Esquire 3000+). The reverse phase column (Nucleosil 100-5 C18 HD) had a length of $250 \mathrm{~mm}$ and an internal diameter of $4.6 \mathrm{~mm}$. The mobile phase was a mixture of water and acetonitrile in 40/60 ratio. During optimalization it was determined that the best separation was obtained with the flow rate of the mobile phase of 0.15 $\mathrm{ml} / \mathrm{min}$. A $10^{-3} \mathrm{M}$ solution of model compound in acetonitrile was injected into the HPLC system in a volume of $5 \mu \mathrm{l}$. After separation, the reaction products were ionized using the Electrospray Ionisation (ESI) technique. The created ions were then identified according to their $\mathrm{m} / \mathrm{z}$ ratio using an ion trap system.

\subsection{Results and discussion}

\subsubsection{GC/MS analysis}

\section{Model compound with mono-functional azides}

To determine how the SA- and AF-functional groups react with a saturated hydrocarbon chain, simple structured mono-functional azide compounds were synthesized and reacted with the fully saturated model hydrocarbon. The reaction products were first analyzed by means of the GC/MS technique. The mass-selective detector (MSD) system, which was used in the experiment, fragments and ionizes any molecular compound which flows from the GC into the ion source by constant electron bombardments. This kind of ionization technique allows to detect any kind of molecule, including the very un-polar structures like 4-methylheptane. 


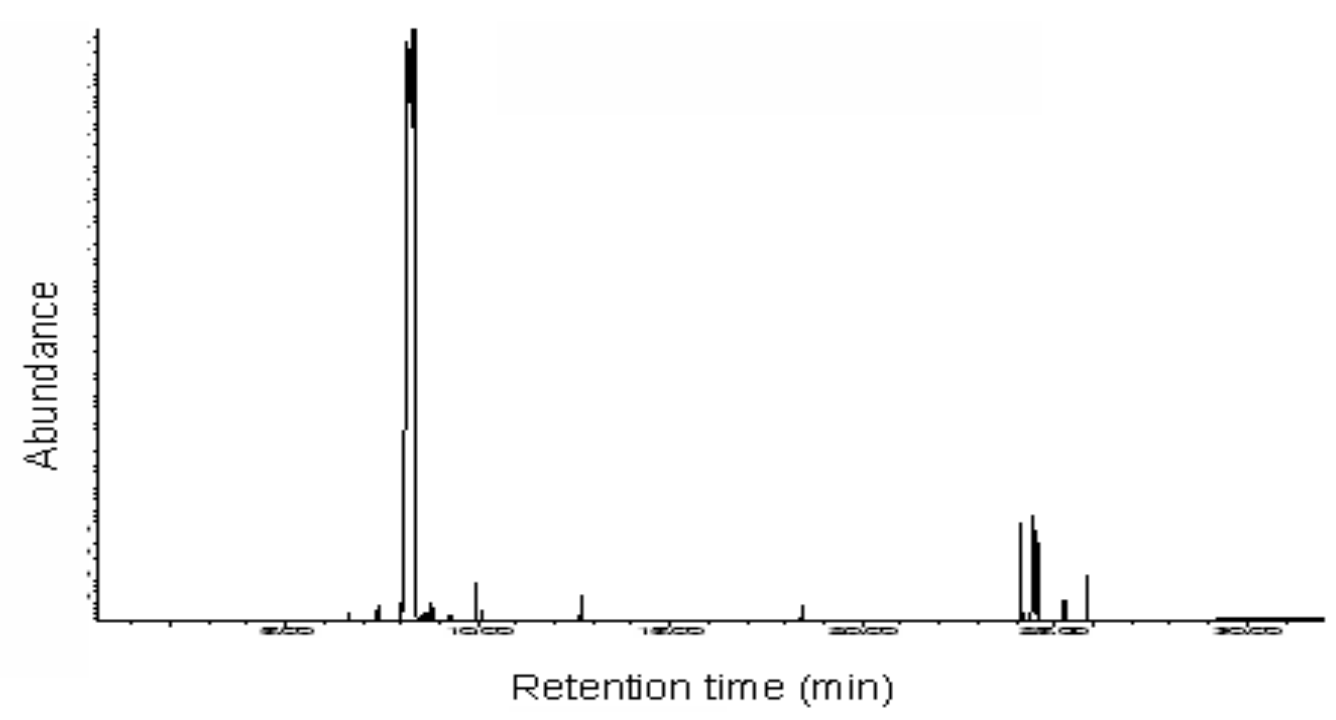

Fig. 7.1: Total Ion Chromatogram (TIC) of the BAF reaction mixture

Fig. 7.1 shows a Total lon Chromatogram (TIC) obtained for the BAF reaction mixture. The high abundance signal with retention time around seven minutes belongs to 4methylheptane. The high intensity of the peak can be explained by the significant excess of this solvent and at the same time reactant in the analyzed sample. The short retention time is caused by its low molecular weight and non-polar character. The small signals surrounding the main peak belong to low molecular weight alkanes, which are partially impurities, present in the starting material. The beginning of the TIC graph is exactly the same for each analyzed sample. Based on their MS-fragmentation patterns, the low intensity signals in the middle part of the chromatogram, retention time 10-20 min, were identified as side products of mono-azide reactions and impurities. In the last part of the chromatogram, with retention times 24-26 minutes, much less intensive signals but still relatively high compared to the 4-methylheptane peak start to appear, which were identified as reaction products between mono-azides and model hydrocarbone. Magnification of this part of the chromatogram shows five peaks of varied intensity, in Fig. 7.2 named A, B, C, D and E.

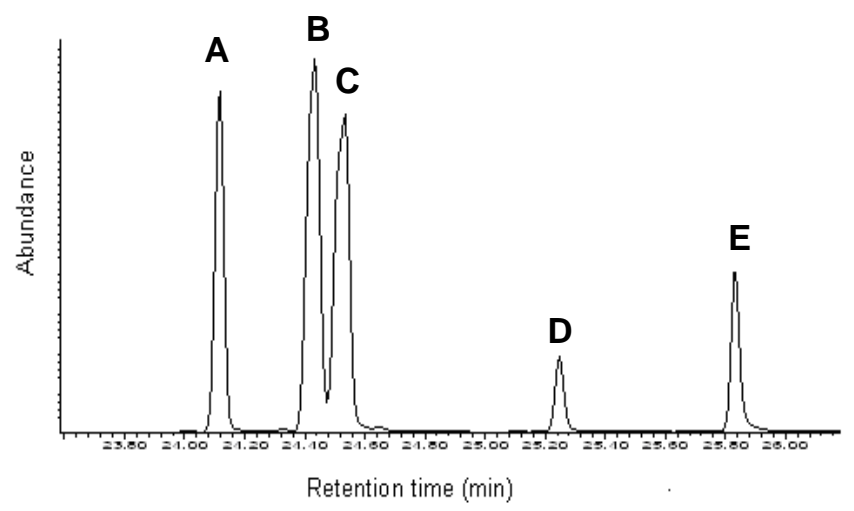

Fig. 7.2: Peaks identified as BAF grafted to the 4-methylheptane 
In Scheme 7.1 (B) the structure of 4-methylheptane with numbered carbon atoms was shown. Based on the fragmentation paterns, signal A was identified as BAF grafted at carbon atom number 4 . The following two signals, $B$ and $C$, have almost identical mass spectra and both of them were recognized as a modification on position 3 . The carbon atom in this position comprises a stereogenic center what may explain why two peaks are detected. The next signal, marked as $D$ and clearly the smallest one, was identified as BAF grafted to the carbon number 1. The last signal $E$ most likely corresponds to the BAF grafted at carbon number 2. The structure of this product however may be questionable. Generally, similar to carbon number 3 also position 2 makes a stereogenic center and thus two products could be expected.

The second azidoformate, PhAF as shown in Fig. 7.3, gives exactly the same sequence of modification products. The main difference between the BAF- and PhAFspectra is that the grafting products of the first one have a longer retention time by around 40 seconds, most probably due to their higher molecular weights. The main masses detected for each peak are given in Table 7.2.

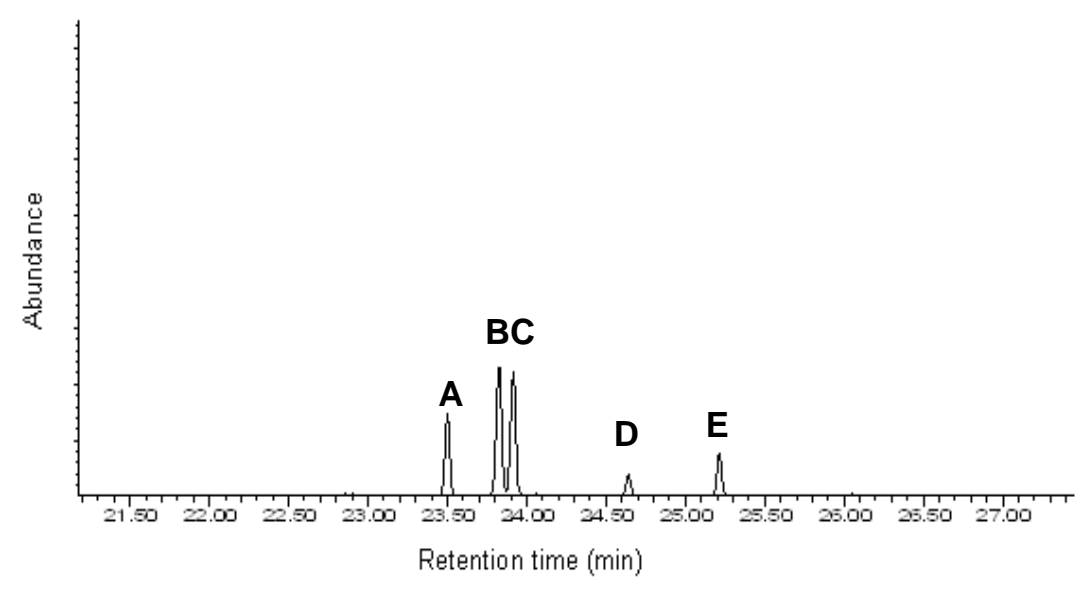

Fig. 7.3: Peaks identified as PhAF grafted to the 4-methylheptane

Table 7.2 Detected molar masses and structures of grafted product

\begin{tabular}{|c|c|c|c|c|c|}
\hline \multicolumn{2}{|c|}{ AZIDE } & & & & \\
\hline BAF & peak & A & $\mathrm{B}, \mathrm{C}$ & $E$ & $\mathrm{D}$ \\
\hline$(R=150)$ & M & 220,263 & $192,234,263$ & 263 & $172,91,263$ \\
\hline PhAF & peak & A & $B, C$ & $E$ & $\mathrm{D}$ \\
\hline$(R=136)$ & M & 206,249 & $178,220,249$ & 249 & 150,249 \\
\hline PhSA & peak & $E$ & $A, B$ & A, C & $\mathrm{D}$ \\
\hline$(R=156)$ & M & 226,269 & $196,240,269$ & $180,254,269$ & 170,269 \\
\hline
\end{tabular}

M: molar mass 
Five peaks are also observed when the sulfonyl azide, PhSA modification products are analyzed, Fig. 7.4. The shape and order of the signals are however completely different from the two chromatograms of the azidoformates. The first three signals; $A$, $B$ and $C$, unlike the AF reaction products, are barely separated and overlap each other largely. After careful analysis of the MS data, signal A was identified as a mixture of products with the PhSA grafted to the carbon atoms numbers 2 and 3 , signal $B$ only carbon 3 and signal $C$ only carbon 2 . Because the areas of the signals $B$ and $C$ were estimated to be more or less equal and half the size compared to signal $A$, the conclusion can be drawn that the PhSA is equally reactive towards both secondary carbon atoms; both modification products result in double signals and have similar retention times. Signals $\mathrm{D}$ and $\mathrm{E}$ were recognized to come from $\mathrm{PhSA}$ grafted to carbons number 1 and number 4, respectively.

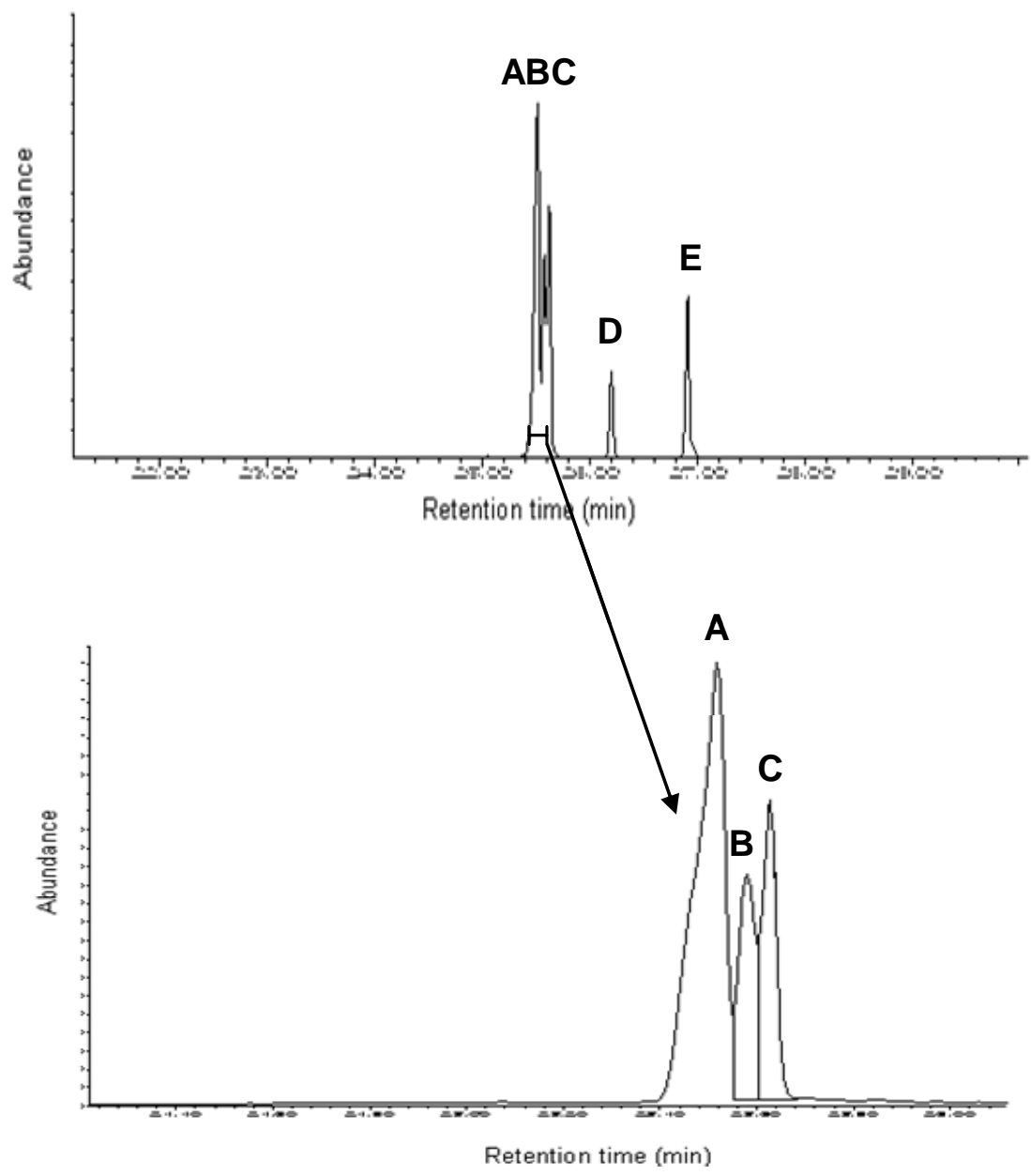

Fig. 7.4: Top: signals identified as PhSA grafted to 4-methylheptane, bottom: modification products with the lowest boiling point

By comparing the signal areas of the different modification products it is possible to estimate which position is the preferred one for grafting. The data are listed in Table 7.3. Taking the symmetry of 4-methylheptane into account, except for the tertiary 
carbon atom the relative reactivities towards the other carbons should be divided by two. PhAF and BAF have almost identical preference towards various carbon atoms. Both of them prefer to react with the secondary carbon atom number 3 and they also show some preference for the tertiary carbon number 4 . PhSA on the other hand has a very clear and balanced preference to react with the two secondary carbon atoms: 2 and 3.

Table 7.3 Mono-azides grafted to different carbon atoms of 4-methylheptane and side products content (\%)

\begin{tabular}{cccc}
\hline carbon nr. & PhAF & BAF & PhSA \\
\hline 1 & 4 & 4.5 & 5.5 \\
2 & 9 & 9.5 & 40.5 \\
3 & 59 & 62 & 40.5 \\
4 & 17 & 20 & 10.5 \\
5 & - & - & - \\
\hline side products & $\sim 11$ & $\sim 4$ & $\sim 3$ \\
\hline
\end{tabular}

Combining the signal areas of BAF grafted to the various carbon atoms of 4methylheptane the estimated modification efficiency is $96 \%$. The side products consist of around $3 \%$ benzyl carbamate and a small amount of benzyl alcohol. Additionally there was also a certain amount of benzylchloride present in the sample, which most probably was inserted together with the azide. BAF was synthesized from benzyl chloroformate which may have contained traces of benzylchloride. The amount of benzylchloride in freshly synthesized BAF, determined using ${ }^{1} \mathrm{H} N M R$, was the same as the amount found in the model compound using the GC/MS system: in both cases it was around $5 \%$.

The reaction of the other mono-azidoformate PhAF, seems to be less efficient compared to BAF, as the percentage of the side products found in this sample was estimated to be around $11 \%$. Out of those, $3 \%$ was indentified as phenyl alcohol and $6 \%$ as a PhAF rearrangement product; the reaction mixture contained also a certain amount of diphenyl carbonate and one other unidentified side product. The monosulfonyl azide PhSA reaction, with the amount of side products estimated at $3 \%$ only, seems to be even more efficient than BAF. As side products were identified traces of non reacted PhSA, butyl-phenyl sulphide, phenylsulfonylamine, and diphenyldisulfide. The relatively low reaction efficiency of PhAF, compared to the other two mono-azides where the azidoformate group is bound to the aromatic ring, is mostly due to a rearrangement reaction, Scheme 7.2. 


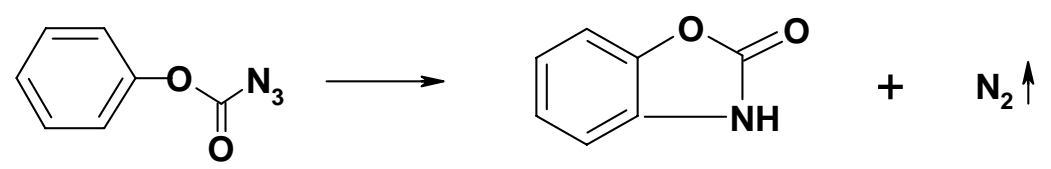

Scheme 7.2: Rearrangement reaction of PhAF (aromatic azidoformate)

Subsequently, the percentage of side products may double for the di-functional molecule and thus the efficiency of the 4,4'DAF reaction just because of this rearrangement could be lowered by around $12 \%$. Cross-link density and mechanical properties of the EPM vulcanizates reported in the previous chapters show clearly that the 4,4'DAF performance was not as good as for the other di-azides. As a matter of fact the mechanical properties for 4,4'DAF were so poor, that the identified side reactions are not enough to explain this poor performance. Unless there are other side products formed which were not identified, other factors like for instance a low solubility in EPM may additionally have negatively influenced its efficiency as curing agent. The large polarity difference between azide and a rubber can significantly lower the reaction efficiency, as described in Chapter 6.

\section{Model compound with coagent and mono-fuctional azides}

To investigate the effect of a maleimide coagent on the azide reaction, two model compounds were prepared: the first one containing phenylmalemide in combination with PhAF, and the second with PhSA. The corresponding chromatograms are shown in Fig. 7.5. It was established that the maleimide itself can be grafted to the 4methylheptane but only in the presence of PhAF. A broad cluster of peaks with a retention time $26-29 \mathrm{~min}$ is typical for a radical reaction, out of the multiple products some of the masses were identified as phenyl-maleimide grafted to the model hydrocarbon. The cluster is not detected for the maleimide in combination with PhSA. As shown in Chapter 5 , the maleimide coagents had a positive effect only during the di-azidoformate reaction. When added to the di-sulfonyl azide curing the mechanical properties of the vulcanizate decreased. The present experiment nicely confirms this as inability of the sulfonyl-azide to promote grafting of the maleimide to the EPM polymer chain. 

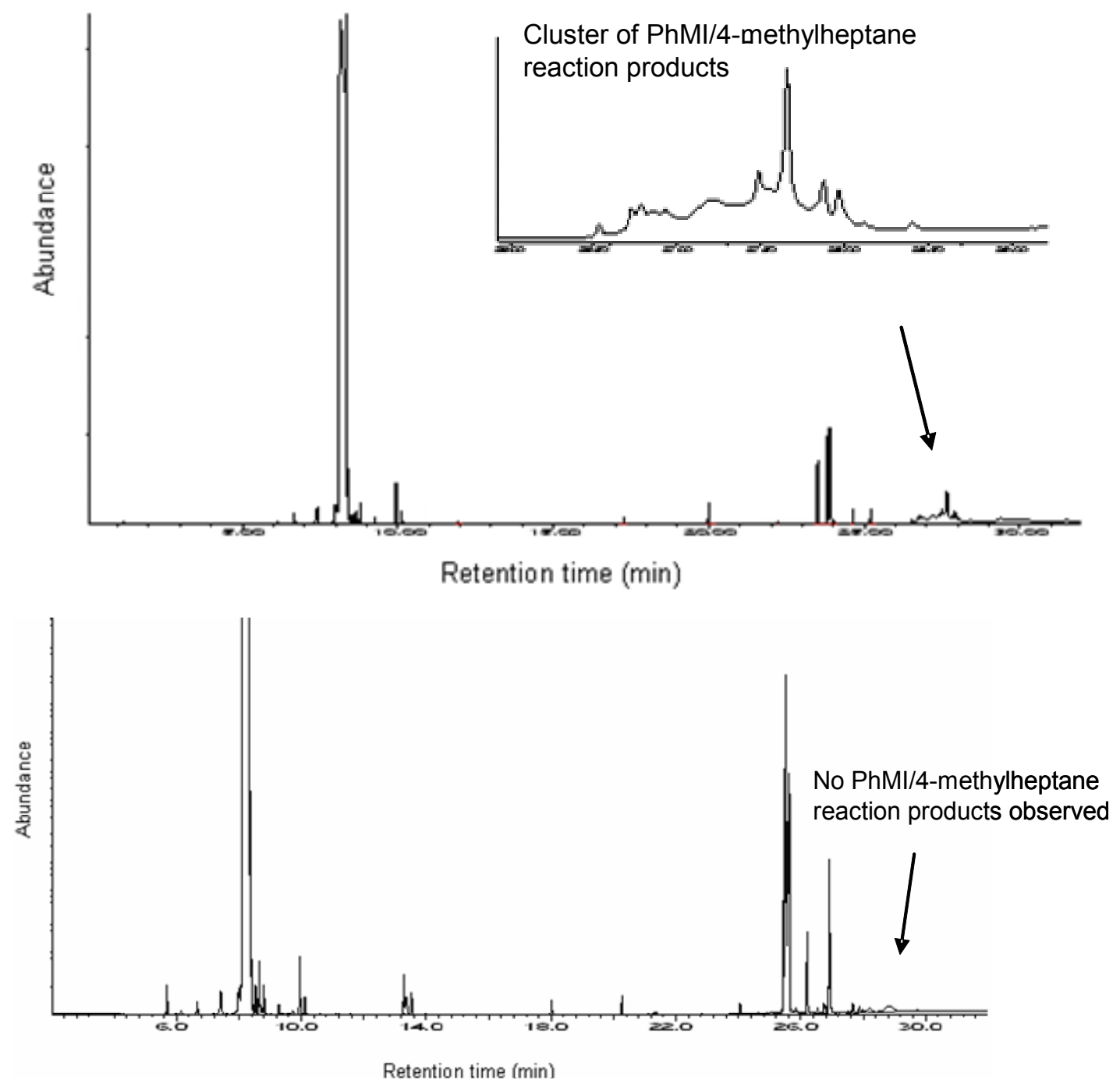

Fig. 7.5: TIC of model compound containing phenylmaleimide Top: combination with PhAF, Bottom: combination with PhSA

\subsubsection{HPLC/MS analysis}

\section{Model compound with mono-fuctional azides}

As a check of the GC/MS results the model compounds based on mono-azides: BAF, PhAF and PhSA were analyzed again, this time using HPLC/MS system. In the HPLCcolumn the ingredients of the reaction mixture are separated according to their polarity. During the experiments a reverse phase column was used where the polar components exit sooner than the non-polar ones. Compared to the GC-technique the HPLC-column is also much less sensitive in regard to the molecular weights of the compounds, thus the same ingredients are expected to elute from both columns in a completely different order. Exactly the same as was observed during the GC/MS analysis however, after passing the HPLC-column every mono-azide reaction mixture shows four peaks, which correspond to an azide molecule grafted to 4-methylheptane. 
When comparing the reaction products of all three mono-azides, it was observed that with the same experimental conditions 4-methylheptane modified with PhSA has the shortest retention time and the longest the one modified with BAF. The short retention time of the PhSA modified model hydrocarbon in spite of it slightly higher molecular weight indicates that the SA functionality is more polar compared to the azidoformate structure. The same conclusion was already drawn based on the solubility experiment described in Chapter 6.

As an example the TIC of the PhSA model compound and the mass spectra of each of the four peaks identified as modification products are given in Fig. 7.6. The masses: $M$ 201.9, M 371.0 and M 393.0 belong to the background, as their intensities are always the same in every mass spectrum. The masses: M 269.8 and M 291.8 belong to the same modification product; the first mass corresponds to a positively charged ion, $M$ $(268.8+1)$ while the second is a combination with sodium, M $(268.8+23)$, typical for the ESI ionization. Generally, the GC/MS results of the mono-azide grafted model hydrocarbon are confirmed. No additional information was gathered with this experiment.
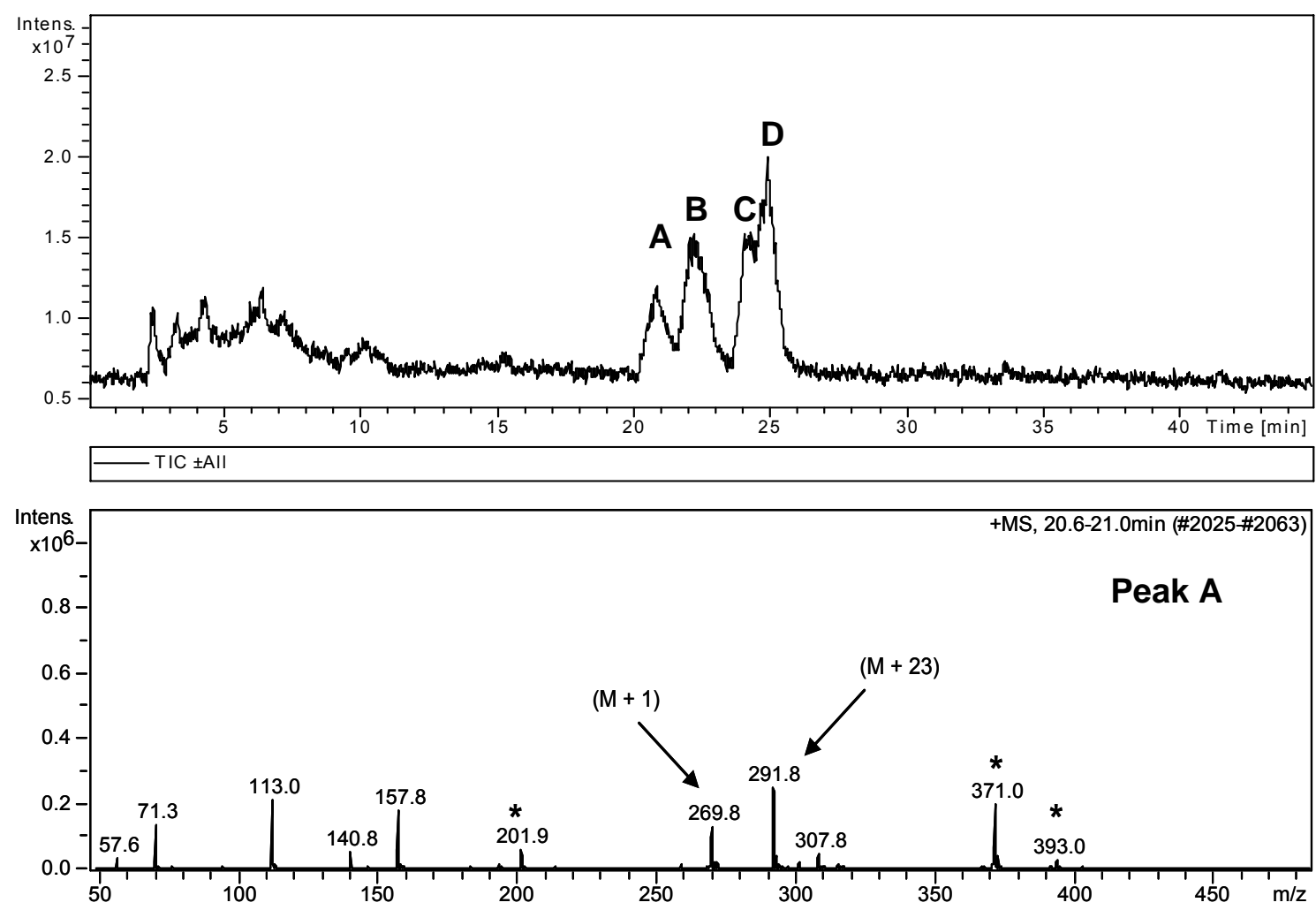

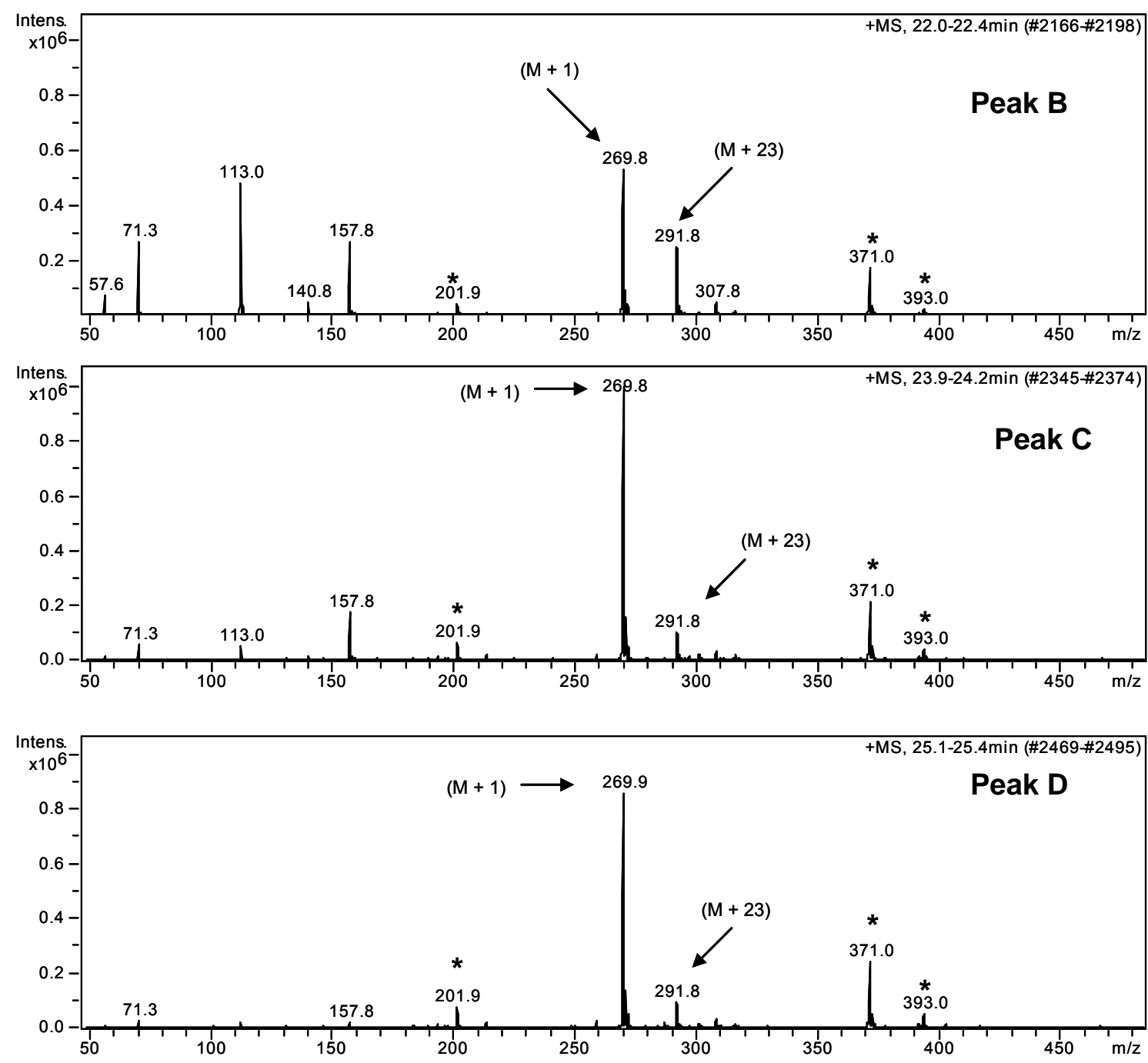

Fig. 7.6: Top: TIC of PhSA grafted to the 4-methylheptane; below: mass spectra of particular modification products ( ${ }^{*}$ background signals)

Model compound vulcanization with di-functional azides

Due to the high molecular weight and polarity of the reaction products of the model compound with di-azides it is impossible to analyze the reaction mixtures by means of the GC/MS technique. Thus the model compounds containing di-azides were analyzed using HPLC/MS only. The conditions applied to separate and identify particular components were the same as for the mono-azide reaction mixtures. Fig. 7.7 shows a typical TIC of the 1,3BDSA reaction products. 


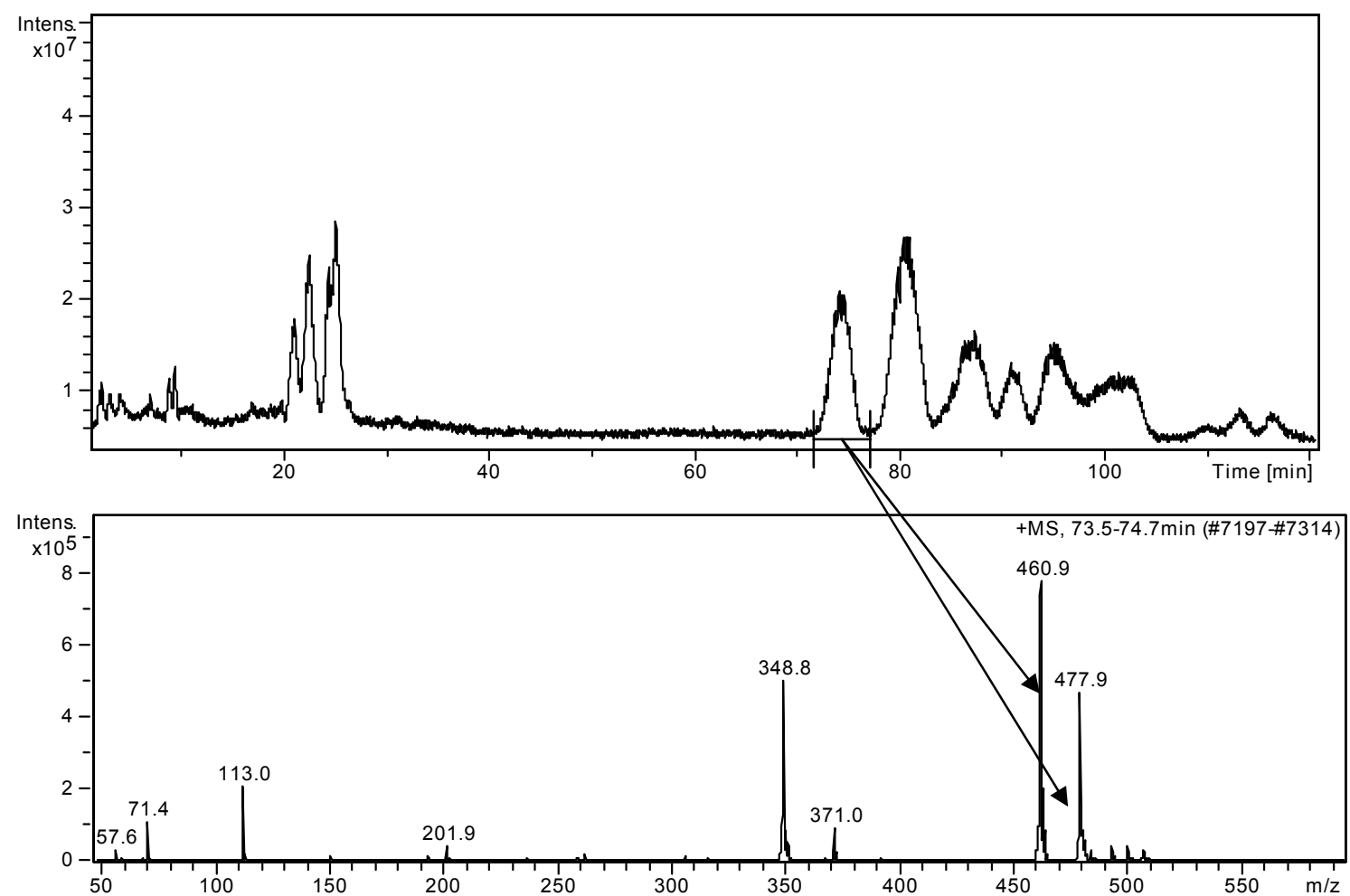

Fig. 7.7: Top: 1,3BDSA reaction products; below: example of a mass spectrum

The first four high intensity peaks on the chromatogram: retention time 20-26 min, were identified as grafting products. The retention time as well as the MS spectra of these peaks are identical to those of the PhSA reaction products given in Figs. 7.6. The purity of 1,3BDSA was determined with ${ }^{1} \mathrm{H}$ NMR as described in Chapter 3 , and no traces of PhSA were detected. Thus, the only explanation is that some of the $1,3 \mathrm{BDSA}$ molecules loose one of the sulfonyl azide groups during the reaction. The phenomena of $\mathrm{SO}_{2}$-formation during sulfonyl azide decomposition was earlier reported by different authors. ${ }^{12,23}$

The second part of the chromatogram contains around ten signals of varying intensity, which are partially overlapping each other, retention times 72-120 minutes. All of the signals could be identified as cross-linking products, consisting of two 4-methylheptane molecules and 1,3BDSA without two nitrogen molecules. The mass spectrum of one of the first signals is shown as an example. The masses M 460.9 and M 477.9 belong to the cross-linked product: the first one is a positively charged ion (M $459.9+1)$, and the second is a combination with ammonium (M 459.9+17), again an ion typical for ESI. The fact that around ten different compounds with exactly the same molecular weight separate from the mixture, is related to the individual azide groups reacted with different carbon atoms of 4-methylheptane. The different intensities of the signals indicate that some of the combinations are more preferred than the others. The possible structures of the 1,3BDSA reaction products are shown in Scheme 7.3: (A) for 
$1,3 \mathrm{BDSA}$ grafted to the 4-methylheptane after one of the sulfonyl group has been released, and $(B)$ for a cross-linked product.

(A)

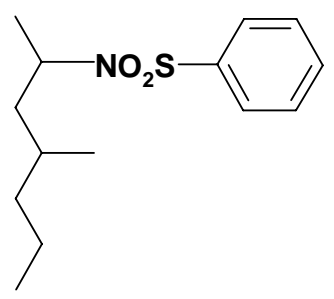

(B)

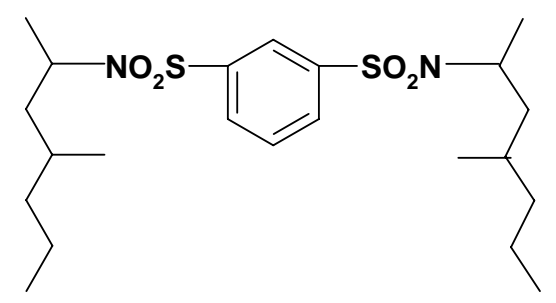

Scheme 7.3: 1,3BDSA reaction products, retention time (A): 20-26 min (side product) and (B):

72-120 min (cross-linked product)

The components of the reaction mixture with the other di-sulfonyl azide: 1,6HDSA, were separated on the HPLC and the obtained TIC is given in Fig. 7.8. The group of signals which leaves the column after 20-25 min correspond to 1,6HDSA with one sulfonyl azide functionality connected to the model hydrocarbon and the other one still not reacted yet. The mass is detected as a positively charged ion and in combination with ammonium. Both 1,3BDSA as well as 1,6HDSA model compounds were prepared in exactly the same way, but apparently the 15 min reaction time was not enough for the second di-sulfonyl azide to fully react with both sides.

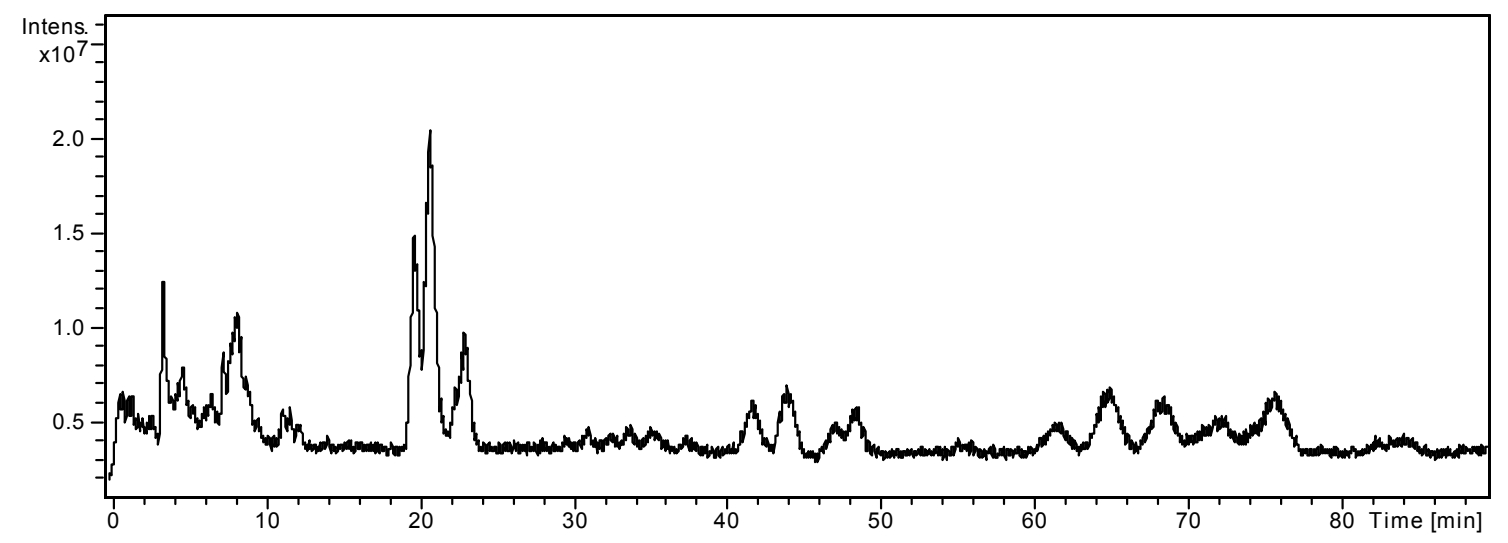

Fig. 7.8: TIC of the 1,6HDSA reaction mixture

The signals with retention time between 40 and 50 min were identified as 1,6HDSA molecules which lost one sulfonyl azide functionality, and with the remaining azide group are grafted to the 4-methylheptane. The cross-linking product with two model hydrocarbons connected by a 1,6HDSA bridge start to elute from the column after around $60 \mathrm{~min}$, thus with retention times similar to 1,3BDSA cross-linking products. The structures of the separated compounds are given in Scheme 7.4. The group of signals with close retention times and identical masses most probably belong to different isomers. 

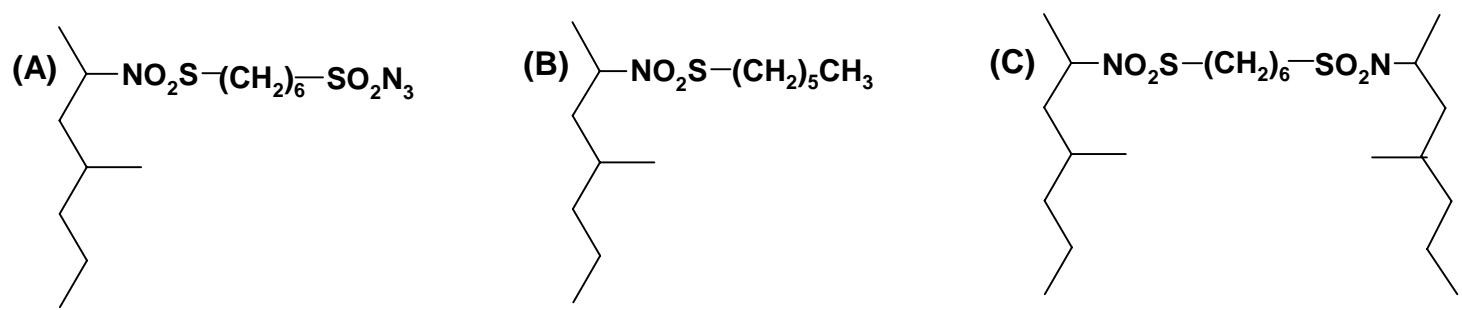

Scheme 7.4: 1,6HDSA reaction products, retention times: (A) 19-25 min: one azide group still not reacted, (B) 40-50 min: side products and (C) 60-90 min: cross-linked products

The TIC of the GDAF model compound is shown in Fig. 7.9. In the chromatogram three sets of products can be distinguished, with retention times 2-11 min, 12-21 min and $40-90 \mathrm{~min}$. Mass spectra of the first set suggest that there are two reaction products with masses M 346 and M 348 that leave the column at the same time (on a septum as positively charged ions). The first mass corresponds to a cyclic structure where both azide functionalities of GDAF have reacted with the same 4-methylheptane molecule. The second mass has only two more protons and it could be a side product, where one of the azide functionalities has reacted with the model molecule while the other one is converted into an amine.
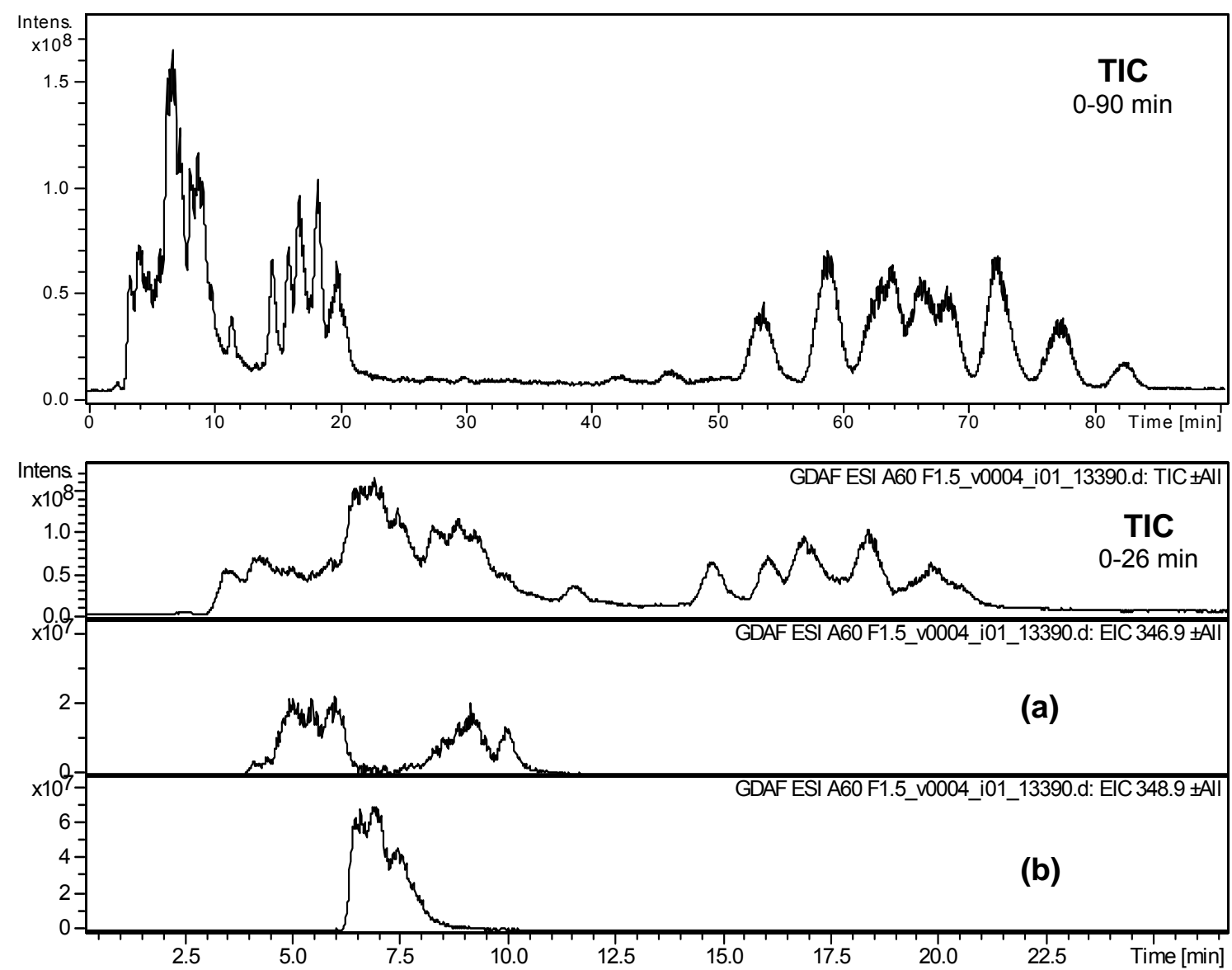


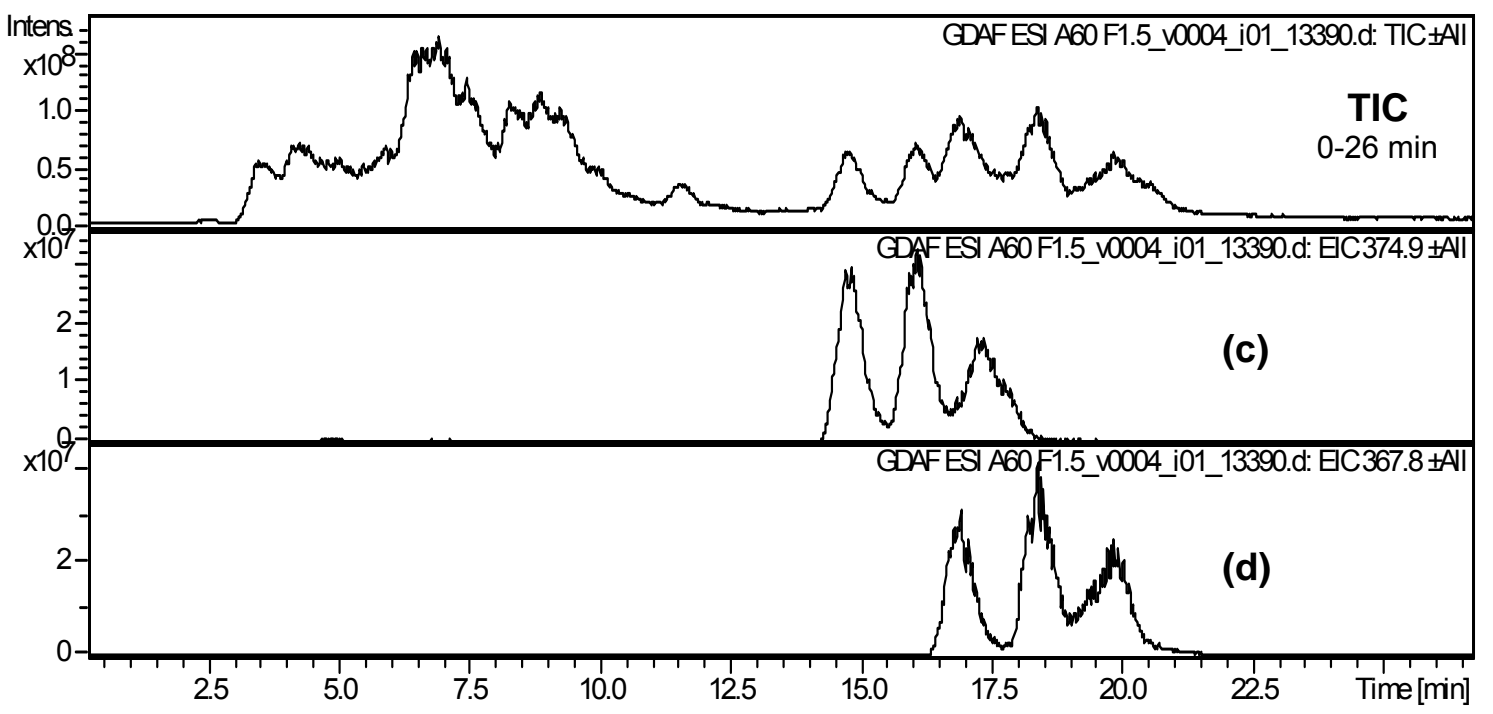

Fig. 7.9: TIC and Excluded Ion Chromatograms (EIC) of GDAF side products (a): EIC 346.9 (M 346+1), (b): EIC 348.9 (M 348+1), (c): EIC 374.9 (M 374+1) and (d): EIC 367.8 (M 367+1)

The cluster of signals in the middle part of the chromatogram: retention time 12-21 min, also combines two products: M 374 and M 367, Figs. 7.9 (c) and (d). The first mass corresponds to a structure were only one azidoformate group of GDAF has decomposed and reacted with the model molecule. The second mass with slightly longer retention time is presumably less polar, though the exact composition was difficult to define. The possible structures of the side products of the GDAF reaction are shown in Scheme $7.5(A)$ - (D).

The last part of the chromatogram shows signals identified as cross-linked products, retention time $40-90 \mathrm{~min}$, Scheme $7.5(\mathrm{E})$. Similar to 1,3BDSA, also GDAF gives around ten different peaks, which correspond to reaction products with varying isomeric structures. The ratio between the peaks however, is clearly different than for the1,3BDSA, Fig. 7.7. Where for the di-sulfonyl azide each signal had a different size, the peaks from the GDAF cross-linking products appear to be rather symmetric. Thus it can be assumed that the two di-azides will have preference towards different isomeric structures and that the GDAF reaction is more selective. This corresponds nicely with the GC/MS data where the preference of the azidoformates towards specific carbon atoms of the model hydrocarbon was clearly visible, Table 7.2. The sulfonyl azide was much less selective and it has an equal preference for any secondary carbon atom. With the same experimental conditions the retention times $40-$ $90 \mathrm{~min}$ are shorter for the GDAF that for 1,3BDSA which again suggests that the first is more polar. 
(A)<smiles>CCC(NC(=O)OCCOCCOCCOCCOC)C(C)CNC(C)C</smiles>

(C)
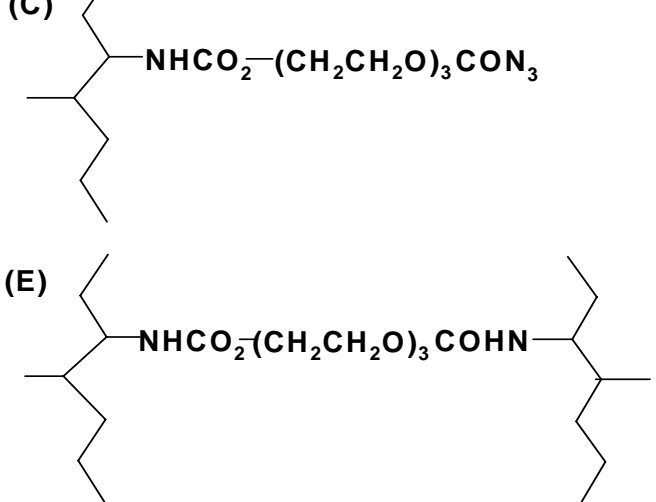

(B)

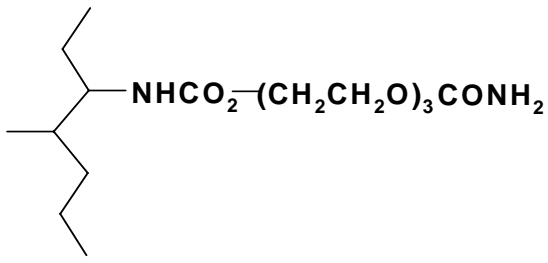

(D)

$M=367$

Scheme 7.4: GDAF reaction products, retention time (A): 2-11 min: backbiting product, (B): $6-10$ min: side product, (C) 12-19 min: one azide group still not reacted, (D) 16-21 min: unidentified structure and (E) 40-90 min: cross-linked product

The analysis of the 4,4'DAF reaction mixture shows a varying combinations of azide molecules grafted onto 4-methylheptane, but no cross-linked products could be identified. This could have been caused by the poor solubility of the azide in 4methylheptane. Even though the molecular weight of 4,4'DAF cross-linking products may be higher compared to the other MCV compositions, the mass would still be in the operational range of the equipment. This once more confirms the poor reactivity of 4,4'DAF observed in Chapter 4.

\subsection{Conclusions}

The GC/MS analysis of the reaction of the model hydrocarbon, 4-methylheptane with mono-functional azides shows that the reactions of the azidoformate group and sulfonyl azide group are quite different. The SA-functionality shows a clear tendency to react with any secondary carbon atom, while the AF-functionality prefers to react with a secondary carbon atom next to a tertiary carbon or with the tertiary carbon atom. Both mono-functional azidoformates, PhAF and BAF result in similar products.

The HPLC/MS analysis of the reaction of the model hydrocarbon with di-sulfonyl azides show that both: 1,3BDSA and 1,6HDSA, tend to lose one of the SA functionalities during the reaction. This observation is consistent with literature data, which report $\mathrm{SO}_{2}$-formation during sulfonyl azide reactions. A side reaction of GDAF is the backbiting, were both azidoformate functionalities react with the same model molecule and two other grafted products. Generally however, the main products of the $1,3 B D S A$ and GDAF reactions are cross-linked structures, consisting of two model 
hydrocarbons and the azide bridge. A cross-linked product of the 4,4'DAF reaction could not be identified, most probably due its large polarity difference with 4methylheptane and consequently low solubility. The phenomena observed with these MCV studies are confirming the observations on cross-linking of the real rubber compounds in the previous chapters.

\subsection{References}

1. D.S. Breslow and H.M. Spurlin, U.S. Patent 3,203,937, Aug. 31, 1965.

2. D.S. Breslow, U.S. Patent 3,220,985, Nov. 30, 1965.

3. D.S. Breslow, U.S. Patent 3,284,421, Nov. 8, 1966.

4. Hercules inc, G.B. Patent 1,087,045, Oct. 11, 1967.

5. J.M. Simson and W. Lwowski, J. Am. Chem. Soc. 91, 5107 (1969).

6. D.S. Breslow, W.D. Willis and L.O. Amberg, Rubber Chem. Technol. 43, 605 (1970).

7. J.L. Benito Gonzalez, L. Ibarra and L. Gonzalez, Kautsch. Gummi, Kunstst. 43, 697 (1990).

8. R.H. Terbrueggen, WO Patent 0,052,091, Sep. 8, 2000.

9. M.A. Lopez Manchado and J.M. Kenny, Rubber Chem. Technol. 74, 198 (2001).

10. M.B. Smith and J. March, "March's advanced organic chemistry reactions, mechanisms and structure", $5^{\text {th }}$ edition, New York (2001).

11. S.A. Bateman and D.Y. Wu, J. Appl. Polym. Sci. 84, 1395 (2002).

12. J.K. Jorgensen, A. Stori and K. Redford, Polymer 46, 12256 (2005).

13. J.K. Jorgensen, A. Stori and K. Redford, Polymer 46, 12073 (2005).

14. Q. Li and C. Tzoganakis, ANTEC 1804 (2006).

15. K. Borve, K. Redford and A. Stori, EP Patent 1,423,466, Jun. 2, 2004.

16. K. Borve, K. Redford and A. Stori, U.S. Patent 7,056,987, Feb.17, 2006.

17. J.M. Dyke, J. Phys. Chem. A 108, 5299 (2004).

18. J.I. Arenas and J.I. Marcos, Int. J. Quantum Chem. 84, 241 (2001).

19. W.B. Wennekes, "Adhesion of RFL-treated cords to rubber: New insights to interfacial phenomena", PhD thesis, University of Twente, Enschede, The Netherlands (2008).

20. S. Mihara, "Reactive processing of silica-reinforced tire rubber", $P h D$ thesis, University of Twente, Enschede, The Netherlands (2009).

21. R. Peters, "Characterization of polymer network structures", $P h D$ thesis, University of Amsterdam, The Netherlands (2009).

22. R.S. Gohlke and F.W. McLafferty, J. Am. Soc. Mass Spectrom. 4, 397 (1993).

23. D.S. Breslow, M.F. Sloan, M.F. Newburg and W.B. Renfrow, J. Am. Chem. Soc., 91, 2273 (1969). 


\title{
Chapter 8
}

\section{Di-azides cross-linked, iPP/EPDM-based thermoplastic vulcanizates}

\begin{abstract}
Two di-azidoformates: GDAF and 4,4'DAF, and one di-sulfonyl azide: $1,3 \mathrm{BDSA}$, are investigated as curing agents for the iPP/EPDM-based dynamically vulcanized thermoplastic vulcanizates (TPVs). Their performance is compared with TPVs cured with peroxides, alone and in combination with a coagent. The di-azides proved already to be effective curing agents for EPDM-rubber in static conditions in the previous chapters. With respect to the production conditions of the investigated TPVs, the reaction temperature of the sulfonyl azide makes it the most suitable curing agent. Exceptionally good mechanical and processing properties are obtained with surprisingly low 1,3BDSA contents. The results indicate that the size of the EPDM-rubber particles in the di-azide cured TPVs in the range of 1-5 $\mu \mathrm{m}$ provide optimal properties.
\end{abstract}




\subsection{Introduction}

Thermoplastic vulcanizates (TPVs) belong to the larger family of thermoplastic elastomers (TPEs); materials which are characterized by the properties of vulcanized rubber and yet can be (re)processed in the molten state as thermoplastic polymers. TPE's usually consist of copolymers or physically mixed polymers. The main difference between standard thermoset elastomers, i.e. vulcanized rubber, and TPEs is the type of network which bonds the structure. Where a typical rubber vulcanizate has a homogeneous covalent network, the cross-links in TPE are created by weak ionic or hydrogen bonding, crystallinity or take place in only one of the material phases. Commercial examples of TPEs are hard/soft segmented block copolymers, elastomeric ionomers or (semi-)crystalline polyolefin/rubber blends. TPVs belong to the last group and consist of a vulcanized rubber phase, dispersed in a thermoplastic matrix $^{1,6}$. They are typically produced in a dynamic vulcanization process, where the elastomeric phase is selectively cross-linked during melt mixing with the thermoplastic. At the high compounding temperatures the viscosity of the thermoplastic and the rubber do not differ much and thus, the component with the higher volume fraction will become the matrix. Once the cross-linking process begins however, the viscosity of the rubber increases and irrespective of the components ratio it is the elastomer which tends to become the dispersed phase.

In the present paper one of the most common TPV systems is studied, based on a mixture of isotactic polypropylene (iPP) and EPDM rubber (40/60 wt \%). In static conditions EPDM is usually cured using a sulfur/accelerator combination, although in some special applications when there is a need for a high thermally resistant material, a peroxide/coagent curing system is applied. Although the EPDM phase in TPVs can be vulcanized with either curing system, the presence of the iPP phase is an important issue. A sulfur/accelerator combination is not applied for commercial iPP/EPDM-based TPVs, as the polypropylene has a relatively high melting temperature, while the sulfur crosslinks have a low thermal stability, giving the material a repulsive smell and a brown/reddish color which cannot be masked by pigments. When a peroxide/coagent combination is used, degradation of iPP occurs due to a $\beta$-scission reaction resulting in inferior properties. Therefore, the usual cross-linkers for the EPDM phase are resol resins. However, also this system has disadvantages such as an off-white color and formation of black specs. Consequently, other curing systems are still being considered and the possibility to apply di-azides has been mentioned as well ${ }^{7,9}$. Some of the di-azides proved already to be effective curing agents for EPDM rubber under static conditions ${ }^{10,11}$. The present study covers a comparison between two diazidoformates and a di-sulfonyl azide for iPP/EPDM-based TPVs from the perspective of processability and material properties. 


\subsection{Experimental}

\subsubsection{Materials}

The rubber used was ENB-EPDM (Keltan 5531A; ethylene content 63 wt \%, propylene content $32.5 \mathrm{wt} \%$ and ENB $4.5 \mathrm{wt} \%$ ) extended with 100 parts of white paraffinic oil, supplied by DSM Elastomers B.V. Polypropylene (Stamylan P11E10 or SABIC PP 531 P) was obtained from SABIC EuroPetrochemicals B.V. Process oil (Paralux 6001R) and talcum (HTP-2) were obtained from ChevronTexaco and Imifabi s.p.a., respectively. Stabilizer: octadecyl-3-(3,5-di-tert-butyl-4-hydroxyphenyl)-propionate (Irganox 1076) was obtained from Ciba-Geigy and zinc oxide (ZnO) from Merck. Coagent: trimethylolpropane trimethacrylate (TRIM or TMPTMA, $96 \%$ ) was purchased from Sigma-Aldrich and the peroxide: 2,5-dimethyl-2,5-di(tert-butylperoxy)hexane (Trigonox 101 E30) from AkzoNobel. All three di-azides: GDAF, 4,4'DAF and 1,3BDSA were synthesized from the corresponding chlorides and sodium azide as described in Chapter 3. The solvents: cyclohexane (99\%), p-xylene (99\%) and 2-butanone ( $\geq 99$ $\%)$ were obtained from Sigma-Aldrich.

\subsubsection{Methods}

Preparation of the thermoplastic vulcanizates

The iPP/EPDM-based TPVs were prepared in a Brabender Plasticorder PL 2000 laboratory internal mixer with a chamber volume of $50 \mathrm{~cm}^{3}$, the rotor speed was 80 rpm and the fill factor 0.75 . The initial set temperature of the mixer: $T_{s}$ was $180^{\circ} \mathrm{C}$. The recipes of the TPVs are given in Table 8.1. The ratio between the compound components is commonly given in phr or wt \%. However, to obtain a fair comparison between the various di-azides it was the amount of functional groups that needed to be kept constant and thus, the curatives are compared on a molar basis. The samples cured with peroxide and the peroxide/coagent combination were taken as references. The components were introduced into the mixer in the following order: iPP $\rightarrow$ stabilizer $\rightarrow \mathrm{EPDM} \rightarrow \mathrm{ZnO} \rightarrow$ talcum $\rightarrow$ oil $\rightarrow$ curatives. From the moment the curing agent had been added, the ingredients were mixed for another $5 \mathrm{~min}$., to allow for vulcanization of the rubber phase. Due to the high temperature required to process iPP, the diazides were not introduced in a pure state, but were first diluted in $1.5 \mathrm{~g}$ of an appropriate solvent. GDAF and 4,4'DAF were dissolved in p-xylene and 1,3BDSA in 2butanone. The solvent evaporated during the mixing and any influences on the material properties can be neglected. 
Table 8.1 Recipes of iPP/EPDM-based TPVs

\begin{tabular}{llllll|lll|l}
\hline Ingredients & Ref I & Ref II & I & II & III & IV & V & VI & \\
\hline EPDM & 200 & 200 & 200 & 200 & 200 & 200 & 200 & 200 & phr \\
iPP & 64.4 & 64.4 & 64.4 & 64.4 & 64.4 & 64.4 & 64.4 & 64.4 & \\
ZnO & 1.8 & 1.8 & 1.8 & 1.8 & 1.8 & 1.8 & 1.8 & 1.8 & \\
Talcum & 30.3 & 30.3 & 30.3 & 30.3 & 30.3 & 30.3 & 30.3 & 30.3 & \\
Stabilizer & 0.85 & 0.85 & 0.85 & 0.85 & 0.85 & 0.85 & 0.85 & 0.85 & \\
Process oil & 37.0 & 37.0 & 37.0 & 37.0 & 37.0 & 37.0 & 37.0 & 37.0 & \\
\hline Peroxide & 6.2 & 6.2 & - & - & - & - & - & - & $\mathrm{mmol} /$ \\
Coagent & - & 5.9 & - & - & - & - & - & - & $100 \mathrm{~g}$ \\
GAF & - & - & 12.4 & - & - & - & - & - & EPDM \\
4,4'DAF & - & - & - & 12.4 & - & - & - & - & \\
1,3BDSA & - & - & - & - & 12.4 & 6.2 & 3.1 & 1.5 & \\
\hline
\end{tabular}

\section{Material characterization}

\section{Cross-link density}

Approximately $200 \mathrm{mg}$ of the TPV was weighed and placed in a cylindrical glass vessel of $50 \mathrm{ml}$ volume and known mass. Subsequently $15 \mathrm{ml}$ of cyclohexane was added to the vessel which was then sealed with a plastic cork and shaken for 24 hours. After that time the solvent was refreshed and the sample was shaken for another 24 hours. Once the cyclohexane was decanted the sample was placed in a vacuum oven and dried until all resident solvent was completely removed. Afterwards the extracted TPV samples were weighed and again swollen in cyclohexane for the purpose of the crosslink density determination of the EPDM-phase. The overall crosslink density was calculated according to the Flory-Rehner equation as described in Chapter 4. However, the values of the crosslink density obtained are only a rough estimation. The presence of the thermoplastic phase restricts swelling of the rubber particles and the measured crosslink densities should not be directly compared with those of thermoset rubbers. Generally, determination of the exact density of the TPV's rubber phase is a difficult issue. Even when the thermoplastic phase is extracted, the very small size of the rubber partcles makes the test rather inaccurate.

\section{Mechanical properties}

The stress-strain properties of the various TPVs were measured using a Zwick tensile tester with dumb-bell shaped specimens of Type 2 and a nominal rate of moving the clamps of $500 \mathrm{~mm} / \mathrm{min}$, according to ISO 37 . The hardness of the cured materials was measured using a Zwick hardness tester Shore A type, according to DIN 53517. The compression sets were measured at $23{ }^{\circ} \mathrm{C}$ for 72 hours and at $70{ }^{\circ} \mathrm{C}$ for 24 hours, according to ISO 815. 
The thin film processing test was performed by pressing approximately $2.5 \mathrm{~g}$ of the TPV in a hot press. First the sample was placed between two teflon sheets and heated in the press up to $210{ }^{\circ} \mathrm{C}$, by slight pressing with minimum force. Once the material starts to melt a force of $180 \mathrm{kN}$ was applied and maintained for 45 seconds. After releasing the pressure the sample was cooled down between two metal plates. The sample was then transferred to an aluminum sheet. The processability of the sample was visually judged with a ranking $0-10$, where 0 corresponds to non-flowing material and 10 corresponds to a large thin film with perfectly smooth edges. Fig. 8.1 shows two examples of a thin film: the first is judged as 3 , the second as 10 .
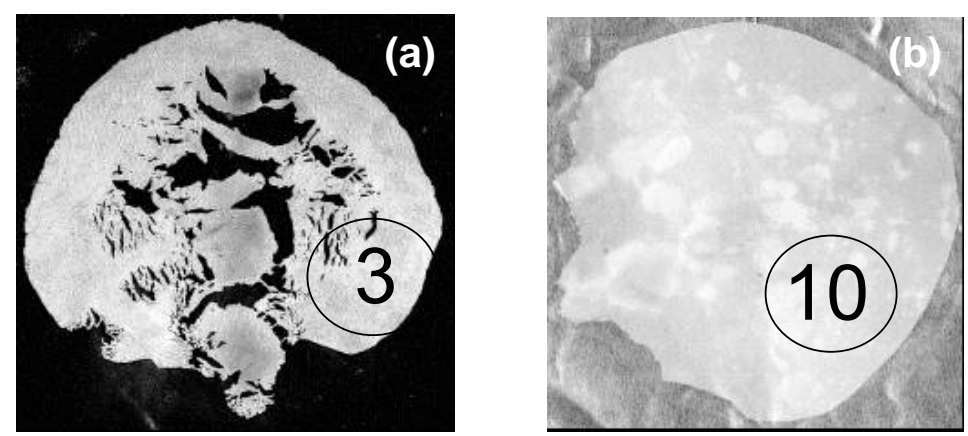

Fig. 8.1: Thin film processability (a): film with score 3 , the sample is flowing but many large cracks are visible, and (b): film with score 10, large surface with perfectly smooth edges

\section{Morphology}

Scanning Transmission Electron Microscopy (STEM) images were obtained using a Titan apparatus (FEI Company, The Netherlands). The measurements were performed on around $100 \mathrm{~nm}$ thick samples, without staining. Another morphological investigation was performed using a Scanning Electron Microscope (SEM), Jed ISM-5600LV. Small TPV pieces were frozen in liquid nitrogen and fractured. Subsequently the samples were dried under vacuum and the fractured surface was sputter-coated with a thin layer of gold using a Blazer Union SCD 040.

\subsection{Results and discussion}

\subsubsection{Comparison of various di-azides with peroxide}

Two di-azidoformates: GDAF, 4,4'DAF and one di-sulfonyl azide: 1,3BDSA, which as shown in Chapter 4, are effective cross-linkers for EPDM-rubber under static conditions, were investigated as potential cross-linking agents for the iPP/EPDMbased TPVs. The compounds were cured with 12.4 (mmol/100 $\mathrm{g}$ EPDM) of each diazide: recipes I-III in Table 8.1. TPVs cured with peroxide, both with and without coagent were used as references. Generally, the decomposition temperature of azidoformates is lower compared to sulfonyl azides. The exact kinetic parameters of all 
three tested di-azide were described in Chapter 3. Under static conditions vulcanization processes are usually carried out at around $150{ }^{\circ} \mathrm{C}$, which corresponds nicely with the azidoformate reaction temperature. However, mixing of the iPP/EPDMbased TPVs needs to be executed above $180{ }^{\circ} \mathrm{C}$ due to the high melting temperature of the isotactic poly(propylene): $\sim 170^{\circ} \mathrm{C}$. The di-azides were therefore introduced into the mixer in a solution with a high boiling solvent to prevent that GDAF and 4,4'DAF decompose completely before reaching the rubber phase. To maintain similar conditions, the di-sulfonyl azide: 1,3BDSA was added in a solution as well.

The difference between di-azides and peroxide cross-linking was clearly observed already during preparation of the TPV samples. Fig. 8.2 shows torques generated in the mixer from the moment the cross-linkers were introduced. The torques measured during peroxide curing are significantly lower compared to the torques generated during the di-azides reactions, where the GDAF and 4,4'DAF give lower and 1,3BDSA higher values.

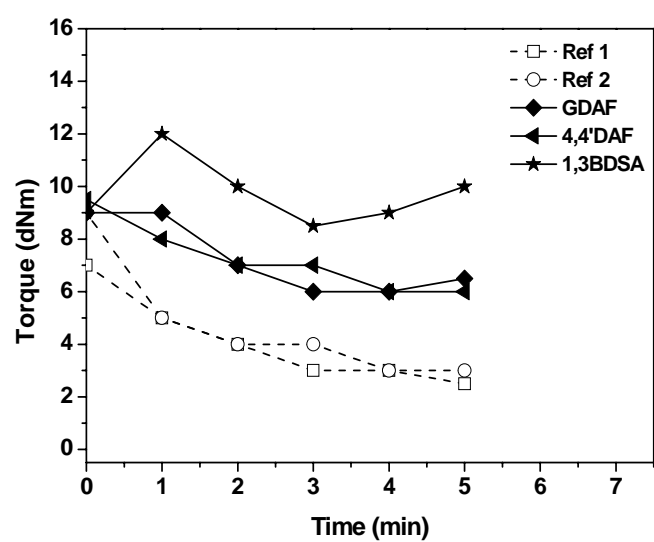

Fig. 8.2: Changes of mixer torque from the moment the curatives were introduced

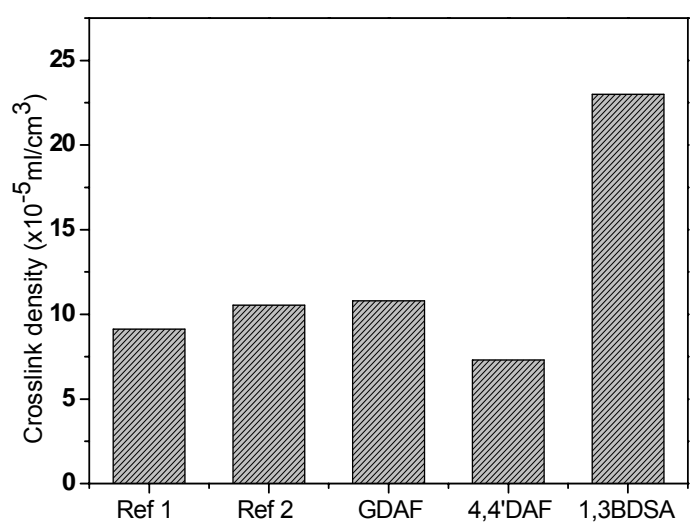

Fig. 8.3: Crosslink density of the EPDM phase

The crosslink densities of the rubber phase, determined using the equilibrium swelling test, are given in Fig 8.3. The crosslink densities of the di-azidoformate cured TPVs are in the same range as the references in spite of the higher torque during mixing. With no crosslink density difference, the higher torques observed during di-azides vulcanization may be considered as an indication that, if the iPP degradation would occur, it happens to a much smaller extent compared to peroxide curing. Degradation of the poly(propylene) by $\beta$-scission is well known to occur during free radical reactions and is the main issue for peroxide cured TPVs. The 1,3BDSA results in a very high crosslink density which is more than double compared to the peroxide/coagent combination. The high torque generated during the $1,3 \mathrm{BDSA}$ reaction is therefore most likely caused by the high crosslink density of that sample. The value is also much higher compared to the TPVs cross-linked with the two di-azidoformates. In the static 
conditions, the crosslink density of 4,4 'DAF vulcanizates was lower compared to the samples vulcanized with the other two di-azides. However, the performance of $1,3 \mathrm{BDSA}$ and GDAF in cross-linking of the thermoset EP(D)M compounds was practically the same. The significant difference in crosslink density of the EPDM phase of the TPVs is thus most like caused by a high processing temperature. As mention above, in the static condition, vulcanization of di-azidoformate compounds was carried out at $150^{\circ} \mathrm{C}$, while the TPVs process temperature is above $180^{\circ} \mathrm{C}$. The fast decomposition of di-azidoformate compounds at those conditions may limit their dispersion in the iPP/EPDM blend. The sulfonyl azides have higher decomposition temperatures and the static vulcanization of EPDM with 1,3BDSA was performed at $180^{\circ} \mathrm{C}$.

The mechanical properties of the investigated TPVs confirmed the good di-azide performance. Fig 8.4 shows the stress-strain properties and Fig. 8.5 the Shore A hardness of the samples vulcanized with various curatives. Compared to the TPV sample vulcanized with the peroxide alone all three di-azides provide improved tensile properties. The stress-strain curves of TPVs cured with two di-azidoformates and the peroxide/coagent reference largely overlap with each other. Out of these three curatives, 4,4'DAF gives the highest tensile strength as well as elongation at break while GDAF cured TPVs are comparable with the peroxide/coagent reference. The highest tensile strength was obtained with 1,3BDSA which exceeds the references significantly, although the elongation at break was the lowest from all samples. The modulus at $100 \%$ elongation, similar to the crosslink density, was much higher for the di-sulfonyl azide than for any other sample. The hardness of the di-azide cured TPVs is higher compared to the peroxide as well as the peroxide/coagent reference, and again the highest value was obtained for 1,3BDSA.
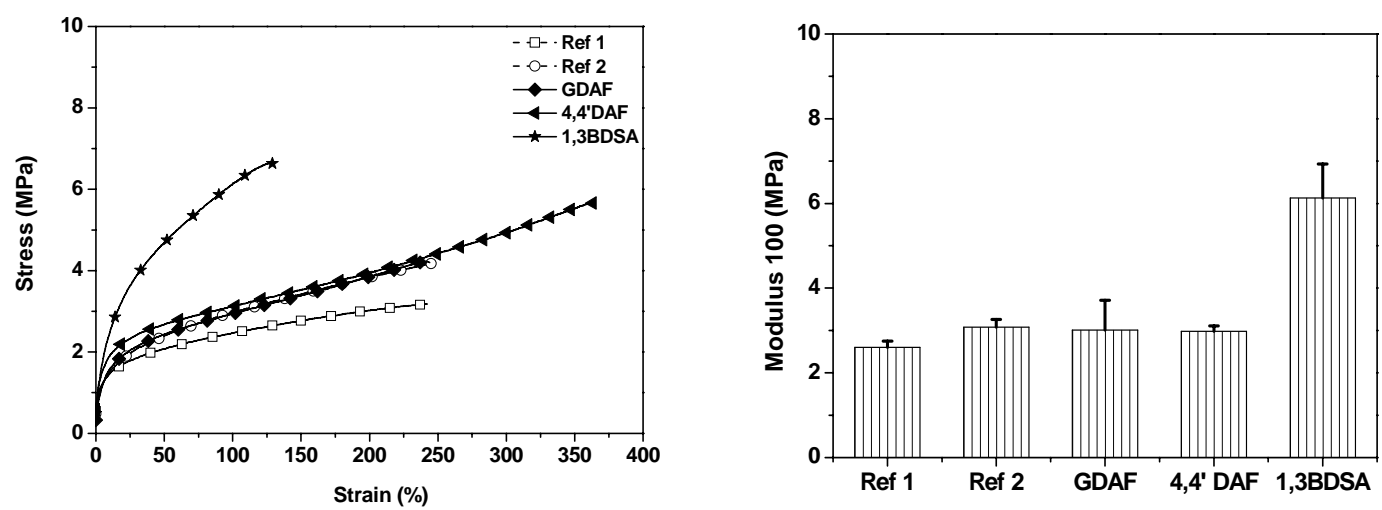

Fig. 8.4: Tensile data for TPVs cured with various di-azides and peroxide (a): stress-strain curves, and (b): modulus at $100 \%$ elongation 


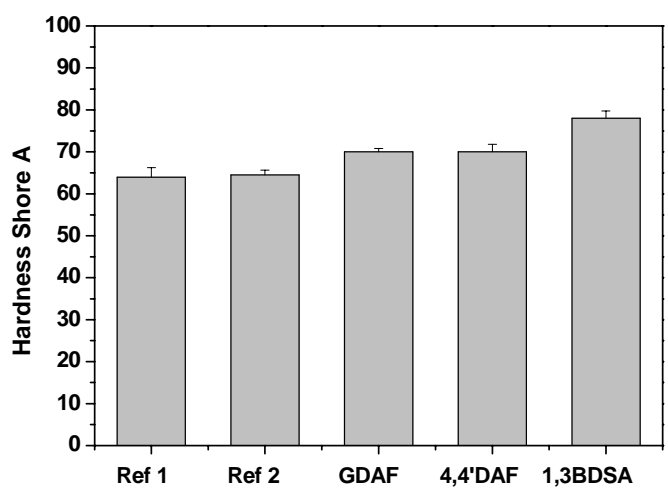

Fig. 8.5: Shore A hardness obtained with various di-azides and peroxide

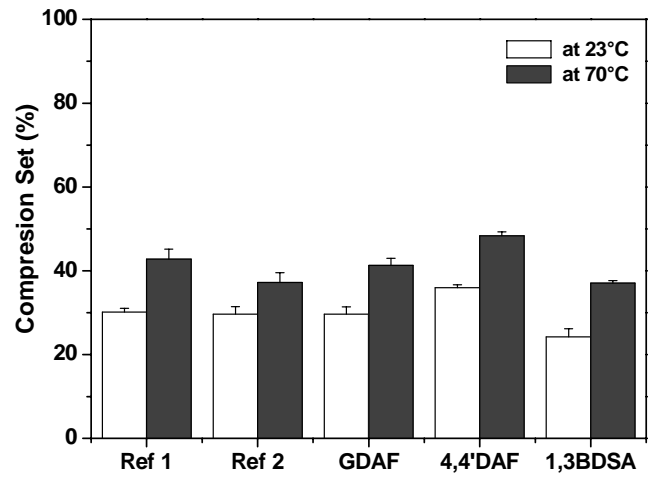

Fig. 8.6: Compression sets at 23 and $70{ }^{\circ} \mathrm{C}$ obtained with various di-azides and peroxide

Fig. 8.6 shows the compression set values obtained with di-azides as well as with the peroxides. At $70{ }^{\circ} \mathrm{C}$ the 1,3BDSA cured TPV has the same compression set as the sample cured with the peroxide/coagent combination, while at room temperature the value is even lower. The compression sets measured for the two di-azidoformates, especially the 4,4 'DAF, are not as good. The GDAF performance is comparable to the reference TPV cured with peroxide alone.

The processability of the materials was estimated by the simple film pressing test. The quality of the films produced by heating and pressing small TPV pieces was judged visually, making this test rather subjective. The data listed in Fig. 8.7 prove however its significance. Both films produced from di-azidoformates cured TPVs were of better quality compared to the peroxide/coagent reference. However, the processability of the $1,3 B D S A$ cured TPV is extremely poor. It is known from the mechanistic study described in Chapter 7 , that the sulfonyl azides have a very strong preference to react with secondary carbon atoms. Additionally, in the prepared blend the EPDM and oil loadings are considerably higher compared to the iPP content. Nevertheless, at this point it can not be fully excluded that cross-linking happens also in the iPP phase. ${ }^{12,13}$ Where all samples were creamy white, the 1,3BDSA cured TPV showed brownish discoloration. As demonstrated also in other studies, a certain discoloration is common for the sulfonyl azide reaction, although the intensity differs for various compounds. ${ }^{14,15}$ The brown color is linked with the low solubility of the polar azide compounds in a polymer matrix and is most probably the result of the sulfonyl azide molecules reacting with each other. Generally, the discoloration is more intense with higher azide concentrations. 


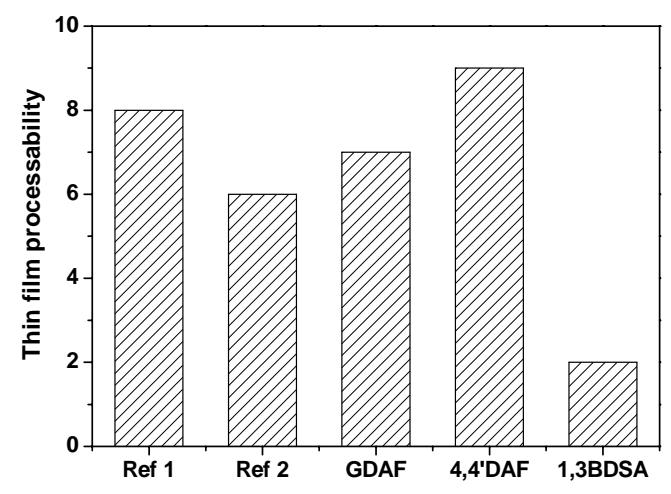

Fig. 8.7: Thin film processability: samples judged visually in ranking 0-10

\subsubsection{TPVs cured with varying concentrations of 1,3BDSA}

\section{Physical properties}

Due to the high crosslink density of the 1,3BDSA cured TPV, further evaluation of this system was carried out by progressively lowering the di-azide content: recipes III-VI, Table 8.1. The mixing torques measured during the cross-linking process are shown in Fig 8.8. Rather surprisingly, the lower di-sulfonyl azide loading the higher the torque increase. With high 1,3BDSA loading the torque developed very quickly, but decreased as the mixing progressed. With lower di-azide contents the developed torques were maintained until the end of the mixing and no drop was observed. The difference between 1,3BDSA and peroxide curing was tremendous. The mixing torques measured for the lowest di-azide content was more than four times higher then the reference values.

As discussed above for the 12.4 (mmol/100 g EPDM) 1,3BDSA-content, the samples undergo a certain brownish discoloration and become dark compared to the creamy white references and di-azidoformates cured TPVs. When $6.2 \mathrm{mmol}$ of 1,3BDSA was applied much less discoloration was observed. At lower di-azide contents, the color was similar to peroxide cured references. 


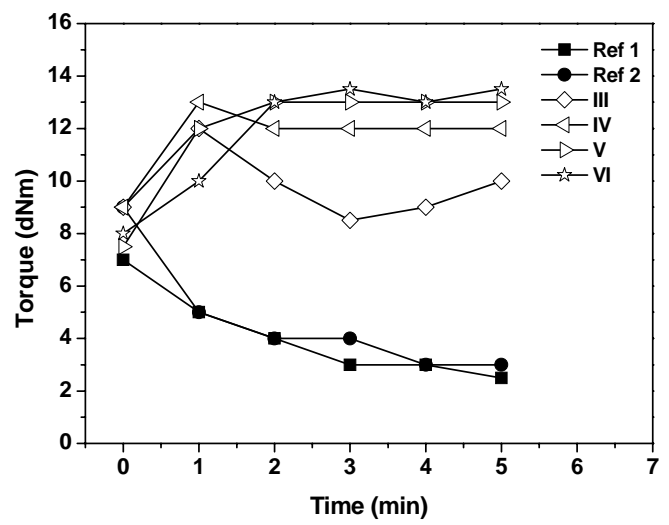

Fig. 8.8: Changes in mixing torques with varied $1,3 B D S A$ contents

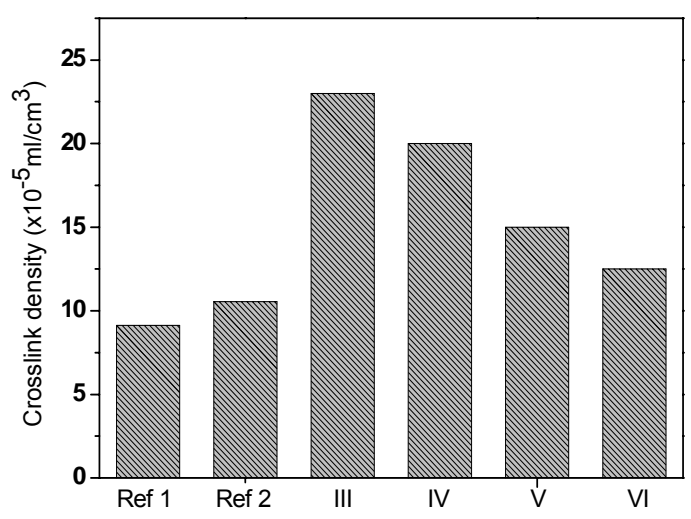

Fig. 8.9: Crosslink density of the EPDM phase with varied 1,3BDSA contents

The crosslink density of the rubber phase decreases with lower 1,3BDSA contents. However, even with the lowest loading, the crosslink density remains higher than for the peroxide/coagent combination, as shown in Fig. 8.9. It should be emphasized at this point, that the curing recipe of the peroxide/coagent reference TPV contains 9.3 $\mathrm{mmol}$ of peroxide and $5.9 \mathrm{mmol}$ of coagent, while only $1.5 \mathrm{mmol}$ of the di-azide already reaches an even higher crosslink density.

Figs. 8.10 (a), (b) and (c) show the tensile strength, elongation at break and modulus $100 \%$ of the TPVs cured with varied 1,3BDSA content. Generally, cross-linking of the rubber phase in the TPVs is essential and only small amounts of curatives already provide a large improvement in tensile properties. At high curatives contents the properties of the conventionally cured TPVs with phenolic resin, peroxide or sulfur, change very little and usually there is no clear optimum crosslink density. One study indicated that the tensile strength of the TPV improved continuously with the crosslink density of the rubber phase ${ }^{16}$, while the other suggested an upper limit of the amount of curatives that must be added ${ }^{17}$. In that respect the present effect of the crosslink density on the mechanical properties is rather surprising. As demonstrated earlier, the tensile strength obtained with high di-sulfonyl azide loading already considerably exceeded both references. However even more significant is that the tensile strength further increases when the 1,3BDSA amount is decreased. It is much unexpected how little of this di-azide is required in order to obtain a good quality TPV material. Compared to the peroxide curing, the 1,3BDSA gives a lower elongation at break. Nevertheless, the elongations are larger with 1.5 and $3 \mathrm{mmol}$ than with higher di-azide contents. The modulus at $100 \%$ elongation is significantly higher for the 1,3BDSA cured TPVs compared to both references, independent of the azide concentration. 
(a)

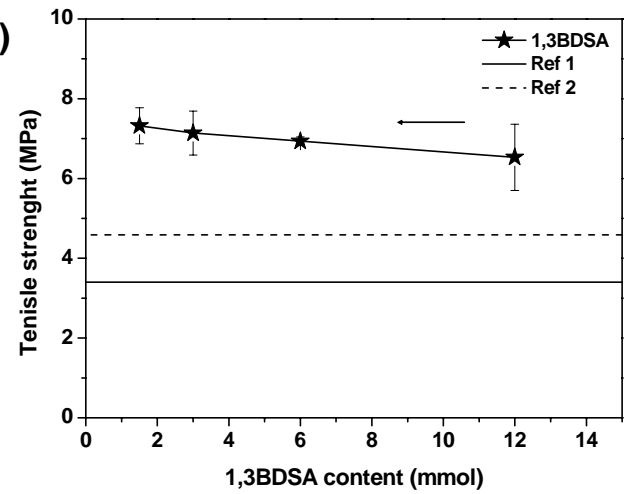

(c)

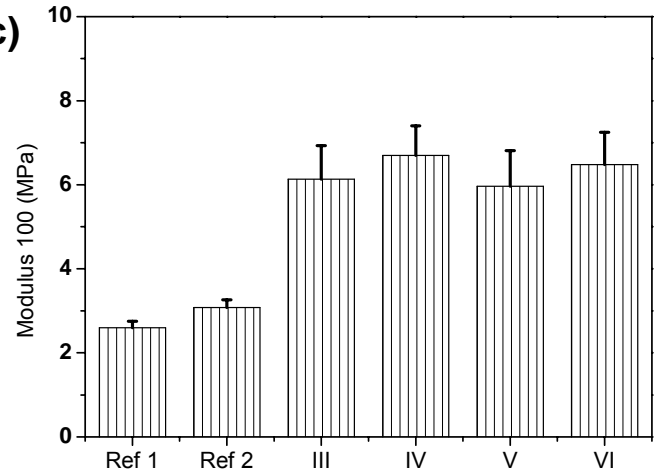

(b)

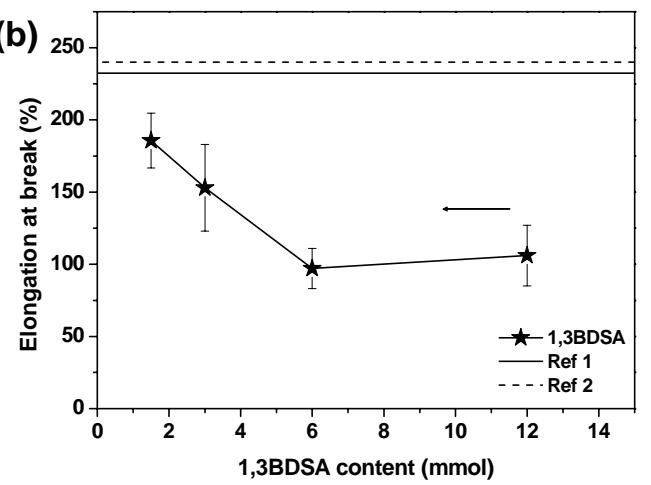

Fig. 8.10: Tensile data for TPVs cured with varying 1,3BDSA contents (a): tensile strength, (b): elongation at break and (c): modulus at $100 \%$ elongation

Hardness of the TPVs decreases with reduced 1,3BDSA contents: Fig. 8.11. However, even with the lowest loading it remains higher compared to the peroxide curing. Fig. 8.12 shows the compression sets of samples cured with varied di-azide contents, measured at room temperature and at $70{ }^{\circ} \mathrm{C}$. At an elevated temperature of $70{ }^{\circ} \mathrm{C}$, the compression sets are constant, within the range of the standard deviation, and similar to the peroxide/coagent reference. At room temperature the compression set of the TPV cured with the highest 1,3BDSA content, as already mentioned above, was lower compared to the peroxide/coagent curing system. When less curative was used, the compression set values tend to rise slightly and with the lowest di-azide loading it becomes equal to the performance of the peroxide/coagent combination. 


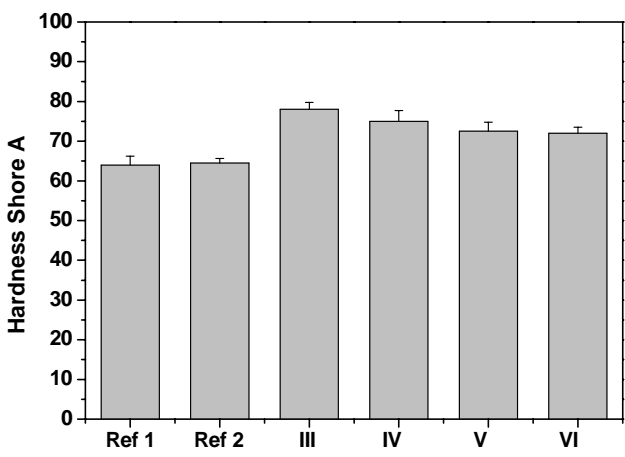

Fig. 8.11: Shore A hardness obtained with varied 1,3BDSA contents

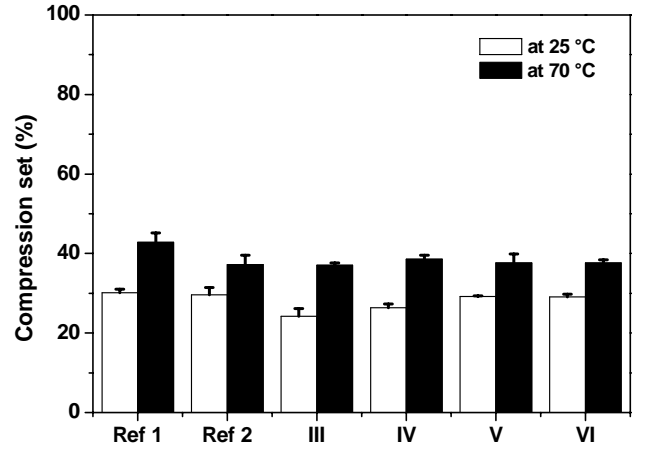

Fig. 8.12: Compression sets obtained with varied $1,3 B D S A$ contents

Not only did the strength of the produced TPVs improve, but also their processability increased when less 1,3BDSA was applied. Fig. 8.13 shows that, where with high disulfonyl azide content the quality of the produced film was judged only as $2-3$, with low loadings it improved to around 7-9. This means that the processability of these materials is expected to be equal, if not better than the peroxide/coagent combination. In general, within the range of tested concentrations, the physical properties like tensile strength, elongation at break and processability improved until very acceptable values when lowering the 1,3BDSA content. The crosslink density, hardness and compression sets are still higher/better or at least equal to the peroxide/coagent reference. It is not excluded that an even smaller amount of 1,3BDSA could be applied, while still giving very good properties.

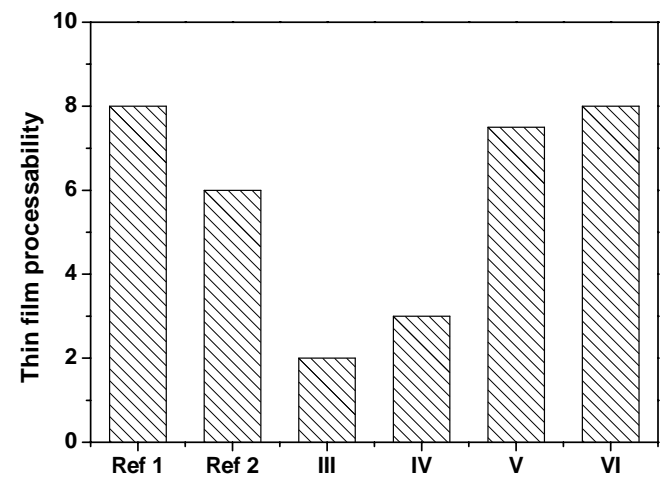

Fig. 8.13: Thin film processability: samples judged visually in ranking 0-10

\section{Morphology}

Fig. 8.14 and Figs. 8.15 (a)-(b) show the STEM images of the TPVs cured with the highest and the lowest 1,3BDSA concentrations as well as with the peroxide/coagent combination. The darker regions in the pictures represent the EPDM phase while the brighter regions are the iPP phase. The white spots, visible here and there, are 
inorganic components: talcum and $\mathrm{ZnO}$. Clearly, for the highest di-sulfonyl azide loadings, the EPDM particles are very small and well below $1 \mu \mathrm{m}$. It was observed in an earlier work by Ellul et al. that an increase in crosslink density of the rubber phase by rising the phenolic resin curatives content caused a narrowing of the EPDM domain size distribution and corresponding increase of the PP phase size. ${ }^{19}$ The effect was however rather small and the size of EPDM particle was always above $1 \mu \mathrm{m}$. In case of 1,3BDSA cured TPVs the particle size strongly decreases at high crosslink density of the EPDM phase: Figs. 8.3 and 8.9. Another observation is that with the highest $1,3 \mathrm{BDSA}$ content the torque develops very quickly once the cross-linker is introduced, Figs. 8.2 and 8.8 , but decreases again as the mixing process proceeds. The drop is much smaller when $6.2 \mathrm{mmol}$ of the 1,3BDSA is used and with this lower concentration, the torque remains constant till the end of mixing. It may be conceived that heavily cross-linked and thus harder EPDM domains break easier during mixing, which results in a decrease of the particle size and a lowering of the torque value. Any other curing system however, does not lead to the significant reduction of the rubber particle size with increasing crosslink density. It may be suspected that in case of diazides there is an additional unique mechanism that supports the process. The explanation could be that some of the azide functionalities react with the iPP molecules acting as a coupling agent between the two phases. Even with the lowest $1,3 \mathrm{BDSA}$ content, the dark regions of the EPDM-rubber phase are clearly smaller than the reference.

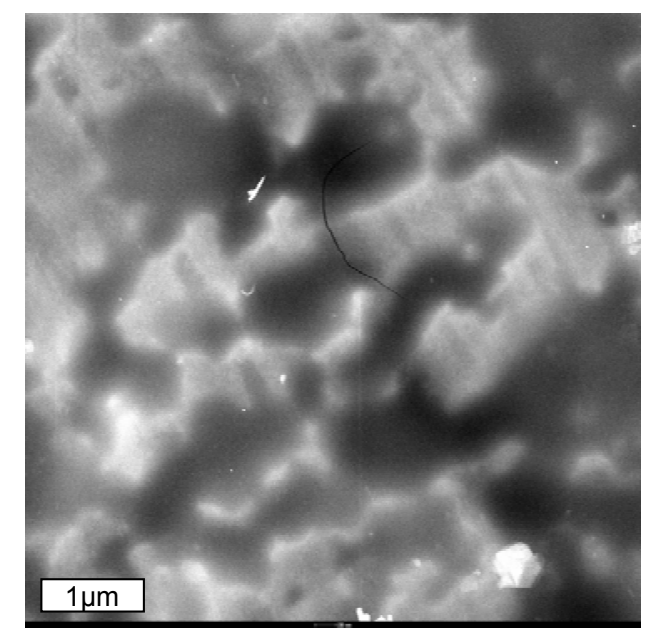

Fig. 8.14: STEM pictures of TPV cured with peroxide/coagent combination 

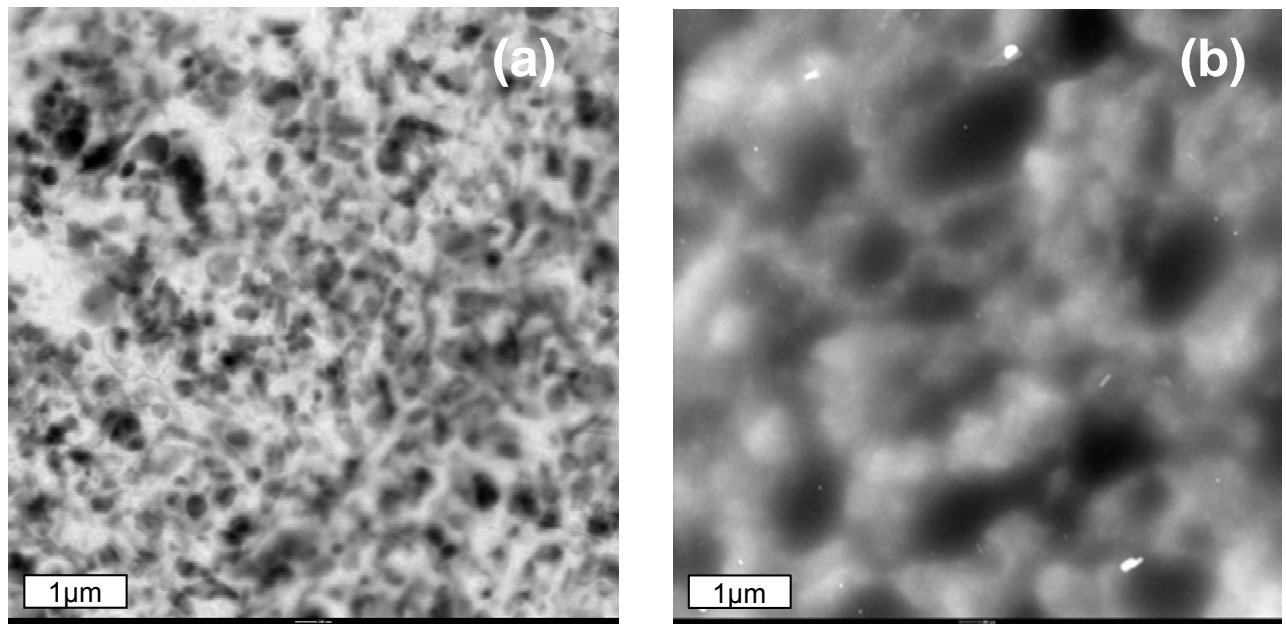

Fig. 8.15: STEM pictures of TPVs cured with (a): the highest 1,3BDSA loading (12.4 $\mathrm{mmol} / 100 \mathrm{~g}$ EPDM) and (b): the lowest 1,3BDSA loading (1.5 mmol/100g EPDM)

In Fig 8.16 and Figs. 8.17 (a)-(d) the SEM images of TPVs cured with peroxide/coagent combination and various di-sulfonyl azide amounts are shown. The sample cured with the peroxide/coagent combination is taken as reference. The most complex morphology of the fractured surface is observed for the highest 1,3BDSA content; the SEM image shows multiple layers and ditches. The images become smoother, as the amount of the di-sulfonyl azide is lowered. Fig. 8.15 (e) shows the TPV cured with $1.5 \mathrm{mmol}$ of the 1,3BDSA: the matrix is homogenous and the EPDM particles can be nicely distinguished, the layers and ditches have completely disappeared.

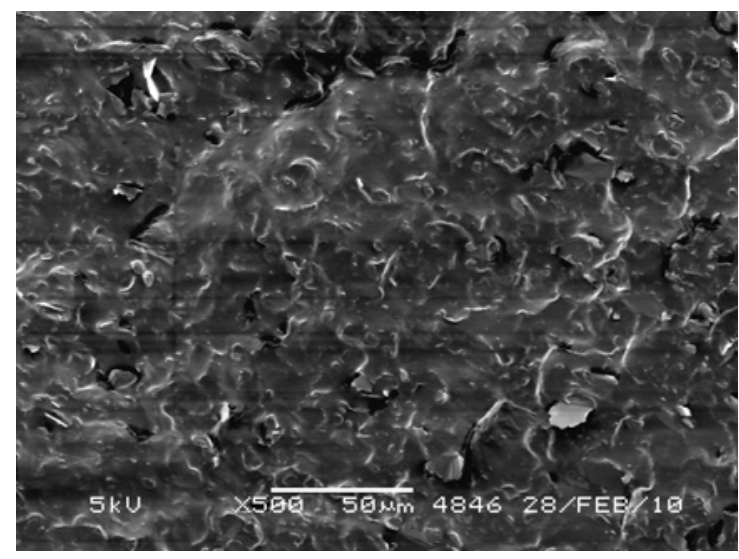

Fig. 8.16: SEM images of TPV cured with peroxide/coagent combination 

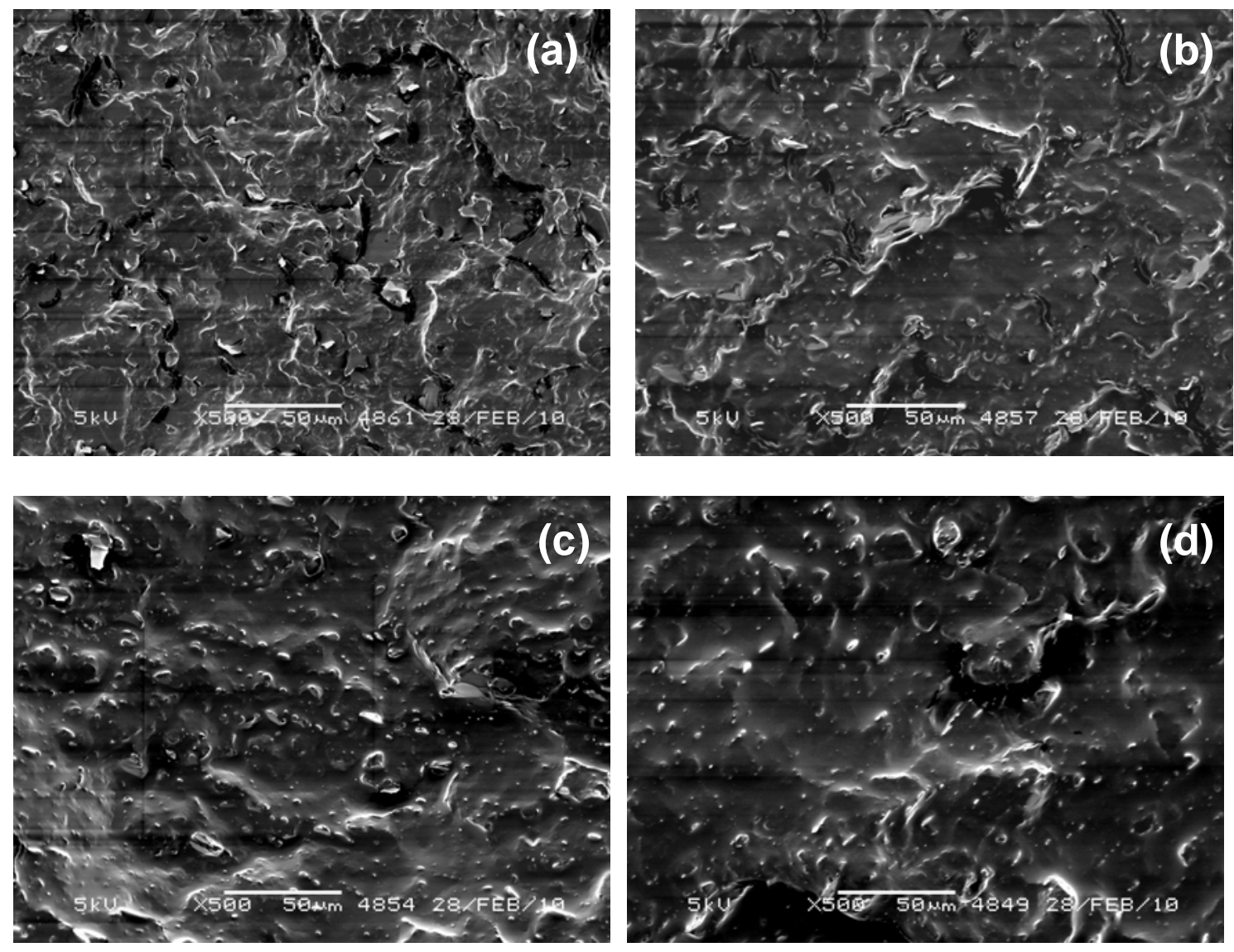

Fig. 8.17: SEM images of TPVs cured with (a)-(d) 1,3BDSA loading 12.4, 6.2, 3.1 and 1.5 (mmol/100g EPDM)

It is noteworthy that for the 1,3BDSA cured TPVs the assumption that sub-micrometer $(<1 \mu \mathrm{m})$ rubber particles would provide better properties than particles in the range 1-5 $\mu \mathrm{m}$ is not confirmed. According to the data obtained, rubber particles in the size around $1 \mu \mathrm{m}$ correspond to the best performance. On the other hand, from the developments of TPVs it is known that rubber particles larger than $5 \mu \mathrm{m}$ result in decrease of properties again. ${ }^{6,16}$ It is worth to mention that straight blends of EP(D)M as impact modifier in iPP, without additional curatives, also spontaneously result in particle sizes of around $1 \mu \mathrm{m}$. Even more general, it is well known that impact modification of many thermoplastics with rubber shows optimal results for that rubber particle size ${ }^{18}$. Correspondingly, a too high level of cross-linking leading to smaller rubber particles results in lower properties compared to the optimum curatives dosage. The latter turned out to be surprisingly low for the di-sulfonyl azide investigated in this study.

\subsection{Conclusions}

With di-azidoformate compounds as cross-linking agents it is possible to produce good quality iPP/EPDM-based TPVs. The products show no discoloration and the properties are comparable with peroxide/coagent curing. The main disadvantage of the 
azidoformate compounds however is their low decomposition temperature, somewhat below the melting temperature of iPP, giving a very fast reaction rate during iPP/EPDM melt mixing. In that respect the di-sulfonyl azide based compounds seem more suitable. By using 1,3BDSA it is not only possible to produce TPVs with outstanding mechanical properties, but the amount of di-azide required is very small. In the range of tested concentrations, the lower the 1,3BDSA dosing the better the overall properties. Also the EPDM particles in the blend become larger, when decreasing the 1,3BDSA loading, reaching a size of around $1 \mu \mathrm{m}$ with the lowest di-azide content 1.5 (mmol/100 g EPDM), corresponding to an universal optimum particle size of rubbers used for impact modification of thermoplastic.

\subsection{References}

1. A.Y. Coran and R.P. Patel, "Thermoplastic Elastomers based on Dynamically Vulcanised Elastomer-Thermoplastic Blends", in "Thermoplastic Elastomers", G. Holden, N.R. Legge, R.P. Quirck and H.E. Schroeder (Eds.), Hanser Publishers, Munich, $2^{\text {nd }} E d$. (1996).

2. C. Koning, M. v Duin, C. Pagnoulle and R. Jerome, Prog. Polym. Sci. 23, 707 (1998).

3. J. Karger-Kocsis, "Thermoplastic Rubbers via Dynamic Vulcanisation", in "Polymer Blends and Alloys", G.O. Shonaike and G.P. Simon (Eds.), Marcel Dekker, New York (1999).

4. K. Naskar, "Dynamically vulcanized PP/EPDM Thermoplastic Elastomers", PhD thesis, University of Twente, Enschede, The Netherlands (2004).

5. F.R. De Risi, "The role of coagent in peroxide cured thermoplastic vulcanizates", $P h D$ thesis, University of Twente, Enschede, The Netherlands (2007)

6. R. I'Abee, "Thermoplastic vulcanizates: the rubber particle size to control the properties-processing balance", PhD thesis, Eindhoven University of Technology, The Netherlands (2009).

7. R.H. Terbrueggen, R.E. Drumright and T.H. Ho, W.O. Patent 0052091 (2000).

8. R.H. Terbrueggen, R.E. Drumright and T.H. Ho, U.S. Patent 6277916 (2001).

9. M.A. Lopez Manchado and J.M. Kenny, Rubber Chem. Technol., 74, 198 (2001).

10. D.S. Breslow, W.D. Willis and L.O. Amberg, Rubber Chem. Technol., 43, 605 (1970).

11. J.L. de Benito Gonzalez, L. Ibarra Rueda and L. Gonzalez Hornandez, Kautsch.

Gummi Kunstst., 43, 697 (1990).

12. J.K. Jorgensen, E. Ommundsen, A. Stori and K. Redford, Polymer, 46, 12256 (2005).

13. Q. Li and C. Tzoganakis, Int Polym Proc 22, 311 (2007).

14. D.A. Baker, G.C. East and S.K. Murhopadhyay, J. Appl. Polym. Sci., 83, 1517 (2002).

15. D.A. Baker, G.C. East and S.K. Murhopadhyay, J. Appl. Polym. Sci., 84, 1309 (2002).

16. A.Y. Coran and R.P. Patel, Rubber Chem. Technol., 53, 141 (1980).

17. M.D. Ellul, A.H. Tsou and W. Hu, Polymer 45, 3351 (2004).

18. N.G. MacCrum, C.P. Buckley and C.B. Bucknall, "Principles of polymer engineering" Oxford University Press (1988). 


\section{Appendix A}

\section{Recycling of di-azides cross-linked EPM}

\section{Summary}

It is possible, by using amine compounds, to completely de-vulcanize 4,4'DAF cross-linked EPM-rubber already at room temperature. The devulcanization process starts with extensive swelling of the rubber and it was noticed that the reaction process was faster when an amine/cyclohexane solution is applied. Although 4,4'DAF-cured vulcanizates dissolve in pure cyclohexylamine, n-butylamine acts as de-cross-linking agent only in a cyclohexane solution. The vulcanizates of the other di-azidoformate, GDAF, are not affected by any of the amines even if the cross-link density of the compounds was very low and an elevated temperature was applied. The most probable de-vulcanization mechanism is a substitution reaction between an urethane-group and an amine. The reason why the GDAFvulcanizates are not affected by the amine compounds is supposed to be a lower reactivity of its leaving group: a phenol vs. aliphatic alcohols. 


\section{Introduction}

Overall, rubbers are thermosetting materials and unlike thermoplastics they do not soften upon heating. Thus it is impossible to reshape them, even at high temperatures. The thermosets posses a three dimensional cross-linked network, what makes them far more difficult to recycle compared to thermoplastics. The most ideal way to recycle vulcanized material would be by breaking the cross-links while the polymer chains remain intact, a so called de-vulcanization process. ${ }^{1,2}$ In principle, the exclusive breakdown of the cross-links is possible only by a selective chemical treatment. In actual practice however, the recycling of sulfur cured rubber is done in a reclaiming process, using a combination of thermal and mechanical treatment, sometimes with the addition of de-vulcanization aids. The result is rupture of the rubber network by breaking down the sulfur bridges as well as the polymer chains. Both main chain and sulfur cross-link scissions occur at the same time. It can be expected that, when external energy is applied, the lower energetic sulfur-sulfur and sulfur-carbon bonds will break more easily then the carbon-carbon bonds in a polymer backbone. In literature many examples of attempts to make cross-link scission most favorable and also to prevent recombination of sulfur radicals can be found. ${ }^{3-5}$ The main problem with selective de-vulcanization of sulfur cured compounds is caused by the non-uniform structure of the cross-links which are characterized by a certain length distribution $\left(S_{x}\right.$, with $1 \geq x \leq 3)$. Chemical treatment can selectively break less energetic poly- and disulfidic cross-links, but the mono-sulfidic bonds are much more stable and require the use of very aggressive chemicals. When peroxide curing is applied, the vulcanizates are even more difficult to recycle because of the high bond strength of carbon-carbon cross-links relative to sulfur containing ones. ${ }^{2}$

\section{Experimental}

\section{Materials}

Ethylene/propylene copolymer rubber, EPM (Keltan 3200A), ethylene content 49 wt \% was kindly supplied by DSM Elastomers BV. Carbon black (N-550) was obtained form Cabot Corporation and paraffinic oil, Sunpar 150 from SunOil Corp. The co-agent: N,N'-m-phenylenebismaleimide (HVA-2, $97 \%$ ) was purchased from Acros. Dicumyl peroxide (DCP, Perkadox BC-40, $40 \%$ on carrier) was provided by Akzo Nobel.

The amines: cyclohexylamine (99\%), n-butylamine (98.5\%) and aniline (99\%) were purchased from Sigma-Aldrich. All three di-azides: GDAF, 4,4'DAF and 1,3BDSA were synthesized from the corresponding chlorides and sodium azide as described in Chapter 3. 


\section{De-vulcanization methods}

The composition of the tested EPM vulcanizates is given in Table A.1, while preparation procedures and properties are described in Chapter 4 of this thesis. The cross-linked compounds were cut into small pieces, using regular scissors. Of each vulcanizate $0.1 \mathrm{~g}$ was placed in a transparent glass ampoule containing a small magnetic stirrer and $2 \mathrm{~g}$ of various mono-amines. Three amines: cyclohexylamine, $\mathrm{n}$ butylamine and aniline were investigated as de-vulcanization agents, initially in a pure state and later on in 1:4 (w/w) cyclohexane solutions. The ampoules were sealed and the samples were left at room temperature under constant stirring.

Table A.1: Curing recipes of EPM compound

\begin{tabular}{|c|c|c|c|c|c|c|c|c|c|}
\hline \multicolumn{10}{|l|}{ Ingredients } \\
\hline EPM & 100 & 100 & 100 & 100 & 100 & 100 & 100 & 100 & phr \\
\hline Carbon Black & 60 & 60 & 60 & 60 & 60 & 60 & 60 & 60 & \\
\hline Paraff. Oil & 30 & 30 & 30 & 30 & 30 & 30 & 30 & 30 & \\
\hline GAF & - & - & 4.4 & - & - & 13.3 & - & - & $\mathrm{mmol}$ \\
\hline 4,4'DAF & - & - & - & 4.4 & - & - & 13.3 & - & \\
\hline $1,3 B D S A$ & - & - & - & - & 4.4 & - & - & 13.3 & \\
\hline DCP (40 \%) & 8.8 & 8.8 & - & - & - & - & - & - & \\
\hline HVA-2 & - & 15 & - & - & - & - & - & - & \\
\hline $\begin{array}{l}\text { Crosslink } \\
\text { density * }\end{array}$ & - & 0.42 & 0.16 & - & 0.12 & 0.42 & 0.22 & 0.40 & $\begin{array}{l}\mathrm{mmol} / \\
\mathrm{cm}^{3}\end{array}$ \\
\hline
\end{tabular}

* In some cases the crosslink density was so low that the measured values were not reliable.

\section{Results and discussion}

The main difference between azidoformate and sulfonyl azide functionalities is that the first one potentially maintains reactivity after the reaction with the polymer, Scheme A.1. Upon decomposition of the azide group the urethane formed during the azidoformate reaction contains a carbonyl group bound to a potential leaving group (OR1) and can undergo a substitution reaction upon nucleophilic attack by expelling the leaving group. The possible reaction scheme between the urethane and an amine, which is known for its nucleophilicity, is given in Scheme A.2. 


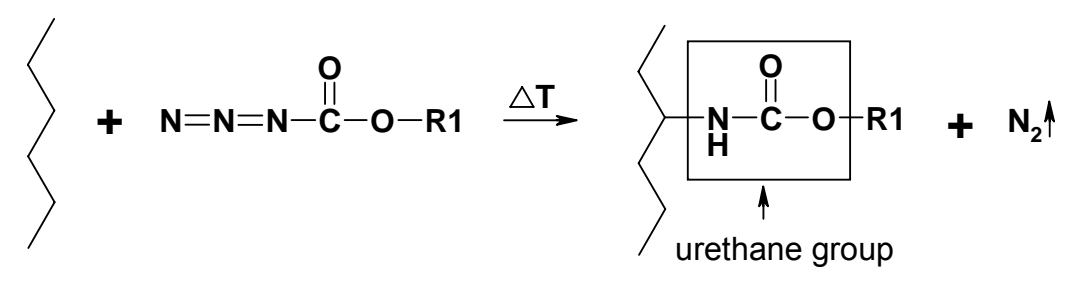

(A)

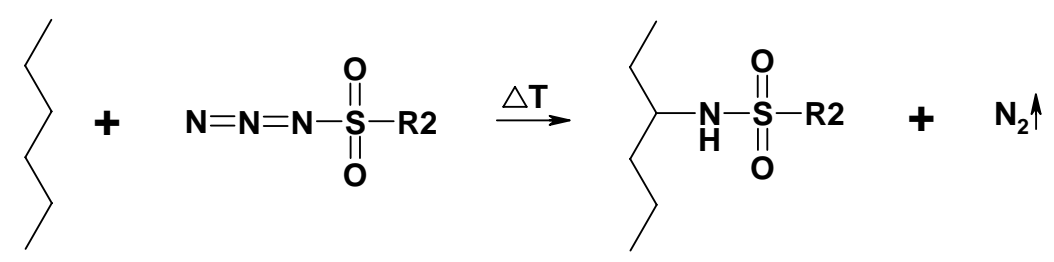

Scheme A.1: Reaction of (A) azidoformate with the formation of an urethane group; and (B) sulfonyl azide<smiles>[R1]O[14CH2]NC(=O)N[C@@H](CC)CCC</smiles>

Scheme A.2: Potential reaction between the urethane group and an amine

If indeed the urethane group is able to react with an amine compound after vulcanization has taken place, the reaction should lead to the selective breakdown of the earlier formed cross-links and therefore to de-vulcanization of the material. To determine whether the reaction actually occurs, various azidoformate and sulfonyl azide vulcanizes were cut into small pieces and immersed in different amines. The samples cured with peroxide and the peroxide/coagent combination were also included. The compositions and crosslink densities of the vulcanizates are shown in Table A1. From the investigated di-azides, 4,4'DAF is the least effective as EP(D)M curing agent and even in high quantities it results in rather low crosslink density compared to GDAF, 1,3BDSA or the peroxide/coagent combination. Therefore, EPM compounds cured with high and low di-azide concentrations were investigated.

Di-sulfonyl azides as well as peroxide vulcanization products were not expected to react with amines. Thus the fact that they were not affected by the treatment is no surprise. However, from the two di-azidoformates only 4,4'DAF seems to be reactive towards amines. It was observed that 4,4'DAF vulcanizates dissolve in cyclohexylamine already at room temperature and the required time depends on the cross-link densities. When $13.3 \mathrm{mmol}$ of 4,4'DAF was used, the dissolving time was around 48 hours, while the sample with low azide content dissolved within 24 hours. The rubber pieces immersed in cyclohexylamine first swell significantly and after that a gradual size reduction occurs while the viscosity of solvent increases. Finally, the 
vulcanizate disappears completely and the sample becomes a homogeneous and highly viscous liquid. The other two mono-amines: n-butylamine and aniline, even after prolonged stirring, did not lead to dissolution.

In another experiment, the cured compounds were immersed in an amine/ cyclohexane solution. Cyclohexane is known to be a very good solvent for EP(D)M rubbers. The de-vulcanization process starts with extensive swelling of the samples. The obtained results for the vulcanizates cured with $13.3 \mathrm{mmol}$ of di-azides are given in Table A.2.

Table A.2: Solubility of various vulcanizates in amine/cyclohexane solution

\begin{tabular}{lccc}
\hline & $\begin{array}{c}\text { Cyclohexylaminel } \\
\text { cyclohexane }\end{array}$ & $\begin{array}{c}\text { n-Butylaminel } \\
\text { cyclohexane }\end{array}$ & $\begin{array}{c}\text { Anilinel } \\
\text { cyclohexane }\end{array}$ \\
\hline GDAF* & - & - & - \\
4,4 'DAF* & $24 \mathrm{~h}$ & $24 \mathrm{~h}$ & - \\
1,3BDSA* & - & - & - \\
DCP/HVA-2 & - & - & - \\
\hline
\end{tabular}

- swelling, but no dissolution,

* di-azide contents $13.3 \mathrm{mmol}$

When a cyclohexane solution was applied, the 4,4'DAF vulcanizates reacted with both cyclohexylamine as well as n-butylamine. Moreover, it was observed that the devulcanization process occurred faster in the cyclohexylamine/cyclohexane solution then in the pure amine. The fact that 4,4'DAF vulcanizates did not dissolve in pure nbutylamine, but in the n-butylamine/cyclohexane solution, and reacted faster when the solution of cyclohexylamine is applied, suggests that extensive swelling is required for the urethane-amine reaction to occur. In this respect, it is difficult to judge why aniline does not give positive results: is it due to a potential reactivity difference between aromatic and aliphatic amines, or is it rather caused by non miscibility of the aromatic amines with the aliphatic EPM-polymer?

The sample cured with the other di-azidoformate, GDAF did not dissolve in any of the solutions even if the cross-link density was very low and elevated temperatures were applied, despite extensive swelling. The popable structures of the GDAF and 4,4'DAF cross-links after reaction with the polymer are shown in Scheme A.3.

(A)

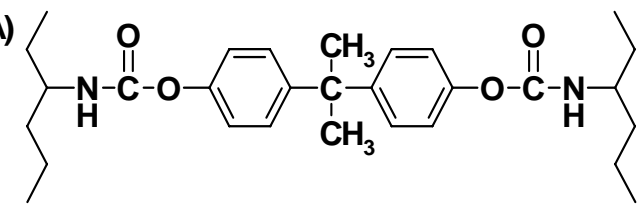

(B)

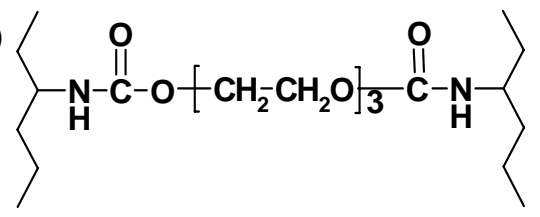

Scheme A.3: Potential crosslink structures formed by; (A) 4,4'DAF and (B) GDAF 
Supposing that for both di-azides, GDAF as well as 4,4'DAF, the azidoformate functionality reacts with a polymer in the same manner, the only difference in structures $(A)$ and $(B)$ is the bridge between the two urethane groups. It seems a logical explanation that the 4,4'DAF cured sample does react with amine, while the one cured with GDAF does not because the reactivity of the leaving group is different in both cases. It is well known that phenols are better leaving groups than aliphatic alcohols.

\section{References}

1. K.A. Dijkhuis "Recycling of vulcanized EPDM-rubber", PhD thesis, University of Twente, Enschede, The Netherlands (2008).

2. M. Verbruggen "Devulcanization of EPDM rubber", $\mathrm{PhD}$ thesis, University of Twente, Enschede, The Netherlands (2007).

3. B. Adhikari, D. De and S. Maiti, Prog. Polym. Sci. 25, 909 (2000).

4. M. Myhre and D. MacKillop, Rubber Chem. Technol. 75, 429 (2002).

5. P. Nicholas, Rubber Chem. Technol. 55, 1499, (1982). 


\section{Summary}

\section{Motivation}

The main advantage of saturated elastomers, such as EPM and EPDM over their unsaturated counter-parts is the absence of carbon-carbon unsaturation in the main polymer chain, resulting in excellent ozone and heat resistance. A consequent disadvantage of the absence of unsaturation is the lack of reactivity of these saturated elastomers. Such reactivity is desired for cross-linking, providing the typical rubber properties like high tensile strength, elasticity and resistance to solvents, and/or for further chemical functionalization of the polymer chain, which yields polymers with increased polarity or reactivity and, thus, enhanced adhesion to polar substrates or compatibility with other polar polymers. The common way to overcome the lack of reactivity for saturated polymers is by pursuing free-radical reactions, usually initiated by thermal decomposition of peroxides. Peroxide cross-linking of EP(D)M-rubbers is commercially applied and also grafting of unsaturated monomers onto $\operatorname{EP}(D) M$, for example maleic anhydride (MA), initiated by peroxides is performed on an industrial scale. A major disadvantage of peroxide-induced reactions is lack of selectivity which leads to a number of side reactions, the most common being disproportionation of two macro-radicals and $\beta$-scission which results in polymer degradation. Organic azides are a class of organic compounds that are known for their reactivity towards saturated hydrocarbons. Hence, it is interesting to study their performance in crosslinking/modification of saturated EP(D)M-rubbers. Upon heating nitrogen is split off from the azides and the resulting nitrene $\mathrm{R}-\mathrm{N}$ species insert into a $\mathrm{C}-\mathrm{H}$ bond. This reaction mechanism is expected to be completely different from the radical processes resulting from peroxides and, most importantly, no side reactions are likely to occur. The purpose of this thesis is therefore to investigate azides as viable alternatives for peroxides in cross-linking and grafting of saturated elastomers, in particular EP(D)M. 


\section{General summary of the results}

During the very first experiments, the main focus laid on designing the right di-azide compounds which would be able to effectively cross-link fully saturated EPM-rubber. In the studies described in Chapter 3, the reactivity of four different azide functionalities: alkyl azides: R- $\mathrm{N}_{3}$; aryl azides: $\mathrm{R}-\mathrm{C}_{6} \mathrm{H}_{4}-\mathrm{N}_{3}$; sulfonyl azides: $\mathrm{R}-\mathrm{SO}_{2}-\mathrm{N}_{3}$; and azidoformates: R-O-C(O)- $\mathrm{N}_{3}$, was investigated. To compare the properties of these different azide types, at least three compounds of each kind, one mono- and two diazides were prepared. It soon became very clear that the type of azide functionality has a major influence on the reaction kinetics. Where all azidoformates decompose in an almost identical temperature range, with the maximum of the DSC curves at around $150{ }^{\circ} \mathrm{C}$, the maximum for sulfonyl azides was at around $180{ }^{\circ} \mathrm{C}$. In the latter case however, a certain difference in a decomposition range between the various sulfonyl azide compounds could be observed. The aryl- and alkyl-azides have even higher decomposition temperatures, and the variation between the different compounds was greater as well. Subsequently, significant differences in reactivity towards EPM were observed between the various azide types. The alkyl-azides are generally not reactive towards saturated polymer chains, most likely due to very quick rearrangement reactions. Di-aryl azides give some, though unsatisfactory, cross-linking. However, excessive formation of porosity in the samples makes them unsuitable for vulcanization purposes. Di-sulfonyl azides and di-azidoformates are the most effective as curing agents, although the performance varies significantly between the particular di-azides tested.

Based on the data obtained in Chapter 3, the three best performing di-azides, two diazidoformates: 4,4'-isopropylidenediphenyl azidoformate (4,4'DAF) and tri(ethylene glycol)-di(azidoformate) (GDAF) and one di-sulfonyl azide: 1,3-benzenedisulfonyl azide (1,3BDSA), were selected for further study. In Chapter 4, their interactions with oil and the effect of di-azides content on vulcanization kinetics as well as on the mechanical properties were investigated. All studies were performed using EP(D)Mrubbers. The di-azides/oil interaction was investigated by comparing the properties of vulcanizates with increasing oil contents. It was observed that the efficiency of the diazide performance is similar to that of a peroxide/coagent combination and by far higher than for pure peroxide curing. For both azidoformate and sulfonyl azide functionalities, the optimum properties were reached at a concentration of 11 and 6.6 mmol (per 100 parts of rubber) for EPM and EPDM, respectively. Except for the compression sets, the properties of GDAF and 1,3BDSA vulcanizates exceed the performance of a peroxide/coagent curing system used as a reference. The reaction 
rate and activation energy, of the di-sulfonyl azide: 1,3BDSA, is significantly different in EPM and EPDM, while the di-azidoformates, especially GDAF, have similar kinetic in all compounds. The influence of carbon black and paraffinic oil, on the di-azides reaction kinetics is rather small and varies depending on the type of di-azide and rubber.

The use of coagents is very important during peroxide cross-linking. Especially for saturated elastomers, like EP(D)M where no or only a small amount of carbon-carbon double bonds is available, the addition of coagents is necessary in order to achieve a sufficient cross-linking efficiency. Although it was assumed beforehand that the diazides follow different curing mechanisms than peroxides, it seemed nevertheless interesting to investigate whether a coagent would have a similar positive effect on diazide curing as well. The study described in Chapter $\mathbf{5}$ shows the effects which the most common coagents have on di-azide curing. It is shown that a small addition of HVA-2 or sulfur to a di-azidoformate cross-linking system increases the cross-link efficiency. However, this effect is only very limited and cannot be compared to the large role of coagents in peroxide vulcanization. In the case of the di-sulfonyl azide: $1,3 \mathrm{BDSA}$, all tested additives caused only a reduction of the properties.

In Chapter 6 mono-azide compounds are tested as carriers of functional groups for grafting onto highly un-polar, fully saturated EPM-rubber. Three mono-azidoformates are investigated: phenylazidoformate (PhAF), benzyl azidoformate (BAF) and 4metoxybenzyloxycarbonyl (M-BAF) and two mono-sulfonyl azides: phenylsulfonyl azide (PhSA) and 4-acetamidobenzenesulfonyl azide (A-PhSA). The mono-azide/EPM reaction was carried out by reactive mixing, which was demonstrated to be very efficient. Subsequently, the properties of the treated polymer and the efficiency of the azide reaction were determined. Overall, the present work demonstrated that the azide-reaction is a powerful tool to graft various chemical groups onto the EPM polymer. The main issue seems to be the compatibility between rubber and the azide compound, once the structure of the latter becomes more complex. Simple phenyland benzyl-azides are very well soluble in EPM already at room temperature and their grafting efficiency is very high. However, the compatibility decreases once a complex second functional group is introduced; A-PhSA containing a polar acetamido-group is no longer soluble in EPM and subsequently does not react with EPM.

Study aimed to reveal the reaction mechanism between azidoformate/sulfonyl azide functionalities and saturated hydrocarbons are described in Chapter 7. In this investigation, the polymeric chains are substituted by a low molecular weight model hydrocarbon, 4-methylheptane, making the reaction mixture much easier to analyze by means of modern instrumental techniques. GC/MS analysis of the mono-azide reaction products clearly shows that the reaction mechanisms of the two azide types are quite different. The SA-functionality has a strong tendency to react with any 
secondary carbon while the AF-functionality seems to be much more selective and prefers to react with only the secondary carbon atom next to a tertiary carbon or with the tertiary carbon atom itself.

LC/MS analysis of the di-azides reaction mixture confirmed that the main products of the 1,3BDSA and GDAF reactions are cross-linked structures, consisting of two model hydrocarbon molecules and the azide bridge. A cross-linked product of the 4,4'DAF reaction could not be identified, most probably due its large polarity difference with 4methylheptane and consequently low solubility. Generally, the phenomena observed with the model compound vulcanization studies confirmed the observations on crosslinking of the real rubber compounds in the previous chapters.

The same three di-azides which proved to be effective curing agents for EPDM under static conditions were applied to produce iPP/EPDM-based dynamically vulcanized thermoplastic elastomers (TPV) in Chapter 8. Their performance was compared with TPVs cured with peroxides, alone and in combination with coagents. With respect to the required processing conditions of the investigated TPVs, the reaction temperatures of the sulfonyl azides make them suitable curing agents. Using 1,3BDSA it was not only possible to produce TPVs with outstanding mechanical properties, but the amount of di-azide required was surprizingly small. The lower the 1,3BDSA dosing, the better the overall properties. Also the EPDM particles in the blend become larger, reaching a size of around $1 \mu \mathrm{m}$ with the lowest di-azide content tested. The di-azidoformate compounds also produce good quality iPP/EPDM-based TPVs. The main disadvantage of the di-azidoformate however is their low decomposition temperature, somewhat below the melting temperature of iPP, giving a very fast reaction rate during iPP/EPDM melt processing.

Finally, a series of short experiments, which proved that some of the di-azidoformate vulcanizates can be completely de-vulcanized are described in Appendix A. 


\section{Samenvatting}

\section{Motivering}

Het grootste voordeel van verzadigde elastomeren, zoals EPM en EPDM, ten opzichte van hun onverzadigde tegenhangers is de afwezigheid van koolstof-koolstof dubbele bindingen in de polymere hoofdketen. Dit resulteert in een uitstekende bestendigheid tegen ozon- en hitte-veroudering. Het ontbreken van zulke onverzadigde bindingen resulteert echter in gebrek aan reactiviteit van deze verzadigde elastomeren. Deze reactiviteit is gewenst voor de vernettingsreactie: de vulkanisatie waaraan het materiaal z'n typische rubber eigenschappen ontleent, zoals treksterkte, elasticiteit en onoplosbaarheid in oplosmiddelen. Daarnaast kan de polymere keten chemisch gemodificeerd worden om de polariteit en reactiviteit te verhogen, om bijvoorbeeld de hechting te verbeteren aan polaire substraten of andere polymeren. De gebruikelijke oplossing voor het gebrek aan reactiviteit bij verzadigde polymeren is de toepassing van vrije radicaal reacties. Vrije radicalen worden meestal geïnitieerd door thermische ontleding van peroxides. Peroxides worden commerciëel toegepast voor het vernetten van $E P(D) M$ rubber. Ook het chemisch binden van onverzadigde monomeren aan $\mathrm{EP}(\mathrm{D}) \mathrm{M}$, bijvoorbeeld maleinezuur anhydride (MA), door middel van peroxides wordt industriëel toegepast. Een groot nadeel van peroxide-geïnitieerde reacties is het gebrek aan selectiviteit. Dit leidt tot een groot aantal nevenreacties. De meest voorkomende nevenreacties zijn disproportionering van twee macro-radicalen en $\beta$ splitsing, wat leidt tot polymeer-degradatie.

Organische azides behoren tot een klasse organische verbindingen bekend om hun reactiviteit met verzadigde koolwaterstoffen. Om die reden is het interessant om hun mogelijkheden te bestuderen voor het vernetten en modificeren van verzadigde EP(D)M rubbers. Wanneer azides verhit worden, ontstaat stikstof en de resulterende nitreen $\mathrm{R}-\mathrm{N}$ verbindingen kunnen koppelen aan een $\mathrm{C}-\mathrm{H}$ binding. Het mechanisme van deze reactie is vermoedelijk totaal anders dan de radicaalreacties van peroxides. Bovendien is de verwachting dat er geen nevenreacties zullen plaatsvinden. Om deze 
redenen is het doel van het onderzoek, zoals beschreven in dit proefschrift, azides te onderzoeken als mogelijke alternatieven voor peroxide vernetting en voor enting van verzadigde elastomeren, in het bijzonder EP(D)M.

\section{Algemene samenvatting van de resultaten}

Bij de eerste experimenten heeft de nadruk gelegen op het ontwikkelen van de juiste di-azide verbindingen, die mogelijk in staat zouden zijn om volledig verzadigde EPM rubber te vernetten. In hoofdstuk 3 wordt het onderzoek beschreven naar vier verschillende azide-functionaliteiten: alkyl azides: $\mathrm{R}-\mathrm{N}_{3}$; aryl azides: $\mathrm{R}-\mathrm{C}_{6} \mathrm{H}_{4}-\mathrm{N}_{3}$; sulfonyl azides: $\mathrm{R}-\mathrm{SO}_{2}-\mathrm{N}_{3}$; en azidoformaten: R-O-C(O)- $\mathrm{N}_{3}$. Om de eigenschappen te vergelijken tussen deze verschillende azide-typen, werden minstens drie varianten van elk soort bereid: één mono- en twee di-azides. Het werd al snel duidelijk dat het type functionaliteit een grote invloed heeft op de reactiekinetiek. Alle azidoformaten braken af bij een vergelijkbare temperatuur van rond $150{ }^{\circ} \mathrm{C}$, bepaald door middel van de maxima van de DSC curves. Het maximum voor sulfonyl azide lag rond $180^{\circ} \mathrm{C}$. In het laatste geval waren echter verschillen waar te nemen tussen de verschillende verbindingen. De aryl- en alkyl-azides hadden nog hogere reactie-temperaturen, en de verschillen tussen de onderscheiden verbindingen waren ook groter. Daarnaast zijn significante verschillen waargenomen tussen de azide-typen in hun reactiviteit met EPM. De alkyl-azides reageren over het algemeen niet met EPM. Waarschijnlijk komt dit door zeer snelle reorganisatiereacties. De di-aryl azides vernetten EPM in enige mate, maar niet voldoende. Bovendien ontstaan hiermee buiten-proportioneel poreuze monsters, wat deze azides ongeschikt maakt voor vulkanisatie doeleinden. De disulfonyl azides en di-azidoformaten zijn het meest effectief als vernettingsreagentia. Wel verschillen de prestaties tussen de afzonderlijke diazides nogal sterk.

Gebaseerd op de gegevens uit hoofdstuk 3, zijn drie di-azides met de beste prestaties gekozen voor verder onderzoek. Dit betreft twee di-azidoformaten: 4,4'isopropylideendiphenyl azidoformaat (4,4'DAF) en tri(ethyleen glycol)-di(azidoformaat) (GDAF), en een di-sulfonyl azide: 1,3-benzeendisulfonyl azide. In hoofdstuk 4 wordt hun interactie met olie onderzocht, samen met het effect van di-azide gehalte op de vernettingskinetiek en de resulterende mechanische eigenschappen. Alle studies zijn uitgevoerd met EP(D)M rubbers. De interactie tussen de di-azides en olie is onderzocht door de eigenschappen te vergelijken van vulkanizaten met toenemende olie-gehaltes. De effectiviteit van de di-azides bleek vergelijkbaar met die van een peroxide/coagent combinatie en veel beter dan die van peroxide alleen. Voor zowel de azidoformaat als voor de sulfonyl azide functionaliteiten werden optimale eigenschappen bereikt bij concentraties van $11 \mathrm{mmol}$ (per 100 delen rubber) voor 
EPM en 6,6 voor EPDM. Met uitzondering van de compression set, overstegen de eigenschappen van de GDAF en de 1,4BDSA vulkanisaten die van de peroxide/coagent combinatie.

De reactiekinetiek, uitgedrukt in reactiesnelheid en activeringsenergie, van de disulfonyl azide: $1,3 B D S A$ is totaal anders wanneer het gebruikt wordt in EPM dan in EPDM. De di-azidoformaten daarentegen, vooral GDAF, lieten vergelijkbare reactiekinetiek parameters zien in alle rubber compounds. De invloed van roet en parafinische olie op de di-azide reactiekinetiek is vrij klein en varieert afhankelijk van het type di-azide en rubber.

Het gebruik van coagentia is erg belangrijk bij peroxide vernetting. Vooral voor verzadigde rubbers, zoals EP(D)M waarin geen of bijna geen koolstof-koolstof dubbele bindingen voorkomen, is de toevoeging van coagentia noodzakelijk om een voldoende effectieve vernetting te verkrijgen. Ook al werd op voorhand aangenomen dat diazides een ander vernettingsmechanisme volgen, leek het toch interessant om te onderzoeken of coagentia vergelijkbare positieve effecten vertonen in combinatie met di-azides. De studie beschreven in hoofdstuk 5 laat de effecten zien die de meest gebruikte coagentia hebben op het di-azide vernettingsproces. Zo wordt aangetoond dat bij een kleine toevoeging van HVA-2 of zwavel de vernettingseffectiviteit vergroot wordt. Dit effect is echter maar heel gering en kan niet worden vergeleken met de grote rol die coagentia spelen bij peroxide vulkanisatie. In het geval van de di-sulfonyl azide: 1,3BDSA, veroorzaakten alle geteste additieven zelfs een reductie in eigenschappen.

In hoofdstuk 6 zijn mono-azides getest als dragers voor functionele groepen om deze te binden aan het zeer apolaire, volledig verzadigde EPM rubber. Drie monoazidoformaten zijn onderzocht: phenylazidoformaat (PhAF), benzyl azidoformaat (BAF) en 4-metoxybenzyloxycarbonyl (M-BAF) en twee mono-sulfonyl azides: phenylsulfonyl azide (PhSA) en 4-acetamidobenzeensulfonyl azide (A-PhSA). De mono-azide/EPM reactie werd uitgevoerd door middel van reactieve menging; dit bleek erg efficiënt te werken. Vervolgens werden de eigenschappen van het behandelde polymeer en de efficiëntie van de azide reactie bepaald. Het werk toonde aan dat de azide-reactie een krachtig middel is om verschillende chemische verbindingen aan een EPM polymeer te koppelen. De voornaamste vraag bleek de compatibiliteit te zijn tussen het rubber en de azide verbinding, zodra de structuur van het azide complexer werd. Eenvoudige phenyl- en benzyl-azides zijn bij kamertemperatuur al goed oplosbaar in EPM en hun effectiviteit is erg hoog. De compatibiliteit neemt af zodra een tweede complexe functionele groep wordt geïntroduceerd: A-PhSA dat een polaire acetamido-groep bevat, is niet langer oplosbaar in EPM en reageert daarom ook niet met EPM. 
Een studie naar het reactiemechanisme tussen azidoformaat/sulfonyl-azide functionaliteiten en verzadigde koolwaterstoffen met behulp van model vulkanisatie is beschreven in hoofdstuk 7. In dit onderzoek zijn de polymeerketens vervangen door een model koolwaterstof met een laag molecuulgewicht, 4-methylheptaan, welke het reactiemengsel veel eenvoudiger maakt om te analyseren met behulp van moderne instrumentele technieken. GC/MS analyse van de mono-azide reactieproducten laat zien, dat de reactiemechanismes van de twee azide-types duidelijk verschillen. De sulfonyl-azide functionaliteit heeft een sterke neiging om met elk secundaire koolstof atoom te reageren, terwijl de azidoformaat functionaliteit meer selectief is en een voorkeur heeft om te reageren met een secundair koolstof atoom, dat zich naast een tertiair koolstof atoom bevindt of met het tertiaire koolstof atoom zelf. LC/MS analyse van het di-azide reactiemengsel bevestigt dat de voornaamste producten van de reacties met 1,3BDSA en GDAF vernette structuren zijn. Deze bestaan uit twee model koolwaterstof-moleculen met een azide brug. Een vernet product van de reactie van 4,4'DAF kon niet worden geïdentificeerd, waarschijnlijk vanwege zijn grote polariteitsverschil met 4-methylheptaan en de lage oplosbaarheid als gevolg daarvan. Over het algemeen bevestigen de waargenomen fenomenen uit de model compound vulkanisatie studie de waarnemingen met de echte rubber compounds in de voorgaande hoofdstukken.

In hoofdstuk 8 werden dezelfde drie di-azides, die effectieve vernettingsreagentia bleken te zijn voor EPDM rubber onder statische condities, toegepast om iPP/EPDM gebaseerde dynamisch gevulkaniseerde thermoplastische elastomeren (TPVs) te bereiden. Hun eigenschappen werden vergeleken met TPVs die vernet zijn met peroxides, zowel puur als in combinatie met coagentia. Wanneer de gewenste procescondities van de onderzochte TPVs worden bekeken, bleken de reactietemperaturen van de sulfonyl-azides het beste geschikt. Bij gebruik van 1,3BDSA was het niet alleen mogelijk TPVs te produceren met uitstekende mechanische eigenschappen, maar de benodigde hoeveelheid di-azide was verbazingwekkend klein. Hoe lager de 1,3BDSA dosering, hoe beter de algehele eigenschappen werden. Ook werden de EPDM deeltjes in het mengsel groter. Uiteindelijk werd een deeltjesgrootte van $1 \mu \mathrm{m}$ bereikt bij de laagste di-azide dosering die is getest. De di-azidoformaat verbindingen resulteerden ook in iPP/EPDM gebaseerde TPVs van goede kwaliteit. Het grootste nadeel van di-azidoformaat was echter de lage ontledingstemperatuur. Deze is iets lager dan de smelttemperatuur van iPP, hetgeen resulteert in een zeer hoge reactiesnelheid tijdens het iPP/EPDM smelten meng-proces.

Als laatste wordt in Appendix A een serie experimenten beschreven, waarbij werd aangetoond dat enkele di-azidoformaat vulkanisaten relatief eenvoudig gedevulkaniseerd kunnen worden. 


\section{Podsumowanie}

\section{Motywacja}

Główną zaletą elastomerów nasyconych, takich jak EPM i EPDM, nad ich nienasyconymi odpowiednikami jest brak podwójnego wiązania, węgiel-węgiel w łańcuchu głównym polimeru, co zapewnia ich doskonałą odporność na działanie ciepła i ozonu. Niekorzystą konsekwencją braku wiązań podwójnych, jest jednak niska reaktywność takich elastomerów. Sprawia ona, że elastomery nasycone trudniej jest usieciować czy poddać chemicznej modyfikacji. Sieciowanie jest processem typowym dla materiałów gumowych i zapewnia ich specyficzne właściwości takie jak wysoka wytrzymałość na rozciaganie, elastyczność i nierozpuszczalność. Modyfikacja polimeru z reguły ma na celu zwiększenie polarności lub reaktywności, a tym samym wzrost jego kompatybilności z innymi polimerami lub adhezji. Powszechna metoda pozwalającą na przezwyciężenie niskiej reaktywności polimerów nasyconych jest zastosowanie reakcji wolnorodnikowych, inicjowanych przez termiczny rozkład nadtlenków. Sieciowanie nadtlenkowe EP(D)M czy jego nadtlenkowo inicjowana modyfikacja bezwodnikiem maleinowym, są powszechnie stosowane także w na skalę przemysłowa. Główną wadą reakcji wolnorodnikowych jest jednak ich niska selektywność prowadząca do licznych reakcji ubocznych. Do najbardziej powszechnych należą: dysproporcjonacja dwóch makrorodników oraz rozpad- $\beta$ ( $\beta$ scission), porowadzący do degradacji polimeru.

Azydki organiczne zaliczają sie do zwiazków organicznych reaktywnych względem weglowodorów nasyconych. Stąd, zainteresowanie badaniem ich wydajności w sieciowaniu/modyfikacji nasyconych elastomerów takich jak EP(D)M. Pod wpływem wysokiej temperatury z grupy azydkowej wydziela się wolny azot a powstała nitryna: R-N ulega reakcji insercji z wiązaniem $\mathrm{C}-\mathrm{H}$. Mechanizm tej reakcji jest zupełnie różny od procesów wolnorodnikowych zachodzacych w wyniku rozkladu nadtlenków, ze znacznie niższym prawdopodobienstwem wystapienia reakcji ubocznych. Celem 
obecnej pracy jest zbadanie możliwości zastowania azydków jako alternatywy dla nadtlenkowego sieciowania i modyfikacji elastomerów nasyconych, w szczególności EP(D)M.

\section{Ogólne zestawienie wyników}

W początkowej fazie pracy główny cel stanowiło zsynezowanie odpowiednich diazydków, które byłyby w stanie skutecznie usieciować w pełni nasycony elastomerEPM. Podczas eksperymentów wstępnych, opisanych w Rozdziale 3, zbadana została reaktywność czterech różnych rodzaji azydków: alkilowych: R-N3; arylowych: R-C6H4-N3, sulfonylowych: R-SO2-N3 oraz mróczanowych: ROC(O)-N3. Aby porównać ich właściwości, z każdego rodzaju przygotowane zostały co najmniej trzy związki, jeden mono- i dwa di-azydki. Jedne z pierwszych obserwacji wskazały jednoznacznie, że typ grupy azydkowej ma ogromny wpływ na kinetykę reakcji. Podczas gdy wszystkie azydki mrówczanowe rozkładaja się w niemal identycznym zakresie temperatur, z maksimum krzywej DSC około $150{ }^{\circ} \mathrm{C}$, to samo maximum dla azydków sulfonylowych wynosi około $180^{\circ} \mathrm{C}$. W tym drugim przypadku można jednak zaobserwować pewną różnorodność temperatury rozkładu pomiędzy poszczególnymi związkami. Temperatury rozkładu azydków arylowych i alkilowych są odpowiednio wyższe, tak jak i większe są różnice pomiędzy poszczególnymi związkami. Kolejne badania wykazały, że zależnie od rodzaju azydka jego reaktywność wobec EPM jest znacząco różna. Azydki-alkilowe generalnie nie reagują z nasyconymi łańcuchami polimerowymi, najprawdopodobniej ze względu na bardzo szybką reakcje przegrupowania nitryny alkilowej. Di-arylo azydki wykazują pewną zdolność sieciowania, jednak nadmierna porowatość próbek czyni je nieodpowiednimi do celów wulkanizacji. Di-sulfonylo azydki oraz di-mróczano azydki są najbardziej skutecznymi substancjami sieciującymi, chociaż obserwowane były znaczne różnice pomiędzy poszczególnymi di-azydkami.

$\mathrm{Na}$ podstawie danych uzyskanych w Rozdziale 3 trzy di-azyki, dające najlepsze rezultaty zostały wybrane do dalszych badań. Są to dwa di-mróczano azydki: 4,4'isopropylidenedifenyl mróczano azydek (4,4' DAF) i trój(glikol etylenowy)-di(mróczano azydek) (GDAF) oraz jeden di-sulfonylo azydek: 1,3-benzenodisulfonylo azydek (1,3BDSA). Ich interakcje $z$ olejem i wpływ zawartości na kinetykę wulkanizacji, a także na właściwości mechaniczne wulkanizatów opisane zostały w Rozdziale 4. Wszystkie badania przeprowadzono przy użyciu elastomerów typu EP(D)M. Wpływ oleju na reakcje di-azydków badany był przez porównanie właściwości wulkanizatów z różną zawartością plastifikatora parafinowego. Badania te wykazały że efektywność sieciowania di-azydkowego jest porównywalna do sieciowania z użyciem kombinacji natlenek/koagent i znacznie wyższa w porównaniu do reakcji samych nadtlenków. Dla wszyskich badanych di-azydków optymalne właściwości osiagnięte zostały przy 
stężeniu 11 (mmol/100 części kauczuku) dla EPM i 6.6 (mmol/100 części kauczuku) dla EPDM. Z wyjątkiem odkształcenia stałego po ściskaniu właściwości mechaniczne wulkanizatów sieciowanych GDAF i 1,3BDSA są lepsze od właściwości próbki wzorcowej, sieciowanej przy użyciu kombinacji nadtlenek/koagent. Szybkości reakcji i energia aktywacji di-sulfonylo azydku: 1,3BDSA, jest znacząco różna w EPM i EPDM, podczas gdy di-mróczano azydki, zwłaszcza GDAF, mają podobne parametry kinetyczne w obu elastomerach. Wpływ sadzy i oleju parafinowego, na kinetykę reakcji di-azydków jest niewielki i waha się w zależności od rodzaju kauczuku i di-azydka.

Koagent pełni ważną rolę podczas sieciowania nadtlenkowego. Szczególnie w przypadu elastomerów nasyconych jak EP(D)M, kiedy wiązania podwójne węgielwęgie nie wystepują lub są dostępne tylko w niewielkiej ilości, dodanie koagentu jest konieczne w celu osiagnięcia odpowiedniej wydajności sieciowania. Pomimo wcześniejszego założenia, że mechanizm sieciowania di-azydkowego jest fundamentalnie różny od nadtlenkowego, wydało się jednak istotne zbadanie czy dodatek koagentu ma równie pozytywny wpływ na proces wulkanizacji. Badania opisane w Rozdziale 5 przedstawiają wpływ najcześciej stosowanych koagentów na wulkanizacje di-azydkową. Okazało się, że mały dodatek HVA-2 lub siarki podczas sieciownania di-mróczanami azydkowymi zwiększa wydajność reakcji. Efekt ten jest jednak bardzo ograniczony i nie można go porównywać do roli koagentów podczas wulkanizacji nadtlenkowej. W przypadku di-sulfonylo azydku: 1,3BDSA, wszystkie badane koagenty powodowały jedynie zmniejszenie wydajności reakcji.

W Rozdziale 6 związki mono-azydkowe testowane są jako nośniki grup funkcyjnych do szczepienia na wysoce nie-polarnym i w pełni nienasyconym elastomerze, jakim jest EPM. Badane są trzy mono-mrówczano azydki: fenylmróczano azydkowy (PhAF), benzyl mróczano azydkowy (BAF) i 4-metoxybenzyloxycarbonyl (M-BAF) i dwa monosulfonylo azydki: fenylsulfonylo azydekowy (PhSA) i 4-acetamidobenzenesulfonylo azydek (A-PhSA). Reakcja pomiedzy mono-azydekiem i EPM prowadzona była metodą reaktywnego mieszania, która okazała się bardzo skuteczna. Następnie ustalone zostały właściwości modyfikowanego polimeru i wydajność reakcji. Ogólnie rzecz biorąc, wykazane zostało, że reakcje azydków są obiecującym narzędziem w szczepieniu różnych grup chemicznych do łancucha polimerowego EPM-u. Głównym problemem wydaje się być kompatybilność pomiędzy elastomerem i azydkiem, szczególnie gdy struktura tego ostatniego staje się bardziej złożona. Zwiąki o prostej strukturze jak fenylo czy benzylo-azydki już w temperaturze pokojowej, są dobrze rozpuszczalne w EPM a wydajność ich reakcji z polimerem jest bardzo wysoka. Kompatybilność zmniejsza się jednak gdy wprowadzona zostaje bardziej złożona druga grupa funkcyjna; zawierający polarną grupę acetamidową A-PhSA jest nierozpuszczalny w EPM i nie wchodzi w nim z reakcje. 
Badania mające na celu wyłonienie mechanizmu reakcji między mróczano i sulfonylo azydkiem a węglowodoram nasyconym, są opisane w Rozdziale 7. W badaniu tym, makroczasteczki polimerowe zastapione zostaly przez model o małej masie cząsteczkowej: 4-metyloheptan. Sprawia to, że mieszanina poreakcyjna jest o wiele łatwiejsza do analizy i pozwala na użycie nowoczesnych technik instrumentalnych. Analiza GC/MS produktów reakcji mono-azydkowych pokazuje wyraźnie, że mechanizm reakcji dwóch badanych rodzajów azydeków jest zupełnie różny. GrupaSA wykazuje silną tendencję do reagowania z jakimkolwiek drugorzędowym atomem węgla, podczas gdy grupa-AF wydaje się być znacznie bardziej selektywna i preferuje rekcje tylko z tymi drugorzędowymi atomami węgla, które są połaczonne $z$ węglem trzeciorzędowym lub samym węglem trzeciorzędowym.

Analiza LC/MS produktów reakcji di-azydkowych potwierdziła, że zarówno 1,3BDSA jak i GDAF jako główny produkt reakcji generują struktury usieciowane, składające się z dwóch modelowych cząsteczek węglowodoru i przeragowanej cząsteczki di-azydka. W przypadku 4,4'DAF, najprawdopodobniej z powodu dużej różnicy polarności z 4metyloheptanem, która przyczynia sie do jego niskiej rozpuszczalności, strukury usieciowane nie zostały zidentyfikowane. Zjawiska zaobserwowane podczas badań mechnizmu wulkanizacji potwierdziły wcześniejsze obserwacje zanotowane podczas sieciowania rzeczywistych mieszanek elastomerowych.

Te same trzy di-azydki, które udowodniły swoją skuteczność w sieciowaniu EPDM w warunkach statycznych, zostały zastosowane do produkcji dynamicznie wulkanizowanych elastomerów termoplastycznych (TPV) na bazie iPP/EPDM. Badania te opisano w Rozdziale 8. Ich wydajność porównana jest z TPV sieciowanymi przy użyciu samych nadtlenków oraz kombinacji nadtlenek/koagent. W odniesieniu do warunków w jakich przetwarza się badane TPV, już sama temperatura reakcji sulfonylo azydków sugeruje że będą one bardziej odpowiednim środkiem sieciującym. TPV produkowane przy użyciu 1,3BDSA mają doskonałe właściwości mechaniczne, a wymagane ilości di-azydka są zaskakująco małe. Otrzymane wyniki wskazują, że w zakresie bananych stężeń im niższa zawartość 1,3BDSA, tym lepsze ogólne właściwości. Ponadto cząstki EPDM w mieszance stają się większe, by przy najniższej testowanej zawartości di-azydku osiagając wielkość około $1 \mu \mathrm{m}$. TPV produkowane przy użyciu di-mrówczano azydków również posiadają dobre wlaściwości mechaniczne. Główną wadą di-mrówczano azydków pozostaje jednak ich niska temperatura rozkładu, nieco niższa od temperatury topnienia iPP, powodująca bardzo szybką reakcję podczas przetwarzania iPP/EPDM.

W Załączniku A opisana jest seria krótkich eksperymentów, które udowodniły, że niektóre z wulkanizatów di-mrówczanowo azydkowych ulegają całkowitej dewulkanizacji. 


\section{Symbols and Abbreviations}

$\alpha$ - Degree of conversion

$\chi$ - Flory-Huggins parameter, depending on polymer-swelling agent interaction

$\rho_{r}$ - Density of the rubber

$\rho_{s}$ - Density of the solvent

$A$ - Pre-exponential factor in Arrhenius' equation

AF - Azidoformates

$A G r$ - Amount of azide grafted to $100 \mathrm{~g}$ of EPM

AHA - 6-Azido-n-hexylamine

$A I n$ - Initial azide content dosed per $100 \mathrm{~g}$ of EPM

A-PhSA - 4-Acetamidobenzenesulfonyl azide

ATR - Attenuated Total Reflectance

BAF - Benzyl azidoformate

1,3BDSA - 1,3-Benzenedisulfonyl azide

BMI PP - N,N'-p-phenylenedimaleimide

BPO - Dibenzoyl peroxide

BR - Polybutadiene Rubber

4,4'DAF - 4,4'-Isopropylidenediphenyl azidoformate

1,6DAH - 1,6-Diazidohexane

1,12DAD - 1,12-Diazidododecane

$C_{o}-$ Beginning concentration

CB - Carbon Black

$\mathrm{CDCl}_{3}-$ Deuterated chloroform

DCP - Dicumyl peroxide

2,6 DPhA - 2,6-bis(4-azidobenzylidene)-4-methylcyclohexanone

DSC - Differential Scanning Calorimetry

$E_{a}$ - Activation energy

EIC - Excluded Ion Chromatogram

EDMA - Ethylene dimethacrylate 
EPM - Ethylene/Propylene copolymer rubber

EPDM - Ethylene/Propylene/Diene copolymer rubber

ESI - Electro-spray Ionization

Fg - Functional group

FT-IR - Fourier transform infrared

GC/MS - Gas Chromatography/Mass Spectrometry

GDAF - Tri(ethylene glycol) diazidoformate

GrEff - Grafting efficiency

${ }^{1} \mathrm{H}-\mathrm{NMR}$ - Proton magnetic resonance spectroscopy

1,6HDSA - 1,6-Hexanedisulfonyl azide

HPLC/MS - High Pressure Liquid Chromatography/Mass Spectrometry

HVA-2 - N,N'-m-phenylenebismaleimide

IIR - Butyl rubber (Isobutylene-Isoprene)

In - Integration of a proton-signal

IR - Infrared spectroscopy

ISO - International organization for standardization

$k$ - Rate constant described by the Arrhenius' equation

MA - Maleic Anhydride

M-BAF - 4-Metoxybenzyloxycarbonyl azide

MCV - Model Compound Vulcanization

$\mathrm{ML}(1+4)$ - Mooney viscosity

$m_{r}$ - Mass of the rubber network;

$m_{s}$ - Mass of the solvent in the swollen sample at equilibrium conditions

$\mathrm{n}$ - Reaction order

NCS-PhA - 4-azidophenyl isothiocyanate

NR - Natural Rubber

PE - Poly(ethylene)

Perkalink 900 - 1,3-Bis(citraconimido)methyl-benzene

PhAF - Phenyl azidoformate

PhSA - Phenylsulfonyl azide

$\mathrm{PhMl}$ - N-phenylmaleimide

phr - parts per hundred of rubber

PP - Poly(propylene)

$\mathrm{R}$ - Gas constant

$\left[8.314 \mathrm{Jmol}^{-}\right.$

$\left.{ }^{1} \mathrm{~K}^{-1}\right]$

RPA - Rubber Process Analyzer

$\mathrm{S}_{8}-$ Sulfur

SA - Sulfonyl azides

SBR - Styrene/Butadiene/Rubber 
3,3'SDPhA - 3,3'-Diazido-diphenyl sulfone

SEBS - Styrene-ethylene/butylene-styrene copolymer

SEM - Scanning Electron Microscopy

$S_{\text {max }}^{\prime}$ - Maximum torque

$S_{\text {min }}^{\prime}$ - Minimum torque

STEM - Scanning Transmission Electron Microscopy

$t$ - Time

$t_{1 / 2}-$ Half-life time

$t_{90}$ - Optimum cure time

$\mathrm{T}$ - Temperature

TAC - Triallylcyanurate

TIC - Total Ion Chromatogram

TRIM (or TMPTMA) - Trimethylolpropane trimethacrylate

VMQ - Silicone rubber (Vinyl Methyl Silicone)

$v$ - Overall crosslink density per unit volume

$V_{0}$ - Molar volume of cyclohexane;

$V_{r}$ - Volume fraction of EPM in the swollen sample

$\mathrm{ZnO}$ - Zinc oxide 


\section{Bibliography}

\section{Journal papers}

Azides as effective curing agents for saturated EPM-rubber: efficiency and reactivity, A.J. Zielińska, J.W.M. Noordermeer, A.G. Talma, W.K. Dierkes and M. van Duin, Kautschuk Gummi Kunststoffe, 63, 308, (2010)

Cross-linking of saturated elastomers with di-azides, Part I: Mechanical properties of vulcanizates, A.J. Zielińska, J.W.M. Noordermeer, A.G. Talma and M. van Duin, Rubber Chem. Technol. (scheduled for publication) 84, (2011)

Cross-linking of saturated elastomers with di-azides, Part II: Mechanistic study, A.J. Zielińska, J.W.M. Noordermeer, A.G. Talma, M. van Duin and R. Peters, Rubber Chem. Technol. (scheduled for publication) 84, (2011)

Di-azides cross-linked iPP/EPDM-based thermoplastic vulcanizates, A.J. Zielińska, J.W.M. Noordermeer, A.G. Talma and M. van Duin, Eur. Polym. J. (submitted for publication)

Modification of EPM-rubber using mono-azides, A.J. Zielińska, J.W.M. Noordermeer, A.G. Talma and M. van Duin (to be submitted) 


\section{External Presentations}

- XIIIth International Science and Technology Conference ELASTOMERS 2009, 18-20 November 2009, Warsaw, Poland

- American Chemical Society Rubber Division, paper \#87, 13-15 October 2009, Pittsburgh, USA

- International Rubber Conference, 29 June- 2 July 2009, Nuremberg, Germany

- American Chemical Society Rubber Division, paper \#71, 14-16 October 2008, Louisville, USA

- XIlth International Science and Technology Conference ELASTOMERS 2007, 14-16 November 2007, Warsaw, Poland 


\section{Acknowledgements}

About the PhD-study I thought already during my master assignment. So when shortly before my graduation, prof. Ślusarski asked me if I ever considered doing a PhD, a big smile came to my face. The moment did not last long however, and my appearance must have changed for something more like a terrified-confusion once he added that the position was in Holland and I started to think about my pretty bad English. And so the challenge began! Now a couple of weeks before my defence, I would like to thank all people whose support and/or company contributed to the development of this thesis (almost completely in English). The obvious truth is that if I would have been left on my own, this book would never look as it does now.

To start, I would like to express my deepest regards to prof. Ślusarski, who supervised my first rubber related project and recommended me for the position at the Rubber Group in Twente. He is always standing up in my memory as an exceptionally strong person.

The man who actually trusted me to work on this project was my promoter, prof. Noordermeer and I will be always grateful for that. I have to admit that his broad knowledge and way of organizing staff impressed on many occasions. He is also a very good teacher, with his enthusiasm towards rubber being often contagious as it was in my case. Thank you.

Very special thanks go to my assistant promoter Auke Talma, whose help during the first two years was the most important to me. When working with him, getting stuck was never an option because of the amount of ideas he always has. What I appreciate mostly is his unique gift to make even the most complex phenomena look silly simple. Another very important person for this project was Martin van Duin. If it weren't for him I'm quite sure some parts of this book would not be here. His results oriented and very to the point approach meant a lot to me.

I also would like to acknowledge the Dutch Polymer Institute (DPI) for the financial support and all DPI committee members: Jan Stamhuis (DPI), Martin van Duin (DSM), 
Patric Meessen (DSM), Montse Alvarez Grima (DSM), Auke Talma (AkzoNobel), Rabin Datta (Teijn), S. Barbera (SKF) for the time they spend to comment on this research.

I would like to thank prof. Bieliński, dr. ir. van Duin, dr. Talma, prof. Dijkstra, prof. Warmoeskerken, prof. Noordermeer and prof. Eising for being committee members of my defence. Karina and Somayeh: thank you for being my paranimffs.

Regarding the experimental work I want to thank Auke Talma (AkzoNobel) for arranging the azide decomposition kinetics measurements. Satoshi Mihara (Yokohama/PhD) for helping me calculate the cross-linking kinetic from RPA. It was not only much faster but also fun! Ron Peters (DSM) for the assistance with the GCMS analyzes. Priscilla Kraan (DSM), Kangbo Lu (TU/e) and Karina Kopeć (UT) for their help during the TPV study. Special thanks to Jacques Noordermeer and Martin van Duin for convincing me to do some extra tests and Wilma Dierkes who was always there, smiling and willing to help, no matter what the issue was.

I would like to thank all of the ETE/RBT group members for the time we spend together! Montse, Marek, Wilco, Tony, Satoshi, Kuno, Hongmei, Rui, Francesca, Mukund, Jacob, Anoma, Kannika, Morteza, Siti, Sreekumar, Somayeh, Arek, Natalia, Sebastian, Yvonne, Aleida, Hillie and finally Auke, Rabin, Wilma and Jacques I'm very glad we had the opportunity to work together.

I would like to express my sincere gratitude to my old colleagues for all support they showed me from the very beginning. Montse is truly a perfect friend! She was the one to show me around when I was a stranger in Enschede. Marek and Wilco, the coffee break masters, they always made sure that the office smells cosy in the very morning. Believe me it was never the same without you! Sitting next to Tony was for sure lucky for me but I'm afraid a bit annoying for him, thanks for all help and patience. Kuno is the loudest and most provoking Dutch I know but he was also a great colleague. Satoshi: an exceptionally kind person. It took me a while before I learn that "maybe" is a Japanese "no" (where I come from it's more like keep talking). I whish all the best to you and your family and I trust that difficulties in Japan will be soon overcome. Montse, Marek, Wilco, Satashi and Tony as well as later on Morteza and Somayeh thanks for being such a good company also after work. Very special thanks for Siti, Salina, Wisut, Somayeh, Morteza and Yvonne for taking care of Jeremi when I was busy with various appointments.

Karina, Srivatsa, Szymon, Olga, Izabela, Alexis, Magda, Artur, Kasia and Tomek thank you for being always so kind and for the time we spend together. Karina and Kasia thanks also for the baby sitting. When I came here I did never dare hope for a friend like Karina (KK 1818). She is cheerful like a sun and reliable like a Swiss Watch. The longer I know her the more and more I appreciate how lucky I am. I'm also sure that this friendship will last forever! 
Chciałabym podziękować mojej rodzinie: tacie, Ewie i Sylwkowi, Jackowi i Madzi, oraz dzieciakom, które właśnie zaczynają dorastać, za to, że przyjmują nas tak ciepło za każdym razem kiedy jesteśmy w Polsce (a jesteśmy często). Cięszę się też niezmiernie, że znaleźli czas, żeby odwiedzać(dzić) nas w Enschede.

Osobą bardzo dla mnie ważną jest moja kochana ciocia Hala. Podziękowanie to najmniej co moge zrobić za jej ciągłe wsparcie, które okazuje mi, także teraz, kiedy jestem tak daleko i że nigdy nie przestała we mnie wierzyć. Specialne podziękowania należą się także mojej siostrze Ewie - dzieki niej zawsze mamy gdzie przenocować, nieważne na jak długo przyjeżdzamy i ile mamy bagażu. Dziekuję, że zawsze dzwonisz! Chiałabym również podziękować mojej kochanej Kinguni za to, że jest taką wspaniałą przyjaciółką i że zawsze tak ochoczo proponuje mi swoje klucze, całusy dla Piotrka i dzidzi Ani.

Ook wil ik graag de familie van mijn echtgenoot bedanken: Lidwine, Wim, Krista en Stefan dat zij mij geaccepteerd hebben als nieuw familielid. Daarnaast wil ik graag mijn schoonouders bedanken voor al hun hulp in ons "nieuwe huis" (bouwjaar 1961). Finally I would like thank my husband, Wilco who is always there for me. Everything is so much easier when you are around. I'm not at all good with growing old but it's so much better to grow old with you. There is nothing more important to me than you and Jeremi. 